\title{
Proteomics as a tool to gain more insight into sub-lethal toxicological effects
}

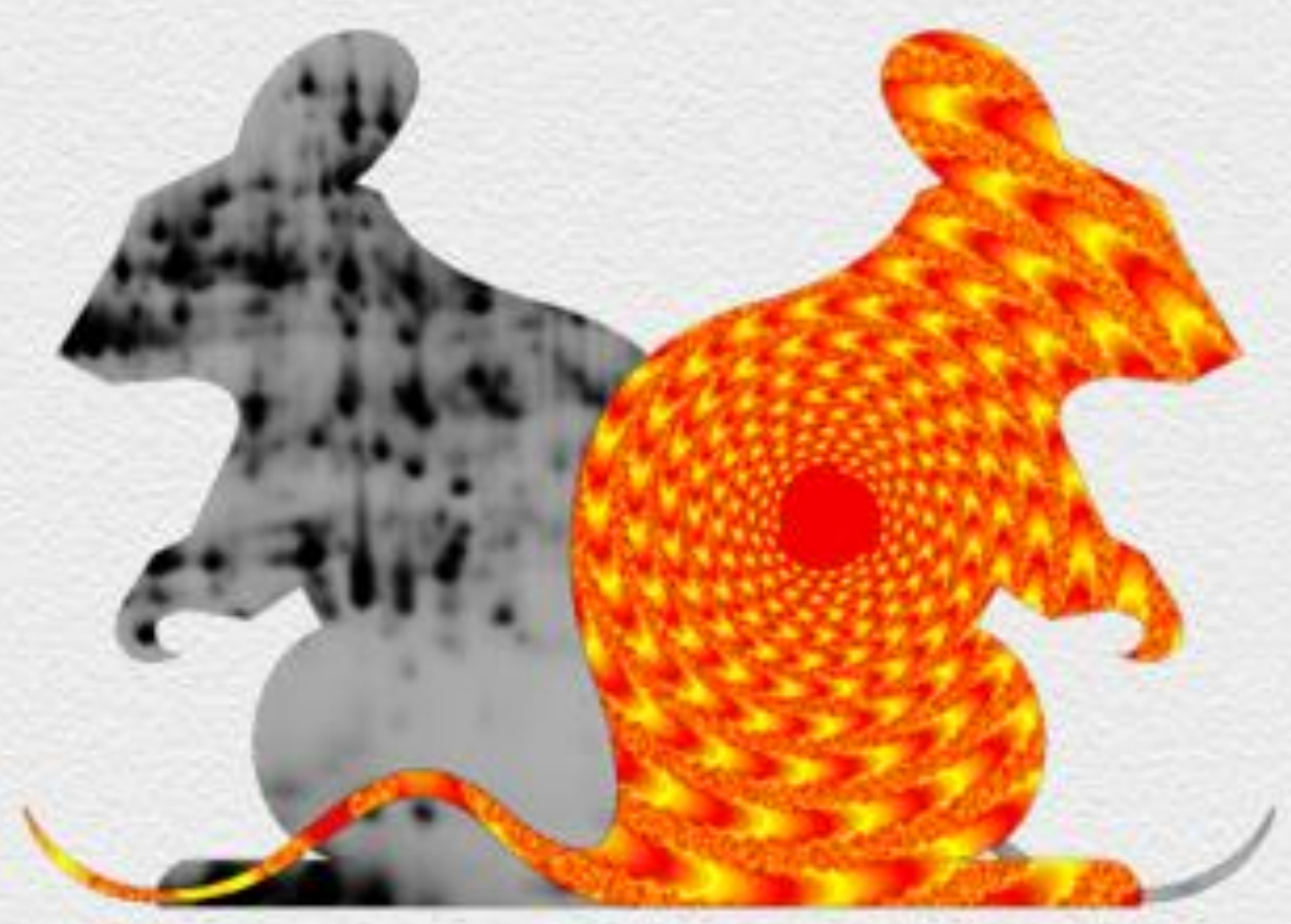

Ingrid Miller 


\section{Proteomics as a tool}

\section{to gain more insight into \\ sub-lethal toxicological effects}

Ingrid Miller 


\section{Thesis committee}

\section{Promotor}

Prof. Dr A.J. Murk

Professor of Marine Animal Ecology

Wageningen University

\section{Co-promotors}

Dr A.C. Gutleb

Group Leader

Luxembourg Institute of Science and Technology (LIST), Luxembourg

Dr T. Serchi

Research Associate

Luxembourg Institute of Science and Technology (LIST), Luxembourg

\section{Other members}

Prof. Dr I.M.C.M. Rietjens, Wageningen University

Dr W.T. Steegenga, Wageningen University

Dr T. Hamers, University of Amsterdam

Prof. Dr A.H. Piersma, Utrecht University

This research was conducted under the auspices of the Graduate School for SocioEconomic and Natural Sciences of the Environment (SENSE). 


\section{Proteomics as a tool \\ to gain more insight into \\ sub-lethal toxicological effects}

Ingrid Miller

Thesis

submitted in fulfilment of the requirements for the degree of doctor at Wageningen University

by the authority of the Rector Magnificus

Prof. Dr A.P.J. Mol,

in the presence of the

Thesis Committee appointed by the Academic Board

to be defended in public

on Thursday 7 July 2016

at 11 a.m. in the Aula. 
Ingrid Miller

Proteomics as a tool to gain more insight into sub-lethal toxicological effects 185 pages.

$\mathrm{PhD}$ thesis, Wageningen University, Wageningen, NL (2016)

With references, with summary in English

ISBN: 978-94-6257-821-0

DOI: http://dx.doi.org/10.18174/382325 
Wege entstehen dadurch, dass man sie geht.

(Roads grow out of going them.)

Franz Kafka 



\section{Table of contents}

page

Abbreviations 9

Chapter $1 \quad$ General introduction and thesis outline 11

Chapter 2 Protein separation strategies in gel-based proteomics 25

Chapter 3 The added value of proteomics for toxicological studies 63

Chapter 4 Hexabromocyclododecane (HBCD) induced changes in the liver proteome of eu- and hypothyroid female rats 87

$\begin{array}{ll}\text { Additional dataset } & 101\end{array}$

Chapter 5 Gender specific differences in the liver proteome of rats exposed to hexabromocyclododecane (HBCD) 109

Additional dataset 133

Chapter 6 Gender-related differences in rat serum proteome under baseline conditions and in inflammation 139

$\begin{array}{lll}\text { Chapter } 7 & \text { General discussion and conclusions } & 151\end{array}$

Summary 167

$\begin{array}{ll}\text { Appendix } & 173\end{array}$

Acknowledgements 175

$\begin{array}{ll}\text { About the author } & 177\end{array}$

List of selected publications $\quad 179$

SENSE diploma 183 


\section{List of abbreviations}

16-BAC, 16-benzyldimethyl-n-hexadecylammonium chloride

2D-DIGE, two-dimensional fluorescence difference gel electrophoresis

2DE or 2-DE, two-dimensional electrophoresis

AhR, aryl hydrocarbon receptor

AL1L1, aldehyde dehydrogenase family 1 member L1

ANOVA, analysis of variation

BFR, brominated flame retardant

BN-PAGE, Blue native PAGE

CBB, Coomassie Brilliant Blue

CHAPS, 3-[(3-cholamidopropyl)dimethylammonio]-1-propanesulfonate

CTAB, cetyltrimethylammonium bromide

CYP, cytochrome P450

DTT, dithiothreitol

ESI, electrospray ionization

ET, euthyroid

ETFB, electron transfer flavoprotein subunit beta

$\mathrm{f}$, female

FSH, follicle-stimulating hormone

GO, Gene Ontology

GST, glutathione-S-transferase

HBCD, hexabromocyclododecane

HMG-CoA, hydroxymethyl-glutaryl-CoA

HT, hypothyroid

ICAT, isotope coded affinity tagging

ICPL, isotope coded protein label

IEF, isoelectric focusing

IMAC, immobilized metal affinity chromatography

IPG, immobilized $\mathrm{pH}$-gradient

iTRAQ, isobaric tags for relative and absolute quantitation

KEGG, Kyoto Encyclopedia of Genes and Genomes

LC, liquid chromatography

LH, luteinizing hormone 
m, male

M2GD, mitochondrial dimethylglycine dehydrogenase

MALDI, matrix assisted laser desorption ionization

MIAPE, minimum information about a proteomic experiment

$\mathrm{Mr}$, molecular weight

MS, mass spectrometry

PAGE, polyacrylamide gel electrophoresis

PBDE, polybrominated diphenylether

PCB, polychlorinated biphenyl

PCR, polymerase chain reaction

PHAH, polyhalogenated aromatic hydrocarbon

pI, isoelectric point

PMF, peptide mass fingerprint

PON, paraoxonase/arylesterase

RIA, radioimmunoassay

RuBP, ruthenium(II) tris(bathophenanthroline disulfonate

SDS, sodium dodecyl sulfate

SDS-PAGE, sodium dodecyl sulfate polyacrylamide gel electrophoresis

SELDI, Surface-enhanced laser desorption/ionization

SEM, standard error of the mean

SILAC, stable isotope labeling by amino acids in cell culture

SRM, selected reactions monitoring

STRING, functional protein association networks

$\mathrm{T}_{3}$, triiodothyronine

$\mathrm{T}_{4}$, thyroxine,

TCDD, 2,3,7,8-tetrachlorodibenzo- $p$-dioxin

$\mathrm{TH}$, thyroid hormone

TMT, tandem mass tags

TOF, time of flight

$\mathrm{TSH}$, thyroid stimulating hormone 


\section{Chapter 1}

General introduction and thesis outline

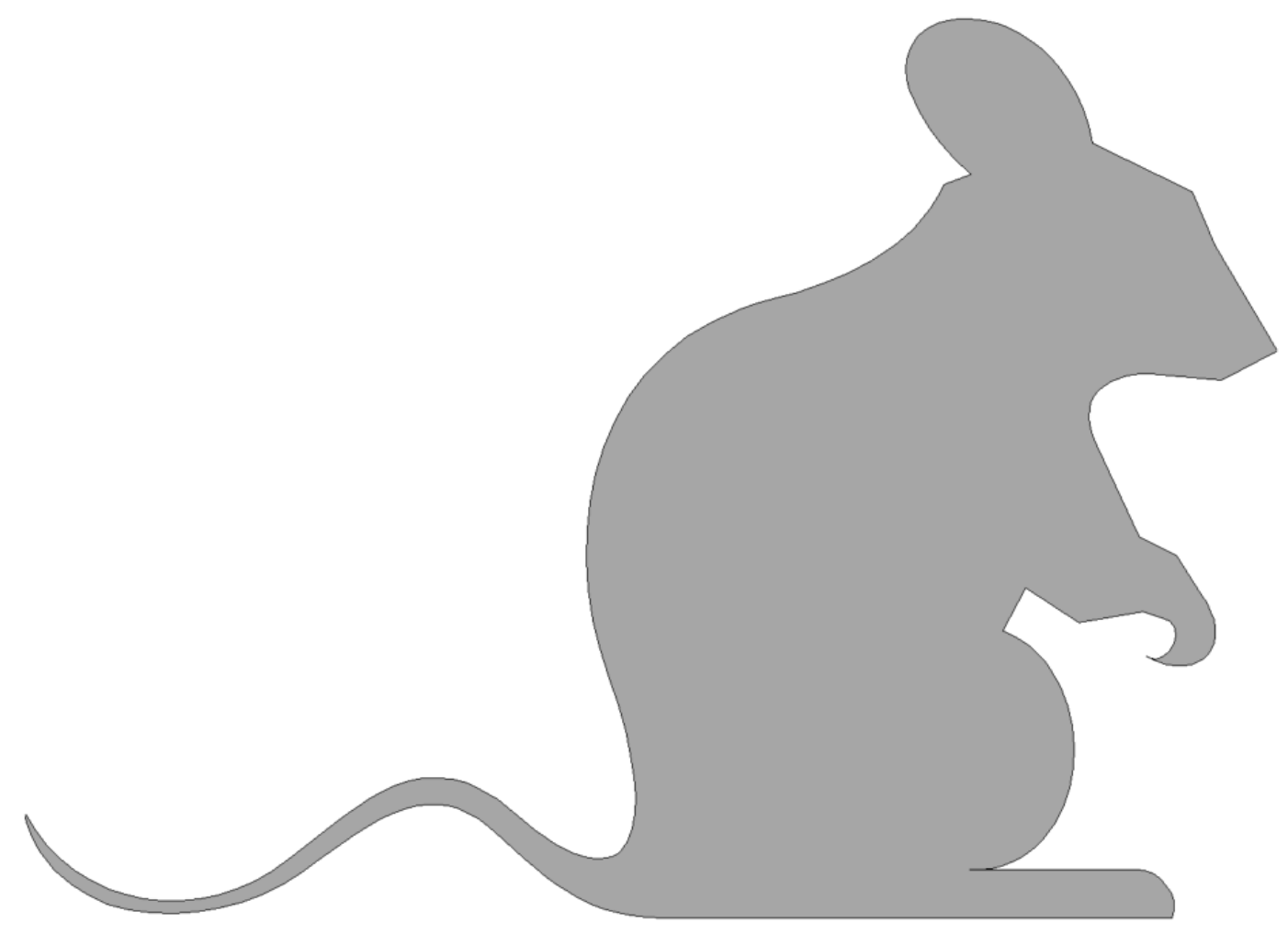





\section{General introduction}

\section{Proteomics}

\section{Definition}

Proteomics aims at analysing the whole set of proteins (the "proteome") present in a complex specimen (body fluid, cell, tissue) at defined conditions within one analysis. The proteome is not constant in its composition, but influenced by multiple factors like age, gender, hormonal and health status, and environment. Over the years, different strategies have developed to determine its complexity and to study abundance of hundreds to thousands of proteins in one experiment. This allows detection of yet unknown protein changes and pathways related to disease/treatment/exposure [Lottspeich and Zorbas, 1998; Anderson and Anderson, 1998].

\section{Proteomic methods}

All proteomic methods have in common that a complex protein mixture is separated in multiple steps to single out proteins (or peptides) for detection, identification and quantification. During the last 20-30 years, these methods have become more and more refined, more complex, adapted to diverse molecule properties, and more sensitive.

Presently there are two main types of proteomic approaches: gel-based (applying twodimensional electrophoresis, 2-DE [Rabilloud et al., 2010; Rogowska-Wrzesinska et al., 2013; Oliveira et al., 2014]) or gel-free (using multi-dimensional liquid chromatography, LC [Liu et al., 2013; Altelaar and Heck, 2012; Zhang et al., 2013]), both together with protein identification by mass spectrometry (MS). Steps of the different approaches are illustrated in Figure 1: red lines for two-dimensional electrophoresis, gel-free or MSbased (usually in combination with different LC-steps) in blue, or a combination of onedimensional electrophoresis and (LC-)MS, in green.

Another difference between gel-based and gel-free proteomics is also displayed in the figure: electrophoretic systems separate intact proteins and resulting electrophoretic patterns are used for quantification and for search of proteins of different abundance. Only then protein spots (from 2-DE gels) or bands (from 1-DE) of interest are collected directly from the gels, proteins digested with specific enzymes and identified by MSmethods. In contrast, gel-free methods usually start with a digestion step and only then 
separate (usually by high-resolution multi-dimensional chromatography), quantify and identify the peptides or proteins from which they derive, respectively.

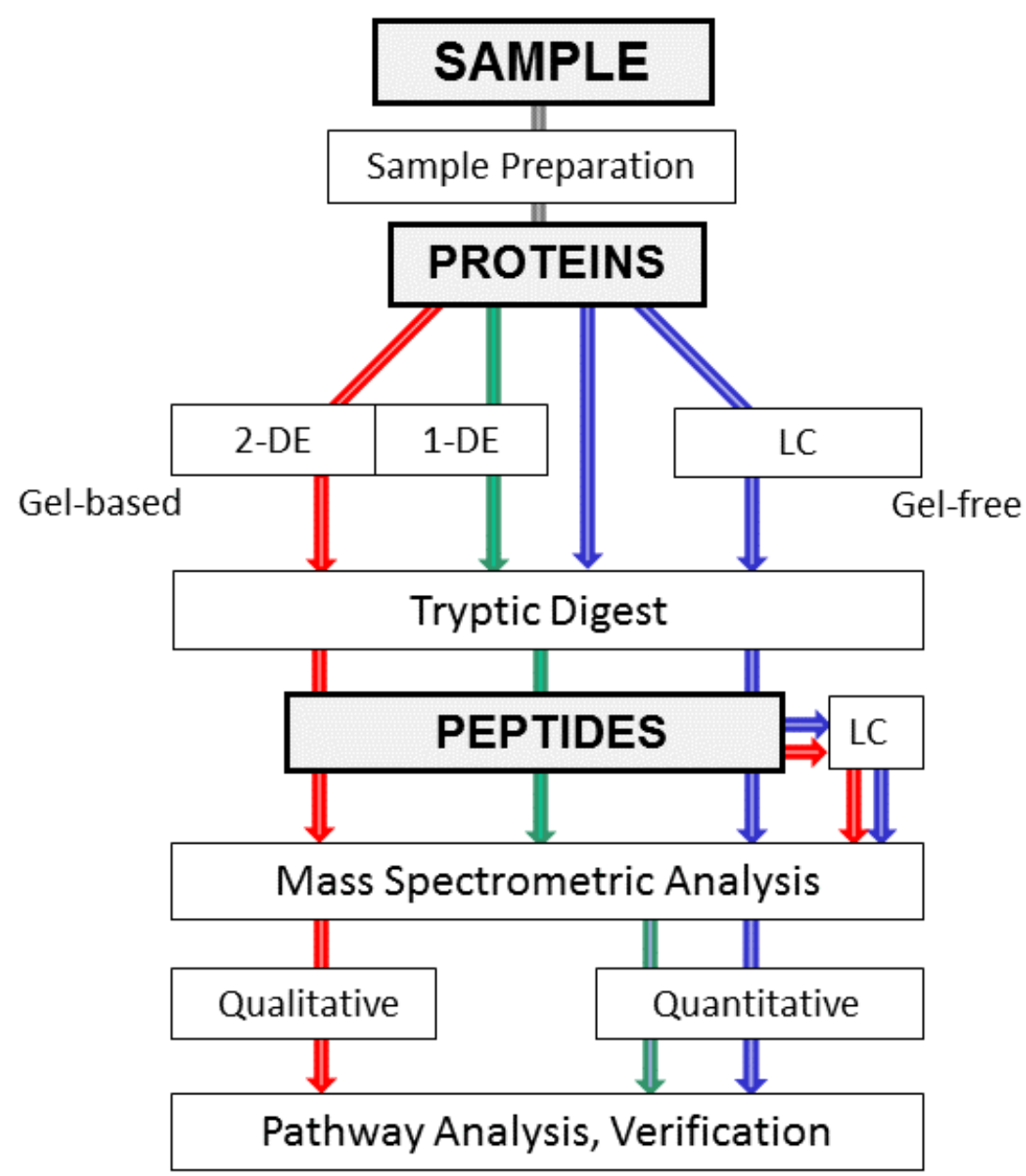

Figure 1: Proteomic workflow. Gel-based approach in red (two-dimensional electrophoresis, 2-DE), gelfree in blue (liquid chromatography, LC). Separation on one-dimensional electrophoresis gels (1-DE, in green) is also possible, often combined with LC on the peptide level, to achieve sufficient resolution.

Proteins are identified based on their peptide patterns obtained after cleavage with an enzyme, usually trypsin, which cuts proteins at specific sites of the amino acid chains. Each protein gives a typical fragmentation pattern under standard conditions, and after mass-based MS-separation its peptides can be determined and the protein identified by comparison of its peptide mass pattern with dedicated databases.

As soon as a set of proteins is known which change abundance under particular conditions, pathway analysis with specific web-based databases may be undertaken to find out more about the proteins, their biological functions and cellular locations in the body as well as their interactions. This allows further interpretation of collected data. 
The present work is based on 2-DE, and Figure 2 gives an example of such a proteomic workflow. In a first step, the sample (e.g. rat liver homogenized in an appropriate buffer) is separated in a $\mathrm{pH}$-gradient, in which proteins focus as sharp zones according to their charge (isoelectric point) [Westermeier, 2001]. A subsequent orthogonal separation is performed in an SDS-PAGE gel (polyacrylamide gel electrophoresis in the presence of sodium dodecyl sulfate) [Laemmli, 1970] where proteins migrate based on their molecular mass. In classical 2-DE, protein patterns are visualized with colorimetric stains. There is a more modern variety, 2D-DIGE (two-dimensional fluorescence difference gel electrophoresis), which works with fluorophores [Uenlue et al., 1997; Marouga et al., 2005]. Three different mass- and charge-matched cyanine dyes exist and are used to label protein samples before undertaking the electrophoresis step. In this way, on each gel two different specimens and an internal standard may be applied. After 2-DE separation, images for each single dye and sample are captured with a fluorescence scanner and single spot intensities evaluated with specifically developed software. The internal standard facilitates gel comparison and increases the reproducibility of the analyses [Alban et al., 2003]. This allows filtering the whole protein spot set for differentially abundant proteins, based on statistical criteria (minimum spot abundance change, $P$-value) and selection of spots of interest for MS-identification (steps highlighted in light green in the figure). Successful protein identification is the basis for pathway analysis and data interpretation together with result from other assays or determinations (e.g. animal data, hormone concentrations, etc.). 


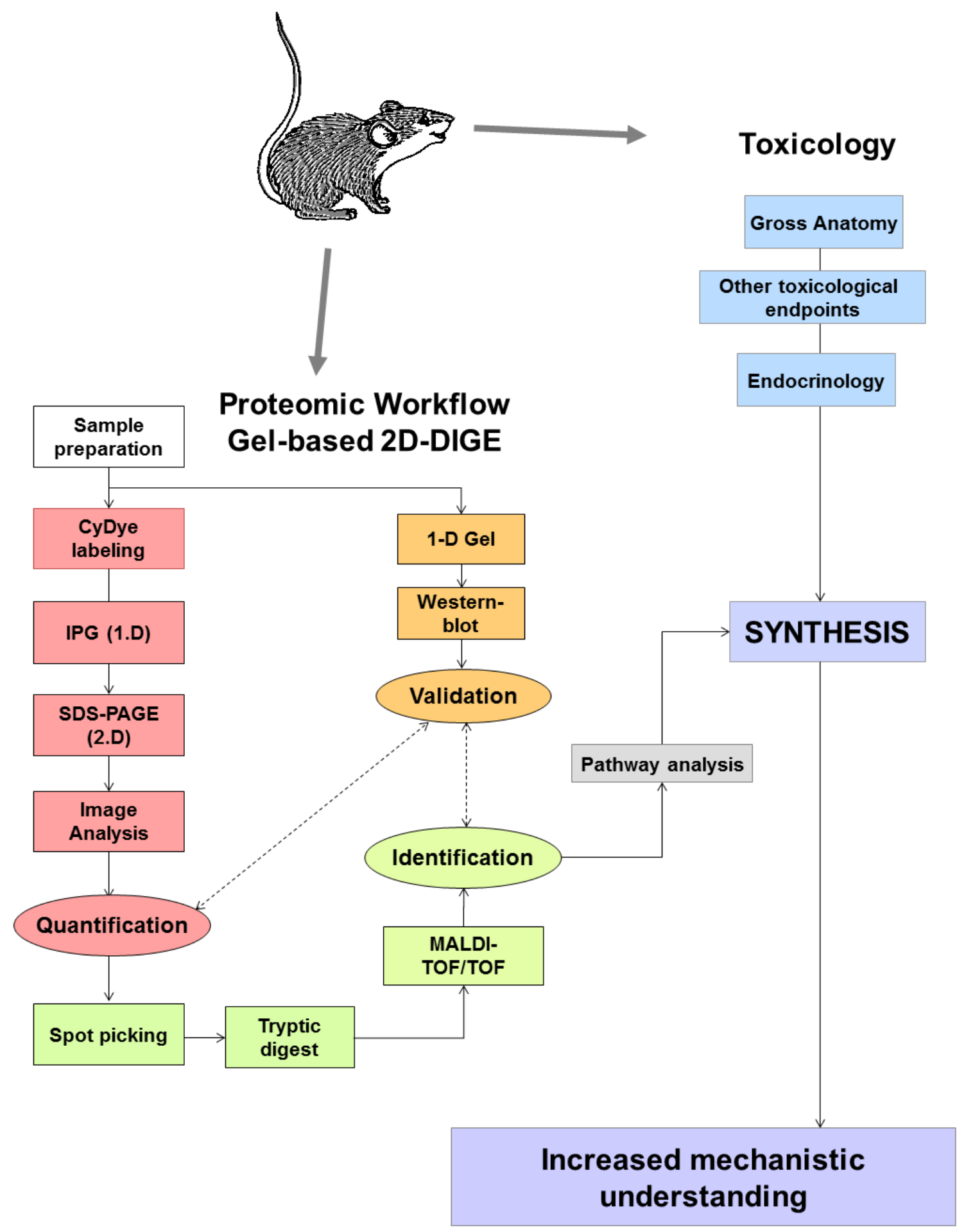

Figure 2: Design of a proteomic experiment. Example for workflow in a gel-based proteomic approach with 2D-DIGE, similar to the one used in this thesis.

Abbreviations: CyDyes, fluorophores for protein labeling; IPG, immobilized pH-gradients for first dimensional separation; MALDI-TOF/TOF, matrix assisted laser desorption ionization-time of flight, a variety of MS. 


\section{Proteomics to study toxicological questions}

Proteomics is nowadays widely used in different fields related to health and disease (for humans and meanwhile also animals), research and diagnosis [Thibault and Gingras, 2015; Eckersall et al., 2012], but still underrepresented in environmental / ecotoxicology research. Only recently, interest in this technique is growing [Nesatyy and Suter, 2007; Miller et al., 2016]. Proteomic methods have in common that they are holistic and nontargeted, investigating all proteins detectable in an analytical system and not specifically a few that had been preselected by induction based on previous results. Thus, proteomic methods are able to detect not yet known to be affected or still little explored proteins and to relate them to specific pathways. In this way proteomics may help to reveal new or clarify ill understood mechanisms of actions of different toxic compounds.

A candidate compound for proteomic study is hexabromocyclododecane (HBCD), because its mechanism of action is confusing and ill understood.

\section{$H B C D$}

\section{The compound}

$\mathrm{HBCD}\left(\mathrm{C}_{12} \mathrm{H}_{18} \mathrm{Br}_{6}\right)$ is a brominated aromatic compound with six bromines bound in the molecule, resulting in 16 possible stereo-isomers. Technical products contain three main diastereomers $(\alpha-, \beta-, \gamma-\mathrm{HBCD})$ besides traces of others (Figure 3 ).
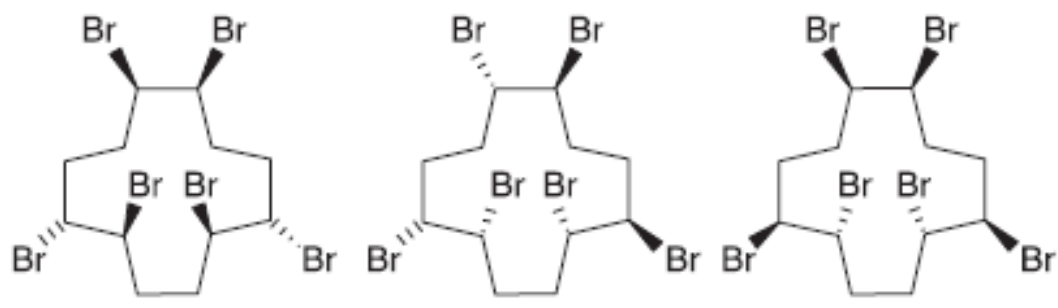

Figure 3. Structures of the main isomers that are present in the technical product of HBCD: $\alpha-$ (left), $\beta-$ (middle) and $\gamma$ - (right) HBCD [Alaee et al., 2003].

In organisms, the different isomers are processed in a different way, the $\alpha$-HBCD isomer being retained the most in nature [Covaci et al., 2006; European Commission, 2008]. In contrast, in animal feeding experiments, the isomer detected is mainly $\gamma-\mathrm{HBCD}$, but 
accumulation may differ in long-term chronic exposure and experiments whose length did not exceed four weeks at maximum [van der Ven et al., 2006].

\section{$H B C D$ and its industrial use}

Till 2013 HBCD has been used as a major brominated flame retardant (BFR), applied to prevent buildings and equipment from catching fire. The large global application of BFRs has led to increasing contamination in the environment as these substances are persistent, lipophilic and accumulate in biota [De Wit, 2002; Darnerud, 2003; Kiciński et al., 2012; Kalachova et al., 2012; Tomko and McDonald, 2013] and are shown to act as endocrine disrupters [Tomko and McDonald, 2013; Law et al., 2008; Covaci et al., 2006]. Earlier bans or withdrawals of other BFRs [Law et al., 2008] have led to a sharp increase of environmental HBCD concentrations, but reports about toxic effects, persistency and accumulation resulted in a ban in 2013 by many industrial countries (Stockholm convention, https://treaties.un.org /doc/Publication/CN/2013/ CN.934.2013Eng.pdf). However, HBCD is still produced and applied in non-European countries, e.g. in the US.

\section{$H B C D$ and its known effects}

HBCD is persistent and accumulates in animals and humans via the food chain, especially in adipose tissue [Covaci et al., 2006]. BFRs have been shown to interfere with several hormone systems, and also for HBCD animal studies indicate toxicological effects, especially in the liver and on the thyroid hormones [Cantón et al., 2008; Germer et al., 2006; van der Ven et al., 2006], though with a low acute toxicity. The thyroid hormone $(\mathrm{TH})$ disruptive potencies shown in vivo cannot be related to a $\mathrm{TH}$ mimicking molecular structure, therefore the mechanism of action is expected to be indirect. This is supported by the fact that HBCD has been shown to enhance the effects of $\mathrm{TH}$ in vitro and ex vivo [Schriks et al., 2006; 2007].

Previous in vivo experiments with Wistar rats exposed to high dosages (up to 100-200 mg $\mathrm{HBCD} / \mathrm{kg}$ body weight/day during 4 weeks) showed for instance increased immunohistological staining of thyroid stimulating hormone (TSH) in the female pituitary, induction of $\mathrm{T}_{4}$-glucuronyl transferase and increased levels of different cytochromes as well as changes in the lipid metabolism [Cantón et al., 2008; van der Ven et al., 2006]. The responses in male and female animals were different, with females being more sensitive to HBCD exposure [Cantón et al., 2008]. All animals used in these experiments 
had a normal thyroid hormone status, while in the human population also hypo- and hyperthyroid hormone levels occur regularly [Diez et al., 2003; Wilson et al., 2012]. A change in thyroid state is expected to increase the stress on the thyroid hormone homeostasis and influence the reaction to HBCD.

Up to now, knowledge on HBCD effects has been collected from toxicological and developmental animal studies, hormonal data (ELISA, RIA), gene regulation data (PCR), or single protein determinations [Cantón et al., 2008; Germer et al., 2006; van der Ven et al., 2006]. Compared to transcriptomics, proteomic studies have the advantage to target the proteins, the actual players at a specific site, and gene and protein regulation are known to not always go in parallel [Greenbaum et al., 2003; Tian et al., 2004]. Only a few previous proteomic studies investigate effects of $\mathrm{HBCD}$, either alone or in combination with other BRFs in vitro on isolated liver cells or in vivo on complete organs, mainly in zebrafish [Kling et al., 2008; Kling and Förlin, 2009]. No comparable studies have been performed in rats or other mammals.

The still considerable use and production outside of Europe, environmental persistence and accumulation in food chains, and the not completely understood mechanism of action of HBCD made us undertake the present short-term exposure study in combination with applying the holistic approach of proteomics.

\section{This thesis}

The aim of the present work is to evaluate the use of proteomics in toxicological research by applying it for studying the influence of HBCD on the liver proteome of female and male rats exposed to sub-lethal doses of this compound for one week.

Liver was chosen as sample, as it is the main detoxifying and protein synthesizing organ and one of the first tissues exposed to HBCD after oral uptake. It is also an example to evaluate the usefulness of gel-based proteomics in the field of environmental proteomics.

Previously performed in vivo research with rats has indicated complex effects [van der Ven et al., 2006] that cannot yet be explained based on known mechanisms of action. 
Therefore the present project follows a proteomic approach to study liver protein changes in global protein distribution in a non-targeted way followed by pathway analysis.

Liver samples have been obtained in a previous study with short term exposure of eu(ET) and hypothyroid (HT) female and male rats to lower HBCD levels (7 days; 0, 3, 30 $\mathrm{mg} \mathrm{HBCD/kg} \mathrm{body} \mathrm{weight/day).} \mathrm{The} \mathrm{liver} \mathrm{proteome} \mathrm{was} \mathrm{analysed} \mathrm{by} \mathrm{modern} \mathrm{gel-based}$ proteomic methods (comprising 2D-DIGE followed by protein identification with the help of mass spectrometric methods). Results were compared with data from thyroid hormones, dietary and reproduction related hormones, and put into a toxicological context. Proteins found changed in abundance were further analyzed and data interpreted by pathway analyses.

These findings were put into context of the proteomic methods applied, of proteomic investigations involving other toxic organic compounds (endocrine disrupters), and compared to monitoring variability of protein pattern in rat serum.

The following research questions have been defined:

1) What are the possibilities and strategies in proteomics as a tool to study sub-lethal toxicological effects of compounds with a long term effect?

2) Is it possible to see changes in the rat liver proteome in sub-lethal and short-term exposure to $\mathrm{HBCD}$, by using a modern gel-based proteomic method?

3) Which liver proteins and pathways are influenced by short term exposure to HBCD in euthyroid versus hypothyroid animals?

4) What is the impact of gender on the liver proteome?

5) Is gender reflected in serum protein composition and what implications does this have on the search for biomarkers?

\section{Thesis outline}

Firstly Chapter 2 provides more information about possibilities and strategies in gelbased proteomics. It describes the workflow including different options/strategies depending on the sample type to investigate and sample pretreatment. 
A more detailed overview on the application and the additional benefit of proteomic methods in toxicological investigations is given in Chapter 3, exemplified on the compound groups dioxins, polychlorinated biphenyls (PCBs), and polybrominated diphenyl ethers (PBDEs).

Chapter 4 investigates pattern changes in the liver proteome of eu- and hypothyroid female rats which underwent short-time exposure with HBCD. The results with female rats are compared to a similar experiment in male rats as detailed in Chapter 5, revealing clear gender differences.

In Chapter 6 gender related differences are studied in the serum proteome of rats under control conditions or during inflammation.

The potential role of proteomic methods and the relevance of the gender-specific findings in rats with or without exposure to HBCD are summarized and discussed in Chapter 7. Future perspectives give an outlook on next steps to be taken to deepen/extend and confirm the present results.

\section{References:}

Alaee, M., Arias, P., Sjodin, A., Bergman, A. (2003). An overview of commercially used brominated flame retardants, their applications, their use patterns in different countries/regions and possible modes of release. Environ. int. 29, 683-689.

Alban, A., David, S. O., Bjoreksten, L., Andersson, C., Sloge, E., Lewis, S., Currie, I. (2003). A novel experimental design for comparative two-dimensional gel analysis: Twodimensional difference gel electrophoresis incorporating a pooled internal standard. Proteomics 3, 36-41.

Altelaar, A. F. M., Heck, A. J. R. (2012). Trends in ultrasensitive proteomics. Curr. Opin. Chem. Biol. 16, 206-213.

Anderson, N. L., Anderson, N. G. (1998). Proteome and proteomics: New technologies, new concepts, and new words. Electrophoresis 19, 1853-1861.

Cantón, R. F., Peijnenburg, A. A., Hoogenboom, R. L., Piersma, A. H., van der Ven, L. T., van den Berg, M., Heneweer, M. (2008). Subacute effects of 
hexabromocyclododecane (HBCD) on hepatic gene expression profiles in rats. Toxicol. Appl. Pharmacol. 231, 267-272.

Covaci, A., Gerecke, A. C., Law, R. J., Voorspoels, S., Kohler, M., Heeb, N. V., Leslie, H., Allchin, C. R., De Boer, J. (2006). Hexabromocyclododecanes (HBCDs) in the environment and humans: A review. Environ. Sci. Technol. 40, 3679-3688.

Darnerud, P. O. (2003). Toxic effects of brominated flame retardants in man and in wildlife. Environ. int. 29, 841-853.

De Wit, C. A. (2002). An overview of brominated flame retardants in the environment. Chemosphere 46, 583-624.

Díez, J. J., Molina, I., Ibars, M. T. (2003). Prevalence of thyroid dysfunction in adults over age 60 years from an urban community. Exp. Clin. Endocrinol. Diabetes 111, 480-485.

Eckersall, D., de Almeida, A. M., Miller, I. (Eds.) (2012), Thematic Issue "Farm Animal Proteomics" in J. Proteomics 75.

European Commission. Risk Assessment Report, Hexabromocyclododecane, CAS No:25637-99-4, R044_0805_env_hh_final_EBC.doc. http://ecb.jrc.ec.europa.eu/esis, 1492. 1-5-2008. Ref Type: Generic.

Germer, S., Piersma, A. H., van der Ven, L., Kamyschnikow, A., Fery, Y., Schmitz, H.J., Schrenk, D. (2006). Subacute effects of the brominated flame retardants hexabromocyclododecane and tetrabromobisphenol A on hepatic cytochrome P450 levels in rats. Toxicology 218, 229-236.

Greenbaum, D., Colangelo, C., Williams, K., Gerstein, M. (2003). Comparing protein abundance and mRNA expression levels on a genomic scale. Genome Biol. 4, 117; doi: 10.1186/gb-2003-4-9-117.

Kalachova, K., Hradkova, P., Lankova, D., Hajslova, J., Pulkrabova, J. (2012). Occurrence of brominated flame retardants in household and car dust from the Czech Republic. Sci. Total Environ. 441, 182-193.

Kiciński, M., Viaene, M. K., Den Hond, E., Schoeters, G., Covaci, A., Dirtu, A. C., Nelen, V., Bruckers, L., Croes, K., Sioen, I., Baeye, W., Van Larebeke, N., Nawrot, T. S. (2012). Neurobehavioral function and low-level exposure to brominated flame retardants in adolescents: a cross-sectional study. Environ. Health 11, 86.

Kling, P., Förlin, L. (2009). Proteomic studies in zebrafish liver cells exposed to the brominated flame retardants HBCD and TBBPA. Ecotoxicol. Environ. Saf. 72, 19851993.

Kling, P., Norman, A., Andersson, P L., Norrgren, L., Förlin, L. (2008). Gender-specific proteomic responses in zebrafish liver following exposure to a selected mixture of brominated flame retardants. Ecotoxicol. Environ. Saf. 71, 319-327. 
Laemmli, U. K. (1970). Cleavage of structural proteins during the assembly of the head of bacteriophage T4. Nature 222, 680-685.

Law, R. J., Herzke, D., Harrad, S., Morris, S., Bersuder, P., Allchinet, C. R. (2008). Levels and trends of HBCD and BDEs in the European and Asian environments, with some information for other BFRs. Chemosphere 73, 223-241.

Liu, Y., Hüttenhain, R., Collins, B, Aebersold, R. (2013). Mass spectrometric protein maps for biomarker discovery and clinical research. Expert Rev. Mol. Diagn. 13, 811825 .

Lottspeich, F., Zorbas, H. (Eds.), Chapter 29: Proteomanalyse, in: Proteinanalytik, Spektrum Akademischer Verlag, Heidelberg, Berlin, 1998; pp. 815-827.

Marouga, R., David, S., Hawkins, E. (2005). The development of the DIGE system: 2D fluorescence difference gel analysis technology. Anal. Bioanal. Chem. 382, 669-678.

Miller, I., Serchi, T., Gutleb, A. C. (Eds.) (2016). Thematic Issue "Environment and (Prote)-OMICS" in J. Proteomics 137.

Nesatyy, V. J., Suter, M. J.-F. (2007). Proteomics for the Analysis of Environmental Stress Responses in Organisms, Environ. Sci. Technol. 41, 6891-6900.

Oliveira, B. M., Coorssen J. R., Martins-de-Souza, D. (2014). 2DE: The Phoenix of Proteomics. J. Proteomics 104, 140-150.

Rabilloud, T., Chevallet, M., Luche, S., Lelong, S. (2010). Two-dimensional gel electrophoresis in proteomics: Past, present and future. J. Proteomics 73, 2064-2077.

Rogowska-Wrzesinska, A., Le Bihan, M.-C., Thaysen-Andersen, M., Roepstorff, P. (2013). 2D gels still have a niche in proteomics. J. Proteomics 88, 4-13.

Schriks, M., Roessig, J. M., Murk, A. J., Furlow, J. D. (2007). Thyroid hormone receptor isoform selectivity of thyroid hormone disrupting compounds quantified with an in vitro reporter gene assay. Environ. Toxicol. Pharmacol. 23, 302-307.

Schriks, M., Zvinavashe, E., Furlow, J. D., Murk, A. J. (2006). Disruption of thyroid hormone-mediated Xenopus laevis tadpole tail tip regression by hexabromocyclododecane (HBCD) and 2,2',3,3',4,4',5,5',6-nona brominated diphenyl ether (BDE206). Chemosphere 65, 1904-1908.

Thibault, P., Gingras, A.-C. (Eds.) (2015), Thematic Issue "Protein Dynamics in Health and Disease" in J. Proteomics 118.

Tian, Q., Stepaniants, S. B., Mao, M., Weng, L., Feetham, M. C., Doyle, M. J., Yi, E. C., Dai, H., Thorsson, V., Eng, J., Goodlett, D., Berger, J. P., Gunter, B., Linseley, P.S ., Stoughton, R. B., Aebersold, R., Collins, S. J., Hanlon, W. A., Hood, L. E. (2004). Integrated Genomic and Proteomic Analyses of Gene Expression in Mammalian Cells. Mol. Cell. Proteomics 3, 960-969. 
Tomko, G., McDonald, K. M. (2013). Environmental fate of hexabromocyclododecane from a new Canadian electronic recycling facility. J. Environ. Manage. 114, 324-327.

Uenlue, M., Morgan, M. E., Minden, J. S. (1997). Difference gel electrophoresis: a single gel method for detecting changes in protein extracts. Electrophoresis 18, 2071-2077.

van der Ven, L. T. M., Leonars, P. E. G., Slob, W., Lilienthale, H., Litens, S., Herlin, M., Håkansson, H., Cantón, R. F., van den Berg, M., Visser, T. J., van Loveren, H., Vos, J. G., Piersma, A. H. (2006). A 28-day oral dose toxicity study enhanced to detect endocrine effects of hexabromocyclododecane in Wistar rats. Toxicol. Sci. 94, 281-292.

Westermeier, R. (Ed.), Method 10: IEF in immobilzed pH gradients, in: Electrophoresis in Practice. A Guide to Methods and Applications of DNA and Protein Separations, 3rd ed. VCH Verlagsgesellschaft GmbH, Weinheim, Germany, 2001; pp. 223-238.

Wilson, K. L., Casey, B. M., McIntire, D. D., Halvorson, L. M., Cunningham, F. G. (2012). Subclinical thyroid disease and the incidence of hypertension in pregnancy. Obstet. Gynecol. 119, 315-320.

Zhang, Y., Fonslow, B. R., Shan, B., Baek, M.-C., and Yates, J. R. III. (2013). Protein Analysis by Shotgun/Bottom-up Proteomics. Chem. Rev. 113, 2343-2394. 


\section{Chapter 2}

\section{Protein separation strategies in gel-based proteomics}

\section{Miller, I.}

Chapter 3: Protein Separation Strategies

in: Methods in Animal Proteomics (Eckersall, P.D., Whitfield, P.D, eds), 2011, John

Wiley \& Sons, Chichester, UK; p.41-76. ISBN: 978-0-8138-1791-0.

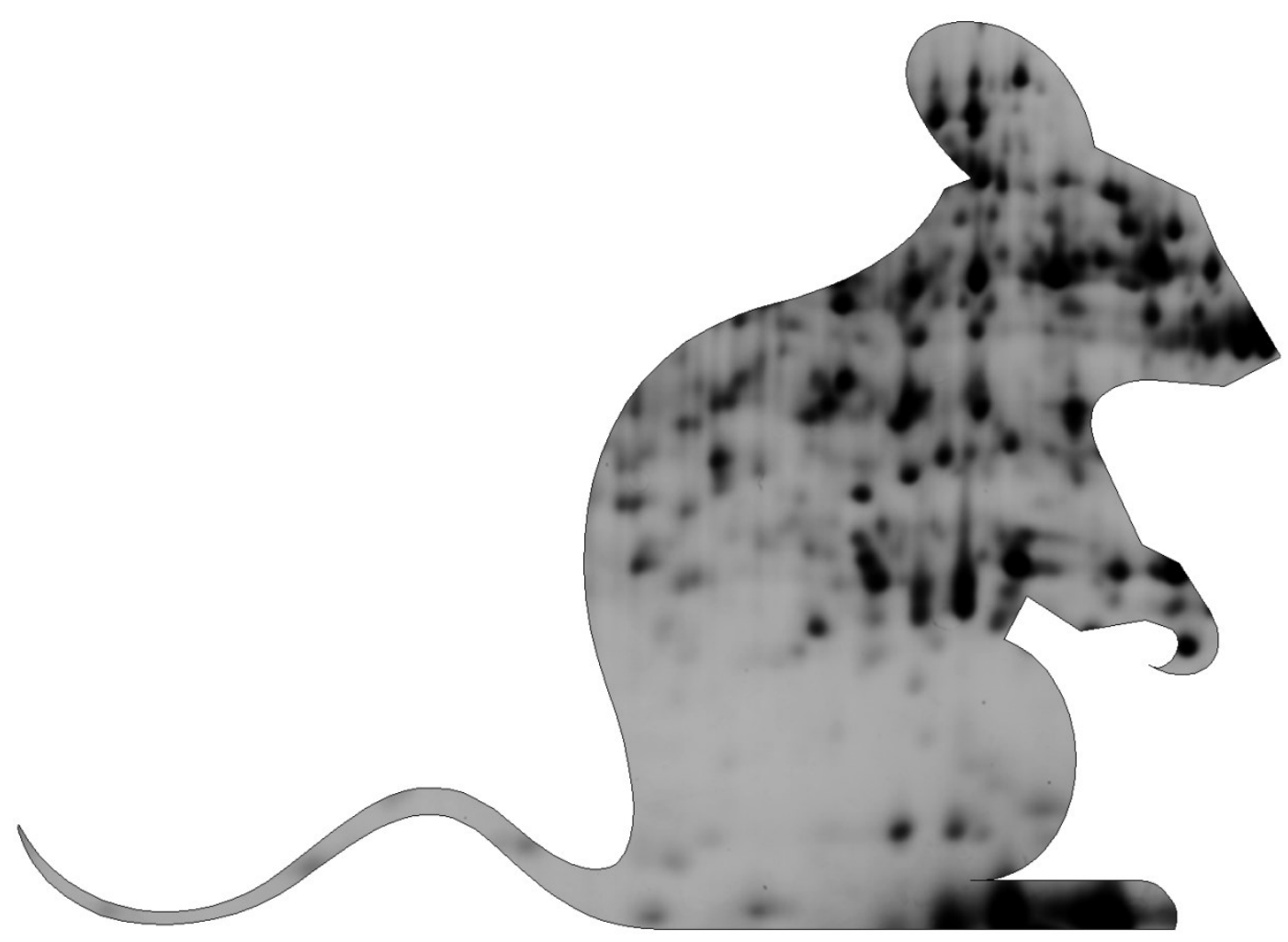





\section{Protein Separation Strategies}

Ingrid Miller

\subsection{Introduction}

Proteomics aims at simultaneous analysis of complex protein mixtures. Contrary to protein analysis, it is not (primarily) interested in characterization or quantification of single proteins. Proteomic investigations mainly rely on protein patterns, and protein identification is achieved only at a later time. Therefore, proteomic strategies aim at high-resolution methods, usually twoor multidimensional, to provide a good overview on protein composition. Nowadays, there are two main types of proteomic workflow: (1) one approach relying on two-dimensional gel electrophoretic (2DE) separations of the sample, followed by appropriate detection, evaluation (including statistical analysis), and identification of possibly interesting protein spots, and (2) the other approach taking advantage of mass spectrometric (MS) methods, usually in combination with one- or multidimensional liquid chromatography, after enzymatic or chemical cleavage of the protein specimen (see Chapter 2 for more details). The present chapter will focus on 2DE and associated protein separation strategies illustrating the numerous methodological possibilities this method can offer. The aim is to address the question, "What is possible; how is it possible?" rather than, "What has been done in the animal proteomic field?" (which is covered elsewhere in this volume).

Therefore, the examples cited do not always concern animal applications, but try to illustrate methodology in an optimal way.

Methods in Animal Proteomics, First Edition. Edited by P. David Eckersall,

Phillip D. Whitfield.

(C) 2011 John Wiley \& Sons, Inc. Published 2011 by John Wiley \& Sons, Inc. 


\section{2 "Classical" 2DE}

\subsubsection{The Method}

The term "(high-resolution) 2DE" is nowadays used for the specific combination of first-dimension isoelectric focusing (IEF) and second-dimension sodium dodecyl sulfate polyacrylamide gel electrophoresis (SDS-PAGE). Thus, two different properties of the protein determine its position on the gel, the isoelectric point (pI) and the molecular weight (Mr). IEF is performed in the presence of denaturing and reducing agents, to inhibit protein interactions, that is, split protein complexes into single components and complex proteins into their subunits. The method was first described almost at the same time by O'Farrell (1975) and Klose (1975). At that time, the $\mathrm{pH}$ gradient for separation in IEF was established by carrier ampholytes and usually performed in tube gels. Later on, immobilized pH gradient (IPG) methodology was developed (Bjellqvist et al., 1982; Gianazza and Righetti, 2009), which allowed more stable $\mathrm{pH}$ gradients in thin-layer horizontal gels. Over the years, 2DE methodology has become more refined in relation to separation range, resolution, and protein detection, until arriving at the present high-level (SWISS-2D PAGE database, http://us.expasy.org/ch2d/protocols/; Görg et al., 2000). It has become an established and widely used technique; precast gels are commercially available, in different types and sizes, together with readymade reagents and kits to help the whole procedure.

The present standard protocols comprise several steps:

1. First dimension: IPG single strips of $0.5 \mathrm{~mm}$ thickness, a few millimeter width, and variable length are rehydrated to contain $8 \mathrm{M}$ urea, $0.5 \%$ (w/v) CHAPS (3-[(3-Cholamidopropyl)dimethylammonio]1-propanesulfonate) as a zwitterionic detergent and $0.5 \%(\mathrm{v} / \mathrm{v})$ carrier ampholytes, both to enhance protein solubilization especially of membrane proteins, and $0.2 \%(\mathrm{w} / \mathrm{v})$ dithiothreitol (DTT) as a reducing agent. Alternatively, instead of urea alone a mixture of $7 \mathrm{M}$ urea and $2 \mathrm{M}$ thiourea is often used for cell or tissue lysates, as this mix has proven beneficial for solubilization of membrane proteins or proteins tending to precipitate around their pI (Rabilloud et al., 1997; Molloy, 2000). Samples are applied and focusing is performed until the optimal amount of volt hours is reached (for additional technical considerations see Section 3.2.3.3). The strips are either immediately used or stored frozen at $-20^{\circ} \mathrm{C}$ or $-80^{\circ} \mathrm{C}$.

2. Equilibration: IPG strips are incubated in two different portions of tris $\mathrm{HCl}$ buffer with additional urea, SDS and glycerol, the first containing DTT for protein reduction, the second iodoacetamide for alkylation. Concentrations may vary slightly, but formulations are mostly based on the methods outlined in the paper by Görg et al. (2000). 
3. Second dimension: The equilibrated IPG strip is transferred on top of an SDS-PAGE gel of variable concentration and cross-linking (gradient or homogeneous gel), with or without stacking gel. Protocols used are mainly based on the classical Laemmli system (Laemmli, 1970).

4. Detection: As appropriate (see later Sections 3.5 and 3.6).

\subsubsection{Applications}

A typical 2DE experiment of an unknown or little characterized sample will usually start with a standard protocol, wide range IPGs, and SDS-PAGE gels with appropriate concentration for an average Mr range. This approach will help to get an overview of the distribution of the protein spots in the respective sample and to decide about further optimization of the separation system.

There are two main strategies that have been applied when investigating new samples or sample types: (1) After optimizing the separation system, the first strategy aims at establishing spot maps and at identifying as many spots as possible (usually the ones with high to medium abundance or spots that seem characteristic of the sample). Once established, these protein identification maps are universal tools for any kind of further investigations. (2) The second approach focuses from the very beginning on a comparison of different samples (e.g., healthy/diseased animals, treated/untreated cells) and is only interested in spot pattern differences. After careful evaluation by quantification (including statistics) differentially regulated protein spots are selected for identification. Nowadays, the second approach is usually preferred; it is indeed valuable when one specific question has to be addressed, in high-resolution patterns with a large number of spots, and with MS methods for spot identification (where differentially regulated spots are cut out from the gel and further analyzed). Although MS procedures are also essential for protein identification maps, Western blotting or other specific detection methods may be equally helpful (see also Section 3.5.2).

Proteomic investigation of animal-derived samples started quite soon after the initial techniques were developed, for example, in a paper comparing 2DE patterns of bovine and human milk (Anderson et al., 1982).

Although 2DE protein patterns and main proteins of, for example, serum, seem comparable between species, homologous proteins may differ in physicochemical parameters (pI, Mr) and/or concentration, while species-specific proteins have been found. Figure 3.1a illustrates all these effects in serum samples of a few randomly selected species: goat (A), horse (B), pig (C), and $\operatorname{dog}(\mathrm{D})$. Two proteins, albumin (marked with " 1 ") and the $\beta$-chain of haptoglobin (marked with "2"), an acute phase protein in most animal species, are indicated. Although homologous and present in all samples, they are localized at different positions on the gels. In contrast, haptoglobin levels of healthy 

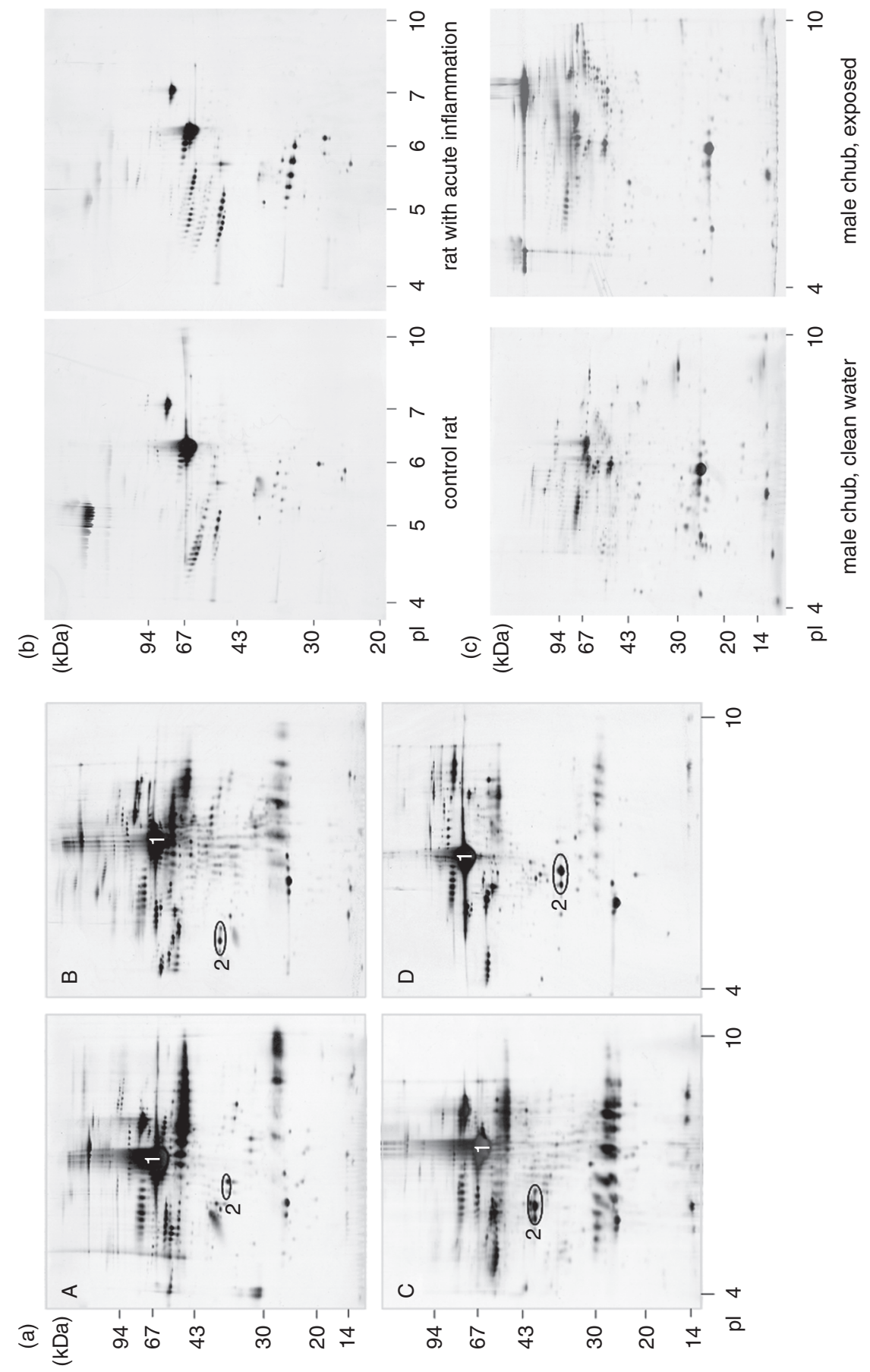
cows are below the detection limit of 2DE (if using unfractionated serum) and the $\beta$-chain is only found in inflammatory states (Wait et al., 2002).

Findings like these have been the reason for setting up reference maps for each species, such as for cat (Felis silvestris; Miller and Gemeiner, 1992), cow (Bos taurus; Wait et al., 2002), horse (Equus caballus; Miller et al., 2004a), and pig (Sus scrofa; Miller et al., 2009). Most of these studies investigate not only the serum pattern of healthy animals, but also changes occurring under specific conditions, such as inflammation or pregnancy (Cairoli et al., 2006). For laboratory animals like rat (Rattus norvegicus; a series of papers starting with Haynes et al., 1998) and mouse (Mus musculus; Duan et al., 2004; Wait et al., 2005b), more detailed studies exist, including followup studies of drug treatment (Eberini et al., 2000; Gianazza et al., 2002), as these species are often used as animal models for human diseases.

More reference patterns, some with clickable maps, can be found on WORLD-2DPAGE (http://www.expasy.org/ch2d/2d-index.html), although the majority are from human or laboratory animal specimens of different types. There are also compilations of, for example, different cow organs and cells (Talamo et al., 2003; D'Ambrosio et al., 2005) and heart proteins of dogs, rats, and humans (HSC-2DPAGE at Harefield Hospital, http://www.doc. ic.ac.uk/vip/hsc-2dpage/).

As mentioned earlier, differential regulation and comparison of at least two different states is an often used proteomic approach; Figure 3.1b,c show typical examples. Serum protein patterns of a control rat and of an animal with acute inflammation differ in (up- and down-) regulation of a number of proteins, depending on the stimulus, resulting in acute and chronic inflammation (Fig. 3.1b; for more details see Eberini et al., 2000; Sironi et al., 2001; Gianazza et al., 2002).

Exposure of male chubs (Leuciscus cephalus) to water contaminated with estrogenes or endocrine-disrupting chemicals leads to expression of moderate to high levels of serum vitellogenin (Flammarion et al., 2000; Grillitsch et al., 2003). It is detectable in the serum of exposed male chubs as different fragments (Fig. 3.1c; Kanaya et al., 2000). Vitellogenin is the major egg yolk

Fig. 3.1 (Left) Classical 2DE as a global approach, with serum as an example. Ten centimeter-long IPGs in the range of $\mathrm{pH} 4-10$ (nonlinear gradient), SDS-PAGE on gradient gels $(10 \%-15 \%)$ of $14 \times 14 \mathrm{~cm}$, silver stain; $0.5 \mu \mathrm{L}$ of each serum sample was applied. (a) Comparison of serum protein patterns of different animal species. Sera have been obtained from clinically healthy animals: (A) goat, (B) horse, (C) pig, (D) dog. Two proteins are indicated: (1) serum albumin, (2) haptoglobin $\beta$-chain. (b) Comparison of two different states: changes due to inflammation. Left image: serum of a male control rat (Sprague Dawley); right image: serum of a male rat with acute inflammation (Miller et al., 1999). (c) Comparison of two different states: changes due to exposure to chemicals. Left image: serum of a healthy male chub (Leuciscus cephalus); right image: serum of a male chub that had been exposed to bisphenol A-contaminated surface water. 
protein and is typically found only in the serum of female fish, with seasonal changes.

\subsubsection{Modifications}

The standard methods are usually able to give a good global view of the proteome of the respective sample, for example, to show the overall $\mathrm{pI}$ and Mr distribution of the proteins, the range with the components of highest/ lowest concentration, and sometimes also gel areas with largest variation. Based on this overview the initial 2DE protocol may be adapted to the specific needs of the sample.

Table 3.1 gives an overview of the individual 2DE steps and their possible modifications leading to moderate or profound changes in methodology. These possible changes in the protocols will be further discussed in following sections.

3.2.3.1 First Dimension IEF allows selection of the $\mathrm{pH}$ gradient according to one's needs, and over the years appropriate protocols have been developed.

Table 3.1 Possible variation in single steps

\begin{tabular}{|c|c|c|}
\hline Steps & Procedure & Variation \\
\hline \multirow[t]{4}{*}{ Sample } & \multirow[t]{2}{*}{ Sample preparation } & $\begin{array}{l}\text { Body fluids: dilution to appropriate concentration } \\
\text { (choice of diluent) }\end{array}$ \\
\hline & & $\begin{array}{l}\text { Tissues: solubilization (complete or sequential/ } \\
\text { differential) }\end{array}$ \\
\hline & Pretreatment & Detergents, labeling \\
\hline & Prefractionation & $\begin{array}{l}\text { For example, chromatography, electrophoresis, } \\
\text { affinity methods }\end{array}$ \\
\hline \multirow[t]{2}{*}{ First dimension } & IEF/IPG & $\begin{array}{l}\text { Conditions: native, unfolding, reducing; additives } \\
\text { Change in pI range } \\
\text { Change in matrix (agarose) }\end{array}$ \\
\hline & $\begin{array}{l}\text { Others (native } \\
\text { PAGE, BN-PAGE) }\end{array}$ & \\
\hline \multicolumn{3}{|l|}{ Equilibration } \\
\hline Second dimension & Zone electrophoresis & $\begin{array}{l}\text { SDS-PAGE, native PAGE; additives (DTT, BAC) } \\
\text { Change in Mr range }\end{array}$ \\
\hline \multirow[t]{3}{*}{ Detection } & \multirow[t]{3}{*}{ Staining } & Overall protein \\
\hline & & $\begin{array}{l}\text { Specific (glyco-, phospho-; zymograms), for } \\
\text { post-detection }\end{array}$ \\
\hline & & Immunoreagents \\
\hline Post-detection & MS, evaluation & \\
\hline
\end{tabular}


In IPGs, the charge-bearing acrylamide derivatives (Immobilines ${ }^{\mathrm{TM}}$ [GE Healthcare Life Sciences, Munich, Germany], acrylamidobuffers ${ }^{\mathrm{TM}}$ [Fluka, Buchs, Switzerland], etc.) that form the $\mathrm{pH}$ gradient are polymerized into the gel. There are commercially available gels or strips, but gels can also be labmade. Different types of $\mathrm{pH}$ ranges and gradient shapes are possible: wide or ultrawide pH ranges (Gianazza et al., 1989), narrow ranges of just a few selected $\mathrm{pH}$ units, or even ultra-narrow "zoom" gels of less than one $\mathrm{pH}$ unit (Hoving et al., 2000). Also, the shape of the obtained pH curve may be adapted to the specific needs: linear gradients for samples with even protein distribution over the whole $\mathrm{pH}$ range, or a nonlinear shape for specimens like serum and related biological fluids. Otherwise, for the latter the $\mathrm{pH}$ range 4.5-6 is rather crowded with many high- to medium-abundance proteins focusing within this range (Gianazza et al., 1985, see also Fig. 3.1b). Narrow $\mathrm{pH}$ gradients allow a more specific look at the selected area, so that low-copy proteins are more clearly seen or a higher resolution of otherwise crowded areas is caught. Due to its higher spatial resolution this approach may reveal previously undetected protein spots or additional isoforms (Westbrook et al., 2001). If sample amount is not limited, narrow-range IPGs can help to avoid prefractionation (and possible alteration of the sample due to this step), when "unwanted" proteins migrate out of the gel and collect at the electrode strips, whereas proteins of interest concentrate and focus at their pIs.

Figure 3.2 compares separation of a commercially available pig immunoglobulin $\mathrm{G}(\mathrm{IgG})$ preparation in a nonlinear $\mathrm{pH} 4-10$ and a linear $\mathrm{pH}$ 6-10 gradient. In particular, the more alkaline spots are better resolved in the less steep pH 6-10 gradient. Furthermore, the clustered light and heavy chains of IgG can be seen as spot chains or single spots, which may be either IgG
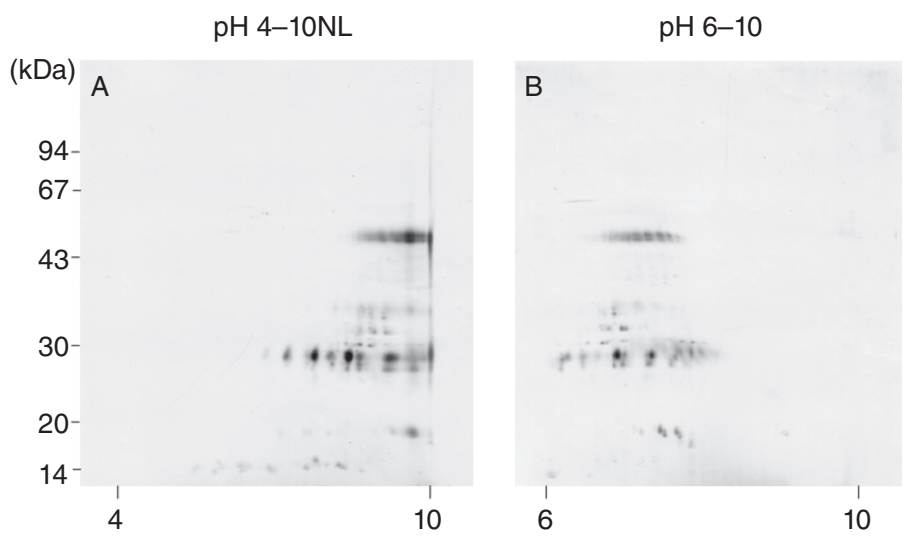

Fig. 3.2 Classical 2DE in different $\mathrm{pH}$ ranges. (A) IPG $\mathrm{pH} 4-10$ (nonlinear gradient). (B) IPG $\mathrm{pH}$ 6-10 (linear); SDS-PAGE and silver staining as in Figure 3.1. Sample: purified pig IgG (Accurate Chemical \& Scientific Corporation, Westbury, NY). 
breakdown products or minor contaminants of the preparation. This also highlights the versatility of $2 \mathrm{DE}$ for product control.

Approaches with varying $\mathrm{pH}$ ranges have been described for human lymphoma samples (Hoving et al., 2000) and heart proteins (with partially overlapping $\mathrm{pH}$ ranges, Westbrook et al., 2001), and also for mouse serum proteins in the $\mathrm{pH}$ ranges 3-6 and 5-8, which were used to study changes due to burn injuries or due to lipopolysaccharide-induced acute-phase response (Duan et al., 2004). Separation of the acidic protein $\alpha_{1}$-acid glycoprotein in a $\mathrm{pH}$ 2.5-5 gradient was also shown in a pig serum protein map in addition to the normal pH 4-10 nonlinear gradient (Miller et al., 2009).

3.2.3.2 Second Dimension 2DE can also be varied in the second dimension, depending on the expected $\mathrm{Mr}$ range of the proteins to separate. The most often used parameter for adaptation is the $\mathrm{T}$ value (the percentage of acrylamide plus bisacrylamide). Slabs can be cast either as homogeneous gels or as gradient gels, usually in the range of $8 \%$ to $15 \% \mathrm{~T}$. Gradient gels give a higher resolution and sharper spots as the pore size decreases during the migration of the proteins. Some additional resolution may be gained with slightly prolonged runs, provided the buffer capacity is high enough (Fig. 3.1b). Use of a stacking gel with lower cross-linking is not obligatory. In addition to the standard Laemmli buffer system (Laemmli, 1970), a tristricine buffer system has been suggested, allowing protein separation in the range of $1-100 \mathrm{kDa}$, so that smaller molecules can be better resolved than with the usual method (Schägger and von Jagow, 1987). In the original recipe the gel consists of a small-pore separation gel $(16 \% \mathrm{~T})$, a spacer $(10 \% \mathrm{~T})$, and a stacking gel $(4 \% \mathrm{~T})$. A taurine buffer system has also been suggested to obtain a wider Mr range (2.5-250 kDa) (Tastet et al., 2003b). Commercial gels are available for several electrophoresis chambers, but with a buffer composition different from the original Laemmli system. Gels thus have a longer shelf life but protein separation patterns might be different.

3.2.3.3 Technical Considerations Discussions on different possibilities in 2DE also have to take into account technical considerations and equipment. At present, the most used setup is a combination of IPG strips run in a horizontal chamber and of vertical SDS-PAGE. At the inception of 2DE, seconddimension SDS-PAGE was also performed in horizontal gels (Görg et al., 1985), but vertical gels offer several advantages: protein transfer from the first to the second dimension is easier; SDS-PAGE gels can have a thickness up to $1.5 \mathrm{~mm}$ allowing higher protein loads; multiple gels can be run in parallel in the same electrophoresis chamber. Another important technical point is the question of strip rehydration and sample application. IPGs are usually processed as dry strips, even if they are lab-made; as it is not easy to cast IPG gels containing denaturing/reducing additives, plain gels with the 
appropriate $\mathrm{pH}$ gradient are polymerized, washed and dried, and when required rehydrated in the appropriate solutions. Strips are either reswollen to the original thickness in cassettes similar to the polymerization chamber, in the presence of excess solution, or the exact amount of liquid is applied in a groove of a reswelling tray and the dry strip is placed onto it, gel-side down. Both incubation procedures take between a few hours to overnight. Samples may be applied in different ways: mixed into the rehydration solution from which they are supposed to be absorbed into the complete strip ("in-gel rehydration"; Rabilloud et al., 1994) or applied onto the already rehydrated strip via cup loading (in small sample cups) or on filter paper pads. In-gel rehydration may be beneficial for dilute or even salt-containing samples, but it takes hours for larger proteins to diffuse into the strips. Therefore, active reswelling may be supported by low voltage (Görg et al., 1999). Sample loading via cups or filter pieces allows selective application at an appropriate $\mathrm{pH}$, which is favorable for labile proteins. The pros and cons of the methods have been discussed in detail (Westermeier and Naven, 2002). Protein patterns may change due to different sample treatment and application (some examples are given in Wait et al., 2005a). In addition, sample application may be one of the steps that is most prone to give rise to protein losses (sometimes also selectively; for an estimation on protein losses in 2DE see Zuo and Speicher, 2000 and Zhou et al., 2005). Sample application is followed by the firstdimension run, performed either gel-side up or down, depending on the electrophoresis chamber. Strips may be protected from drying out and from oxidation by a cover fluid (paraffin oil). The length of the run depends on strip length, $\mathrm{pH}$ range, and sample type, and is usually given in $\mathrm{kVh}$. Focused strips may be stored frozen (at $-20^{\circ} \mathrm{C}$ or $-80^{\circ} \mathrm{C}$ ).

\subsection{Other Varieties of 2DE}

\subsubsection{Different Additives and Separation Conditions}

Protein classes with specific properties (e.g., hydrophobic or alkaline proteins) need adaptations to the 2DE systems that are larger than the ones described in the previous section.

3.3.1.1 Detergents Detergents in combination with the denaturants urea and thiourea usually help to dissolve membrane proteins if they are not too hydrophobic. Nevertheless, it has been found that in most cases membrane proteins are underrepresented in the 2DE patterns (Rabilloud et al., 2008), especially in semi-preparative gels. Nonionic or zwitterionic detergents like CHAPS help to solubilize proteins by interaction, but are not supposed to change the surface charge and the electrophoretic mobility of the respective 
proteins. In addition to the formerly used Triton X-100 and Nonidet P-40, several other detergents have been synthesized and tested for their suitability to improve solubility of membrane proteins. These include linear sulfobetaines, amidosulfobetaines, or dodecylmaltoside (Rabilloud et al., 2008). Although some systematic studies exist (Tastet et al., 2003a), the efficiency of detergents is best tested empirically; selection will not only depend on the specific sample type but also on the question that needs to be addressed with 2DE. Changing the detergent in the separation system (e.g., solubilization plus IPG run) may have a large impact on the spot patterns. This has been shown for instance for human red blood cell ghosts (Luche et al., 2003). Approaches for membrane protein separations other than classical 2DE will be discussed in Section 3.3.2.

\subsubsection{Reducing Agents and Alkaline Proteins The formerly used volatile} and intensely smelling reducing agent $\beta$-mercaptoethanol has nowadays been replaced by dithiothreitol (DTT) for most applications. DTT works very well in acidic, neutral, and slightly alkaline $\mathrm{pH}$ ranges. Being a weak acid, it becomes ionized above $\mathrm{pH} 8$ and migrates toward the anode. Without further precautions, the alkaline region becomes more and more depleted of reducing agents and inadequately protected cysteines may be reoxidized under these conditions. This phenomenon is seen on the gel as horizontal streaks of basic spots. Tributylphosphine has been proposed as an alternative (introduced by Herbert et al., 1998), usually with an additional alkylation step with iodoacetamide, as it is poorly stable (Herbert et al., 2001). Unfortunately, complete alkylation of all proteins in a mixture is not easy to control and, furthermore, pIs of basic proteins become modified upon reaction. The use of organic disulfides like hydroxyethyldisulfide (HED) has also been suggested (Olsson et al., 2002), as they form mixed disulfides upon oxidation of the protein cysteinyl groups. HED can be used in combination with DTT and is able to maintain reducing conditions during the complete course of the first-dimension separation, even in alkaline $\mathrm{pH}$ ranges.

There are several precautions that should be taken when separating alkaline proteins in wide-range IPGs, and more importantly in narrow-range alkaline strips. IPGs should be run under paraffin oil protection to avoid oxidation; additionally, this oil may be degassed and flushed with argon. Samples should be applied anodically by cup loading to avoid longer exposure to alkaline pIs. Alkaline IPGs need less $\mathrm{Vh}$ than wider $\mathrm{pH}$ ranges, and overfocusing also results in streaking. It has been recommended that dimethylacrylamide is used in place of acrylamide and that up to $16 \%$ isopropanol and/or methylcellulose is included in the gel to suppress reverse electroosmotic flow (water transport to the anode) (Görg et al., 1997). Depletion of DTT during the run can be reduced with higher DTT starting concentrations in the gel and additional electrode pads soaked in DTT (Hoving et al., 2002). Taking into account all 
these measures, even histones with pI of up to 12 can be focused with good quality (Righetti et al., 1996; Görg et al., 1997).

3.3.1.3 Redox Options Reducing agents such as DTT break disulfide bonds and turn them into sulfhydryl groups. This concerns intra- as well as interchain disulfide bonds and, in the presence of chaotropes, leads to destruction of secondary and tertiary structure (unfolding), and-for proteins consisting of more than one chain - to the destruction of quaternary structure (dissociation of the molecule into subunits). If reduction of the sample is omitted and proteins are only exposed to SDS, the quaternary structure is not destroyed and unfolding of the proteins is only partial. Properties of the proteins, including apparent $\mathrm{Mr}$ and $\mathrm{pI}$, are in this case closer to that of the native protein, but these shifts very much depend on the protein and its particular structure. This effect can be utilized in 2DE for separation of proteins that show similar properties in classical 2DE (found as close spots/spot chains in crowded regions on the $2 \mathrm{DE}$ gels). This approach can be used instead of, or in combination with, the strategies described in Section 3.2.3. Examples have been reported for mouse serum (fig. 2 of Wait et al., 2005b), where better separation of $\alpha_{1}$-antitrypsin, serum protease inhibitor, $\alpha_{2}$-HS-glycoprotein, and group-specific component can be achieved using nonreducing gels. This approach is similarly beneficial for acidic bovine proteins in $\mathrm{pH}$ range 4-6 (Cairoli et al., 2006) and thus allows more exact follow-up of single-protein levels during gravidity. Theoretical and practical aspects of this redox approach have been detailed in Wait et al. (2005a), and illustrated by examples of human, mouse, rat, and cow serum protein patterns.

Proteins consisting of a single polypeptide chain usually show small to moderate $\mathrm{pI}$ and $\mathrm{Mr}$ shifts due to reducing/nonreducing treatment. Wellknown examples are albumin (lower $\mathrm{pI}$ without reduction, at the same time an apparent $\mathrm{Mr}$ of about $55 \mathrm{kDa}$ instead of $68 \mathrm{kDa}$ ) and transferrin (Wait et al., 2005a). Both proteins have a considerable number of intra-chain disulfide bonds. The described shifts are demonstrated in Figure 3.3a (compare images A2/A3, B3/B4). Changes in multimeric proteins are even more pronounced: native homodimers are about twice as large as their monomers, whereas $1 \mathrm{D}$ SDS-PAGE single bands of heterodimers upon DTT treatment are split into more than one band with lower Mr. Examples of multimeric proteins are the Igs: the main representatives - $\operatorname{IgG}, \operatorname{IgA}, \operatorname{IgM}$ - each consist of two light and two heavy chains connected via disulfide bonds, and, depending on the Ig class, they exist as mono-, di-, or pentamers. They are responsible for primary and secondary immune response and host defense, but can also be a sign of a plasma cell tumor. In the latter case they appear as monoclonal antibodies, all produced as identical replicates of one specific molecule produced by only one replicating cell clone. They give a typical electrophoretic pattern with very distinct spots/spot chains, especially the Ig light chains. Image A1 in 


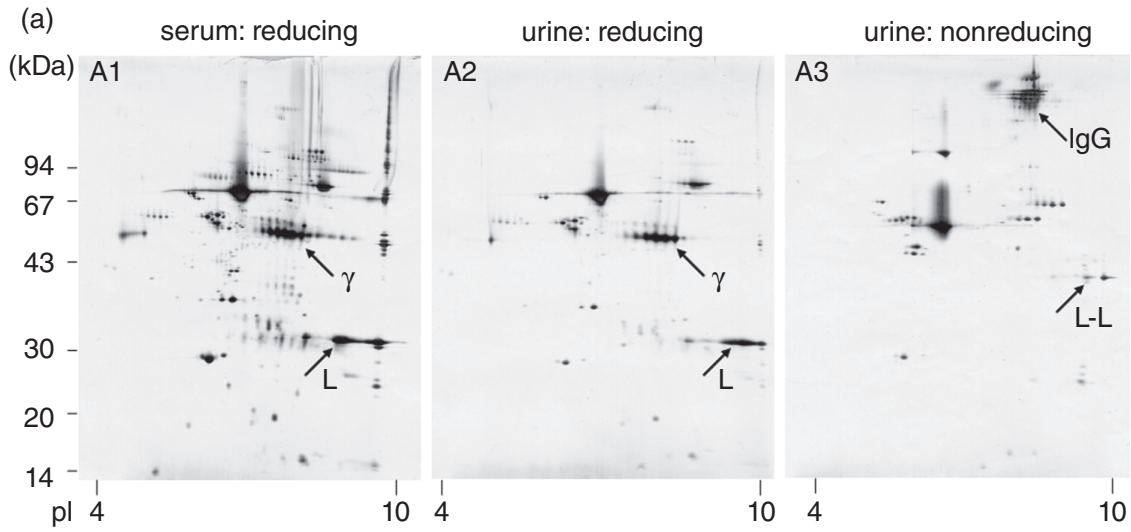

(b)

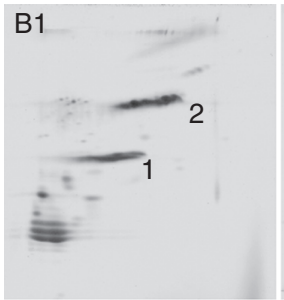

non-denaturing IPG native PAGE

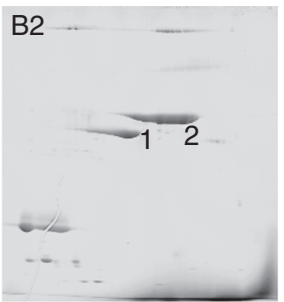

non-denaturing IPG SDS-PAGE

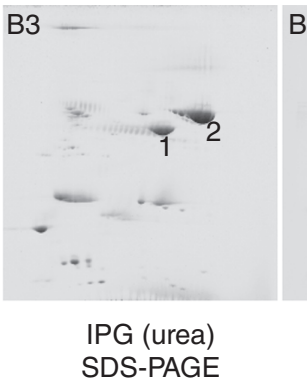

B4

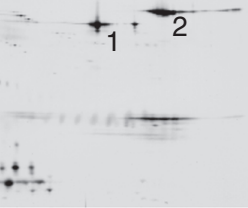

IPG (urea, DTT)

SDS-PAGE (DTT)

Fig. 3.3 Nonclassical 2DE (2DE under different conditions). (a) Reduction or not: detection of single chains and subunits. Case study of a dog with monoclonal gammopathy ( $\operatorname{IgG})$ : the $\operatorname{IgG}$ subunits, light (L) and heavy $(\gamma)$ chains, were detected under reducing conditions in serum (A1) and urine (A2); nonreducing 2DE revealed that in the urine free light chains (as dimers, L-L) and complete IgG were present (A3). (b) Influence of denaturation and reduction: the pattern of rabbit milk. Conditions as indicated below the images; gels B1-B3 were stained with Coomassie R-250 (milk volumes applied: $10 \mu \mathrm{L}$ in $\mathrm{B} 1,4 \mu \mathrm{L}$ in B2 and B3), gel B4 with silver $(0.2 \mu \mathrm{L}$ milk, heated in the presence of DTT and SDS). Notice the shift of the two indicated proteins: albumin (1) and transferrin (2); SDS-PAGE gels are aligned according to $\mathrm{Mr}$.

Figure 3.3a shows the serum protein pattern of a dog with lymphoma; the monoclonal light (indicated with L-) and heavy chain (type $\operatorname{IgG}$ ) can be clearly distinguished using classical reducing/denaturing 2DE. For diagnosis it is often interesting to learn about the presence of Bence Jones proteins (free monoclonal light chains) or complete monoclonal Ig. Bence Jones proteinuria is a sign of spillover of excess free monoclonal light chains, whereas the appearance of intact Ig marks the beginning of renal damage, which often develops in the course of gammopathies. The urinary protein pattern corresponding to the canine patient in image A1 is depicted in image A2. This specimen also reveals the two chains of the monoclonal antibody in reductive 
testing. When omitting DTT in 2DE (image A3, otherwise same sample), one can easily discern intact monoclonal Ig and some free light chains (in this case present as a dimer). Two other examples for dogs with monoclonal disorders, chronic lymphatic leukemia and plasmacytoma, and differing Ig patterns have been previously discussed (Miller et al., 2004b). All these examples show that the nonreducing pattern is most useful for the study of complex intact molecules versus asynchronous production of single chains (which in addition may have a different degree of polymerization).

3.3.1.4 Denaturing versus Native 2DE The native structure of a protein is determined by its sequence, but is only observed in appropriate environments. A protein in solution may exist as a mixture of interconverting conformations, in different isomeric forms, or as aggregates, or complexes with other proteins or small molecules. Changing the solvent conditions by adding chaotropes usually leads to loss of structure, accompanied by loss of biological activity (denaturation) and dissociation of molecular assemblies. The presence of high concentrations of reagents such as urea leads to an unfolding of proteins and exposure of groups otherwise buried inside the molecule. Thus, protein properties may change considerably, depending on the studied protein. 2DE can also be performed under native conditions, when in all separation steps urea, SDS, and reducing agents are omitted. The patterns obtained look quite different, for instance, for bovine adult and fetal serum (Manabe et al., 1987), compared with classical 2DE patterns of adult bovine serum (Wait et al., 2002). Native 2DE has the advantage that proteins retain their biological function, thus making it possible to apply enzymatic staining for the identification of particular proteins. This has been described for the detection of esterases and transferases in cytosol of bovine retina (Shimazaki et al., 2004a) or dehydrogenases in mouse liver (Shimazaki et al., 2004b). In addition, using immunodetection after native $2 \mathrm{DE}$, antibodies with specificity for conformational epitopes can be applied. A series of immunoblots with different specific antibodies has been used for the identification of bovine serum/plasma proteins (Manabe et al., 1987).

Manabe et al. (1999) have suggested performing 2DE series with increasing degree of denaturation/reduction to gather systematic information on proteins and their constituent polypeptides. The group has shown a series of 2DE images obtained with human serum as a sample and IEF with carrier ampholytes in the first dimension. Similar results have been obtained with pig serum (own unpublished results). The following four types of separations have been suggested:

- type I: non-denaturing IEF and native PAGE; this type reflects physiological conditions.

- type II: non-denaturing IEF and SDS-PAGE; this combination allows studying dissociation of noncovalently bound protein subunits. 
- type III: non-denaturing IEF and reducing SDS-PAGE (with urea and DTT in the intermediate equilibration step); disulfide-bonded polypeptides are dissociated during equilibration.

- type IV: classical 2DE (denaturing/reducing IEF and SDS-PAGE).

For the described types I-III the pI distribution of the serum proteins does not change; only differences in Mr due to dissociation of subunits and aggregates are noticed, resulting usually in more, smaller fragments. Between type III and IV there is a noticable pI shift due to inclusion of denaturing and reducing agents, but less change in $\mathrm{Mr}$.

A similar series of separations is shown in Figure 3.3b, but using IPGs for the focusing step and a slightly different combination of running conditions: rabbit milk has been separated using native 2DE (image B1), non-denaturing IPG/SDS-PAGE without reduction (image B2), denaturing IPG/SDS-PAGE (both dimensions without reduction, image B3), and classical 2DE (image B4). Images B2-B4 are aligned with reference to Mr. Two proteins, albumin (1) and transferrin (2) are marked throughout the series to illustrate their shifts as a function of separation conditions.

\subsubsection{Combination of Other Media or Separation Methods}

3.3.2.1 IEF in Agarose High Mr proteins may not be appropriately separated in IPGs or well transferred to the second-dimension gel, especially as solubility of most proteins decreases at their pIs. One possibility to overcome this limitation is performing IEF in agarose gels, a matrix that has much larger pores than polyacrylamide. Agarose IEF (with carrier ampholytes mixed into the gel) can also be performed under denaturing conditions, in the presence of $5 \mathrm{M}$ urea and $1 \mathrm{M}$ thiourea and with an SDS-PAGE step in the second dimension (Oh-Ishi and Maeda, 2002). The method has been applied to tissue extracts and in the study of different diseases, for example, cancer and endocrine disorders (Oh-Ishi and Maeda, 2007).

3.3.2.2 Zone Electrophoresis in Agarose The first dimension of 2DE need not always be IEF. Zone electrophoresis offers a wide variety of possibilities for separation under native conditions, as $\mathrm{pH}$, ionic strength, and buffer ions may be selected for the specific separation task. In a series of older papers the genetic polymorphism of several serum proteins was studied by a combination of zone electrophoresis under different conditions: The first dimension was performed in the non-sieving matrix agarose, usually at low $\mathrm{pH}$ (e.g., 5.0 or 5.4), and the second dimension in alkaline 12\% PAGE. Gels were stained with Coomassie, but also specifically for enzymatic activity. This 
setup has been applied to study $\mathrm{Pi}\left(\alpha_{1}\right.$-antitrypsin) phenotypes in horse (Juneja et al., 1979) and cattle (Juneja and Gahne, 1980), as well as to other polymorphic horse serum proteins (with agarose electrophoresis at higher $\mathrm{pH}$ in the first dimension; Juneja et al., 1984).

\subsubsection{Diagonal Electrophoresis Proteins of a complex mixture may also} be separated by SDS-PAGE in a 2D manner, using the $\mathrm{Mr}$ as a separation criterion in both dimensions. As in classical 2DE, a lane/gel strip from a firstdimension run is laid on top of a second SDS gel and electrophoresis is performed perpendicular to the first dimension. With identical runs in both dimensions, proteins align as spots in a diagonal. By introducing minor changes in one of the dimensions, deviations from this pattern are generated and may give hints concerning the composition of the sample mixture and the structure of the separated proteins. Using gels of different cross-linking or pore size may cause changes in behavior of anomalously migrating SDSprotein complexes (e.g., glycoproteins, highly basic or hydrophobic proteins) due to sieving effects. Protein reduction between first and second dimension gives information about intra- or inter-subunit disulfide bonds (see scheme in Wait et al., 2005a). Urea influences the folding and SDS binding of the proteins, while the introduction of other buffer ions (glycine, tricine, bicine) affects the mobility of the protein zones (Braun et al., 2007). Further diversity is achieved by inclusion of cationic detergents such as 16-benzyldimethyln-hexadecylammonium chloride (16-BAC; Hartinger et al., 1996) or cetyltrimethylammonium bromide (CTAB; Akins et al., 1992). These detergents proved particularly beneficial for integral membrane proteins with more than one transmembrane domain, but need first-dimension separations at low $\mathrm{pH}$ where proteins migrate to the cathode (Hartinger et al., 1996). For the very alkaline histones an acetic acid-urea (AU) or AU triton X-100 (AUT) system has been developed, which allows separation of histone species or variants. AU may be combined with a second-dimension run in a gel containing a nonionic detergent (Lubrol-WX) that also produces diagonal electrophoresis-like patterns (Bhatnagar and Bellvé, 1978). AU or AUT can also be used as a first or second dimension of SDS-PAGE, either with equilibration alone or with staining of the first-dimension lane between the runs (Davie, 1982). Both approaches allow further differentiation of histone modifications.

3.3.2.4 Blue Native (BN-) PAGE and Clear Native (CN-) PAGE Most of the described approaches denature the protein sample, by addition of either strong detergents or chaotropes. BN-PAGE uses milder conditions than classical $2 \mathrm{DE}$ and this allows the study of protein complexes, giving insight into the interaction of proteins in the cell. The specific features of BN-PAGE are mild detergents (triton X-100, dodecylmaltoside, digitonin), separation at $\mathrm{pH} 7.5$, 
6-aminocaproic acid as non-detergent zwitterionic compound to enhance solubilization, and inclusion of the blue dye Coomassie Brilliant Blue G-250 (CBB G) in the cathodic electrophoresis buffer (Wittig and Schägger, 2008). Protein complexes are separated according to size, and gradient gels of different pore size may be used. During the electrophoretic run, blue bands of stained proteins/protein complexes are visible; separation can be followed, and there is no need for further staining that may lead to damage of proteins or to loss of small molecules. CBB G causes a negative charge shift of the proteins; it remains tightly bound to the proteins and membrane proteins are thus converted to water-soluble proteins. Subsequent to separation, BN-PAGE allows in-gel measurements of enzyme activity by histological staining as well as isolation of membrane protein complexes in enzymatically active form (e.g., by electroelution) (Schägger and von Jagow, 1991). In a second dimension the complexes may be resolved into individual polypeptides by SDS-PAGE (Brookes et al., 2002). The first samples studied, and still a very prominent application, were mitochondria from different species, namely, the five mitochondrial respiratory subcomplexes that separate nicely in a poresize gradient. The single complexes were isolated with around 95\% purity, and enriched up to 20-fold (Wittig and Schägger, 2008). After a denaturing second-dimension SDS-PAGE their component subunits were identified by immunoblotting and MS. This combination of methods allows the establishment not only of an "inventory" of the mitochondrial subproteome but also of the ability to monitor changes due to treatment, for example, with the protein synthesis inhibitor chloramphenicol (Brookes et al., 2002). Further refinements of the method have been suggested, for instance, the use of agarose in the first dimension, which makes it possible to analyze protein complexes up to $8 \mathrm{MDa}$ (Nijtmans et al., 2002).

Clear (or colorless) native PAGE uses the same protein solubilization conditions and buffers as BN-PAGE, but without $\mathrm{CBB} G$ in the sample and cathode buffer. It is not a charge shift technique; it fully relies on the intrinsic charge of the molecules. Thus, in contrast to BN-PAGE, proteins with alkaline $\mathrm{pI}$ migrate to the cathode and are lost, and membrane proteins often tend to give smearing bands. CN-PAGE is the mildest electrophoretic technique and allows analysis of physiological supramolecular structures. Lately, there have been attempts to introduce charge shift induced by noncolored mixed micelles of neutral or anionic detergent in the cathode buffer, but this modified method is not as mild as CN-PAGE and favors dissociation of labile subunits from protein complexes (Wittig et al., 2007).

Refined setups also exist for 2D separation combining two runs of BNPAGE with different detergents. Disruption of supramolecular structures into smaller protein complexes is achieved only in the second dimension. Features and applications of all described varieties of this type of native PAGE have been reviewed (Wittig and Schägger, 2008). 


\subsection{Sample Complexity}

At present, only extrapolations exist for determination of the number of proteins in a cell, for instance, in yeast $20,000-30,000$ proteins or protein spots have been estimated for the $\mathrm{pH}$ range 3.5-11.5 (based on an extrapolation from narrow-range gradient IPG 2DE, yielding 2700 spots for $0.7 \mathrm{pH}$ units; Corthals et al., 2000). Practical experiments have shown many more spots than predicted in theory, most likely due to isoforms, posttranslational modifications, breakdown products, and so on. Higher sample concentrations may even increase the spot number as long as the overall protein load does not reduce separation quality. For human serum a list of 289 proteins that have all been detected and quantified (Anderson and Anderson, 2002) has been compiled. The concentration range between the highest and lowest abundance proteins (albumin and Interleukin 6, respectively) spans over 10 orders of magnitude. This large range derives from the fact that apart from the classical "plasma proteins" this body fluid contains not only tissue proteins (as leakage markers), but also, for example, low concentrations of mediators such as the interleukins. In general, the proteome of cells or tissues shows a more consistent protein distribution, but even so concentration ranges of 6-8 orders of magnitude have been estimated for cells (Anderson and Anderson, 1998; Lescuyer et al., 2007). With conventional proteomic methods 2-4 orders of magnitude may be covered (Anderson and Anderson, 2002), but sensitivity may be increased by sample pretreatment. Prefractionation simplifies the protein mixture by reducing the amount and number of proteins to be loaded into the gel matrix. In general it is advisable to use prefractionation methods that are based on principles not involved in the following 2DE step (solubilities, properties at native conditions, affinities). The following sections will deal with selected examples.

\subsubsection{Protein Solubility}

Some of the most frequently used samples for proteomic analysis are body fluids or cells/tissues. In the first case, proteins are already in a solution and the questions that arise include how to introduce the appropriate additives for proteomic analysis; how to achieve the appropriate protein concentration; or how to remove possibly interfering contaminants (such as salts, lipids, nucleic acids, and other proteins). For cellular material there are two approaches: (1) to lyse cells/tissues completely and to try to get all proteins into solution, and (2) to apply a stepwise solubilization with solutions of different dissolving power. A lysis buffer that allows complete lysis is, for instance, $9 \mathrm{M}$ urea, $4 \%$ CHAPS, $1 \%$ DTT, and $0.8 \%$ carrier ampholytes, with or without appropriate protease inhibitors (for other recipes see http://us.expasy.org/ch2d/protocols/ 
protocols.fm1.html). The composition of the lysis buffer is usually adapted according to the specific needs of the sample (see Chapter 2). Tissue material of more rigid structure or bacteria may need an additional mechanical disruption before extraction (the range of methods spans from simple freezing/ thawing or sonication to grinding under liquid nitrogen, bead beating, processing by pressure cycling technology, or French press).

Sequential extraction applies stepwise buffers/solvents with increasing extraction power. First developed for differential solubilization of Escherichia coli proteins (Molloy et al., 1998), this approach has proven similarly helpful for plasma membrane proteins of mammalian cells (Abdolzade-Bavil et al., 2004). Solubilization, assisted by vortexing and sonication, proceeds from a simple tris buffer (extracting many cytosolic proteins) to a lysis buffer with urea, CHAPS, DTT, and another buffer containing urea, thiourea, tributylphosphine, and multiple zwitterionic surfactants. The residual pellet is solubilized in an SDS-containing buffer with boiling and may be analyzed by 1D SDS-PAGE or, appropriately diluted, by $2 \mathrm{DE}$.

\subsubsection{Precipitation}

Protein precipitation is an easy way to remove nonprotein contaminants (salt, lipids, nucleic acids) from the sample. In addition, the protein content of the sample may be increased. The most commonly used precipitating agents in proteomic applications are trichloroacetic acid (TCA)/cold acetone or ethanol, as shown for human platelets (Zellner et al., 2005). These two precipitants are often the basis for commercial sample preparation kits. The patterns of the pretreated samples may differ depending on the preconcentration method, and also in comparison with the original sample, but should be highly comparable for samples with the same history. However, as for all additional steps introduced into the method, the pros (removal of interfering substances) and cons (new source of technical errors/changes) have to be carefully considered.

\subsubsection{Subcellular Fractionation}

Subcellular fractionation has two important benefits: it not only reduces protein complexity and diversity but also preselects for biologically associated proteins. The aim of subcellular fractionation is to separate cell organelles with as little damage as possible. Fractionation protocols have to be adapted to the specific tissue type and the species. Organelles differ in size and density; therefore, they can be separated by differential pelleting (stepwise increase of centrifugation speed and collecting the pellet after each step) or by centrifugation in a density gradient (Graham and Rickwood, 1997). There are a large number of applications for this procedure (e.g., Pasquali et al., 1997; Guillemin et al., 2005; de Araújo et al., 2008). 


\subsubsection{Ultrafiltration}

Small centrifugal ultrafiltration devices containing membranes of defined cutoffs (usually 3, 10, 30, and $100 \mathrm{kDa}$ ) are commercially available. When cutoff filters of $4-10 \mathrm{kDa}$ are used, ultrafiltration of protein samples has two advantages: the sample is desalted and concentrated, which both may prove beneficial for the obtained 2DE protein pattern, and a low $\mathrm{Mr}$ fraction is obtained whose contents of peptides or protein breakdown products may be further investigated by other means, like high-resolution MS. This approach has successfully been tested on cell and tissue lysates (bovine liver) and serum (Chernokalskaya et al., 2004).

\subsubsection{Prefractionation by Electrophoretic Methods}

Most of the electrophoretic methods used for prefractionation include separation in solution. The absence of a solid matrix minimizes protein surface interactions and consequent loss of protein. The most often used separation parameters are pI and mobility/size, but affinity may also be included. Separation conditions selected often differ from the 2DE system applied later on. An overview on electrophoretic prefraction methods is given in Righetti et al. (2003).

3.4.5.1 pI-Based Separations Over the years several devices that allow gelfree separations according to $\mathrm{pI}$ have been developed and manufactured. Some of them are available in different sizes, as they can be equally used to purify proteins on a preparative scale or for sample pretreatment prior to 2DE. Proteins are fractionated in solution within defined $\mathrm{pH}$ ranges either (1) under conditions comparable with 2DE (e.g., to preconcentrate proteins of a selected $\mathrm{pI}$ range as a step prior to narrow-range IPGs), or (2) utilizing $\mathrm{pI}$ shifts due to inclusion/omission of additives during sample pretreatment.

The Rotofor ${ }^{\mathrm{TM}}$ cell (Bio-Rad Laboratories, Hercules, CA) performs liquidphase separations in carrier ampholyte solutions. After focusing, samples are collected from the up to 20 compartments that are separated by liquidpermeable nylon screens (for a schematic drawing see fig. 2 in Righetti et al., 2003).

Figure 3.4a shows an example for such a fractionation: pig serum has been focused under non-denaturing conditions in the $\mathrm{pH}$ range $3-10$. Single fractions were tested afterwards in reducing SDS-PAGE. From the graph of Figure $3.4 \mathrm{~b} \mathrm{pH}$ and protein content of the fractions can be read. Fractions 5 and 6 contain mainly albumin, in high concentrations, whereas from fraction 10 onward IgG dominates. Two acidic, consecutive fractions were selected for testing in 2DE (Fig. 3.4c,d). Although the average $\mathrm{pH}$ of these two fractions are 3.95 and 4.48, respectively, 2DE reveals proteins with pIs between about 3.3 

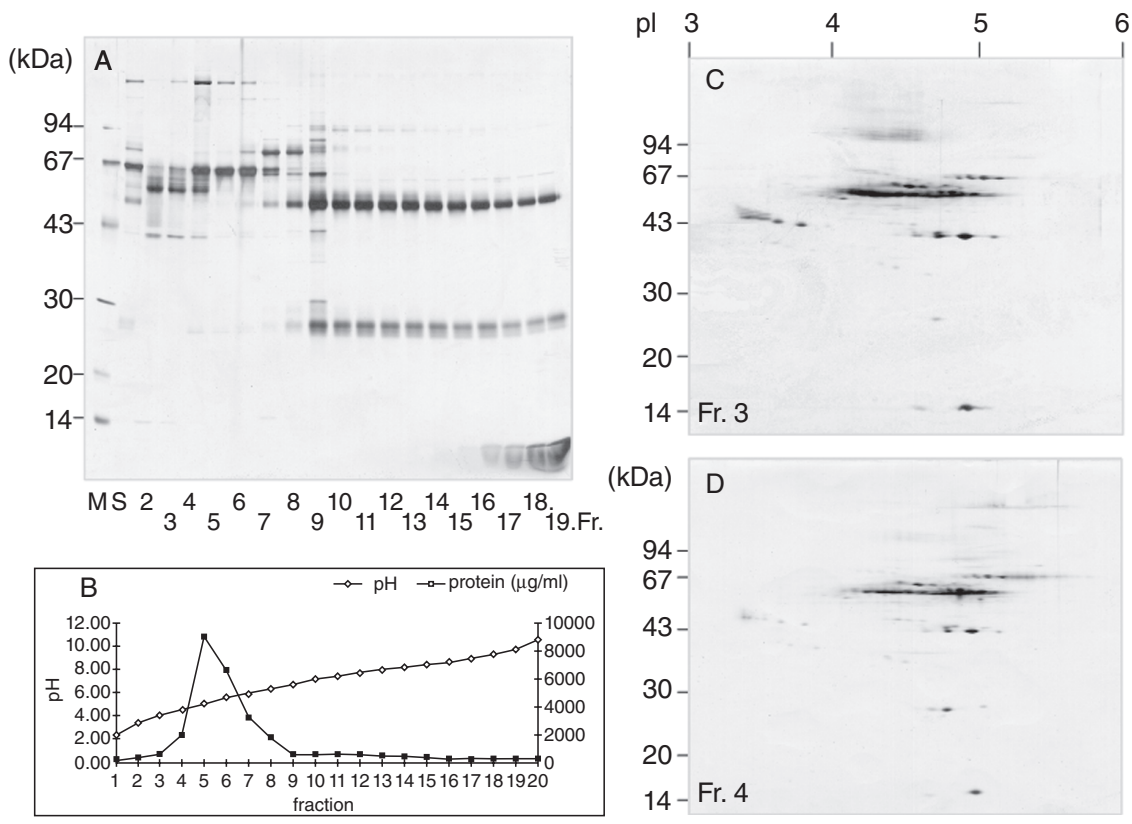

Fig. 3.4 Sample prefractionation. Prefractionation: separation of pig serum on a Rotofor ${ }^{\mathrm{TM}}$ (BioRad) in a pH 3-10 gradient under non-denaturing conditions. (A) Equal protein amounts of the 20 fractions collected were tested in reducing SDS-PAGE in a 10\%-15\% gradient gel and the pattern was silver stained. M, Mr marker; $\mathrm{S}$, serum (original sample). (B) The $\mathrm{pH}$ and the protein content in the 20 fractions were determined and depicted as curves. Two consecutive fractions ( 3 and 4$)$ were selected and analyzed in 2DE (classical system) using a pH 3-6 gradient. The silver stained patterns are shown in (C) and (D).

and 5.5 in both cases. There are two reasons for the broader pI distribution: the heterogeneity of the single proteins, seen in the spot trains, and $\mathrm{pI}$ discrepancies for some proteins between the Rotofor run (without denaturants) and the firstdimension IPG of classical 2DE. As prefractionation was also performed in the absence of reducing agents, acidic spots of Ig light chains and the $\mu$-chain are missing in this pattern (compared with pig serum 2DE in Fig. 3.1a).

Using denaturing/reducing conditions in both prefractionation and IPGs has also been helpful, for instance, for enrichment of low-abundance serum proteins. Identification of these preconcentrated proteins was much easier by immunological means (Hochstrasser et al., 1991), and this should also be the case for MS identifications. Carrier ampholyte-based preparative IEF has also been applied to skim milk proteins (Kim and Jimenez-Flores, 1993).

The multicompartment electrolyzer relies on the use of isoelectric membranes, fabricated with the same Immobiline chemicals as used in IPGs. Proteins of interest are trapped in solution between membranes of selected 
pIs that act as "pH barriers." The method was originally designed for purification of protein isoforms to gain enough material for their further physicochemical characterization (Righetti et al., 1990). As a small-size prefractionation device with several compartments and fixed pIs of isoelectric membranes it has been commercialized and utilized for the separation of plasma proteins or bacteria (Herbert and Righetti, 2000; Zuo et al., 2001). Fractionation is run with the same additives as subsequent IPGs, thus, protein solutions can be directly processed in 2DE.

3.4.5.2 Free-Flow Electrophoresis Samples are continuously injected into a solution flowing as a thin film $(0.4 \mathrm{~mm})$ between two parallel glass plates and, by introducing an electric field perpendicular to the flow direction, proteins are separated and finally collected into up to 96 fractions (Wildgruber et al., 2008). The system can be run for a long time under stable conditions while continuously feeding with sample. Separation is performed either as IEF in selected $\mathrm{pH}$ ranges or as zone electrophoresis. Being a gel-free system, it allows separation of a variety of samples, including components of larger size—complete cells (Baier et al., 1988), single organelles (Mohr and Völkl, 2002), and protein complexes or mixtures (Burggraf et al., 1995; Wildgruber et al., 2008).

3.4.5.3 Preparative Gel Electrophoresis One commercial apparatus exists for fractionation of proteins in polyacrylamide gels based on native electrophoresis or SDS-PAGE (PrepCell ${ }^{\mathrm{TM}}$, Bio-Rad). Proteins are separated in a gel polymerized in cylindrical form around a cooling finger by continuous elution electrophoresis. The ring-shaped protein bands migrate off the bottom of the gel and are continuously collected in a fraction collector. Separation parameters are adapted by selection of the concentration of the homogenous polyacrylamide gel and allow enrichment of low-abundance proteins as well as separation of protein isoforms with only small mass or mobility differences. Protein fractions are not always collected in buffers immediately suitable for subsequent 2DE, thus, often an additional desalting step may be needed. SDS removal, also partly from proteins, can be achieved for instance by precipitation using potassium ions (Sandri et al., 1993). Fountoulakis and collaborators have used this system for fractionation of different complex samples in order to enrich low-abundance proteins (e.g., mouse brain proteins, Fountoulakis and Juranville, 2003; or human urine, Zerefos et al., 2006).

There are several other systems used for sample prefractionation, for example, Off-Gel ${ }^{\mathrm{TM}}$ electrophoresis (Michel et al., 2003) commercialized as the OFFGEL fractionator (Agilent, Santa Clara, CA), which is also based on the principle of IPGs, or the Gradiflow ${ }^{\mathrm{TM}}$ system (Gradipore, Sydney, Australia), an electrokinetic membrane apparatus that can process proteins on the basis of pI, mobility, size, or affinity (Locke et al., 2002). 


\subsubsection{Prefractionation by Chromatographic Methods}

Chromatography includes a broad range of physical methods that separate components of a complex mixture as a function of their distribution between the stationary phase and a mobile phase that percolates through the stationary bed. The mobile phase drives the single components of the mixture through the chromatographic column; the retention time or their binding behavior depends on their affinity toward the respective chromatographic material. Several chromatographic methods have been tried for prefractionation purposes prior to 2DE separations: ion exchange, hydrophobic interaction, reverse-phase, gel permeation, and affinity chromatography, the latter in numerous varieties (Lescuyer et al., 2004). A brief overview of the different types is given in the following sections, with a special focus on affinity methods.

3.4.6.1 Chromatographic Methods Ion exchange chromatography uses a charged stationary phase to separate charged compounds; the stationary phase carries functional groups that interact with oppositely charged groups on the proteins. Bound proteins are released by increasing salt concentration or after shifts in $\mathrm{pH}$. Ion exchange chromatography separates under non-denaturing conditions based on the charge of the folded proteins; therefore, fractionation patterns may differ considerably from the ones obtained in IEF. Changes in low-abundance brain proteins of rats treated with kainic acid, a potent neurotoxin and excitatory amino acid, were detected more clearly when the sample material was prefractionated on an anion exchange resin (Krapfenbauer et al., 2001). For nuclear proteins of sea urchin embryos subfractionation was achieved using a weak cation exchange resin and compared with the original map (Harrington et al., 1992). Cation exchange chromatography using various types of resin was also the method of choice for fractionation of bovine whey; although here 1DE was sufficient to document pattern differences (Hahn et al., 1998).

Hydrophobic interaction chromatography separates proteins on the basis of differences in hydrophobicity. Proteins are adsorbed in the presence of salt onto hydrophobic groups of an uncharged matrix and are then eluted by lowering the salt concentration or even by adding acetonitrile. Adsorption can be performed under denaturing conditions in the presence of urea and detergents. This was one type of fractionation applied to soluble proteins of the bacterium Haemophilus influenza and maps obtained were compared with protein patterns from chromatofocusing and heparin chromatography (Fountoulakis et al., 1999).

Reverse-phase chromatography uses a nonpolar stationary phase with alkyl chains; polar compounds are eluted first while nonpolar compounds are retained and released only upon addition of organic solvents into the aqueous buffer system. Differentially expressed proteins between striate cortex of 
kitten and adult cat were detected by this protein enrichment method (Van den Bergh et al., 2003).

Gel permeation chromatography is not often used as a prefractionation method prior to proteomic applications, as it sorts molecules according to size, similar to SDS-PAGE. However, it could be applied making use of different conditions (e.g., native/denaturing).

3.4.6.2 Affinity Chromatography and Depletion Affinity chromatography separates protein mixtures based on a highly specific biologic interaction, such as that between antigen and antibody, enzyme and substrate, or receptor and ligand. It thus offers high flexibility and allows development of tailormade solutions for specific problems.

There are two general strategies in affinity material used for prefractionation: it can either be used to enrich proteins bearing specific groups (e.g., phospho-, glyco-) or for the specific removal of high-abundance proteins (depletion methods).

Immobilized metal affinity chromatography (IMAC) is a useful method for enriching metal-associated proteins and peptides. It is based on the interaction between proteins and transition metal ions (e.g., copper, nickel, and zinc) immobilized on a solid support. It allows, for instance, enrichment of phosphoproteins and -peptides (Dubrovska and Souchelnytskyi, 2005), and is often used as a prefractionation step for MS analysis.

Lectins react specifically with different carbohydrate residues on proteins, which makes glycoprotein enrichment through lectin affinity chromatography possible (Mechref et al., 2008). Binding or nonbinding proteins may be further investigated by proteomic methods (Yang et al., 2005). It has to be taken into account that-when comparing samples from different states (e.g., treated/untreated cells) - the glycosylation pattern of proteins may change and, due to altered binding behavior, modified proteins may then appear in different fractions.

Depletion strategies usually aim at removing high-abundance proteins from complex mixtures in order to enable analysis of the residual mixture more clearly. The majority of applications concern albumin and $\mathrm{IgG}$ depletion from serum. The immobilized triazine dye Cibacron Blue F3GA is known to retain human serum albumin with high affinity (Travis et al., 1976), but it works less well with albumin of other species (Miller and Gemeiner, 1998). Staphylococcal protein A or protein $\mathrm{G}$ binds $\mathrm{IgG}$, and immobilized protein $\mathrm{A}$ or $\mathrm{G}$ is often the reactive part of commercial depletion cartridges. Not all $\mathrm{IgG}$ isoforms bind equally well, especially when comparing different animal species. Other commercial products used for albumin and IgG depletion take advantage of antibody-based affinity. In addition, products that bind up to six or more highly abundant serum proteins (including $\operatorname{IgA}$, transferrin, $\alpha_{1}$ antitrypsin, haptoglobin) have been developed. Quite a number of commercial 
products have been developed and validated for application on human serum (Björhall et al., 2005; Brand et al., 2006). It was noticed, however, that albumin depletion might also remove low-abundance proteins including cytokines (Granger et al., 2005).

There are only few reports on use of depleted animal sera. One of them applied a specific anti-mouse-albumin coupled adsorbent in a study of burn injuries in mice (Duan et al., 2005). Although some other proteins were also removed by this treatment, inter $\alpha$-trypsin inhibitor heavy chain 4 was detected as a novel acute-phase protein in this species. Whether the commercial products developed for human serum proteins may also be successfully applied for animal samples has to be tested for each single case. In the author's knowledge, up to now only one product has been specifically produced to remove mouse and rat albumin (Qiagen, Hilden, Germany).

3.4.6.3 Further Mining of the Proteome As for protein purification, one single chromatographic step allows enrichment of particular proteins, but multidimensional chromatography or combinations with other methods are more effective. Digging deeper into the proteome with this more sophisticated approach resulted in the identification of 325 distinct proteins (from 3700 spots) for human serum and 150 proteins for human urine (Pieper et al., 2003; Pieper et al., 2004). Similar results would be expected for the respective animal body fluids.

A few years ago a new idea for detection of very low-abundance proteins was developed: originally called "Equilizer technology" (Righetti et al., 2006), this product is now commercialized as ProteoMiner Beads ${ }^{\mathrm{TM}}$ (Bio-Rad). Polymeric beads coated with a combinatorial library composed of millions of hexameric peptide baits are incubated with the sample. As there is only a limited number of similar peptides, only a small part of the high-abundance but all of low-abundance protein molecules are bound, thus resulting in an enrichment of the latter. As this method shifts proportions of the proteins in a mixture, it is suitable for detecting yet unknown proteins of low abundance, but seems less well suited for comparison of quantitative differences.

\subsubsection{Additional Methods}

Immunoprecipitation, for instance, with antibodies against functional groups, is another method for enrichment of protein classes. Immunocomplexes obtained by reaction of antigen and antibody are bound to immobilized protein A or G, from which they can be eluted with chaotropes or SDS-sample buffer. Phosphoproteins have thus been investigated, utilizing antisera against phosphotyrosine (Stancato and Petricoin, 2001).

Selectivity in sample collection may further help to limit diversity of the material under investigation: laser capture microdissection allows to selec- 
tively pick only cells with specific properties (Banks et al., 1999); diversity of cell populations may be reduced by fluorescence-activated cell sorting (FACS) or antibody-coated magnetic beads (Thadikkaran et al., 2008).

\subsection{The Influence of Staining}

\subsubsection{General Protein Stains}

The most used dyes for staining of overall protein patterns in proteomic applications are $\mathrm{CBB}$ R and $\mathrm{CBB} G$, silver, and the fluorescent dyes of the SYPRO $^{\mathrm{TM}}$ family (Invitrogen, Carlsbad, CA) as well as CyDyes ${ }^{\mathrm{TM}}$ (GE Healthcare, Little Chalfont, UK) (Miller et al., 2006a). CBB R is used in solutions with organic solvents (methanol, ethanol) in combination with acids (acetic acid, trichloroacetic acid) to fix the proteins (Gianazza et al., 2002). For CBB G this is possible as well, but lately it has often been applied as a colloidal stain (Neuhoff et al., 1985; Miller et al., 2004a). Silver staining exists in many varieties, being either based on a gel impregnation step in neutral silver nitrate solution followed by development under alkaline conditions (sodium carbonate) or performed as an ammoniacal silver staining (Rabilloud, 1992). Besides CBB and silver, which produce stained protein patterns visible to the human eye, fluorescent dyes are increasingly used; they need gel scanning under specific illumination (ultraviolet [UV], laser) to visualize the spot patterns. These fluorophores include the family of SYPRO stains, mainly SYPRO Ruby (Berggren et al., 2002), which are post-electrophoretic stains like the colorimetric dyes mentioned before. Pre-electrophoretic labeling of proteins is performed with CyDyes, which react specifically with amino acids present in the investigated proteins: lysine (CyDye DIGE Fluor Minimal Dyes, GE Healthcare, Little Chalfont, UK; Viswanathan et al., 2006) or cysteines (CyDye DIGE Fluor Labeling Kit for Scarce Samples, saturation labeling, GE Healthcare, Little Chalfont, UK; Greengauz-Roberts et al., 2005).

Staining mechanisms of the mentioned dyes are different, and also their sensitivity. Whereas sensitive silver stains may detect as little as $1 \mathrm{ng}$ protein in a spot, CBBs need an approximately 10 -fold greater concentration. Fluorescent dyes lie in a range similar to silver or even below. They offer the advantage that the linearity range of the measured signal is much larger (about 3-4 orders of magnitude), whereas in silver staining concentration changes of a factor of only up to 10 may be reliably quantified. The less sensitive CBB shows a slightly broader range for staining proteins proportionally to their concentration than silver (Miller et al., 2006a).

Figure 3.5 depicts a series of 2DE gels of one horse serum sample. The protein concentration applied onto the gel is adapted according to the sensitivity of the respective stain, to achieve comparable intensity of spot patterns. In the upper row $5 \mu \mathrm{L}$ serum was separated in each panel and stained with 

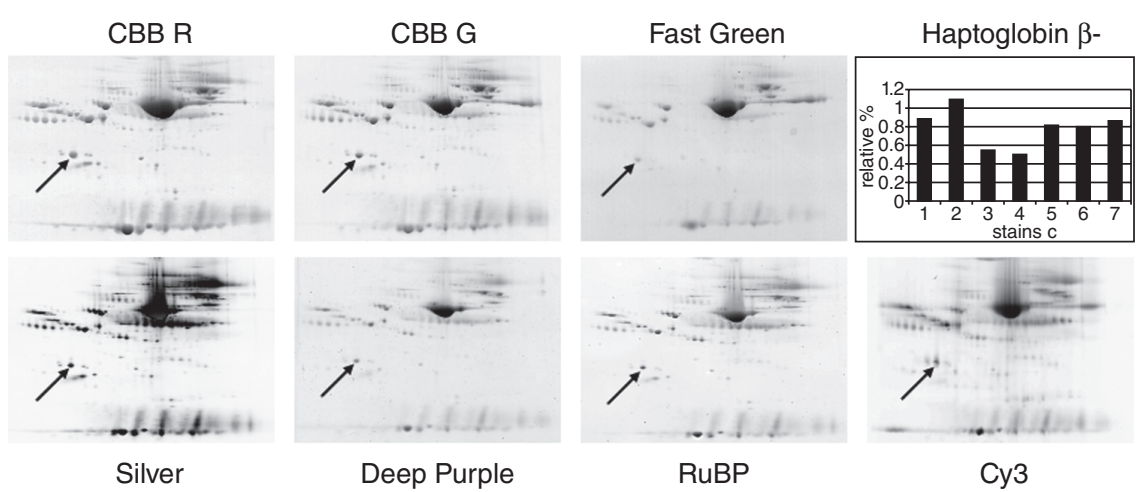

Fig. 3.5 Influence of staining. Horse serum was separated in 2DE (classical system) and proteins detected with different stains. A close-up of the $25-120 \mathrm{kDa}$ region. Upper panel: $5 \mu \mathrm{L}$ horse serum as sample; proteins were stained with Coomassie Brilliant Blue R-250 (CBB R), Coomassie Brilliant Blue G-250 (CBB G), and Fast Green FCF (Fast Green). Lower panel: 0.5 $\mu$ L horse serum as sample; proteins were stained with silver stain (Silver), Deep Purple ${ }^{\mathrm{TM}}$ (GE Healthcare Life Sciences), the fluorescent dye ruthenium II tris (bathophenanthroline disulfonate) (RuBP; Miller et al., 2006b), and pre-electrophoretically labeled with the cyanine dye CyDye DIGE Fluor Minimal Dye Cy3 ${ }^{\mathrm{TM}}$ (GE Healthcare Life Sciences). The major spot of the haptoglobin $\beta$-chain is indicated by arrows. The upper right panel shows the percentage of this spot (single spot volume compared with sum of spot volumes present on the respective gel) on each of the shown gels. Labeling on the $\mathrm{X}$-axis corresponds to CBB R (1), CBB G (2), Fast Green (3), Silver (4), Deep Purple (5), RuBP (6), Cy3 (7).

CBB R, CBB G, and Fast Green FCF. In the lower row the sample amount was $0.5 \mu \mathrm{L}$ each for silver stain, the fluorescence stains Deep Purple ${ }^{\mathrm{TM}}$ (GE Healthcare) and ruthenium II tris (bathophenanthroline disulfonate) (which is similar to SYPRO Ruby; Lamanda et al., 2004), and the cyanine dye Cy3 (minimal dye). Besides this factor of 10 in sensitivity between stains, it is obvious that staining intensity of spots may vary depending on the detection method. This concerns, for instance, IgG heavy and light chains, and also one spot that is marked with an arrow. This is the main spot of the haptoglobin $\beta$-chain. When calculating the amount of this spot (single spot volume compared with sum of spot volumes present on the respective gel), a different percentage is obtained for each of the staining methods. A histogram in the upper right panel of Figure 3.5 illustrates these data. For the investigated spot, levels happen to be considerably lower for Fast Green FCF and silver stain. More details on this study of horse serum proteins and the influence of staining are given elsewhere (Miller et al., 2006a).

One advantage of cyanine minimal dyes has not been mentioned yet: three dyes (Cy2, Cy3, Cy5) with similar chemical and electrophoretic but different spectral properties have been developed. This allows a difference gel electrophoresis (DIGE) approach where three different samples are labeled each with one of the fluorophores, then mixed and separated in one single 2DE 
gel. Scanning with three different settings allows an image to be obtained for each dye and easier comparison of comigrating spots. Only a small percentage of the lysine residues present in the proteins are labeled; therefore, the protocol is called "minimal labeling." There exist also two cyanine dyes (Cy3, Cy5) for saturation labeling that modify cysteine residues. This amino acid is less widely and less evenly distributed in the proteins than lysine; therefore, patterns obtained with this stain may look quite different. In addition, proteins without cysteine residues exist.

\subsubsection{Specific Stains}

Besides general protein stains, dyes specific to different functional groups have been developed. There are two modern fluorescent dyes (Pro-Q ${ }^{\mathrm{TM}}$ Diamond and Pro- $\mathrm{Q}^{\mathrm{TM}}$ Emerald, by Molecular Probes, Eugene, OR) that are used as stains after electrophoresis to detect phosphoproteins or glycoproteins, respectively. Both can be combined with each other and with the overall protein stain SYPRO Ruby (Wu et al., 2005; Zong et al., 2008). In addition, it has been shown that a combination of CyDyes and Pro-Q ${ }^{\mathrm{TM}}$ Diamond is possible and can be used for protein quantification (Stasyk et al., 2005). Care has to be taken as results from phospho-specific stains do not always correspond to radioactive ${ }^{32} \mathrm{P}$-labeling (Chen et al., 2004).

Other specific gel stains that may be applied after 2DE are-apart from the older classical periodic acid-Schiff stain for glycoproteins that is not very sensitive-enzymatic stains, provided that a separation system is used that does not impair enzymatic function (Shimazaki et al., 2004a,b).

Blotting to nitrocellulose or polyvinylidene difluoride (PVDF) is a versatile tool for further specific staining. It conserves the patterns obtained by the separation, concentrates the proteins during the transfer, and immobilizes them on the membrane. Blots are incubated with antibodies against functional groups or single proteins, which are then detected by enzyme-conjugated antibodies against the primary antibody and a specific colorimetric substrate reaction. Alternatively, enhancement systems with chemiluminescence may be used (Gallagher et al., 1998). Stripping of blots and reprobing with different antibodies is also possible. For exact localization of the spots in the context of the overall pattern, general protein stains can be applied for the membrane: for high protein load the reversible dye Ponceau S (Salinovich and Montelaro, 1986), the more sensitive colorimetric gold stain (Daneels et al., 1986), or SYPRO Ruby (or ruthenium II tris [bathophenanthroline disulfonate]) for fluorescence detection (Miller et al., 2006b).

Antibodies against phosphoproteins are directed against P-tyrosine, Pserine, or P-threonine and thus may give hints about the position of the phosphate group. For glycoproteins, different enzyme-labeled lectins are 
available. The best known is concanavalin A, one with broad specificity (against $\alpha$-mannosyl groups).

Detection and identification of particular animal proteins is often hampered by the lack of specific antibodies. If the protein of interest has an evolutionary conserved structure, cross-reactive antibodies may be used after carefully pretesting. This was one of the methods successfully applied for establishing reference serum protein maps of different species (see Section 3.2.2).

\section{6 "Post-detection"}

Staining protein spots in a $2 \mathrm{DE}$ gel is not always the end of the experiment. For a comparison of samples representing two different states (of health, treatment, etc.), quantification of spot volumes and comparison of multiple gels are necessary. To achieve reliable results, it is important to select the appropriate staining method, sample amount (in order to avoid saturated spots), and the necessary number of technical and biological replicates (Miller et al., 2006a). For instance, silver staining has to be carefully controlled to obtain patterns that allow subsequent quantification. Minimal CyDyes allow a setup with two samples (labeled with $\mathrm{Cy} 3$ and $\mathrm{Cy} 5$ ) and an internal standard (a pool of all samples in the respective experiment, labeled with Cy2); the latter allows more reliable normalization (Alban et al., 2003). This approach lowers technical variation, and thus smaller differences between single samples may be detected with statistical significance (Miller et al., 2006a; Karp and Lilley, 2007).

Based on quantitative and statistical evaluation spots of interest are often selected as candidates for identification. Those may be cut out from the gel, enzymatically digested and identified by MS methods. Having this in mind, the 2DE approach has to include a staining method that allows identification afterwards (such as by modifying the silver stain, omitting glutaraldehyde and part of the formaldehyde; Shevchenko et al., 1996), sometimes also an upscaling of the method to be able to analyze small spots (by increasing sample amounts and using a different stain). For manual spot picking from DIGE-gels it is advisable to restain the gels, preferably with a colorimetric stain. When investigating animal proteins, protein identification by MS methods is often hampered by the lack of annotations for animal proteins in the databases. In some cases, these problems can be solved by de novo sequencing and cross-species identification as discussed in detail in Wait et al. (2002) for bovine serum proteins.

During the last years it has become state-of-the-art to verify proteomic data with another, independent method. This is often done by 1D immunoblotting (see Section 3.5.2). Nevertheless, this method may give results that are divergent to proteomic data: for example, isoforms that differ only in $\mathrm{pI}$ cannot be 
detected by $1 \mathrm{D}$ blots. In this case, 2DE blots may solve the problem. Another source of variation lies in the biological nature of the antibodies: being specific for defined epitopes on the protein molecule, they may react with different molecular species of the same protein with different avidity.

\section{7 $\quad$ Future Trends}

$2 \mathrm{DE}$ is a high-resolution and versatile method for analysis of proteomic questions. Comparing different proteomic approaches (classical and alternative 2DE, LC-MS/MS), it has been shown in several studies that even analysis of the same samples may result in identification of different protein subsets with only partial overlap of the detected "subproteomes" (Anderson et al., 2004; Hunzinger et al., 2006). Each of the investigated methods has its strengths, the one of classical 2DE being that it gives a rapid overview on hundreds of proteins/protein spots and allows detection of isoforms. Only the combination of as many methods as possible can lead us to a global view and understanding of biological questions. This will also mean involving even more than the presently applied approaches, even modifications of "old-fashioned" methods if they help to complement our knowledge.

\section{Further Reading}

Westermeier, R. 2004. Electrophoresis in Practice. A Guide to Methods and Applications of DNA and Protein Separations, 4th ed. VCH Verlagsgesellschaft GmbH, Weinheim, Germany.

Westermeier, R., Naven, T., and Höpker, H.-R. 2008. Proteomics in Practice. A Guide to Successful Experimental Design, 2nd ed. Wiley-VCH Verlag-GmbH, Weinheim, Germany.

Creighton, T. E. 1989. Protein Structure. A Practical Approach. Practical Approach Series (series editors: Rickwood, D. and B. D. Hames). IRL Press at Oxford University Press, Oxford, UK.

Lottspeich, F. and Engels, J. W. 2006. Bioanalytik, 2nd ed. Spektrum Akademischer Verlag $\mathrm{GmbH}$, Heidelberg, Germany.

Swiss Institute of Bioinformatics. SWISS-2DPAGE. Available at: http://www.expasy.org/ch2d/2dindex.html.

Swiss Institute of Bioinformatics. Technical information on SD-PAGE. Available at: http://us.expasy. org/ch2d/protocols/.

\section{References}

Abdolzade-Bavil, A., Hayes, S., Goretzki, L., Kroeger, M., Andres, J., and Hendriks, R. 2004. Convenient and versatile subcellular extraction procedure, that facilitates classical protein expression profiling and functional protein analysis. Proteomics 4:1397-1405.

Akins, R.E., Leving, P.M., and Tuan, R.S. 1992. Cetyltrimetylammonium bromide discontinuous gel electrophoresis: Mr-based separation of proteins with retention of enzymatic activity. Anal. Biochem. 202:172-178. 
Alban, A., David, S.O., Bjoreksten, L., Andersson, C., Sloge, E., Lewis, S., and Currie, I. 2003. A novel experimental design for comparative two-dimensional gel analysis: two-dimensional difference gel electrophoresis incorporating a pooled internal standard. Proteomics 3:36-41.

Anderson, N.L. and Anderson, N.G. 1998. Proteome and proteomics: new technologies, new concepts, and new words. Electrophoresis 19:1853-1861.

Anderson, N.L. and Anderson, N.G. 2002. The human plasma proteome. Mol. Cell. Proteomics 1: $845-867$.

Anderson, N.G., Powers, M.T., and Tollaksen, S.L. 1982. Proteins of human milk. I. Identification of major components. Clin. Chem. 28:1045-1055.

Anderson, N.L., Polanski, M., Pieper, R., Galin, T., Tirumalai, R.S., Conrads, T.P., Veenstra, T.D., Adkins, J.N., Pounds, J.G., Fagan, R., and Lobley, A. 2004. The human plasma proteome. A nonredundant list developed by combination of four separate sources. Mol. Cell. Proteomics 3:311-326.

Baier, T.G., Weber, G., Hartmann, K., Heinrich, U., and Schönberg, D. 1988. Preparative separation of human B and T lymphocytes by free flow electrophoresis. Anal. Biochem. 171:91-95.

Banks, R.E., Dunn, M.J., Forbes, M.A., Stanley, A., Pappin, D., Naven, T., Gough, M., Harnden, P., and Selby, P.J. 1999. The potential use of laser capture microdissection to selectively obtain distinct populations of cells for proteomic analysis_-preliminary findings. Electrophoresis 20:689-700.

Berggren, K.N., Schulenberg, B., Lopez, M.F., Steinberg, T.H., Bogdanova, A., Smeijkal, G., Wang, A., and Patton, W.F. 2002. An improved formulation of SYPRO Ruby protein gel stain: comparison with the original formulation and with a ruthenium II tris (bathophenanthroline disulfonate) formulation. Proteomics 2:486-498.

Bhatnagar, Y.M. and Bellvé, A.R. 1978. Two-dimensional electrophoretic analysis of major histone species and their variants from somatic and germ-line tissue. Anal. Biochem. 86:754-760.

Bjellqvist, B., Ek, K., Righetti, P.G., Gianazza, E., Görg, A., Westermeier, R., and Postel, W. 1982. Isoelectric focusing in immobilized $\mathrm{pH}$ gradients: principle, methodology, and some applications. J. Biochem. Biophys. Methods 6:317-339.

Björhall, K., Miliotis, T., and Davidsson, P. 2005. Comparison of different depletion strategies for improved resolution in proteomic analysis of human serum samples. Proteomics 5:307-317.

Brand, J., Haslberger, T., Zolg, W., Pestlin, G., and Palme, S. 2006. Depletion efficiency and recovery of trace markers from a multiparameter immunodepletion column. Proteomics 6:32363242.

Braun, R.J., Kinki, N., Beer, M., and Ueffing, M. 2007. Two-dimensional electrophoresis of membrane proteins. Anal. Bioanal. Chem. 389:1033-1045.

Brookes, P.S., Pinner, A., Ramachandran, A., Coward, L., Barnes, S., Kim, H., and Darley-Usmar, V.M. 2002. High throughput two-dimensional blue-native electrophoresis: a tool for functional proteomics of mitochondria and signaling complexes. Proteomics 2:969-977.

Burggraf, D., Weber, G., and Lottspeich, F. 1995. Free flow-isoelectric focusing of human cellular lysates as sample preparation for protein analysis. Electrophoresis 16:1010-1015.

Cairoli, F., Battocchio, M., Veronesi, M.C., Brambilla, D., Conserva, F., Eberini, I., Wait, R., and Gianazza, E. 2006. Serum protein pattern during cow pregnancy: acute-phase proteins increase in the peripartum period. Electrophoresis 27:1617-1625.

Chen, Z.Y., Sputhwick, K., and Thulin, C.D. 2004. Initial analysis of the phosphoproteome of Chinese hamster ovary cells using electrophoresis. J. Biomol. Tech. 15:249-256.

Chernokalskaya, E., Gutierrez, S., Pitt, A.M., and Leonard, J.T. 2004. Ultrafiltration for proteomic sample preparation. Electrophoresis 25:2461-2468.

Corthals, G.L., Wasinger, V.C., Hochstrasser, D.F., and Sanchez, J.-C. 2000. The dynamic range of protein expression: a challenge for proteomic research. Electrophoresis 21:1104-1115.

D’Ambrosio, C., Arena, S., Talamo, F., Ledda, L., Renzone, G., Ferrara, L., and Scaloni, A. 2005. Comparative proteomic analysis of mammalian animal tissues and body fluids: bovine proteome database. J. Chromatogr. B 815:157-168. 
Daneels, G., Moeremans, M., De Raeymaeker, M., and De Mey, J. 1986. Sequential immunostaining (gold/silver) and complete protein staining (AuroDye) on Western blots. J. Immunol. Methods 89:89-91.

Davie, J.R. 1982. Two-dimensional gel systems for rapid histone analysis for use in minislab polyacrylamide gel electrophoresis. Anal. Biochem. 120:276-281.

de Araújo, A.E.G., Huber, L.A., and Stasyk, T. 2008. Isolation of endocitic organelles by density gradient centrifugation. Methods Cell Biol. 424:317-331.

Duan, X., Yarmush, D.M., Berthiaume, F., Jayaraman, A., and Yarmush, M.L. 2004. A mouse serum two-dimensional gel map: application to profiling burn injury and infection. Electrophoresis 25: 3055-3065.

Duan, X., Yarmush, D., Berthiaume, F., Jayaraman, A., and Yarmush, M.L. 2005. Immunodepletion of albumin for two-dimensional gel detection of new mouse acute-phase protein and other plasma proteins. Proteomics 5:3991-4000.

Dubrovska, A. and Souchelnytskyi, S. 2005. Efficient enrichment of intact phosphorylated proteins by modified immobilized metal-affinity chromatography. Proteomics 5:4678-4683.

Eberini, I., Agnello, D., Miller, I., Villa, P., Fratelli, M., Ghezzi, P., Gemeiner, M., Chan, J., Aebersold, R., and Gianazza, E. 2000. Proteins in rat serum V: adjuvant arthritis and its modulation by nonsteroidal anti-inflammatory drugs. Electrophoresis 21:2170-2179.

Flammarion, P., Brion, F., Babut, M., Garric, J., Migeon, B., Noury, P., Thybaud, E., Tyler, C.R., and Palazzi, X. 2000. Induction of fish vitellogenin and alterations in testicular structure: preliminary results of estrogenic effects in chub (Leuciscus cephalus). Ecotoxicology 9:127-135.

Fountoulakis, M. and Juranville, J.-F. 2003. Enrichment of low-abundance brain proteins by preparative electrophoresis. Anal. Biochem. 313:267-282.

Fountoulakis, M., Takács, M.-F., and Takács, B. 1999. Enrichment of low-copy-number gene products by hydrophobic interaction chromatography. J. Chromatogr. A 833:157-168.

Gallagher, S., Winston, S.E., Fuller, S.A., and Hurrell, J.G.R. 1998. Immunoblotting and immunodetection. Curr. Protoc. Immunol. Suppl. 26:8.10.1-8.10.21.

Gianazza, E. and Righetti, P.G. 2009. Immobilized pH gradients. Electrophoresis 30:S112-S121.

Gianazza, E., Giacon, P., Sahlin, B., and Righetti, P.G. 1985. Non-linear pH courses with immobilized $\mathrm{pH}$ gradients. Electrophoresis 6:53-56.

Gianazza, E., Celentano, F., Magenes, S., Ettori, C., and Righetti, P.G. 1989. Formulations for immobilized pH gradients including pH extremes. Electrophoresis 10:806-808.

Gianazza, E., Eberini, I., Villa, P., Fratelli, M., Pinna, C., Wait, R., Gemeiner, M., and Miller, I. 2002. Monitoring the effects of drug treatment in rat models of disease by serum protein analysis. $J$. Chromatogr. B 771:107-130.

Görg, A., Postel, W., Günther, S., and Weser, J. 1985. Improved horizontal two-dimensional electrophoresis with hybrid isoelectric focusing in immobilized $\mathrm{pH}$ gradients in the first dimension and laying-on transfer to the second dimension. Electrophoresis 6:599-604.

Görg, A., Obermaier, C., Boguth, G., Csordas, A., Diaz, J.-J., and Madjar, J.-J. 1997. Very alkaline immobilized $\mathrm{pH}$ gradients for two-dimensional electrophoresis of ribosomal and nuclear proteins. Electrophoresis 18:328-337.

Görg, A., Obermaier, C., Boguth, G., and Weiss, W. 1999. Recent developments in two-dimensional gel electrophoresis with immobilized $\mathrm{pH}$ gradients: wide $\mathrm{pH}$ gradients up to $\mathrm{pH} 12$, longer separation distances and simplified procedures. Electrophoresis 20:712-717.

Görg, A., Obermaier, C., Boguth, G., Harder, A., Scheibe, B., Wildgruber, R., and Weiss, W. 2000. The current state of two-dimensional electrophoresis with immobilized $\mathrm{pH}$ gradients. Electrophoresis 21:1037-1053.

Graham, J.M. and Rickwood, D. 1997. Subcellular Fractionation. A Practical Approach. Oxford University Press, Oxford, UK.

Granger, J., Siddiqui, J., Copeland, S., and Remick, D. 2005. Albumin depletion of human plasma also removes low abundance proteins including the cytokines. Proteomics 5:4713-4718. 
Greengauz-Roberts, O., Stöppler, H., Nomura, S., Yamaguchi, H., Goldenring, J.R., Podolsky, R.H., Lee, J.R., and Dynan, W.S. 2005. Saturation labeling with cysteine-reactive cyanine fluorescent dyes provides increased sensitivity for protein expression profiling of laser-microdissected clinical specimens. Proteomics 5:1746-1757.

Grillitsch, B., Gemeiner, M., Gleiß, A., Leitner, M., Miller, I., Möstl, E., Schabuss, M., Schober, U., Tschulenk, W., and Walter, I. 2003. Bioindikation. Untersuchungen an Fischen. Pages II.1II.132 in Hormonwirksame Stoffe in Österreichs Gewässern-ein Risiko? Project Report. ed. Federal Environmental Agency, Vienna, Austria.

Guillemin, I., Becker, M., Ociepka, K., Friauf, E., and Nothwang, H.G. 2005. A subcellular prefractionation protocol for minute amounts of mammalian cell cultures and tissue. Proteomics 5: $35-45$.

Hahn, R., Schulz, P.M., Schaupp, C., and Jungbauer, A. 1998. Bovine whey fractionation based on cation-exchange chromatography. J. Chromatogr. A 795:277-287.

Harrington, M.G., Coffman, J.A., Calzone, F.J., Hood, L.E., Britten, R.J., and Davison, E.H. 1992. Complexity of sea urchin embyo nuclear proteins that contain basic domains. Proc. Natl. Acad. Sci. U.S.A. 89:6252-6256.

Hartinger, J., Stenius, K., Högemann, D., and Jahn, R. 1996. 16-BAC/SDS-PAGE: a two-dimensional gel electrophoresis system suitable for the separation of integral membrane proteins. Anal. Biochem. 240:126-133.

Haynes, P., Miller, I., Aebersold, R., Gemeiner, M., Eberini, I., Lovati, M.R., Manzoni, C., Vignati, M., and Gianazza, E. 1998. Proteins of rat serum: I. Establishing a reference 2-DE map by immunodetection and microbore high performance liquid chromatography—electrospray mass spectrometry. Electrophoresis 19:1484-1492.

Herbert, B. and Righetti, P.G. 2000. A turning point in proteome analysis: sample prefractionation via multicompartment electrolyzers with isoelectric membranes. Electrophoresis 21:3639-3648.

Herbert, B.R., Molloy, M.P., Gooley, A.A., Walsh, B.J., Bryson, W.G., and Williams, K.L. 1998. Improved protein solubility in two-dimensional electrophoresis using tributyl phosphine as reducing agent. Electrophoresis 19:845-851.

Herbert, B., Galvani, M., Hamdan, M., Olivieri, E., MacCarthy, J., Pedersen, S., and Righetti, P.G. 2001. Reduction and alkylation of proteins in preparation of two-dimensional map analysis: why, when, and how? Electrophoresis 22:2046-2057.

Hochstrasser, A.-C., James, R.W., Pometta, D., and Hochstrasser, D. 1991. Preparative isoelectrofocusing and high resolution 2-dimensional gel electrophoresis for concentration and purification of proteins. Appl. Theor. Electrophor. 1:333-337.

Hoving, S., Voshol, H., and van Oostrum, J. 2000. Towards high performance two-dimensional gel electrophoresis using ultrazoom gels. Electrophoresis 21:2617-2621.

Hoving, S., Gerrits, B., Voshol, H., Müller, D., Roberts, R.C., and van Oostrum, J. 2002. Preparative two-dimensional gel electrophoresis at alkaline $\mathrm{pH}$ using narrow range immobilized $\mathrm{pH}$ gradients. Proteomics 2:127-134.

Hunzinger, C., Wozny, W., Schwall, G.P., Poznanovic, S., Stegmann, W., Zengerling, H., Schoepf, R., Groebe, K., Cahill, M.A., Oslewacz, H.D., Jägemann, N., Bloch, M., Dencher, N.A., Krause, F., and Schrattenholz, A. 2006. Comparative profiling of the mammalian mitochondrial proteome: multiple aconitase- 2 isoforms including $\mathrm{N}$-formylkynurenine modifications as part of a protein biomarker signature for reactive oxidative species. J. Proteome Res. 6:625-633.

Juneja, R.K. and Gahne, B. 1980. Two-dimensional gel electrophoresis of cattle plasma proteins: genetic polymorphism of an $\alpha_{1}$-protease inhibitor. Anim. Blood Groups Biochem. Genet. $11: 215-228$.

Juneja, R.K., Gahne, B., and Sandberg, K. 1979. Genetic polymorphism and close linkage of two $\alpha$-protease inhibitors in horse serum. Anim. Blood Groups Biochem. Genet. 10:235-251.

Juneja, R.K., Andersson, L., Sandberg, K., Gahne, B., Adalsteinsson, S., and Gunnarsson, E. 1984. Two-dimensional electrophoresis of horse serum proteins: genetic polymorphism of ceruloplasmin and two other serum proteins. Anim. Blood Groups Biochem. Genet. 15:237-250. 
Kanaya, S., Ujile, Y., Hasegawa, K., Sato, T., Imada, H., Kinouchi, M., Kudo, Y., Ogata, T., Ohya, H., Kamada, H., Itamoto, K., and Katsura, K. 2000. Proteome analysis of Oncorhynchus species during embryogenesis. Electrophoresis 21:1907-1913.

Karp, N.A. and Lilley, K.S. 2007. Design and analysis issues in quantitative proteomics. Pract. Proteomics 1:42-50.

Kim, H.-H.Y. and Jimenez-Flores, R. 1993. Two-dimensional analysis of skim milk proteins using preparative isoelectric focusing followed by polyacrylamide gel electrophoresis. J. Food Biochem. 16:307-321.

Klose, J. 1975. Protein mapping by combined isoelectric focusing and electrophoresis of mouse tissues. A novel approach to testing for induced point mutations in mammals. Humangenetik 26:231-243.

Krapfenbauer, K., Berger, M., Friedlein, A., Lubec, G., and Fountoulakis, M. 2001. Changes in the levels of low-abundance brain proteins induced by kainic acid. Eur. J. Biochem. 268:3532-3537.

Laemmli, U.K. 1970. Cleavage of structural proteins during the assembly of the head of bacteriophage T4. Nature 222:680-685.

Lamanda, A., Zahn, A., Röder, D., and Langen, H. 2004. Improved ruthenium II tris (bathophenanthroline disulfonate) staining and destaining protocol for a better signal-to-background ratio and improved baseline resolution. Proteomics 4:599-608.

Lescuyer, P., Hochstrasser, D.F., and Sanchez, J.-C. 2004. Comprehensive proteome analysis by chromatographic protein prefractionation. Electrophoresis 25:1125-1135.

Lescuyer, P., Hochstrasser, D., and Rabilloud, T. 2007. How shall we use the proteomics toolbox for biomarker discovery? J. Proteome Res. 6:3371-3376.

Locke, V., Gibson, T.S., Thomas, T.M., Corthals, G.L., and Rylatt, D.B. 2002. Gradiflow as a prefractionation tool for two-dimensional electrophoresis. Proteomics 2:1254-1260.

Luche, S., Santoni, V., and Rabilloud, T. 2003. Evaluation of nonionic and zwitterionic detergents as membrane protein solubilizers in two-dimensional electrophoresis. Proteomics 3:249-253.

Manabe, T., Takahashi, Y., and Okuyama, T. 1987. Identification of bovine fetal and adult serum/ plasma proteins by two-dimensional electrophoresis and immunochemical staining. Electrophoresis 8:573-579.

Manabe, T., Mizuma, H., and Watanabe, K. 1999. A nondenaturing protein map of human plasma proteins correlated with a denaturing polypeptide map combining techniques of micro twodimensional gel electrophoresis. Electrophoresis 20:830-835.

Mechref, Y., Madera, M., and Novotny, M.V. 2008. Glycoprotein enrichment through lectin affinity techniques. Methods Mol. Biol. 424:373-396.

Michel, P.E., Reymond, F., Arnaud, I.L., Josserand, J., Girault, H.H., and Rossier, J.S. 2003. Protein fractionation in a multicompartment device using Off-Gel ${ }^{\mathrm{TM}}$ isoelectric focusing. Electrophoresis 24:3-11.

Miller, I. and Gemeiner, M. 1992. Two-dimensional electrophoresis of cat sera: protein identification by cross reacting antibodies against human serum proteins. Electrophoresis 13:450-453.

Miller, I. and Gemeiner, M. 1998. An electrophoretic study on interactions of albumins of different species with immobilized Cibacron Blue F3G A. Electrophoresis 19:2506-2514.

Miller, I., Haynes, P., Eberini, I., Gemeiner, M., Aebersold, R., and Gianazza, E. 1999. Proteins of rat serum: III. Gender-related differences in protein concentration under baseline conditions and upon experimental inflammation as evaluated by two-dimensional electrophoresis. Electrophoresis 20:839-845.

Miller, I., Friedlein, A., Tsangaris, G., Maris, A., Fountoulakis, M., and Gemeiner, M. 2004a. The serum proteome of Equus caballus. Proteomics 4:3227-3234.

Miller, I., Teinfalt, M., Leschnik, M., Wait, R., and Gemeiner, M. 2004b. Nonreducing two-dimensional gel electrophoresis for the detection of Bence Jones proteins in serum and urine. Proteomics 4:257-260.

Miller, I., Crawford, J., and Gianazza, E. 2006a. Protein stains for proteomic applications: which, when, why? Proteomics 6:5385-5408. 
Miller, I., Radwan, M., Strobl, B., Müller, M., and Gemeiner, M. 2006b. Contribution of cell culture additives to the two-dimensional protein patterns of mouse macrophages. Electrophoresis 27:1626-1629.

Miller, I., Wait, R., Sipos, W., and Gemeiner, M. 2009. A proteomic reference map for pig serum proteins as a prerequisite for diagnostic applications. Res. Vet. Sci. 86:362-367.

Mohr, H. and Völkl, A. 2002. Isolation of peroxisomal subpopulations from mouse liver by immune free-flow electrophoresis. Electrophoresis 23:2130-2137.

Molloy, M.P. 2000. Two-dimensional electrophoresis of membrane proteins using immobilized $\mathrm{pH}$ gradients. Anal. Biochem. 280:1-10.

Molloy, M.P., Herbert, B.R., Walsh, B.J., Tyler, M.I., Traini, M., Sanchez, J.-C., Hochstrasser, D.F., Williams, K.L., and Gooley, A.A. 1998. Extraction of membrane proteins by differential solubilization for separation using two-dimensional gel electrophoresis. Electrophoresis 19:837-844.

Neuhoff, V., Stamm, R., and Eibl, H. 1985. Clear background and highly sensitive protein staining with Coomassie Blue dyes in polyacrylamide gels: a systematic analysis. Electrophoresis 6:427-448.

Nijtmans, L.G.J., Hendersen, N.S., and Holt, I.J. 2002. Blue native electrophoresis to study mitochondrial and other protein complexes. Methods 26:327-334.

O'Farrell, P.H. 1975. High-resolution two-dimensional electrophoresis of proteins. J. Biol. Chem. 250:4007-4021.

Oh-Ishi, M. and Maeda, T. 2002. Separation techniques for high-molecular-mass proteins. J. Chromatogr. B 771:49-66.

Oh-Ishi, M. and Maeda, T. 2007. Disease proteomics of high-molecular-mass proteins by twodimensional gel electrophoresis with agarose gels in the first dimension (Agarose 2-DE). J. Chromatogr. B 849:211-222.

Olsson, I., Larsson, K., Palmgren, R., and Bjellqvist, B. 2002. Organic disulfides as a means to generate streak-free two-dimensional maps with narrow range basic immobilized $\mathrm{pH}$ gradient strips as first dimension. Proteomics 2:1630-1632.

Pasquali, C., Fialka, I., and Huber, L.A. 1997. Preparative gel electrophoresis of membrane proteins. Electrophoresis 18:2573-2581.

Pieper, R., Gatlin, C.L., Makusky, A.J., Russo, P.S., Schatz, C.R., Miller, S.S., Su, Q., McGrath, A.M., Estock, M.A., Parmar, P.P., Zhao, M., Huang, S.-T., Zhou, J., Wang, F., Esquer-Blasco, R., Anderson, N.L., Taylor, J., and Steiner, S. 2003. The human serum proteome: display of nearly 3700 chromatographically separated protein spots on two-dimensional electophoresis gels and identification of 325 distinct proteins. Proteomics 3:1345-1364.

Pieper, R., Gatlin, C.L., McGrath, A.M., Makusky, A.J., Mondal, M., Seonarain, M., Field, E., Schatz, C.R., Estock, M.A., Ahmed, N., Anderson, N.G., and Steiner, S. 2004. Characterization of the human urinary proteome: a method for high-resolution electrophoresis gels with a yield of nearly 1400 distinct potein spots. Proteomics 4:1159-1174.

Rabilloud, T. 1992. A comparison between low background silver diammine and silver nitrate protein stains. Electrophoresis 13:429-439.

Rabilloud, T., Valette, C., and Lawrence, J.J. 1994. Sample application by in-gel rehydration improves the resolution of two-dimensional electrophoresis with immobilized $\mathrm{pH}$ gradients in the first dimension. Electrophoresis 15:1552-1558.

Rabilloud, T., Adessi, C., Giraudel, A., and Lunardi, J. 1997. Improvement of the solubilization of proteins in two-dimensional electrophoresis with immobilized $\mathrm{pH}$ gradients. Electrophoresis 18:307-316.

Rabilloud, T., Chevallet, M., Luche, S., and Lelong, C. 2008. Fully denaturing two-dimensional electrophoresis of membrane proteins: a critical update. Proteomics 8:3965-3973.

Righetti, P.G., Wenisch, E., Jungbauer, A., Katinger, H., and Faupel, M. 1990. Preparative purification of human monoclonal antibody isoforms in a multi-compartment electrolyser with Immobiline membranes. J. Chromatogr. 500:681-696. 
Righetti, P.G., Bossi, A., Görg, A., Obermaier, C., and Boguth, G. 1996. Steady-state two-dimensional maps of very alkaline proteins in an immobilized $\mathrm{pH} 10-12$ gradient, as exemplified by histone types. J. Biochem. Biophys. Methods 31:81-91.

Righetti, P.G., Castagna, A., Herbert, B., Reymond, F., and Rossier, J.S. 2003. Prefractionation techniques in proteome analysis. Proteomics 3:1397-1407.

Righetti, P.G., Boschetti, E., Lomas, L., and Citterio, A. 2006. Protein Equalizer Technology: the quest for a "democratic proteome". Proteomics 6:3980-3992.

Salinovich, O. and Montelaro, R.C. 1986. Reversible staining and peptide mapping of proteins transferred to nitrocellulose after separation by sodium dodecylsulfate-polyacrylamide gel electrophoresis. Anal. Biochem. 156:341-347.

Sandri, M., Rizzi, C., Catani, C., and Carraro, U. 1993. Selective removal of free dodecyl sulfate from 2-mercaptoethanol-SDS-solubilized proteins before KDS-protein precipitation. Anal. Biochem. 213:34-39.

Schägger, H. and von Jagow, G. 1987. Tricine-sodium dodecyl sulfate-polyacrylamide gel electrophoresis for the separation of proteins in the range from 1 to $100 \mathrm{kDa}$. Anal. Biochem. 166: 368-379.

Schägger, H. and von Jagow, G. 1991. Blue native electrophoresis for isolation of membrane protein complexes in enzymatically active form. Anal. Biochem. 199:223-231.

Shevchenko, A., Wilm, M., Vorm, O., and Mann, M. 1996. Mass spectrometric sequencing of proteins silverstained polyacrylamide gels. Anal. Chem. 68:850-858.

Shimazaki, Y., Hiraka, Y., Uesugi, M., and Manabe, T. 2004a. Simultaneous analysis of esterase and transferase activities in cytosol proteins from the bovine retina by using microscale nondenaturing two-dimensional electrophoresis. Biochim. Biophys. Acta 1696:51-57.

Shimazaki, Y., Sugawara, Y., and Manabe, T. 2004b. Nondenaturing two-dimensional electrophoresis enzyme profile involving activity and sequence structure of cytosol proteins from mouse liver. Proteomics 4:1406-1411.

Sironi, L., Tremoli, E., Miller, I., Guerrini, U., Calvio, A.M., Eberini, I., Gemeiner, M., Asdente, M., Paoletti, R., and Gianazza, E. 2001. Acute-phase proteins before cerebral ischemia in strokeprone rats: identification by proteomics. Stroke 32:753-760.

Stancato, L.F. and Petricoin, E.F. 2001. Fingerprinting of signal transduction pathways using a combination of anti-phosphotyrosine immunoprecipitations and two-dimensional polyacryamide gel electrophoresis. Electrophoresis 22:2120-2124.

Stasyk, T., Morandell, S., Bakry, R., Feuerstein, I., Huck, C.W., Stecher, G., Bonn, G.K., and Huber, L.A. 2005. Quantitative detection of phosphoproteins by combination of two-dimensional difference gel electrophoresis and phosphospecific fluorescent staining. Electrophoresis 26:2850-2854.

Talamo, F., D’Ambrosio, C., Arena, S., Del Vecchio, P., Ledda, L., Zehender, F., Ferrara, L., and Scaloni, A. 2003. Proteins from bovine tissues and biological fluids: defining a reference electrophoresis map for liver, kidney, muscle, plasma and red blood cells. Proteomics 3:440-460.

Tastet, C., Charmont, S., Chevallet, M., Luche, S., and Rabilloud, T. 2003a. Structure-efficiency relationships of zwitterionic detergents as protein solubilizers in two-dimensional electrophoresis. Proteomics 3:111-121.

Tastet, C., Lescuyer, P., Diemer, H., Luche, S., van Dorsselaer, A., and Rabilloud, T. 2003b. A versatile electrophoresis system for the analysis of high- and low-molecular-weight proteins. Electrophoresis 24:1787-1794.

Thadikkaran, L., Rufer, N., Benay, C., Crettaz, D., and Tissot, J.-D. 2008. Methods for human CD8 ${ }^{+}$ T lymphocyte proteome analysis. Methods Mol. Biol. 484:45-65.

Travis, J., Bowen, J., Tewksbury, D., Johnson, D., and Pannell, R. 1976. Isolation of albumin from whole human plasma and fractionation of albumin-depleted plasma. Biochem. J. 157:301306.

Van den Bergh, G., Clerens, S., Vandesande, F., and Arckens, L. 2003. Reversed-phase highperformance liquid chromatography prefractionation prior to two-dimensional difference gel 
electrophoresis and mass spectrometry identifies new differentially expressed proteins between striate cortex of kitten and adult cat. Electrophoresis 24:1471-1481.

Viswanathan, S., Ünlü, M., and Minden, J.S. 2006. Two-dimensional difference gel electrophoresis. Nat. Protoc. 1:1351-1358.

Wait, R., Miller, I., Eberini, I., Cairoli, F., Veronesi, C., Battocchio, M., Gemeiner, M., and Gianazza, E. 2002. Strategies for proteomics with incompletely characterized genomes: the proteome of Bos taurus serum. Electrophoresis 23:3418-3427.

Wait, R., Begum, S., Brambilla, D., Carabelli, A.M., Conserva, F., Rocco Guerini, A., Eberini, I., Ballerio, R., Gemeiner, M., Miller, I., and Gianazza, E. 2005a. Redox options in two-dimensional electrophoresis. Amino Acids 28:239-272.

Wait, R., Chiesa, G., Parolini, C., Miller, I., Begum, S., Brambilla, D., Galluccio, L., Ballerio, R., Eberini, I., and Gianazza, E. 2005b. Reference maps of mouse serum acute-phase proteins: changes with LPS-induced inflammation and apolipoprotein A-I and A-II transgenes. Proteomics 5:4246-4253.

Westbrook, J.A., Yan, J.X., Wait, R., Welson, S.Y., and Dunn, M.J. 2001. Zooming-in on the proteome: very narrow-range immobilized $\mathrm{pH}$ gradients reveal more protein species and isoforms. Electrophoresis 22:2865-2871.

Westermeier, R. and Naven, T. 2002. Proteomics in Practice, 1st ed. Wiley-VCH Verlag-GmbH, Weinheim, Germany, pp. 35-40.

Wildgruber, R., Yi, J., Nissum, M., Eckerskorn, C., and Weber, G. 2008. Free-flow electrophoresis system for plasma proteomic applications. Methods Mol. Biol. 424:287-300.

Wittig, I. and Schägger, H. 2008. Features and applications of blue-native and clear-native electrophoresis. Proteomics 8:3974-3990.

Wittig, I., Karas, M., and Schägger, H. 2007. High resolution clear native electrophoresis for in-gel functional assays and fluorescence studies of membrane protein complexes. Mol. Cell. Proteomics 6:1215-1225.

Wu, J., Lenchik, N.J., Pabst, M.J., Solomon, S.S., Shull, J., and Gerling, I.C. 2005. Functional characterization of two-dimensional gel-separated proteins using sequential staining. Electrophoresis 26:225-237.

Yang, Z., Hancock, W.S., Chew, T.R., and Bonilla, L. 2005. A study of glycoproteins in human serum and plasma reference standards (HUPO) using multilectin affinity chromatography coupled with RPLC-MS/MS. Proteomics 5:3353-3366.

Zellner, M., Winkler, W., Hayden, H., Diestinger, M., Eliasen, M., Gesslbauer, B., Miller, I., Chang, M., Kungl, A., Roth, E., and Oehler, R. 2005. Quantitative validation of different protein precipitation methods in proteome analysis of blood platelets. Electrophoresis 26:2481-2489.

Zerefos, P., Vougas, K., Dimitraki, P., Kossida, S., Petrolekas, A., Stravodimos, K., Giannopoulos, A., Fountoulakis, M., and Vlahou, A. 2006. Characterization of the human urine proteome by preparative electrophoresis in combination with 2-DE. Proteomics 6:4346-4355.

Zhou, S., Bailey, M.J., Dunn, M.J., Preedy, V.R., and Emery, P.W. 2005. A quantitative investigation into the losses of proteins at different stages of a two-dimensional gel electrophoresis procedure. Proteomics 5:2739-2747.

Zong, C., Young, G.W., Wang, Y., Lu, H., Deng, N., Drews, O., and Ping, P. 2008. Two-dimensional electrophoresis-based characterization of post-translational modifications of mammalian $20 \mathrm{~S}$ proteasome complexes. Proteomics 8:5025-5037.

Zuo, X. and Speicher, D.W. 2000. Quantitative evaluation of protein recoveries in two-dimensional electrophoresis with immobilized pH gradients. Electrophoresis 21:3035-3047.

Zuo, X., Echan, L., Hembach, P., Tang, H.Y., Speicher, K.D., Santoli, D., and Speicher, D.W. 2001. Towards global analysis of mammalian proteomes using sample prefractionation prior to narrow $\mathrm{pH}$ range two-dimensional gels and using one-dimensional gels for insoluble and large proteins. Electrophoresis 22:1603-1615. 


\section{Chapter 3}

\section{The added value of proteomics for toxicological studies}

Miller, I, Serchi, T, Murk, AJ, Gutleb, AC.

The Added Value of Proteomics for Toxicological Studies

Journal of Toxicology and Environmental Health, Part B, 2014, 17, 225-246.

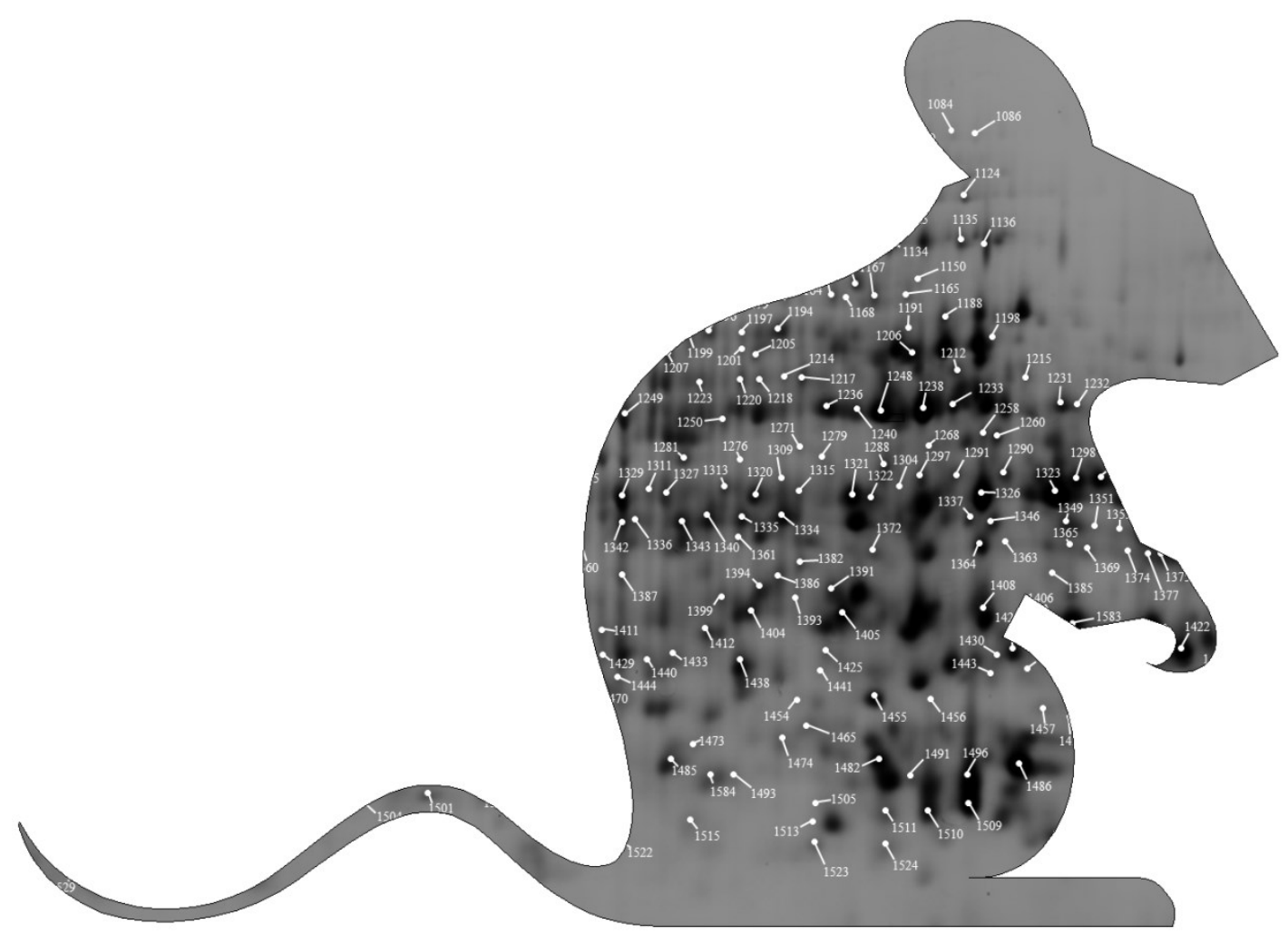



Journal of Toxicology and Environmental Health, Part B, 17:225-246, 2014

Copyright $(\odot)$ Taylor \& Francis Group, LLC

ISSN: 1093-7404 print / 1521-6950 online

DOI: $10.1080 / 10937404.2014 .904730$

\title{
THE ADDED VALUE OF PROTEOMICS FOR TOXICOLOGICAL STUDIES
}

\author{
I. Miller ${ }^{1}$, T. Serchi ${ }^{2}$, A. J. Murk ${ }^{3,4}$, A. C. Gutleb ${ }^{2}$ \\ ${ }^{1}$ Institute for Medical Biochemistry, Department for Biomedical Sciences, University of Veterinary \\ Medicine Vienna, Vienna, Austria \\ ${ }^{2}$ Department Environment and Agro-biotechnologies, Centre de Recherche Public-Gabriel \\ Lippmann, Belvaux, Grand-duchy of Luxembourg \\ ${ }^{3}$ Toxicology Group, Wageningen University, Wageningen, The Netherlands \\ ${ }^{4}$ Wageningen IMARES, ljmuiden, The Netherlands
}

Proteomics has the potential to elucidate complex patterns of toxic action attributed to its unique holistic a posteriori approach. In the case of toxic compounds for which the mechanism of action is not completely understood, a proteomic approach may provide valuable mechanistic insight. This review provides an overview of currently available proteomic techniques, including examples of their application in toxicological in vivo and in vitro studies. Future perspectives for a wider application of state-of-the-art proteomic techniques in the field of toxicology are discussed. The examples concern experiments with dioxins, polychlorinated biphenyls, and polybrominated diphenyl ethers as model compounds, as they exhibit a plethora of sublethal effects, of which some mechanisms were revealed via successful proteomic studies. Generally, this review shows the added value of including proteomics in a modern tool box for toxicological studies.

Proteomics aims at investigating the proteome, that is, the whole repertoire of proteins present in a specific sample, such as body fluid, cell, or tissue, under well-defined circumstances, within one analysis. Proteomics is one of the pillars of the "omics" approaches, which also include transcriptomics and metabolomics. The relevance of the proteome compared to the transcriptome is that it includes the posttranslational processes and thereby is closer to the functional effects. The proteome is not constant, but variable over time and dependent on many conditions, such as gender, age, hormonal, health status, and environmental influences, including exposure to compounds. Although the term "proteomics" was coined in 1994 by Marc Wilkins, the first papers describing one of the key methods date back even to the year 1975 (O'Farrell, 1975; Klose, 1975) and were based on general protein analytical techniques. At that time, proteomics was a synonym for a single method, two-dimensional electrophoresis (2-DE). Since then, besides improvements in 2-DE, additional methods and approaches have been developed, mainly different mass spectrometric (MS) techniques complemented by liquid chromatography (LC) steps to further improve separation and identification. Thus, today a large panel of methods for proteomic investigations is available, as described later.

Proteomics determines the protein composition of a sample in qualitative and quantitative respects. Currently available instrumentation and techniques allow the simultaneous detection of hundreds to thousands of proteins present in the same sample by the use of highresolution multidimensional separations. Such

Current address for A. J. Murk is Sub-department of Environmental Technology, Bornse Weilanden 9, 6708 WG Wageningen, The Netherlands.

Address correspondence to A. C. Gutleb, Department Environment and Agro-biotechnologies, Centre de Recherche Public-Gabriel Lippmann, 41, rue du Brill, L-4422 Belvaux, Grand-duchy of Luxembourg. E-mail: gutleb@lippmann.lu 
an approach provides a good overview of the whole proteome and may reveal differences in protein patterns between samples from different treatments or exposure scenarios in vitro or in vivo.

Although classical protein investigations start from a hypothesis and focus on specific proteins accordingly, current proteomic analyses are in general not target driven, but rather looking for differences in the overall protein pattern and then setting out to identify and investigate those proteins more specifically. The observed changes or differences between exposure groups of such an agnostic search can then be put into the context of already known mechanisms. Following this approach, potentially new and additional links between different pathways are revealed. Such results complement already known mechanisms based on hypothesis-driven experimental data, and in this way further increase our knowledge and understanding regarding biological processes or toxicological mechanisms. Therefore, proteomics has become an important tool for investigations in the biochemical and medical field, to elucidate mechanisms, understand species differences, or find biomarkers for specific diseases (Megger et al., 2013), for example, for cancer (Polanski and Anderson, 2007). Compared to this, toxicological research does not yet use the full potential of proteomics. Only in a small number of studies have such approaches been successfully applied to date, for investigation of compounds with a low acute toxicity (Lasserre et al., 2009, 2012; Sotoca et al., 2011; Campos et al., 2012).

In this review, first, the currently available methods are examined for different approaches to separate, quantify, and identify the proteins and interpret resultant data. Proteomics-related specificities of sample preparation and experimental setup are provided. Successful applications of proteomics in animal studies testing dioxins, polychlorinated biphenyls (PCB), and polybrominated diphenyl ethers (PBDE) are described, illustrating this in investigations focused on liver as a target organ. Finally, the review discusses the added value of including proteomics in a tool box for in vivo and in vitro toxicological studies.

\section{CURRENT PROTEOMIC METHODS}

In general, any proteomic workflow consists of several distinct steps like sample preparation, separation, quantification, identification, and data interpretation. In detail, there are different approaches that rely on different separation principles and technical equipment, which are described in the following sections. There are two main approaches, as illustrated in Figure 1: the gel-based (two-dimensional electrophoresis, indicated in red lines) and the gel-free or MS-based (relying on MS methods, usually in combination with LC steps, shown as blue lines). In addition, there is also a combination of one-dimensional electrophoresis, to prefractionate the sample, and further MS-based separation/detection, as displayed in violet.

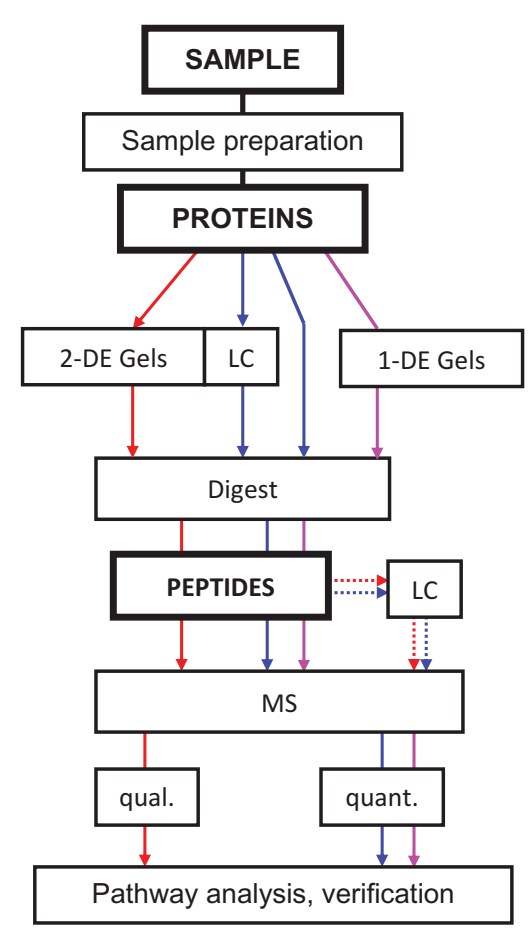

FIGURE 1. Proteomic workflow, general overview of the main approaches. Red lines display gel-based workflow, blue lines MSbased approaches, and violet a combination of both; dotted lines show optional steps. The terms "qualitative" and "quantitative" MS distinguish between identification of proteins based on a sufficient number of peptides, and quantitative comparison between samples, both by MS methods. 
Proteomic analysis can be performed on the level of intact proteins, as in gel-based approaches, starting with a separation step. Gel pieces are collected and embedded proteins are cleaved to peptides, usually with the enzyme trypsin that cuts peptide bonds at specific sites. Peptide mixtures are then separated according to size by MS methods and identified by comparison of their masses with dedicated databases (Westermeier and Naven, 2002). The mass distribution of these patterns obtained under standardized conditions is typical for the respective proteins, as is further discussed in the following. Alternatively, protein mixtures may be digested without previous fractionation and the separation step only performed on the peptide level, followed by quantitative MS analysis (Gevaert and Vanderkerckhove, 2011). Both approaches allow additional LC steps, helping to reduce the complexity of the protein or peptide mixtures.

The following sections describe the workflows of the different approaches.

\section{GEL-BASED METHODS}

\section{Protein Separation}

In 2-DE, proteins are separated according to two different criteria, based on their physicochemical properties: In the first step, proteins are focused as sharp zones according to their charge in a gel containing a $\mathrm{pH}$ gradient. This step is called isoelectric focusing, as proteins migrate to the position in the gradient where their net charge is zero (their isoelectric point). After a buffering step (equilibration), a second orthogonal separation is performed, this time in sodium dodecyl sulfate polyacrylamide gel electrophoresis (SDS-PAGE), that is, polyacrylamide gel electrophoresis in the presence of sodium dodecyl sulfate. The latter compound is a detergent that enhances the solubility of proteins and by providing a negative charge causes the proteins to separate in the gel according to their molecular mass (Laemmli, 1970). Both dimensions are typically performed under reducing and denaturing conditions, such as in gels containing urea/thiourea, reducing agents, or SDS; thus, the proteins are no longer in their native state, but are rather split into subunits and are unable to interact with each other. This prevents uncontrolled reactions during analysis. Variations of this suggested protocol exist, often for specific applications (Miller et al., 2010a).

Following electrophoresis, protein patterns are stained for visualization and image capture. Depending on the stain applied, Coomassie (Kling et al., 2008; Kling and Forlin, 2009), silver (Son et al., 2003; Berg et al., 2011), fluorophores (Oberemm et al., 2005; Strathmann et al., 2007; Miller, 2012), spot patterns are detectable in the visible light range or by fluorescence with appropriate scanners and with different sensitivity. Single spot intensities are evaluated with specifically developed software (Miller et al., 2006).

2-DE comprises multiple single steps, including (non-automatable) manipulations, that all may add up to considerable gel-to-gel variation/technical error in the analysis, as they may influence spot pattern/intensities. Therefore, a new technology was developed several years ago, two-dimensional fluorescence difference gel electrophoresis (DIGE), where three mass- and charge-matched cyanine dyes were developed for chemical labeling of protein samples prior to electrophoresis; a mix of up to three samples may be run on one gel, and 2-DE patterns detected by scanning at different wavelengths match perfectly (Uenlue et al., 1997; Marouga et al., 2005; Greengauz-Roberts et al., 2005; Timms and Cramer, 2008). For analysis of more than three samples, the concept of an internal standard was introduced. A pool of all samples of the respective experiment is labeled with one of the dyes and included in all the gels. This leaves the two other dyes for the samples under investigation. The use of an internal standard facilitates comparison of different gels and lowers the minimally detectable difference of the method (Alban et al., 2003). Thus, approximately a 30\% difference in single spots between samples is reliably detectable, whereas for conventional gels (one sample/gel) a factor of 1.5-2 may be required. DIGE is sensitive and allows quantification of protein 
spot concentrations with a higher dynamic range (about 2-4 orders of magnitude), but needs specific and expensive equipment and reagents. This method enabled the comparison of brain-region-specific changes of proteins in polychlorinated biphenyl (PCB)-exposed (Kodavanti et al., 2011) and polybrominated diphenyl ether (PBDE) 99-exposed (Alm et al., 2008) rodents with high sensitivity, pointing out also small differences during fetal or neonatal development. This may potentially have high importance in the light of chronic effects of early-life-stage low-dose exposure and may be the cause of observed behavioral changes (Kaya et al., 2002; Winneke et al., 2002; Erhard and Rhind, 2004; Zala and Penn, 2004; Lilienthal et al., 2006; Gutleb et al., 2011).

The next step after 2-DE or DIGE separation and quantification is the identification of the proteins present in the spots of interest. Usually, proteomic approaches are performed to compare different states of the proteome (with/without treatment or exposure, healthy and diseased state), and only differentially regulated spots are subjected to identification. These are cut out from the gel, tryptically digested into peptides, which are subsequently eluted from the gel plugs, and identified by MS methods as detailed in the following section.

\section{Protein Identification by MS}

In a mass spectrometer molecules are ionized, sorted, and separated according to their mass to charge ratio and subsequently measured. Depending on the conditions used, such as the energy applied, charge and obtained fragments of each molecule may vary, but are typical for the respective compound.

Trypsin cleaves proteins at specific sites of the polypeptide chain (typically at the carboxylic side of the amino acids lysine and arginine), thus not only reducing the size of the molecule (which enhances exact molecular mass determination), but also creating a larger number of peptides that are individually detected by MS. Protein identification relies on those specific, reproducible, and predictable fragmentation patterns. Peptide-mass fingerprinting (PMF) is the simplest way of identifying a protein. In this approach, experimentally determined peptide masses are searched against a comprehensive database, retrieving the hits with highest probability according to mass accuracy and peptide number for a particular protein (predicted masses obtained by a theoretical digestion of the respective protein). The predominant limitation of this approach is that it is applicable only to proteins from sequenced genomes and that identification can be most easily achieved with pure proteins. Therefore, it is limited to well-investigated species and to simple protein samples or gelbased experiments (isolated spots or bands). PMF is performed on matrix assisted laser desorption ionization-time of flight (MALDI-TOF) instruments. To confirm PMF results or determine the amino acid sequence of unidentified peptides, single peptides may be further fragmented by changing analyzing conditions or the type of instrument. This approach may be performed on a MALDI-TOF/TOF (including a second time-of-flight step) instrument or on an electrospray ionization (ESI) mass spectrometer (Westermeier and Naven, 2002). In addition, all 2-DE experiments cited in the previous section applied this approach for protein identification.

\section{GEL-FREE OR MS-BASED APPROACHES}

The most simple, though nowadays seldom applied, gel-free approach is "shotgun" proteomics, that is, the immediate tryptic digestion of a complex protein mixture, followed by MS analysis of the peptides. The large number of proteins present limits the number of detectable peptides and thus sensitivity of the approach considerably, as for each protein of the mixture several to many peptides were created in the cleavage step. This challenge is overcome by reducing the sample complexity, for instance by additional liquid chromatography (LC), and sometimes also SDS-PAGE, which are both helpful steps for quantitative MS applications. 


\section{Liquid Chromatography as a Separation Step}

Liquid chromatography (LC) is a wellknown, often-applied, and much-appreciated separation method to reduce the complexity of the protein samples (Oliver, 1989). As indicated in Figure 1, it may be utilized for separation of proteins as well as peptides (also as a prefractionation step of original protein mixtures before 2-DE; Krapfenbauer and Fountoulakis, 2009). A variety of different chromatographic methods are available, depending on the physicochemical properties that are selected as separation criteria. Ionexchange and reversed-phase chromatography were found helpful, as well as different affinity chromatography steps (e.g., group-specific enrichment for phosphoproteins; Thingholm et al., 2009). Chromatographic separation of peptide mixtures may also be a versatile step to facilitate protein identification in approaches involving a one-dimensional SDS-PAGE step (Sarioglu et al., 2006; Campagna et al., 2011; Brunelli et al., 2012), when proteins with major abundance tend to mask minor protein components.

LC is performed in miniaturized systems that handle small amounts of liquids (nanoLC) and is a key method especially in gel-free proteomics (Brewis and Brennan, 2011; Matros et al., 2011; Capriotti et al., 2011). In combination with quantitative MS it currently allows detection and reliable quantification of thousands of peptides in a single LC run.

\section{Quantitative MS}

Compared to MS varieties applied in gelbased approaches, which are mainly directed toward qualitative issues (protein identification), in the present case MS also covers the quantitative aspect. It is performed in peptide mixtures by most often including one- or multidimensional LC for reduction of the sample complexity, especially in case of labeled samples (as detailed below). Many different types of instruments are available, with even more possible setups and configurations (Gevaert and Vanderkerckhove, 2011).
The main strategies for quantification of proteins or peptides are metabolic labeling, chemical (enzymatic) labeling, use of standards spiked into the samples, and label-free quantification. The first three strategies (Table 1) rely on stable isotopes as labels that differ between samples. The labels do not affect the separation of the samples, while allowing them to be distinguished in the mass spectrometer. The concept behind these approaches is to introduce in every protein or peptide an amino acid with heavy isotopes (usually ${ }^{13} \mathrm{C},{ }^{15} \mathrm{~N}$, or ${ }^{18} \mathrm{O}$ ), which result in an amino acid with higher molecular mass, but with all the other physicochemical properties unchanged. MS is able to distinguish different isotopes of a given element and even in mixtures the "heavy" (e.g., ${ }^{13} \mathrm{C}$ ) and the "light" (e.g., ${ }^{12} \mathrm{C}$ ) isotopes may be quantified through the comparison of the relative intensities. The introduction of a stable isotope label in the protein/peptide may be achieved by metabolic labeling or by chemical/enzymatic labeling, at different stages of the proteomic experiment (Table 1). A typical example for metabolic labeling is SILAC, where cells growing in medium supplemented with heavy arginine and lysine result in a complete labeling of the whole proteome in five to seven generations. This approach was successfully applied to mammalian cell lines (Ong et al., 2003; Piechura et al., 2012), but also to organisms like mouse (Kruger et al., 2008) or zebrafish (Westman-Brinkmalm et al., 2011), by providing feed containing heavy amino acids. Refined protocols allow application of this approach for

TABLE 1. Different Labeling Approaches in Quantitative MS

\begin{tabular}{llll}
\hline & Metabolic labeling & Chemical labeling & Spiking \\
\hline Organism & + (SILAC) & - & - \\
(Living) cell & + (SILAC) & - & - \\
Protein & - & + (iTRAQ) & + \\
Peptide & - & + (ICAT, TMT) & + \\
\hline
\end{tabular}

Note. Labeling or adding a labeled compound is or may be performed at different stages before or in the proteomic investigation (indicated by "+"). SILAC, stable isotope labeling by amino acids in cell culture. iTRAQ, isobaric tags for relative and absolute quantitation. ICAT, isotope coded affinity tagging. TMT, tandem mass tags. Methods reviewed in Bantscheff et al. (2007) and Gevaert and Vanderkerckhove (2011). 
larger animals and humans (this approach is known as "SUPER-SILAC" (Geiger et al., 2010, 2011).

Chemical labeling introduces stable isotope labels in proteins or peptides typically at the $\mathrm{N}$-terminus or at the $\varepsilon$-amino group of lysine, mostly in the form of complex tags (TMTs, iTRAQ). These tags are specifically developed well-matched sets of up to 6-10 multifunctional molecules that ensure specific binding to the protein/peptide. Differently tagged molecules still show similar elution behavior on chromatographic resins, but isotope mass differences become obvious in MS analysis. Quantitative analyses in MS may be performed in parallel, in one single run (in up to 10 channels for the TMT and up to 8 for iTRAQ).

Label-free approaches, so called because there is no use of stable-isotope tags, achieve quantification by counting matching spectra for each protein (spectral count approach; Lundgren et al., 2010; Bantscheff et al., 2012) or by integrating the area under the peaks in the mass spectrum (Binz et al, 2008; Neilson et al., 2011). For obtaining quantitative results, they require absolute reproducibility in the peptide separation and a high number of technical replicates, to ensure statistical relevance to the obtained results. In a semiquantitative approach, label-free MS was applied to study the influence of PCB138 on fetal brain proteins (Campagna et al., 2011).

\section{An Additional Electrophoretic Separation Step}

One-dimensional electrophoresis is sometimes used as an additional separation step of the original protein sample even in the MS-based and otherwise gel-free proteomic approach. The benefits are an additional cleaning and fractionation step of the proteins according to selectable criteria and tryptic ingel cleavage. Such an approach with SDS-PAGE was selected when investigating the influence of PCB on rat brain cells (Brunelli et al., 2012) or fetal brain proteins (Campagna et al., 2011). Stained bands were cut out of the gel and proteins were digested to peptides, which were further separated, identified, and evaluated with MS methods.

\section{EVALUATION AND INTERPRETATION}

Proteomics includes a strong quantitative aspect. The only qualitative issue, as previously pointed out, is protein identification by MS methods, based on a sufficient number of peptides characteristic for a particular protein. Score values obtained in database searches with dedicated search engines such as MASCOT and SEQUEST express the likelihood of a correct identification and a ranking in case of multiple hits.

Most of the proteomic methods and investigations rely on relative quantification, expressing the concentration of single proteins or peptides in relation to an internal standard (e.g., DIGE) or to the overall applied protein amount (e.g., 2-DE with conventional staining). This is also the basis for most MS applications. Only recent MS methods allow absolute quantification by addition of a spiked internal standard.

Statistical evaluation follows the usual guidelines of good laboratory practice (GLP) (number of experiments, analysis of variance [ANOVA], statistical tests). Recommended cutoff values for selection of differentially expressed proteins have already been discussed for gel-based approaches in a previous section. There exist also community-based standards and guidelines for the analysis and documentation of mass spectrometric proteomic experiments (MIAPE $=$ minimum information about a proteomics experiment: Binz et al., 2008; Taylor et al., 2008).

The general aim of a proteomic approach includes also an interpretation of the observed differential regulations, that is, putting the identified proteins with changed concentration into a biological context. There are databases available (e.g., GO, which is gene ontology; see www.ncbi.nlm.nih.gov/sites/entrez? $\mathrm{Db}=$ gene) that allow one to classify findings according to their biological functions or subcellular localization and attribute them to specific pathways. These comparatively new tools 
gain popularity as they may help to detect less evident connections between proteins. Still, some connections may be missed if single components of a pathway do not show up as statistically significantly regulated ("false negative") or are not found due to modifications/missing peptides or incomplete databases (less well annotated species).

\section{SAMPLE PREPARATION}

This topic is dealt last within this review, as sample preparation depends on the type of proteomics experiment. Almost any kind of biological material might be subjected to proteome analysis, but with different needs for sample preparation. Proteins in body fluids are already in solution and only additives appropriate for proteomic analysis need to be added, taking care to achieve an adequate protein concentration and remove possibly interfering substances (e.g., high concentrations of salts from urine). Cells and tissues have to be lysed, for example, in urea and detergent-containing buffers, if necessary also aided by freezing/thawing, sonication, or homogenizing with mechanical disruption. Tissue material of more rigid structure or small organisms may be pulverized in frozen state in liquid nitrogen by grinding with mortar and pestle followed by extraction with lysis buffer. Lipophilic or membrane proteins may need additional or specific types of detergents for solubilization (for 2-DE) or extraction with organic solvents (for LC, MS). Numerous protocols, depending on sample source and analysis method, have been published (see Posch [2008], a compilation for 2-DE).

Depending on the sample type, the obtained protein solutions may be highly complex and at the same time display an uneven distribution of proteins, that is, a few highly abundant proteins besides a large number of minor proteins. For example, albumin, transferrin, and immunoglobulins comprise more than $70 \%$ of the whole protein content of serum, and the concentration range of proteins detectable in this body fluid spans more than 10 orders of magnitude, from albumin with approximately $35-50 \mathrm{mg} / \mathrm{ml}$ to interleukin-6 in the picograms per milliliter range (Anderson and Anderson, 2002). In tissues and cells, protein concentration ranges differ by 6-8 orders of magnitude (Lescuyer et al., 2007), while proteomic approaches have been estimated to cover 3-4 orders of magnitude in protein concentration simultaneously in one separation (Anderson and Anderson, 2002). Several strategies were developed for enrichment of minor components or depletion of major proteins which allow mining deeper into the proteome (Miller, 2011). Prefractionation of the original sample is an appropriate means to arrive at subproteomes, for example, of subcellular organelles (Bruno et al., 2002; Lasserre et al., 2012). In addition, chromatographic steps (1) based on different separation criteria and (2) taking advantage of specific protein properties, such as isoelectric point, hydrophobicity, and interaction with affinity matrices, may reduce sample complexity and reveal otherwise hidden proteins (Miller, 2011; Capriotti et al., 2012).

\section{EXAMPLES OF PROTEOMICS ADDED VALUE IN TOXICOLOGICAL STUDIES (DIOXINS, PCB, AND PBDE)}

For a widely studied group of ubiquitous compounds, polyhalogenated aromatic hydrocarbons (PHAH), a literature search was performed to study the application of proteomic methods and the value thereof. More specifically the focus was on PCB, PBDE, and dioxinlike compounds. These lipophilic chemicals occur in complex mixtures in the environment and accumulate in organisms including humans. Metabolism of PCB and PBDE is species, gender, and age dependent (Murk et al., 1994; Berg et al., 2010), and these metabolites accumulate (Montaño et al., 2013) and possess their own toxic properties (Freitas et al., 2011; Montaño et al., 2012; Kraugerud et al., 2012), which further complicates the understanding of the mechanism of action of these compounds. In vivo effects are diverse and strongly depend on species, gender, time 
of exposure, endpoint of interest, or exposure concentrations (Kaya et al., 2002; Lyche et al., 2004; Oskam et al., 2005; Gutleb et al., 2007; 2010a; 2010b; Zimmer et al., 2008). A similarly wide range of effects was observed in vitro in different cell systems (Aarts et al., 1995; Bingham et al., 2007; Huljic et al., 2008; Lauer et al., 2009).

The mechanisms underlying the adverse effects have been studied with many different techniques, such as histopathology, enzyme activity measurement, reporter gene assays, and genomics, but also proteomics. Here, the proteomic methods applied in this field and their results are reviewed, including details of proteomics related specificities of sample preparation and experimental setup. The added value of successful applications of proteomics is discussed in toxicological studies testing dioxins, PCB, and PBDE. Focus will be on the often-investigated liver as target organ and location of predominant metabolism.

A systematic literature review searching in the database Ovid SP Version OvidSP UI3.10.00.104 (http://ovidsp.tx.ovid.com; including Resources Animal Production and Veterinary Science 1973 to 2013 Week 42, and Ovid Medline, all topics 1946 to October 30, 2013) for peer-reviewed publications until October 2013 using proteomic terms in combination with 2,3,7,8-tetrachlorodibenzop-dioxin (TCDD), PCB, and PBDE as keywords resulted in 34 full-length articles (Suppl. Table 1), which is less than $0.2 \%$ of the number of full length publications obtained without the proteomic keywords.

Supplementary Table 1 presents the proteomic methods applied in the reported studies, thereby detailing investigated species, applied sample types, separation principles, detection and identification method, and the most important findings. The majority of the proteomic studies summarized in this table are based on 2-DE methods, applying MS only for protein identification. Among them, an increased shift toward 2D-DIGE applications was noted during the last years. The greater sensitivity of this method allows working with smaller sample amounts. Since 2006 only 5 of
34 references mostly rely on MS in combination with fractionation via SDS-PAGE and LC or magnetic beads. They were applied as semiquantitative MS (Brunelli et al., 2012; Campagna et al., 2011; Chen et al., 2009) and quantitative MS (Sarioglu et al., 2006; Hu et al., 2013). Due to recent technical developments making them more applicable, the use of MS-based methods is likely to increase in the future.

As Supplemental Table 1 also shows, the compound groups selected for this review were mainly studied in rodents, mostly in liver and brain, but also other organs. As the liver is the main detoxifying and protein synthesizing organ, data focused on liver to describe effects found via proteomic methods. Both the reported liver effects from in vivo experiments and in vitro experiments with primary hepatocytes or hepatoma cell lines are included and summarized in Table 2 (and in a more comprehensive form in Suppl. Table 2).

A number of investigations focused on the impact of dioxin (TCDD) on the protein pattern in rat liver. The aryl hydrocarbon receptor (AhR) plays a central role in the responses to dioxins, together with the ARNT protein (Okey et al., 2005). Differences in status of the AhR may (to a large extent) explain differences in sensitivity of rat strains for TCDD, as for example LongEvans rats are more sensitive than Han/Wistar rats (Pohjanvirta et al., 1993). A comparative 2DE investigation in these two rat strains showed that the abundance changes in several liver proteins of exposed animals was related either to the strain only, or to TCDD exposure (a single oral dose of $100 \mu \mathrm{g}$ TCDD/kg body weight [bw] $5 \mathrm{~d}$ prior to proteomic analysis), or to both (Pastorelli et al., 2006). Evidence indicated that TCDD- and strain-related changes were oxidative stress-related proteins (e.g., carbonic anhydrase, peroxonase 3 , and apolipoprotein A-I as protective response to lipid peroxidation) and apoptosis inducing factor and the so-called MAWD-binding protein. The latter is a novel target for TCDD, but its biochemical and physiological role is not yet clarified. Similar effects were found in Sprague-Dawley rats $7 \mathrm{~d}$ after a single high dose (1-50 $\mu \mathrm{g}$ TCDD/kg bw) 


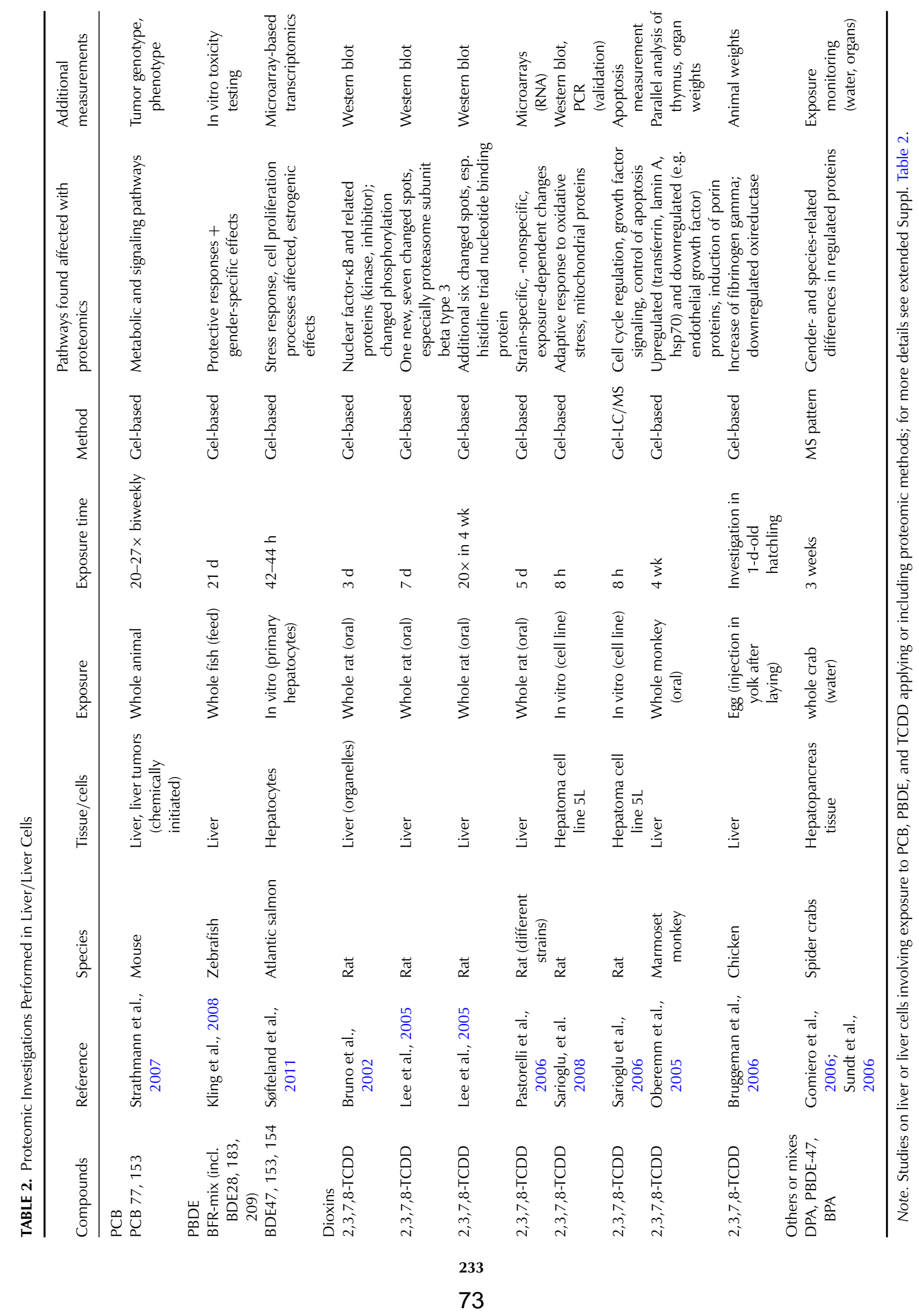


as well as after 4 wk of a daily administration of a lower dose $(0.01-2.5 \mu \mathrm{g}$ TCDD $/ \mathrm{kg}$ bw) (Lee et al., 2005). Again protective mechanisms were induced, such as proteins protecting against lipid peroxidation (like apolipoprotein A-IV) or counteracting TCDD-induced hyperthyroidism (like phosphoglycerate mutase) (Lee et al., 2005).

As discussed previously, protein complexity may be reduced and method sensitivity for selected protein subpopulations increased by subcellular fractionation. This was accomplished by preparation of microsomes isolated from rat liver (Bruno et al., 2002). They represent the endoplasmic reticulum fraction of the cells, with functions in protein and lipid synthesis, regulation, and detoxification. Upon TCDD challenge, the xenobiotic-metabolizing enzymes were studied, as well as changes in the transactivating factor nuclear factor (NF)-кB pathway and NF- $\mathrm{KB}$ binding proteins. Changes were gender dependent in regulation and appearance (isoform pattern of single proteins) (Bruno et al., 2002).

Two in vitro studies on TCDD-exposed rat hepatoma cells (cell line 5L, i.e., epitheliallike cells that express both AhR and ARNT), performed by the same group of investigators, used the same exposure protocol but different proteomic methods: nano-LC-MS/MS of isotope-labeled proteins (Sarioglu et al., 2006) or 2-DE with fluorophore staining (Sarioglu et al., 2008). The main technical improvements introduced with these studies were the use of several narrow-range $\mathrm{pH}$ gradients in the first dimension and a sensitive protein stain for 2-DE (Sarioglu et al., 2008), as well as a quantitative MS approach (Sarioglu et al., 2006); both approaches allowed reliable detection of small concentration changes between samples. Thus, both studies yielded a high number of regulated proteins, 89 by the MS approach and 73 in the gels, respectively. Several pathways were affected, such as cell cycle regulation, growth factor signaling, and control of apoptosis. Among them were also some alterations that could be interpreted as adaptive response to TCDD-induced oxidative stress and affected mitochondrial functions.
Interestingly, only nine of the proteins were found in both studies, although similar pathways were affected. This surprisingly small overlap may be explained by the basics of the methods, specifically the nature and properties of the detectable proteins, but indicated the complementarity of the two approaches. Previous studies, on quite different topics, also reported that the choice of methodology affects the spectrum of proteins detected (Anderson et al., 2004; Wolff et al., 2006; Wu et al., 2006). Overall, the described two proteomic studies by Sarioglu et al. $(2006,2008)$ showed up aspects not covered by a previous nontargeted transcriptomic approach whose main new findings were related to potential protein myristoylation in carcinogenesis (Kolluri et al., 2001).

In marmosets, 4 wk after a single dose of $100 \mathrm{ng}$ TCDD/kg bw administered subcutaneously, no apparent histological alterations were observed in the liver. Proteomic investigation of this organ, however, identified a TCDD-induced spot as porin, an ion channel protein, and changed levels of proteins attributed to increased catabolism, which might be an indication of later obvious adverse effects (Oberemm et a., 2005). At the same time, parallel investigation of thymus proteins showed deregulation of immune-responseregulated proteins. The effect of TCDD exposure on the protein pattern in this organ even was greater than that on the liver (Oberemm et al., 2005). This is in accordance with noted immunotoxic effects of TCDD (de Swart et al., 1994; Ross et al., 1996; Luebke et al., 2006).

Only one early paper described the application of 2D-DIGE to a TCDD study in birds (Hisex White, a layer chicken strain). In ovo injection of 20 ng TCDD immediately after laying and before incubation of the egg was investigated for its effects in the liver proteome of 1-d-old chickens (Bruggeman et al., 2006). Two spots that were affected most were consistently regulated and identified: One upregulated spot belonged to the $\gamma$-chain of fibrinogen, a protein responsible for blood clotting. A spot with decreased intensity was identified as a homologue to NADH ubiquitine oxyreductase, which 
is involved in electron transport and energy supply, connected to the mitochondrial respiratory chain. Bruggeman et al. (2006) suggested a correlation to the lower body weight gain noted in the exposed hatchlings. So-called wasting syndrome (reduced body weight without reduced food intake) is a well-known effect of dioxin exposure, and might be related to the changes revealed by proteomic results. These results need further verification; only one fibrinogen spot was found regulated although the protein consists of three spot chains, each consisting of multiple spots (Miller et al., 2010b).

Thus far, the influence of PBDE on the liver proteome was only reported in fish, applying exclusively gel-based approaches. The liver is an important target organ of PBDE in fish. In an in vivo experiment male and female zebrafish were exposed to a mix of 11 brominated flame retardants including BDE28, 183, and 209 in feed (10-100 nmol/g feed) for $21 \mathrm{~d}$ (Kling et al., 2008). Proteins of cellular maintenance were found differentially regulated in all animals, but interestingly the oxidative stress protein response differed between genders. In addition, in female fish protein levels related to iron homeostasis were decreased. Due to the applied substance mixture, effects cannot be attributed to single components (Kling et al., 2008). Proteomic analysis with 2D-DIGE of Atlantic salmon (Salmo salar L.) primary hepatocytes exposed to three different PBDE congeners, either separately or as a mixture, was performed in addition to a larger scale gene microarray analysis. Overall results revealed compound-specific effects on several biological systems (glucose homeostasis, endocrine metabolism, cell cycle control, proliferation signal pathway) (Søfteland et al., 2011). Methods proved complementary, as not all protein regulations found in DIGE could be validated on the gene level in additional real-time quantitative polymerase chain reaction (RT-qPCR) experiments. This illustrates that protein and gene regulation may differ, but proteins are the functional compounds on site. On the other hand, the lack of comprehensive species-specific databases hampered protein identifications. These issues are discussed in more details in the following section.

These examples show the additional value of including proteomics in a toolbox for pathway analysis for in vivo and in vitro toxicological studies. Proteomics could fill the gaps in understanding the mechanism underlying observed toxic effects of TCDD such as wasting syndrome, hepatotoxicity, immunotoxicity, hyperkeratosis, or changes in retinoid levels. Findings from proteomic investigations may also indicate yet unknown mechanisms due to its holistic approach.

\section{IMPORTANT ASPECTS TO CONSIDER IN EXPERIMENTAL SETUP/STUDY DESIGN}

In addition to the normal requirements for performing a good experiment (appropriate controls and biological and technical replicates, adequate sample material and storage), there are some aspects specific to proteomic experiments.

\section{Sensitivity of Proteomic Approaches}

Proteomic approaches that reveal in an untargeted manner overall protein distribution monitor all changes visible in the sample material. Focusing research topic as precisely as possible, with ideally only one variable parameter between samples to compare, helps to detect only changes relevant to the specific topic. Consistent contamination of the samples with other proteins lowers the sensitivity to detect small pattern changes, as only a limited protein amount may be applied per analysis to achieve optimal protein separation. Inconsistent accompanying proteins, present due to inappropriate sample preparation, lead either to highly variable data or to inappropriate data interpretation and erroneous selection of candidates for further investigations (Miller et al., 2006). Most proteomic methods rely on relative quantification, relating concentration of single components to overall protein content, and monitor changes of ratios. Variable protein composition of samples due to inconsistent sample 
preparation alters these ratios. With an appropriate experimental setup, proteomic methods are sensitive enough to detect also biological variation of healthy individuals (Winkler et al., 2008).

\section{Protein Microheterogeneity}

Proteins may show microheterogeneity, which is either gene based or due to posttranslational modifications (phosphorylation, glycosylation). In contrast to genomic approaches, proteomics discerns these different isoforms (also called protein species) of the same protein, for instance, as multiple spots in 2-DE or different masses of tryptic peptides in MS. Changes of those modifications may be specific for pathophysiological conditions. It was reported that oxidation results in a reversible shift of the peroxiredoxin-1 spot in 2-DE gels to lower isoelectric points (Wagner et al., 2002; Chevallet et al., 2003). This effect is not noticeable in one-dimensional electrophoresis, as the mass of the intact protein does not markedly change. Thus, although this microheterogeneity makes protein or peptide patterns more complex and more difficult to interpret, it may provide insight into subtle but toxicologically relevant changes in fine structure of the affected proteins.

\section{Selection of Sample Type}

Whole-body lysates yield too general proteomes and should therefore be avoided unless the organisms are too small to dissect. Preferably single organs or even better isolated organelles need to be analyzed. Selection of subsamples needs to be based on the likely primary target of the studied toxic compound or the type of interaction of interest. Often the liver is studied as major protein synthesizing and detoxification organ. Other tissues are also relevant, such as the thymus as discussed earlier (Oberemm et al., 2005), the nervous system, the reproductive system, and embryonic tissue. Target organs reflect local effects, and detection of local specific marker proteins may display greater sensitivity than detection of the same proteins diluted in serum or plasma (Hartwell et al., 2006). For nondestructive and chronic biomonitoring, however, plasma proteins seem more suitable and may be a valuable source for new methods of targeted proteomics.

In vivo protein responses, either in animals naturally exposed or from animal experiments, integrate the homeostatic feedback reactions of the body to the compound, thereby sometimes masking specific primary effects. In vitro cell culture or ex vivo experiments with primary cells from selected tissues allow studying primary effects without compensating mechanisms. Unfortunately, immortal cell lines often do not fully reflect the qualities of the original cells anymore, while primary cells can only be kept in culture medium for a limited length of time (usually days) as they tend to change their behavior (Spreafico et al., 2006). This is known from studies with enzyme activity, for example, cytochrome P-450 isoenzymes (Wortelboer et al., 1990). A more uniform reaction is to be expected from in vitro experiments with cell lines; however, they may have lost some of their original tissue-type properties (Gutleb, 2011).

\section{Selection of Species}

As MS identification needs reliable and extensive databases for protein identification, the selection of animal species is important when planning an in vivo or in vitro proteomic experiment. Animal protein or gene databases-although increasing in number of species and details covered-are usually less complete than human. Although cross-species identification of evolutionary conserved proteins is possible as well as manual sequencing of peptides, these approaches may not always be successful and are also time-consuming (Medzihradszky and Chalkley, 2014). Homologous proteins, even if existing in the selected species, may differ in single amino acids or protein modifications, and those changes not only can be seen in their electrophoretic or chromatographic behavior but also induce different tryptic cleavage, resulting in a distinctly altered peptide pattern. Similarly, for less well characterized animal species, immunoreagents for verification of 
results are often not available. All these issues may be rather limiting when dealing with ecotoxicological questions, especially when working with marine species and pollution (Apraiz et al., 2006; Gomiero et al., 2006). If protein identification is not possible due to paucity of databases, establishing protein signatures for potentially harmful conditions may be a useful alternative.

\section{Selection of Exposure Time}

In general, changes on the protein level as a response to challenges occur more slowly than on the transcriptome level. The speed is dependent on the protein of interest, with a wide time range from minutes to days (Hough et al., 2012; Gan et al., 2012; Smith et al., 2011). Breakdown of proteins due to exposure may occur rapidly, but visibility of an altered protein production depends on the cell type, the halflife/turnover rate, and the original level of the affected protein (Gerner et al., 2002). Absolute changes in abundant proteins are less well detected than the same changes in minor proteins, unless only newly synthesized protein is monitored (e.g., by incorporation of isotopically labeled amino acids; Gerner et al., 2002). With increasing exposure time, side effects and compensation reactions within the cell occur, also in vitro, resulting in time-dependent, slightly different protein patterns. Time-course studies thus seem advisable to obtain additional useful information.

\section{Compound-Specific Marker Proteins}

Exposure of organisms to any type of agents most often leads to both general as well as specific protein responses. The general ones comprise often a similar set of proteins (sometimes called "balancer proteins" [Petrak et al., 2008; Wang et al., 2009] or general stress-response proteins). Besides this general reaction of the body, the biomarkers that indicate specific reactions to the toxic agent may be difficult to filter out. For example, in a recent PCB-153 exposure study in Atlantic cod (Gadus morhua), Berg et al. (2011) reported that approximately
$80 \%$ of proteins found regulated in brain were among those frequently noted general-response proteins and therefore most likely not stressor specific; still, six proteins were regarded as specific responses, among them the most strongly upregulated ones. Other examples show that also the usually more abundant general stressresponse proteins have their benefits and may be indicative for a specific stage of disease, if their time course and ratios are taken into account; for instance, acute and chronic inflammation in the rat affected the same proteins, but to a different degree (Gianazza et al., 2002).

\section{FUTURE PERSPECTIVES OF PROTEOMICS FOR TOXICOLOGICAL STUDIES}

New technologies or developments aim at creating easier to handle and high-throughput applications for routine analyses, or for use by less specialized scientists. Large-scale search for regulated proteins can be performed with antibody microarrays (Spisak et al., 2007). These rely on comprehensive antibody panels immobilized on chips for specific detection of large sets of proteins and are species specific. Elaborate to establish, they may be easy to apply as soon as commercially manufactured and available for the species of interest. Contrary to this broad-range screening, there is an MS-based trend toward specific detection of selected proteins called "targeted proteomics." Here, modern "assays" based on selected reaction monitoring (SRM) are developed specifically for proteins or peptides of interest. SRM quantifies, by MS methods, peptides that are unique for selected proteins. This allows specific simultaneous detection of multiple targets at low amounts in complex mixtures. Each of these assays needs to be set up and validated (Picotti et al., 2009; Picotti and Aebersold, 2012), but then they can be applied in a highthroughput manner. This method provides an interesting perspective and the potential for future biomonitoring and screening, also on a large scale, once the databases have been 
improved and potential target proteins have been identified.

In situ proteomics is a new keyword for methods derived from a combination of protein analysis and histological methods. They allow tissue-, cell-, and organelle-specific localization of proteins and the study of their distribution, for example, by proteomic investigation of particular cell populations. In addition to the more traditional immunostaining, confocal microscopy, and collection of specific cell populations under the microscope by laser capture microdissection for proteomic applications (Banks et al., 1999; Gillespie et al., 2004), recently developed MALDI imaging adds MS methods to this panel (Schwartz and Caprioli, 2010; Seeley et al., 2011). First applications were mainly focused on smaller molecules, for answering metabolomic questions, but there are already reports on proteomics data (Burnum et al., 2008; Seeley and Caprioli, 2008). In the MS field, new technical developments are to be expected, including more easy to use variations of present methods. Together with improved protein databases, proteomics will offer an exciting addition to the current toolbox of toxicological research.

\section{SUPPLEMENTAL DATA}

Supplemental data for this article can be accessed at http://dx.doi.org/10.1080/ 10937404.2014.904730

\section{REFERENCES}

Aarts, J. M., Denison, M. S., Cox, M. A., Schalk, M. A., Garrison, P. M., Tullis, K., de Haan, L. H., and Brouwer, A. 1995. Speciesspecific antagonism of Ah receptor action by 2,2',5,5'-tetrachloro- and 2,2',3,3'4,4'hexachlorobiphenyl. Eur. J. Pharmacol. 293: 463-474.

Alban, A., David, S. O., Bjoreksten, L., Andersson, C., Sloge, E., Lewis, S., and Currie, I. 2003. A novel experimental design for comparative two-dimensional gel analysis: Two-dimensional difference gel electrophoresis incorporating a pooled internal standard. Proteomics 3: 36-41.

Alm, H., Kultima, K., Scholz, B., Nilsson, A., Andrén, P. E., Fex-Svenningsen, A., Dencker, L., and Stigson, M. 2008. Exposure to brominated flame retardant PBDE-99 affects cytoskeletal protein expression in the neonatal mouse cerebral cortex. Neurotoxicology 29: 628-637.

Alm, H., Scholz, B., Fischer, C., Kultima, K., Viberg, H., Eriksson, P., Dencker, L., and Stigson, M. 2006. Proteomic evaluation of neonatal exposure to $2,2^{\prime}, 4,4^{\prime}, 5$ pentabromodiphenyl ether. Environ. Health Perspect. 114: 254-259.

Alm, H., Scholz, B., Kultima, K., Nilsson, A., Andrén, P. E., Savitski, M. M., Bergman, A., Stigson, M., Fex-Svenningsen, A., and Dencker, L. 2010. In vitro neurotoxicity of PBDE-99: Immediate and concentrationdependent effects on protein expression in cerebral cortex cells. J. Proteome Res. 9: 1226-1235.

Anderson, N. L., and Anderson, N. G. 2002. The human plasma proteome. Mol. Cell. Proteomics 1: 845-867.

Anderson, N. L., Polanski, M., Pieper, R., Gatlin, T., Tirumalai, R. S., Conrads, T. P., Veenstra, T. D., Adkins, J. N., Pounds, J. G., Fagan, R., and Lobley, A. 2004. The Human Plasma Proteome. A nonredundant list developed by combination of four separate sources. Mol. Cell. Proteomics 3: 311-326.

Apraiz, I., Mi, J., and Cristobal, S. 2006. Identification of proteomic signatures of exposure to marine pollutants in mussels (Mytilus edulis). Mol. Cell. Proteomics 5: 1274-1285.

Azkargorta, M., Fullaondo, A., Laresgoiti, U., Aloria, K., Infante, A., Arizmendi, J. M., and Zubiaga, A. M. 2010. Differential proteomics analysis reveals a role for E2F2 in the regulation of the Ahr pathway in $\mathrm{T}$ lymphocytes. Mol. Cell. Proteomics 9: 2184-2194.

Banks, R. E., Dunn, M. J., Forbes, M. A., Stanley, A., Pappin, D., Naven, T., Gough, M., Harnden, P., and Selby P. J. 1999. The potential use of laser capture microdissection to selectively obtain distinct populations 
of cells for proteomic analysis-Preliminary findings. Electrophoresis 20: 689-700.

Bantscheff, M., Lemeer, S., Savitski, M. M., and Kuster, B. 2012. Quantitative mass spectrometry in proteomics: Critical review update from 2007 to the present. Anal. Bioanal. Chem. 404: 939-965.

Bantscheff, M., Schirle, M., Sweetman, G., Rick, J., and Kuster, B. 2007. Quantitative mass spectrometry in proteomics: A critical review. Anal. Bioanal. Chem. 389: 1017-1031.

Berg, V., Gutleb, A. C., Lie, E., Lyche, J. L., Skaare, J. U., Aleksandersen, M., and Ropstad, E. 2010. Distribution of PCB 118 and PCB 153 and hydroxylated metabolites $(\mathrm{OH}-\mathrm{CBs})$ in maternal tissue and foetal and lamb tissues of sheep exposed during gestation and lactation. Chemosphere 80: 1144-1150.

Berg, K., Puntervoll, P., Klungsøyr, J., and Goksøyr, A. 2011. Brain proteome alterations of Atlantic cod (Gadus morhua) exposed to PCB 153. Aquat. Toxicol. 105: 206-217.

Bingham, B., Jones, P. G., Uveges, A. J., Kotnis, S., Lu, P., Smith, V. A., Sun, C.-C., Resnick, L., Chlenov, M., He, Y., Strassle, B. W., Cummons, T. A., Piesla, M. J., Harrison, J. E., Whiteside, G. T., and Kennedy, J. D. 2007. Speciesspecific in vitro pharmacological effects of the cannabinoid receptor $2\left(\mathrm{CB}_{2}\right)$ selective ligand AM1241 and its resolved enantiomers. Br. J. Pharmacol. 151: 1061-1070.

Binz, P. A., Barkovich, R., Beavis, R. C., Creasy, D., Horn, D. M., Julian, R. K., Jr, Seymour, S. L., Taylor, C. F., and Vandenbrouck, Y. 2008. Guidelines for reporting the use of mass spectrometry informatics in proteomics. Nat. Biotechnol. 26: 862.

Brewis, I. A., and Brennan, P. 2010. Proteomics technologies for the global identification and quantification of proteins. Adv. Protein Chem. Struct. Biol. 80: 1-44.

Bruggeman, V., Van den Bergh, G., Clerens, S., Dumez, L., Onagbesan, O., Arckens, L., and Decuypere, E. 2006. Effect of a single in ovo injection of 2,3,7,8-tetra-chlorodibenzo$p$-dioxin on protein expression in liver and ovary of the one-day-old chick analyzed by fluorescent two-dimensional difference gel electrophoresis and mass spectrometry. Proteomics 6: 2576-2585.

Brunelli, L., Llansola, M., Felipo, V., Campagna, R., Airoldi, L., De Paola, M., Fanelli, R., Mariani, A., Mazzoletti, M., and Pastorelli, R. 2012. Insight into the neuroproteomics effects of the food-contaminant non-dioxin like polychlorinated biphenyls. J. Proteomics 75: 2417-2430.

Bruno, M. E., Borchers, C. H., Dial, J. M., Walker, N. J., Hartis, J. E., Wetmore, B. A., Barrett, J. C., Tomer, K. B., and Merrick, B. A. 2002. Effects of TCDD upon IkappaB and IKK subunits localized in microsomes by proteomics. Arch. Biochem. Biophys. 406: 153-164.

Burnum, K. E., Frappier, S. L., and Caprioli, R. M. 2008. Matrix-assisted laser desorption/ ionization imaging mass spectrometry for the investigation of proteins and peptides. Annu. Rev. Anal. Chem. (Palo Alto Calif.) 1: 689-705.

Campagna, R., Brunelli, L., Airoldi, L., Fanelli, R., Hakansson, H., Heimeier, R. A., De Boever, P., Boix, J., Llansola, M., Felipo, V., and Pastorelli, R. 2011. Cerebellum proteomics addressing the cognitive deficit of rats perinatally exposed to the food-relevant polychlorinated biphenyl 138. Toxicol. Sci. 123: 170-179.

Campos, A., Tedesco, S., Vasconcelos, V., and Cristobal, S. 2012. Proteomic research in bivalves: Towards the identification of molecular markers of aquatic pollution. J. Proteomics 75: 4346-4359.

Capriotti, A. L., Caruso, G., Cavaliere, C., Piovesana, S., Samperi, R., and Laganà, A. 2012. Comparison of three different enrichment strategies for serum low molecular weight protein identification using shotgun proteomics approach. Anal. Chim. Acta 740: 58-65.

Capriotti, A. L., Cavaliere, C., Foglia, P., Samperi, R., and Laganà, A. 2011. Intact protein separation by chromatographic and/or electrophoretic techniques for top-down proteomics. J. Chromatogr. A 1218: 8760-8776. 
Chen, X., Ma, S., Ma, X., Xu, Y., and Tang, N. 2012. Changes in fibrinopeptide A peptides in the sera of rats chronically exposed to low doses of 2,3,7,8-tetrachlorodibenzo- $p$ dioxin (TCDD). Environ. Toxicol. Pharmacol. 33: 191-196.

Chen, X., Ma, X., Ma, S., Coenraads, P. J., Zhang C., Liu, J., Zhao, L., Sun, M., and Tang, N. 2009. Proteomic analysis of the rat ovary following chronic low-dose exposure to 2,3,7,8-tetrachlorodibenzo-p-dioxin (TCDD). J. Toxicol. Environ. Health A 72: 717-726.

Chevallet, M., Wagner, E., Luche, S., van Dorsselaer, A., Leize-Wagner, E., and Rabilloud, T. 2003. Regeneration of peroxiredoxins during recovery after oxidative stress: Only some overoxidized peroxiredoxins can be reduced during recovery after oxidative stress. J. Biol. Chem. 278: 37146-37153.

Choi, J., Kim, I., Hwang, S., Shin, B., and Kim, S. 2008. Effect of 2,3,7,8tetrachlorodibenzo-p-dioxin on testicular spermatogenesis-related panels and serum sex hormone levels in rats. Br. J. Urol. Int. 101: 250-255.

de Swart, R. L., Ross, P. S., Vedder, E. J., Timmerman, H., Heisterkamp, S. H., van Loveren, H., Vos, J. G., Reijnders, P. J. H., and Osterhaus, A. D. M. E. 1994. Impairment of immunological functions of harbour seals (Phoca vitulina) feeding on fish from polluted coastal waters. AMBIO 23: 155-159.

Erhard, H. W., and Rhind, S. M. 2004. Prenatal and postnatal exposure to environmental pollutants in sewage sludge alters emotional reactivity and exploratory behaviour in sheep. Sci. Total Environ. 332: 101-108.

Freitas, J., Cano, P., Craig-Veit, C., Goodson, M. L., Furlow, J. D., and Murk, A. J. 2011. Detection of thyroid hormone receptor disruptors by a novel stable in vitro reporter gene assay. Toxicol. in Vitro 25: 257-266.

Gan, L., Guo, K., Cremona, M. L., McGraw, T. E., Leibel, R. L., and Zhang, Y. 2012. TNF- $\alpha$ up-regulates protein level and cell surface expression of the leptin receptor by stimulating its export via a PKC- dependent mechanism. Endocrinology 153: 5821-5833.

Geiger, T., Cox, J., Ostasiewicz, P., Wisniewski, J. R., and Mann, M. 2010. Super-SILAC mix for quantitative proteomics of human tumor tissue. Nat. Methods 7: 383-385.

Geiger, T., Wisniewski, J. R., Cox, J., Zanivan, S., Kruger, M., Ishihama, Y., and Mann, M. 2011. Use of stable isotope labeling by amino acids in cell culture as a spikein standard in quantitative proteomics. Nat. Protocols 6: 147-157.

Gerner, C., Vejda, S., Gelbmann, D., Bayer, E., Gotzmann, J., Schulte-Hermann, R., and Mikulits, W. 2002. Concomitant determination of absolute values of cellular protein amounts, synthesis rates, and turnover rates by quantitative proteome profiling. Mol. Cell. Proteomics 1: 528-537.

Gevaert, K., and Vandekerckhove, J. (Eds.). 2011. Gel-free proteomics-Methods and protocols. Methods Mol. Biol. 753. Heidelberg, Germany: Springer.

Gianazza, E., Eberini, I., Villa, P., Fratelli, M., Pinna, C., Wait, R., Gemeiner, M., and Miller, I. 2002. Monitoring the effects of drug treatment in rat models of disease by serum protein analysis. J. Chromatogr. B 771: 107-130.

Gillardin, V., Silvestre, F., Dieu, M., Delaive, E., Raes, M., Thome, J.-P., and Kestemont, P. 2009. Protein expression profiling in the African clawed frog Xenopus laevis tadpoles exposed to the polychlorinated biphenyl mixture Aroclor 1254. Mol. Cell. Proteomics 8: 596-611.

Gillespie, J. W., Gannot, G., Tangrea, M. A., Ahram, M., Best, C. J., Bichsel, V. E., Petricoin, E. F., Emmert-Buck, M. R., and Chuaqui, R. F. 2004. Molecular profiling of cancer. Toxicol. Pathol. 32(suppl 1): 67-71.

Gin, D., Kim, H., Lee, D., Lee, S., Seong, A., Hwang, J., and Park, J. 2010. 2,3,7,8-Tetrachlorodibenzo- $p$-dioxin up-regulates stath$\min 1$ in the eye: Suggestive evidence for the involvement of stathmin 1 in accelerated eye opening in mice induced by $2,3,7,8$ tetrachlorodibenzo-p-dioxin. Toxicol. Lett. 196: 87-94. 
Gomiero, A., Pampanin, D. M., Bjørnstad, A., Larsen, B. K., Provan, F., Lyng, E., and Andersen, O. K. 2006. An ecotoxicoproteomic approach (SELDI-TOF mass spectrometry) to biomarker discovery in crab exposed to pollutants under laboratory conditions. Aquat. Toxicol. 78(suppl 1): S34-S41.

Greengauz-Roberts, O., Stöppler, H., Nomura, S., Yamaguchi, H., Goldenring, J. R., Podolsky, R. H., Lee, J. R., and Dynan, W. S. 2005. Saturation labeling with cysteinereactive cyanine fluorescent dyes provides increased sensitivity for protein expression profiling of laser-microdissected clinical specimens. Proteomics 5: 1746-1757.

Gutleb, A. C. 2011. Potential of in vitro methods to study particulate matter induced cardiopulmonary toxicity. Crit. Rev. Environ. Sci. Technol. 41: 1971-2002.

Gutleb, A. C., Arvidsson, D., Örberg, J., Larsson, S., Skaare, J. U., Aleksandersen, M., Ropstad, E., and Lind, P. M. 2010a. Effects on bone tissue in ewes (Ovies aries) and their foetuses exposed to PCB 118 and PCB 153. Toxicol. Lett. 192: 126-132.

Gutleb, A. C., Cenijn, P., van Velzen, M., Lie, E., Ropstad, E., Skaare, J.U., Malmberg, T., Bergman, Å., Gabrielsen, G.W., and Legler, J. 2010b. Complete saturation of thyroid hormone transport capacity of TTR in wild living polar bear (Ursus maritimus) by metabolites of PCBs. Environ. Sci. Technol. 44: 3149-3154.

Gutleb, A. C., Mossink, L., Schriks, M., Berg, J. H. J., and Murk, A. J. 2007. Delayed effects of environmentally relevant concentrations of 3,3',4,4'-tetrachlorobiphenyl (PCB-77) and non-polar sediment extracts detected in the prolonged-FETAX. Sci. Total Environ. 381: 307-315.

Gutleb, A. C., Zimmer, K. E., Lilienthal, H., Erhard, H. W., Skaare, J. U., and Ropstad, E. 2011. Effects of low-dose prenatal PCB exposure on emotional reactivity observed in lambs before weaning. Ecotoxicol. Environ. Safety 74: 1396-1401.

Hartwell, L., Mankoff, D., Paulovich, A., Ramsey, S, and Swisher, E. 2006. Cancer biomarkers: A systems approach. Nat. Biotechnol. 24: 905-908.

Hough, C., Radu, M., and Doré, J. J. 2012. Tgfbeta induced Erk phosphorylation of smad linker region regulates smad signaling. PLoS One 7: e42513.

Hu, Q, Rice, R. H., Qin, Q, Phinney, B. S., Eigenheer, R. A., Bao, W., and Zhao, B. 2013. Proteomic analysis of human keratinocyte response to 2,3,7,8tetrachlorodibenzo-p-dioxin (TCDD) exposure. J. Proteome Res. 12: 5340-5347.

Huljic, S., Bruske, E. I., Pfitzenmaier, N., O'Brien, E., and Dietrich, D. R. 2008 Species-specific toxicity of aristolochic acid (AA) in vitro. Toxicol In Vitro 22:1213-1221.

Jeon, C., Kim, H., and Park, J. 2009. Induction of S100A4, S100A6, and galectin-1 during the lineage commitment of CD4+CD8+ thymocyte cell line is suppressed by $2,3,7,8$ tetrachlorodibenzo-p-dioxin. Toxicol. Lett. 187: 157-163.

Kaya, H., Hany, J., Fastabend, A., Roth-Härer, A., Winneke, G., and Lilienthal, H. 2002. Effects of maternal exposure to a reconstituted mixture of polychlorinated biphenyls on sex-dependent behaviors and steroid hormone concentrations in rats: Dose-response relationship. Toxicol. Appl. Pharmacol. 178: 71-81.

Kling, P., and Forlin, L. 2009. Proteomic studies in zebrafish liver cells exposed to the brominated flame retardants HBCD and TBBPA. Ecotoxicol. Environ. Safety 72: 1985-1993.

Kling, P., Norman, A., Andersson, P. L., Norrgren, L., and Förlin, L. 2008. Genderspecific proteomic responses in zebrafish liver following exposure to a selected mixture of brominated flame retardants. Ecotoxicol. Environ. Safety 71: 319-327.

Klose, J. 1975. Protein mapping by combined isoelectric focusing and electrophoresis of mouse tissues. A novel approach to testing for induced point mutations in mammals. Humangenetik 26: 231-243.

Kodavanti, P. R. S., Osorio, C., Royland, J. E., Ramabhadran, R., and Alzate, O. 2011. Aroclor 1254, a developmental neurotoxicant, alters energy metabolism- and 
intracellular signaling-associated protein networks in rat cerebellum and hippocampus. Toxicol. Appl. Pharmacol. 256: 290-299.

Kolluri, S. K., Balduf, C., Hofmann, M., and Göttlicher, M. 2001. Novel target genes of the Ah (dioxin) receptor: Transcriptional induction of $\mathrm{N}$-myristoyltransferase 2. Cancer Res. 61: 8534-8539.

Krapfenbauer, K., and Fountoulakis, M. 2009. Improved enrichment and proteomic analysis of brain proteins with signaling function by heparin chromatography. Methods Mol. Biol. 566: 165-180.

Kraugerud, M., Aleksandersen, M., Nyengaard, J. R., Østby, G. C., Gutleb, A. C., Dahl, E., Berg, V., Farstad, W. K., Schweder, T., Skaare, J. U., and Ropstad, E. 2012. In utero and lactational exposure to PCB 118 and PCB 153 alters ovarian follicular dynamics and $\mathrm{GnRH}$ induced $\mathrm{LH}$ secretion in female lambs. Environ. Toxicol. 26: 623-634.

Kruger, M., Moser, M., Ussar, S., Thievessen, I., Luber, C. A., Forner, F., Schmidt, S., Zanivan, S., Fassler, R., and Mann, M. 2008. SILAC mouse for quantitative proteomics uncovers kindlin-3 as an essential factor for red blood cell function. Cell 134:353-364.

Laemmli, U. K. 1970. Cleavage of structural proteins during the assembly of the head of bacteriophage T4. Nature 222: 680-685.

Lasserre, J.-P., Fack, F., Revets, D., Planchon, S., Renaut, J., Hoffmann, L., Gutleb, A. C., Muller, C., and Bohn, T. 2009. Effects of the endocrine disruptors atrazine and PCB 153 on the protein expression of MCF-7 human cells. J. Proteome Res. 8: 5485-5496.

Lasserre, J.-P., Fack, F., Serchi, T., Revets, D., Planchon, S., Renaut, J., Hoffmann, L., Gutleb, A. C., Muller, C. P., and Bohn, T. 2012. Atrazine and PCB 153 and their effects on the proteome of subcellular fractions of human MCF-7 cells. Biochim. Biophys. Acta 1824: 833-841.

Lauer, B., Tuschl, G., Kling, M., and Mueller, S. O. 2009. Species-specific toxicity of diclofenac and troglitazone in primary human and rat hepatocytes. Chem. Biol. Interact. 179: 17-24.
Lee, S., Lee, D., Son, W., Joo, W., and Kim, C. 2005. Proteomic characterization of rat liver exposed to 2,3,7,8-tetrachlorobenzo- $p$ dioxin. J. Proteome Res. 4: 335-343.

Leroy, D., Haubruge, E., De Pauw, E., Thomé, J. P., and Francis, F. 2010. Development of ecotoxicoproteomics on the freshwater amphipod Gammarus pulex: Identification of PCB biomarkers in glycolysis and glutamate pathways. Ecotoxicol. Environ. Safety 73: 343-352.

Lescuyer, P., Hochstrasser, D., and Rabilloud, T. 2007. How shall we use the proteomics toolbox for biomarker discovery? J. Proteome Res. 6: 3371-3376.

Lilienthal, H., Hack, A., Roth-Härer, A., Grande, S. W., and Talsness, C. 2006. Effects of developmental exposure to $2,2^{\prime}, 4,4^{\prime}, 5$ pentabromodiphenyl ether (PBDE-99) on sex steroids, sexual development, and sexually dimorphic behavior in rats. Environ. Health Perspect. 114: 194-201.

Luebke, R. W., Chen, D. H., Dietert, R., Yang, Y., King, M., Luster, M. I., Immunotoxicology Workgroup. 2006. The comparative immunotoxicity of five selected compounds following developmental or adult exposure. J. Toxicol. Environ. Health B 9: 1-26.

Lundgren, D.H., Hwang, S. I., Wu, L., and Han, D. K. 2010. Role of spectral counting in quantitative proteomics. Expert Rev. Proteomics 7: 39-53.

Lyche, J. L., Oskam, I. C., Skaare, J. U., Reksen, O., Sweeney, T., Dahl, E., Farstad, W., and Ropstad, E. 2004. Effects of gestational and lactational exposure to low doses of PCBs 126 and 153 on anterior pituitary and gonadal hormones and on puberty in female goats. Reprod. Toxicol. 19: 87-95.

Ma, X., Chen, X., Ma, S., Coenraads, P. J., Liu, J., Zhang, C., Zhao, L., Sun, M., and Tang, N. 2010. Protein expression profile in the testis of rats chronically exposed to lowdose 2,3,7,8-tetrachlorodibenzo-p-dioxin. Toxicol. Environ. Chem. 92: 1715-1727.

Marouga, R., David, S., and Hawkins, E. 2005. The development of the DIGE system: 2D fluorescence difference gel analysis technology. Anal. Bioanal. Chem. 382: 669-678. 
Matros, A., Kaspar, S., Witzel, K., and Mock, H. P. 2011. Recent progress in liquid chromatography-based separation and label-free quantitative plant proteomics. Phytochemistry 72: 963-974.

Megger, D. A., Bracht, T., Meyer, H. E., and Sitek, B. 2013. Label-free quantification in clinical proteomics. Biochim. Biophys. Acta 1834: 1581-1590.

Medzihradszky, K. F., and Chalkley, R. J. 2014. Lessons in de novo peptide sequencing by tandem mass spectrometry. Mass Spectrometr. Rev. doi:10.1002/mas.21406

Miller, I. 2011. Chapter 3: Protein separation strategies. In Methods in animal proteomics, ed. P. D. Eckersall and P. D. Whitfield, 41. Chichester, UK: John Wiley \& Sons.

Miller, I. 2012. Application of 2D-DIGE in animal proteomics. Methods Mol. Biol. 854: 373-396.

Miller, I., Crawford, J., and Gianazza, E. 2006. Protein stains for proteomic applications: Which, when, why? Proteomics 6: 5385-5408.

Miller, I., Eberini, I., and Gianazza, E. 2010a. Other than IPG-DALT: Two-dimensional electrophoresis variants. Proteomics 10: 586-610.

Miller, I., Gianazza, E., and Gemeiner, M. 2010b. Any use in proteomics for low-tech approaches? Detecting fibrinogen chains of different animal species in two-dimensional electrophoresis patterns. J. Chromatogr. $B$ 878: 2314-2318.

Miller, I., Radwan, M., Strobl, B., Müller, M., and Gemeiner, M. 2006. Contribution of cell culture additives to the two-dimensional protein patterns of mouse macrophages. Electrophoresis 27: 1626-1629.

Montaño, M., Cocco, E., Guignard, C., Marsh, G., Hoffmann, L., Bergman, $\AA$., Gutleb, A. C., and Murk, A. J. 2012. New approaches to assess the transthyretin binding capacity of bioactivated thyroid hormone disruptors. Toxicol. Sci. 130: 94-105.

Montaño, M., Gutleb, A. C., and Murk, A. J. 2013. Persistent toxic burdens of halogenated phenolic compounds in humans and wildlife. Environ. Sci. Technol. 47: 6071-6081.

Murk, A. J., Morse, D., Boon, J., and Brouwer, A. 1994. In vitro metabolism of $3,3^{\prime}, 4,4^{\prime}$-tetrachlorobiphenyl in relation to ethoxyresorufin-O-deethylase activity in liver microsomes of some wildlife species and rat. Eur. J. Pharmacol. 270: 253-261.

Neilson, K. A., Ali, N. A., Muralidharan, S., Mirzaei, M., Mariani, M., Assadourian, G., Lee, A., van Sluyter, S. C., and Haynes, P. A. 2011. Less label, more free: Approaches in label-free quantitative mass spectrometry. Proteomics 11: 535-553.

Oberemm, A., Meckert, C., Brandenburger, L., Herzig, A., Lindner, Y., Kalenberg, K., Krause, E., Ittrich, C., Richter-Reichhelm, H.-B., and Gundert-Remy, U. 2005. Differential signatures of protein expression in marmoset liver and thymus induced by single-dose TCDD treatment. Toxicology 206: 33-48.

O'Farrell, P. H. 1975. High-resolution twodimensional electrophoresis of proteins. J. Biol. Chem. 250: 4007-4021.

Oliver, R. W. A. (Ed.). 1989. HPLC of macromolecules, a practical approach. Practical Approach Series (series ed. D. Rickwood and B. D. Hames). Oxford, UK: IRL Press.

Ong, S. E., Blagoev, B., Kratchmarova, I., Kristensen, D. B., Steen, H., Pandey, A., and Mann, M. 2002. Stable isotope labeling by amino acids in cell culture, SILAC, as a simple and accurate approach to expression proteomics. Mol. Cell. Proteomics 1: 376-386.

Okey, A. B., Franc, M. A., Moffat, I. D., Tijet, N., Boutros, P. C., Korkalainen, M., Tuomisto, J., and Pohjanvirta, R. 2005. Toxicological implications of polymorphisms in receptors for xenobiotic chemicals: The case of the aryl hydrocarbon receptor. Toxicol. Appl. Pharmacol. 207: 43-51.

Oskam, I. C., Lyche, J. L., Krogenaes, A., Thomassen, R., Skaare, J. U., Wiger, R., Dahl, E., Sweeney, T., Stien, A., and Ropstad, E. 2005. Effects of long-term maternal exposure to low doses of PCB126 and PCB153 on the reproductive system and related hormones 
of young male goats. Reproduction 130: 731-742.

Pastorelli, R., Carpi, D., Campagna, R., Airoldi, L., Pohjanvirta, R., Viluksela, M., Hakansson, H., Boutros, P. C., Moffat, I. D., Okey, A. B., and Fanelli, R. 2006. Differential expression profiling of the hepatic proteome in a rat model of dioxin resistance. Mol. Cell. Proteomics 5: 882-894.

Petrak, J., Ivanek, R., Toman, O., Cmejla, R., Cmejlova, J., Vyoral, D., Zivny, J., and Vulpe, C. D. 2008. Déjà vu in proteomics. A hit parade of repeatedly identified differentially expressed proteins. Proteomics 8: 1744-1749.

Picotti, P., and Aebersold, R. 2012. Selected reaction monitoring-based proteomics: Workflows, potential, pitfalls and future directions. Nat. Methods 9: 555-566.

Picotti, P., Bodenmiller, B., Mueller, L. N., Domon, B., and Aebersold, R. 2009. Full dynamic range proteome analysis of $\mathrm{S}$. cerevisiae by targeted proteomics. Cell 138: 795-806.

Piechura, H., Oeljeklaus, S., and Warscheid, B. 2012. SILAC for the study of mammalian cell lines and yeast protein complexes. Methods Mol. Biol. 893: 201-221.

Pohjanvirta, R., Unkila, M., and Tuomisto, J. 1993. Comparative acute lethality of $2,3,7,8-$ tetrachlorodibenzo- $p$-dioxin (TCDD), 1,2,3, 7,8-pentachlorodibenzo- $p$-dioxin and 1,2,3, $4,7,8$-hexachlorodibenzo- $p$-dioxin in the most TCDD-susceptible and the most TCDD-resistant rat strain. Pharmacol. Toxicol. 73: 52-56.

Polanski, M., and Anderson, N. L. 2007. A list of candidate cancer biomarkers for targeted proteomics. Biomarker Insights 1: 1-48.

Posch, A. (Ed.). 2008. 2D PAGE: Sample preparation and fractionation. Methods Mol. Biol. 424. Heidelberg, Germany: Springer.

Riva, C., Cristoni, S., and Binelli, A. 2012. Effects of triclosan in the freshwater mussel Dreissena polymorpha: A proteomic investigation. Aquat. Toxicol. 118-119:62-71.

Ross, P. S., de Swart, R. L., van Loveren, H., Osterhaus, A. D. M. E., and Vos, J. G. 1996. The immunotoxicity of environmental contaminants to marine wildlife: A review. Annu. Rev. Fish Dis. 6: 151-165.

Sarioglu, H., Brandner, S., Haberger, M., Jacobsen, C., Lichtmannegger, J., Wormke, M., and Andrae, U. 2008. Analysis of 2,3,7,8-tetrachlorodibenzo-p-dioxin-

induced proteome changes in $5 \mathrm{~L}$ rat hepatoma cells reveals novel targets of dioxin action including the mitochondrial apoptosis regulator VDAC2 Mol. Cell. Proteomics 7: 394-410.

Sarioglu, H., Brandner, S., Jacobsen, C., Meindl, T., Schmidt, A., Kellermann, J., Lottspeich, F., and Andrae, U. 2006. Quantitative analysis of 2,3,7,8tetrachlorodibenzo- $p$-dioxin-induced proteome alterations in $5 \mathrm{~L}$ rat hepatoma cells using isotope-coded protein labels. Proteomics 6: 2407-2421.

Schwartz, S. A., and Caprioli, R. M. 2010. Imaging mass spectrometry: Viewing the future. Methods Mol. Biol. 656: 3-19.

Seeley, E. H., and Caprioli, R. M. 2008. Molecular imaging of proteins in tissues by mass spectrometry. Proc. Natl. Acad. Sci. USA 105: 18126-18131.

Seeley, E. H., Schwamborn, K., and Caprioli, R. M. 2011. Imaging of intact tissue sections: Moving beyond the microscope. J. Biol. Chem. 286: 25459-25466.

Smith, D. A., Minthorn, E. A., and Beerahee, M. 2011. Pharmacokinetics and pharmacodynamics of mepolizumab, an anti-interleukin5 monoclonal antibody. Clin. Pharmacokinet. 50: 215-227.

Søfteland, L., Petersen, K., Stavrum, A.K., Wu, T., and Olsvik, P. A. 2011. Hepatic in vitro toxicity assessment of PBDE congeners BDE47, BDE153 and BDE154 in Atlantic salmon (Salmo salar L.). Aquat. Toxicol. 105: 246-263.

Son, W., Lee, D., Lee, S., Joo, W., and Kim, C. 2003. Analysis of proteins expressed in rat plasma exposed to dioxin using 2dimensional gel electrophoresis. Proteomics 3: 2393-2401.

Sotoca, A. M., Sollewijn Gelpke, M. D., Boeren, S., Ström, A., Gustafsson, J.-Å., Murk, A. J., Rietjens, I. M. C. M., and Vervoort, J. 2011. 
Quantitative proteomics and transcriptomics addressing the estrogen receptor subtypemediated effects in T47D breast cancer cells. Mol. Cell. Proteomics 10: 1-17.

Spisak, S., Tulassay, Z., Molnar, B., and Guttman, A. 2007. Protein microchips in biomedicine and biomarker discovery. Electrophoresis 28: 4261-4273.

Spreafico, A., Frediani, B., Capperucci, C., Chellini, F., Paffetti, A., D'Ambrosio, C., Bernardini, G., Mini, R., Collodel, G., Scaloni, A., Marcolongo, R., and Santucci, A. 2006. A proteomic study on human osteoblastic cells proliferation and differentiation. Proteomics 6: 3520-3532.

Strathmann, J., Paal, K., Ittrich, C., Krause, E., Appel, K. E., Glauert, H. P., Buchmann, A., and Schwarz, M. 2007. Proteome analysis of chemically induced mouse liver tumors with different genotype. Proteomics 7: 3318-3331.

Sundt, R. C., Pampanin, D. M., Larsen, B. K., Brede, C., Herzke, D., Bjørnstad, A, and Andersen, O. K. 2006. The BEEP Stavanger Workshop: Mesocosm exposures. Aquat. Toxicol. 78S: S5-S12.

Taylor, C. F., Binz, P.-A., Aebersold, R., Affolter, M., Barkovich, R., Deutsch, E. W., Horn, D. M., Hühmer, A., Kussmann, M., Lilley, K., Macht, M., Mann, M., Müller, D., Neubert, T. A., Nickson, J., Patterson, S. D., Raso, R., Resing, K., Seymour, S. L., Tsugita, A., Xenarios, I., Zeng, R., and Julian, R. K., Jr. 2008. Guidelines for reporting the use of mass spectrometry in proteomics. Nat. Biotechnol. 26: 860-861.

Thingholm, T. E., Jensen, O. N., and Larsen, M. R. 2009. Analytical strategies for phosphoproteomics. Proteomics 9: 1451-1468.

Timms, J. F., and Cramer, R. 2008. Difference gel electrophoresis. Proteomics 8: 4886-4897.

Uenlue, M., Morgan, M. E., and Minden, J. S. 1997. Difference gel electrophoresis: A single gel method for detecting changes in protein extracts. Electrophoresis 18: 2071-2077.

Wagner, E., Luche, S., Penna, L., Chevallet, M., Van Dorsselaer, A., Leize-Wagner, E., and Rabilloud, T. 2002. A method for detection of overoxidation of cysteines: Peroxiredoxins are oxidized in vivo at the active-site cysteine during oxidative stress. Biochem. J. 366: 777-785.

Wang, P., Bouwman, F. G., and Mariman, E. C. M. 2009. Generally detected proteins in comparative proteomics-A matter of cellular stress response? Proteomics 9: 2955-2966.

Westermeier, R., and Naven, T. (Eds.). 2002. Proteomics in practice. A laboratory manual of proteome analysis. Weinheim, Germany: Wiley-VCH.

Westman-Brinkmalm, A., Abramsson, A., Pannee, J., Gang, C., Gustavsson, M. K., von Otter, M., Blennow, K., Brinkmalm, G., Heumann, H., and Zetterberg, H. 2011. SILAC zebrafish for quantitative analysis of protein turnover and tissue regeneration. J. Proteomics 75: 425-434.

Winkler, W., Zellner, M., Diestinger, M., Babeluk, R., Marchetti, M., Goll, A., Zehetmayer, S., Bauer, P., Rappold, E., Miller, I., Roth, E., Allmaier, G., and Oehler, R. 2008. Biological variation of the platelet proteome in the elderly population and its population for biomarker research. Mol. Cell. Proteomics 7: 193-203.

Winneke, G., Walkowiak, J., and Lilienthal, H. 2002. PCB-induced neurodevelopmental toxicity in human infants and its potential mediation by endocrine dysfunction. Toxicology 181-182:161-165.

Wolff, S., Otto, A., Albrecht, D., Zeng, J. S., Buttner, K., Gluckmann, M., Hecker, M., and Becher, D. 2006. Gel-free and gel-based proteomics in Bacillus subtilis, a comparative study. Mol. Cell. Proteomics. 5: 1183-1192.

Wortelboer, H. M., de Kruif, C. A., van lersel, A. A. J., Falke, H. E., Noordhoek, J., and Blaauboer, B. J. 1990. The isoenzyme pattern of cytochrome P450 in rat hepatocytes in primary culture, comparing different enzyme activities in microsomal incubations and in intact monolayers. Biochem. Pharmacol. 40: 2525-2534.

Wu, W., Wang, G., Baek, S. J., and Shen, R. F. 2006. Comparative study of three proteomic quantitative methods, DIGE, CICAT, and 
iTRAQ, using 2D gel- or LC-MALDI TOF/TOF. J. Proteome Res. 5: 651-658.

Yuan, X., Liu, L., Pu, Y., Zhang, X., He, X., and $\mathrm{Fu}, \mathrm{Y} .2012 .2,3,7,8$-Tetrachlorodibenzo$p$-dioxin induces a proteomic pattern that defines cleft palate formation in mice. Food Chem. Toxicol. 50: 2270-2274.

Zala, A. M., and Penn, D. J. 2004. Abnormal behaviours induced by chemical pollution: A review of the evidence and new challenges. Anim. Behav. 68: 649-664.

Zimmer, K., Gutleb, A. C., Lyche, J. L., Dahl, E., Oskam, I., Krogenæs, A., Skaare, J. U., and Ropstad, E. 2008. Altered stress-induced cortisol levels in goats exposed to polychlorinated biphenyls (PCB 126 and PCB 153) during foetal and postnatal development. J. Toxicol. Environ. Health A 72: 164-172. 


\section{Chapter 4}

\section{Hexabromocyclododecane (HBCD) induced changes in the liver proteome of eu- and hypothyroid female rats}

Miller, I, Serchi, T, Cambier, S, Diepenbroek, C, Renaut, J, Van den Berg, JHJ, Kwadijk, C, Gutleb, AC, Rijntjes, E, Murk, A.J.

Hexabromocyclododecane (HBCD) induced changes in the liver proteome of eu- and hypothyroid female rats

Toxicology Letters 2016, 245, 40-51.

Miller, I, Serchi, T, Cambier, S, Diepenbroek, C, Renaut, J, Van den Berg, JHJ, Kwadijk, C, Gutleb, AC, Rijntjes, E, Murk, A.J.

Dataset of liver proteins changed in eu- and hypothyroid female rats upon in vivo exposure to hexabromocyclododecane (HBCD)

Data in Brief 2016, 7, 386-392.

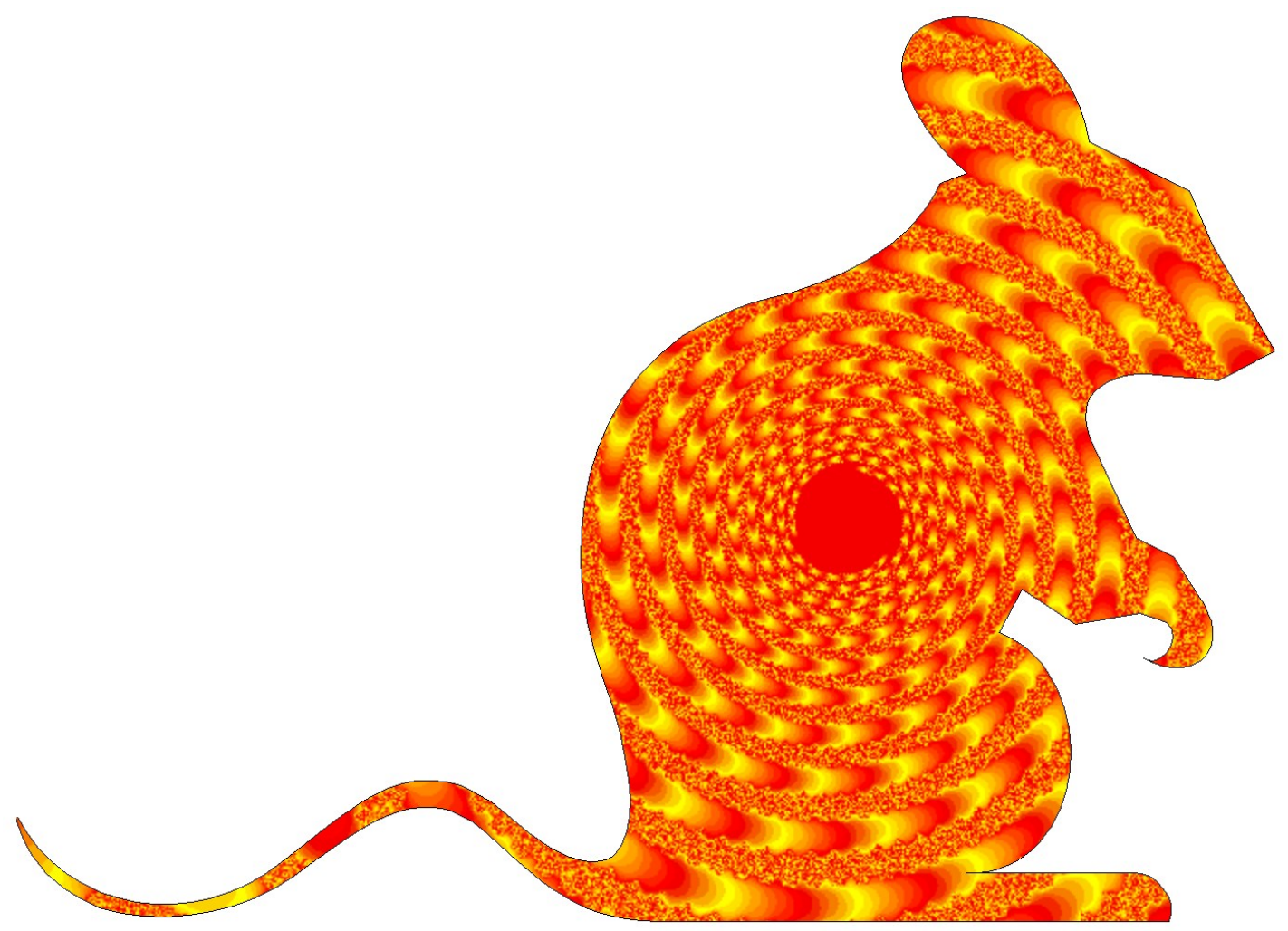





\title{
Hexabromocyclododecane (HBCD) induced changes in the liver proteome of eu- and hypothyroid female rats
}

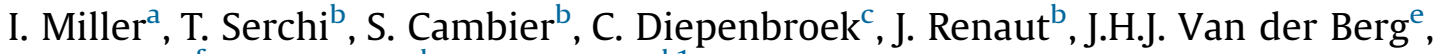 \\ C. Kwadijk ${ }^{\mathrm{f}}$, A.C. Gutleb ${ }^{\mathrm{b}}$, E. Rijntjes ${ }^{\mathrm{c}, \mathrm{d}, 1}$, A.J. Murk ${ }^{\mathrm{e}, *}$ \\ a Institute for Medical Biochemistry, Department for Biomedical Sciences, University of Veterinary Medicine Vienna, Veterinaerplatz 1, A-1210 Vienna, Austria \\ ${ }^{\mathrm{b}}$ Environmental Research and Innovation (ERIN) Department, Luxembourg Institute of Science and Technology (LIST), 5, Avenue des Hauts-Forneaux, L- \\ 4362 Esch-sur-Alzette, Luxembourg \\ ${ }^{\mathrm{c}}$ Wageningen University, Human and Animal Physiology Group, P.O. Box 338, 6700 AH Wageningen, The Netherlands \\ d Charité-Universitätsmedizin Berlin, Institute for Experimental Endocrinology, Augustenburger Platz 1, 13353 Berlin, Germany \\ ${ }^{\mathbf{e}}$ Wageningen University, Division of Toxicology, Tuinlaan 5, 6703 HE Wageningen, The Netherlands \\ ${ }^{\mathrm{f}}$ Wageningen Institute for Marine Resources \& Ecosystem Studies, IMARES, IJmuiden, The Netherlands
}

\section{H I G H L I G H T S}

- Exposure of female rats to HBCD for 7 days leads to liver proteome changes.

- Thirty-one spots were of significantly different abundance due to HBCD exposure.

- Proteins with similar functions were affected in eu- and hypothyroid states.

- Main protein targets were in metabolic processes and oxidative stress response.

- Overall 150 spots varied significantly when comparing thyroid states.
GRAPH ICALABSTRACT

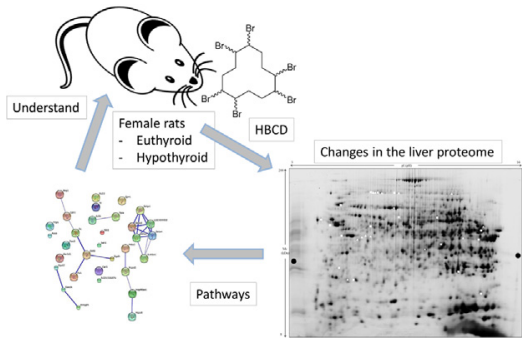

\section{A R T I C L E I N F O}

\section{Article history:}

Received 17 November 2015

Received in revised form 24 December 2015

Accepted 8 January 2016

Available online 12 January 2016

\begin{abstract}
A B S T R A C T
Hexabromocyclododecane (HBCD) is a brominated flame retardant known for its low acute toxicity as observed in animal experiments. However, HBCD exposure can affect liver functioning and thyroid hormone $(\mathrm{TH})$ status. As exact mechanisms are unknown and only limited toxicological data exists, a gelbased proteomic approach was undertaken. In a eu- and hypothyroid female rat model, rats were exposed to 3 and $30 \mathrm{mg} / \mathrm{kg}$ bw/day HBCD for 7 days via their diet, and exposure was related to a range of canonical endpoints (hormone status, body weight) available for these animals. Alterations in the liver proteome under HBCD exposure were determined in comparison with patterns of control animals, for both thyroid
\end{abstract}

Abbreviations: 2D-DIGE, two-dimensional fluorescence difference gel electrophoresis; AL1L1, aldehyde dehydrogenase family 1 member L1; BFR, brominated flame

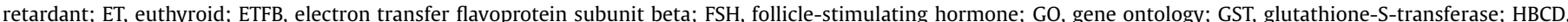

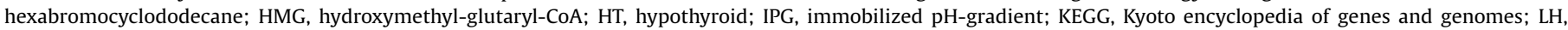

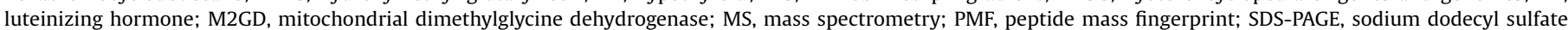
polyacrylamide gel electrophoresis; STRING, functional protein association networks; $\mathrm{T}_{3}$, triiodothyronine; $\mathrm{TH}$, thyroid hormone; TSH, thyroid stimulating hormone.

* Corresponding author. Current address: Wageningen University, Marine Animal Ecology Group, De Elst 1, 6708 WD Wageningen, The Netherlands.

E-mail addresses: ingrid.miller@vetmeduni.ac.at (I. Miller), tommaso.serchi@list.lu (T. Serchi), sebastien.cambier@list.lu (S. Cambier), charlenediepenbroek@gmail.com

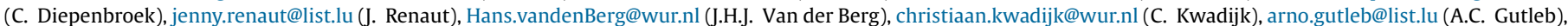
eddy.rijntjes@charite.de (E. Rijntjes),Tinka.Murk@WUR.nl (A.J. Murk).

1 Shared senior authorship. 
Keywords:

HBCD

Proteomics

Rat

Liver

Hypothyroidism

Lipid metabolism states. This revealed significantly changed abundance of proteins involved in metabolic processes (gluconeogenesis/glycolysis, amino acid metabolism, lipid metabolism), but also in oxidative stress responses, in both euthyroid and hypothyroid rats. The results provide a more detailed picture on the mechanisms involved in these alterations, e.g. at the protein level changes of the proposed influence of HBCD on the lipid metabolism. Present results show that proteomic approaches can provide further mechanistic insights in toxicological studies.

(C) 2016 Elsevier Ireland Ltd. All rights reserved.

\section{Introduction}

Hexabromocyclododecane ( $\mathrm{HBCD}, \mathrm{C}_{12} \mathrm{H}_{18} \mathrm{Br}_{6}$ ) was one of the most commonly used brominated flame retardants (BFRs) used until 2013, mainly in the building industry as an addition to extruded and expanded polystyrene foams and to a lesser extent also for impregnation of equipment. Earlier bans of other BFRs led to an increased production and use of HBCD that was followed by increasing environmental concentrations (Law et al., 2008). In 2013 the compound was banned in many industrial countries under the Stockholm convention (https://treaties.un.org/doc/Publication/ CN/2013/CN.934.2013-Eng.pdf), but it is still produced and applied in the USA as non-signatory. Technical grade $\mathrm{HBCD}$ consists of a mixture of three diastereomers, namely $\alpha-(\sim 10 \%), \beta-(\sim 9 \%)$ and $\gamma$-HBCD ( $\sim 81 \%)$, which differ in bioaccumulation potential (Szabo et al., 2010). The large global application of BFRs including HBCD has led to increasing contamination of the environment as these lipophilic substances are persistent and accumulate in various biota and adipose tissue of humans (Covaci et al., 2006; Darnerud, 2003; De Wit, 2002; Kalachova et al., 2012; Kiciński et al., 2012; Tomko and McDonald, 2013). Many BFRs including HBCD are known to act as endocrine disrupters (Covaci et al., 2006; Law et al., 2008; Tomko and McDonald, 2013; van der Ven et al., 2009).

Animal studies have confirmed low acute toxicity of HBCD. However, there are clear indications of toxicological effects, especially in the liver, on the immune system and on serum thyroid hormone $(\mathrm{TH})$ concentrations, TH dependent developmental processes and sex-dependent responses (Canton et al., 2008; Germer et al., 2006; van der Ven et al., 2006). Results from in vivo studies give evidence for the potential disruption of $\mathrm{TH}$ dependent processes, where exposure occurs physiologically in the presence of circulating THs. Interestingly, HBCD did not respond in the in vitro T-Screen when tested without any thyroid hormone present, while it potentiated the effect of 3,3',5-triiodothyronine (Schriks et al., 2006).

These three factors (still considerable use and production outside of Europe despite of the ban in 2013, environmental persistence and accumulation in food chains, and the not completely understood mechanism of action) convinced us to undertake the present short-term exposure study in combination with applying the holistic a posteriori approach of proteomics.

Low serum concentrations of TH (hypothyroidism) negatively affect neurological development, energy metabolism, early development and can also lead to heart failure, whereas hyperthyroidism, the elevation of TH concentrations, typically induces fatigue and tachycardia and negatively affects bone health and fertility (Cooper, 2003; Roberts and Ladenson, 2004; Warner and Mittag, 2012). Prevalence of hypothyroidism varies by region, iodine status and gender with women having a higher prevalence (Canaris et al., 2000) and as many as 3-5\% of pregnant women are developing sub-clinical hypothyroidism (Teng et al., 2013). Variations of $\mathrm{TH}$ and thyroid stimulating hormone (TSH) concentrations within the reference ranges are associated with adverse health outcomes (Taylor et al., 2013), stressing the potential impact of even moderate TH disruptions. Current human exposure to TH disrupting compounds falls in the range of in vitro effect concentrations and exposure is even much higher in wildlife (Montaño et al., 2013), resulting in TH alterations in wild living animals (Gutleb et al., 2010).

In standard in vivo toxicological research, generally healthy, euthyroid (ET) rats are used as models. However, for compounds such as HBCD the comparison of ET versus hypothyroid (HT) animals provides an alternative when exploring modes of action that are currently not fully understood but where TH is known to modulate HBCD effects (Schriks et al., 2006).

Especially as mechanisms of HBCD toxicity are so complex and still far from being understood, proteomics, with its unique holistic a posteriori approach, may contribute important information and may identify biomarker candidates for chronic effects (Miller et al., 2014). In order to elucidate if HBCD induced subtle effects dependent on the thyroid status, state-of-the-art gel-based proteomic experiments were performed on liver samples from ET and HT HBCD exposed female rats for which concentrations were chosen based on previously published in vivo studies (Canton et al., 2008; van der Ven et al., 2006). The data on affected pathways from the proteomic approach were compared and linked with classical biochemical and hormonal endpoints.

\section{Animals, materials and methods}

\subsection{Animals, treatment and experimental protocol}

The animal experiment was approved under number 2007-041 by the Animal Welfare Committee of Wageningen University (Wageningen, The Netherlands). Wistar WU (HsdCpbWU) rats were obtained from Harlan (Horst, the Netherlands). Female rats were put on an iodide-poor diet based on AIN 1993 requirements (Research Diet Services, Wijk bij Duurstede, the Netherlands) (Reeves et al., 1993; Schroder-van der Elst et al., 1998 Schroder-van der Elst et al., 1998), supplemented with $0.75 \%$ sodium perchlorate in the drinking water to deplete endogenous iodide stores (Rijntjes et al., 2009). Control rats received the iodide poor diet supplemented with $7 \mu$ g iodide per $100 \mathrm{~g}$ dry weight of the diet to fulfill normal iodide requirements. After two weeks these rats mated and the offspring was weaned at postnatal day 28 and group housed per diet. The offspring was kept on the respective diet throughout their life and housed individually on day 86 postpartum. As HBCD exposure was performed in custard pudding to avoid discomfort due to oral gavage (ter Veld et al., 2008), these rats were accustomed to eat $0.5 \mathrm{ml}$ of custard pudding (Campina, Zaltbommel, the Netherlands, packed in glass bottles) at the age of 99 days. The HBCD was dissolved in corn oil and on a daily basis freshly mixed with commercial custard pudding ( $100 \mu \mathrm{l}$ corn oil added to $0.9 \mathrm{ml}$ custard pudding). After four days of training, HBCD exposure started. The ET and HT animals were assigned to 3 exposure groups each $(n=6)$ and orally administered 0,3 or $30 \mathrm{mg}$ of $\mathrm{HBCD} / \mathrm{kg}$ body weight in $0.2 \mathrm{ml}$ commercial custard pudding per $100 \mathrm{~g}$ body weight. They received the exposure custard 5-30 min before the start of the dark period for 7 consecutive days, and all finished it within $5 \mathrm{~min}$. All rats within a group were of different breeding couples to prevent parent-dependent effects. The room temperature $\left(20.5-21.5^{\circ} \mathrm{C}\right)$, 
humidity (55-65\%) and light regime (60-80lux) were kept constant. At the termination of the experiment, all animals were sacrificed 5-6h after the start of the light period using $\mathrm{CO}_{2} / \mathrm{O}_{2}$. Blood was collected by heart puncture ( $5 \mathrm{IU}$ heparin per $\mathrm{ml}$ blood), followed by decapitation. Liver and white adipose tissues were snap frozen and stored at $-80^{\circ} \mathrm{C}$. Serum was frozen at $-20^{\circ} \mathrm{C}$.

\subsection{Hormone measurements}

Radioimmunoassays (RIAs) for total and free $T_{3}$ (Diagnostic Systems Laboratories, Webster, TX, USA; DSL-3100 and DSL-41100, respectively), corticosterone (MP Biomedicals, Santa Ana, CA, USA; 07-120102) and leptin (Merck Millipore; RL-83K) were performed according to the manufacturer's protocols. Luteinizing hormone (LH), follicle-stimulating hormone (FSH), and TSH were determined by validated in-house double-antibody RIAs for rat serum analysis (Mattheij et al., 1995; Palm et al., 2001a,b) using materials supplied by the National Institute of Diabetes and Digestive and Kidney Diseases (NIDDK; Bethesda, MD, USA). For LH, rLH-I-9 was used as label and anti-rLH-S-11 as antiserum; for FSH, rFSH-I-7 as label and anti-rFSH-S-11 as antiserum; for TSH, rTSH-I-9 as label and anti-TSH-RIA-6 as antiserum; and using Sac-Cel donkey antirabbit (Wellcome Diagnostics; Dartford, UK) as a secondary antibody. The levels of hormones were expressed in terms of the NIDDK standards. The detection limit of the assays were: $0.25 \mathrm{ng} / \mathrm{ml}$ for $\mathrm{T}_{3}, 25 \mathrm{ng} / \mathrm{ml}$ for corticosterone, $1 \mathrm{ng} / \mathrm{ml}$ for leptin, $0.03 \mathrm{ng} / \mathrm{ml}$ for $\mathrm{LH}, 0.4 \mathrm{ng} / \mathrm{ml}$ for FSH and $0.1 \mathrm{ng} / \mathrm{ml}$ for TSH. The intra- and interassay variation was determined using several pools of rat serum and were less than $10 \%$ for all purchased RIAs and less than $9 \%$ for all in-house RIAs.

\subsection{Determination of internal $H B C D$ dose}

Chemical analyses to determine the internal levels of HBCD were performed at IMARES. In short, $100 \mathrm{mg}$ of adipose tissue samples were extracted by use of a Soxhlet apparatus with (hexane/acetone 3:1) and samples were spiked with ${ }^{13} \mathrm{C}$-labeled $\alpha-, \beta$ - and $\gamma$-HBCD (Cambridge Isotope Laboratories; Andover, MA, USA) before extraction for quantification purposes. The obtained extracts were cleaned-up using concentrated sulphuric acid. Next, extracts were evaporated and dissolved in $1 \mathrm{ml}$ methanol. $\alpha$-, $\beta$ - and $\gamma$-diastereomeres were determined by LC-ESI-MS using a Surveyor LC coupled with an LCQ Advantage Ion Trap MS according to the method described by van der Ven et al. (2009). Calibration ranged from 5 to $1000 \mathrm{ng} / \mathrm{ml}$, samples with concentrations above the calibration curve were diluted to fall within the calibration range. $R^{2}$ was $>0.999$ for all compounds. The lower limit of quantification was $5 \mathrm{ng} / \mathrm{ml}$ in the final extract.

\subsection{Statistical analysis (for hormonal measurements)}

Data is expressed as mean \pm standard error of the mean (SEM). Statistical analysis was carried out using SPSS 19.0 for Windows. Data was tested for normality using the Shapiro-Wilk test. If normality could not be assumed, dose groups were LOG10 transformed. Means of all rats were compared using a two-way Univariate Analysis of Variance (ANOVA). Correlation between internal $\gamma$-HBCD dose and other measured parameters was tested with the Spearman's rank correlation test. Values of $P<0.05$ were considered to be significant.

\subsection{Proteomics}

Four samples per experimental group (ET and HT; 0, 3 and $30 \mathrm{mg}$ / $\mathrm{kg}$ /day HBCD, respectively) were randomly selected for proteomic experiments. Liver samples were subjected to two-dimensional fluorescence difference gel electrophoresis (2D-DIGE) following the protocol previously reported with minor modifications (Haas et al., 2011; Pasquali et al., 2013). In brief, rat livers were homogenized with the GE sample grinding kit in lysis buffer (urea $7 \mathrm{M}$; thiourea $2 \mathrm{M}$; CHAPS $2 \% \mathrm{w} / \mathrm{w}$; tris $30 \mathrm{mM}$ ) containing protease inhibitor Complete Mini (Roche, Brussels, Belgium). After centrifugation for $15 \mathrm{~min}$ at $30,000 \times g$ the supernatant was collected and stored at $-20^{\circ} \mathrm{C}$ until use. Fifty $\mu \mathrm{g}$ per sample, as determined by the Bradford method (Bradford, 1976), were labelled with CyDyes according to the manufacturer's instructions and separated on IPGs of a non-linear 3-10 pH-range followed by SDS-PAGE in 12.5\% precast gels (SERVA Electrophoresis GmbH, Heidelberg, Germany). Gel images acquired using a Typhoon 9400 were analyzed by the DeCyder 7.0 software package (both GE Healthcare, Diegem, Belgium). Gels were matched and subjected to univariate and multivariate analysis in order to highlight differentially expressed spots with the following criteria: for univariate analysis fold change of at least $1.3, P<0.05$ and ANOVA $P<0.05$; for multivariate analysis two way ANOVA $P$-value was considered to be significant when $P<0.05$.

Differentially abundant spots were automatically picked, tryptically digested and spotted on the MALDI target by the use of the Ettan Spot Handling Workstation (GE Healthcare, Diegem, Belgium). Protein identification was carried out on the Applied Biosystems MALDI-Tof-Tof 4800 Proteomics Analyser (Applied Biosystem, Gent, Belgium) as previously described (Haas et al., 2011). Protein identification was performed by searching peptide mass fingerprints (PMF) and MS/MS spectra against the SwissProt database with "Rattus norvegicus" as taxonomy. Searches were performed using the ProteinPilot software (Sciex, Nieuwerkerk aan den Ijssel, The Netherlands) and the searching algorithm MASCOT (Matrix Science, www.matrixscience.com, London, UK). For each spot one PMF and up to $8 \mathrm{MS} / \mathrm{MS}$ spectra were generated. Parameters for the search were set as follow: up to two missed cleavages allowed, $100 \mathrm{ppm}$ tolerance in PMF, $0.75 \mathrm{Da}$ mass tolerance for precursor ion mass, carbamidomethyl cysteine as fixed modification, oxidation of methionine and oxidation of tryptophan (single oxidation, double oxidation and kynurenin) as variable modifications. Identifications were considered to be significant when the combined MOWSE score had $P<0.05$.

Statistics, including univariate analysis (ANOVA and $t$-test) and multivariate analysis (two way ANOVA), was performed using the Extended Data Analysis (EDA) module, which is present inside the Decyder 7.0 software package.

Publicly available websites were used to retrieve additional information on proteins (localization, function) and to perform pathway analysis: UniProtKB database (http://www.uniprot.org/), STRING: functional protein association networks, v 9.1 (http:// string-db.org/) (Snel et al., 2000; Franceschini et al., 2013), for Rattus norvegicus proteins or genes, respectively, and for proteins with accession numbers from UniProt.

STRING classifies proteins of a candidate list according to Gene ontology (GO) categories (cell component, function, process) and allows graphical display of genes (and gene products) that previous research has found connected (enrichment analysis can find overor under-represented genes). STRING uses different databases as input, among them also KEGG (Kyoto Encyclopedia of Genes and Genomes, http://www.genome.jp/kegg/pathway.html), for mapping of genes/gene products in biological pathways and establishing connections between them.

\section{Results}

\subsection{Basic animal data and hormone measurements}

The induction of hypothyroidism was successfully achieved as the plasma concentration of TSH was increased over 40 -fold, while 
plasma total $T_{3}$ and free $T_{3}$ were decreased by $16 \%$ and $78 \%$ respectively (Table 1 ). The body weight of the HT rats was approximately half of that of the ET non-treated controls and did not change over the course of the dietary HBCD exposure. Plasma leptin concentrations were statistically significantly elevated in the HT rats $(P<0.001)$, whereas corticosterone and the levels of the gonadotropins LH and FSH were not altered (Table 1).

\section{2. $H B C D$ tissue concentrations}

Internal HBCD concentrations were determined in adipose tissue to evaluate uptake and accumulation of HBCD in the rats following exposure to 3 or $30 \mathrm{mg} / \mathrm{kg} /$ day HBCD for 7 days. Whereas the $\alpha$ - and $\beta$-HBCD levels were below the limit of detection for all of the non-exposed animals, and below the limit of quantification for the $3 \mathrm{mg} / \mathrm{kg}$ dose group, $\gamma$-HBCD was present in the $30 \mathrm{mg} / \mathrm{kg}$ treated rats. Accumulated $\gamma-\mathrm{HBCD}$ content of the higher exposed $30 \mathrm{mg} / \mathrm{kg} /$ day dose groups was only about 2-3 times higher than that of the $3 \mathrm{mg} / \mathrm{kg} /$ day groups for ET and HT rats, respectively (Table 1).

\section{3. $H B C D$ effects on hormone levels}

The 7-day exposure to HBCD did not result in changes in the plasma TH or TSH concentrations, nor did it affect leptin or corticosterone (two way ANOVA; Table 1). However, the increase in TSH concentration was positively correlated with the internal $\gamma$-HBCD concentration in ET rats (Spearman's Rho $=0.719$, $P<0.001$ ), while no such correlation was observed in the HT rats, which already had substantially elevated TSH levels (Spearman's Rho $=-0.259, P=0.299$ ) (Fig. 1 ). The gonadotropic hormone LH, but not FSH, were significantly decreased in the $3 \mathrm{mg} / \mathrm{kg} /$ day $\mathrm{HBCD}$ group compared to the non-exposed controls $(P<0.05)$. However, no such effect was observed in the highly exposed groups (Table 1 ).

\subsection{Proteomics}

Two-dimensional electrophoresis of liver proteins resulted in complex patterns of about 3000 spots per gel (Fig. 2). Patterns of 24 gels from different exposures of ET and HT rats were evaluated.
Thirty-one spots were of significantly different abundance due to HBCD exposure (Fig. 2 and Table 2). Overall 150 spots varied significantly when also including the thyroid status and the full dataset is shown in (Fig. 1 and Table 2a in Miller et al., submitted), whereas Table 2 displays only the proteins/protein spots discussed in more detail here. Proteins were successfully identified by MS analyses (Supplementary 1 and Table 1 in Miller et al., submitted). Proteins may show up as a row of spots (reflecting microheterogeneity, e.g. due to present post-translational modifications) or consist of more than one spot row (in the case of subunits or protein degradation). This is due to the separation conditions in two-dimensional electrophoresis (denaturing, reducing). Also in the current study, some proteins were found on more than one location of the gel.

\subsubsection{Influence of $H B C D$ on liver protein patterns}

A pairwise comparison of groups with different exposure to $\operatorname{HCBD}(0,3,30 \mathrm{mg} / \mathrm{kg} /$ day) revealed 13 proteins (18 spots) with significant changes in abundance amongst ET rats and 9 proteins (13 spots) between the HT groups (Table 2). The affected proteins are mainly located in mitochondria and cytoplasm, and have various functions (Table $2 \mathrm{~b}$ in Miller et al., submitted). HBCDdependent changes in protein levels were generally small (in the range of 30-60\%), and resulted in different lists of affected proteins depending on the actual thyroid status, with little overlap. Whereas in ET animals similar numbers of spots showed either increased or decreased abundance and the $3 \mathrm{mg} / \mathrm{kg} / \mathrm{day}$ group seemed to be more affected than the $30 \mathrm{mg} / \mathrm{kg}$ /day group, in HT animals HBCD treatment led to reduced levels of proteins, especially in the higher exposed group (Fig. 3a and b, Table 2, Table 2a in Miller et al., submitted). For thirteen of the overall 31 affected spots significant variations appeared between the two HBCD exposed groups (e.g. serum albumin; Table 2, Table 2a in Miller et al., submitted).

Only two proteins, namely aldehyde dehydrogenase family 1 member L1 (AL1L1) and electron transfer flavoprotein subunit beta (ETFB) showed a statistically significant change depending on both HBCD and thyroid status (Table 2 and Fig. 3a and b).

All proteins with significant abundance changes were searched in the various modules of the STRING database. In the category of

Table 1

Animal data.

\begin{tabular}{|c|c|c|c|c|c|c|c|c|}
\hline & $\begin{array}{l}\text { HBCD- } \\
\text { group }\end{array}$ & 0 & 3 & 30 & $\begin{array}{l}\text { Thyroid effect ( } P \text { - } \\
\text { value) }\end{array}$ & $\begin{array}{l}\text { HBCD effect }(P- \\
\text { value })\end{array}$ & $\begin{array}{l}\text { Interaction }(P- \\
\text { value })\end{array}$ & Spearman's Rho \\
\hline \multirow[t]{2}{*}{ Body weight (g) } & ET & $267 \pm 8$ & $261 \pm 9$ & $276 \pm 10$ & $<0.001$ & 0.768 & 0.540 & 0.162 \\
\hline & HT & $143 \pm 15$ & $136 \pm 9$ & $132 \pm 10$ & & & & -0.010 \\
\hline \multirow[t]{2}{*}{ Liver weight (g) } & ET & $9.50 \pm 0.44$ & $8.95 \pm 0.57$ & $9.63 \pm 0.47$ & $<0.001$ & 0.452 & 0.839 & -0.048 \\
\hline & HT & $4.56 \pm 0.61$ & $4.02 \pm 0.29$ & $4.23 \pm 0.29$ & & & & -0.059 \\
\hline \multirow[t]{2}{*}{$\mathrm{TSH}(\mathrm{ng} / \mathrm{ml})$} & ET & $0.33 \pm 0.03$ & $0.42 \pm 0.04$ & $0.48 \pm 0.06$ & $<0.001$ & 0.553 & 0.528 & 0.719* \\
\hline & HT & $14.68 \pm 4.18$ & $16.36 \pm 2.60$ & $11.86 \pm 0.66$ & & & & -0.259 \\
\hline \multirow[t]{2}{*}{ TT3 (ng/ml) } & ET & $362 \pm 32$ & $369 \pm 24$ & $305 \pm 16$ & 0.003 & 0.177 & 0.385 & -0.200 \\
\hline & HT & $305 \pm 8$ & $259 \pm 40$ & $265 \pm 22$ & & & & -0.343 \\
\hline \multirow[t]{2}{*}{ fT3 (pg/ml) } & ET & $6.62 \pm 0.45$ & $7.30 \pm 0.30$ & $6.56 \pm 0.50$ & $<0.001$ & 0.478 & 0.460 & -0.061 \\
\hline & HT & $1.41 \pm 0.40$ & $1.66 \pm 0.08$ & $1.91 \pm 0.40$ & & & & 0.214 \\
\hline \multirow{2}{*}{$\mathrm{LH}(\mathrm{ng} / \mathrm{ml})$} & ET & $3.64 \pm 0.49$ & $1.72 \pm 0.34$ & $2.49 \pm 0.30$ & 0.487 & 0.042 & 0.795 & -0.346 \\
\hline & HT & $3.09 \pm 0.76$ & $1.91 \pm 0.54$ & $2.81 \pm 0.60$ & & & & -0.060 \\
\hline \multirow[t]{2}{*}{$\mathrm{FSH}(\mathrm{ng} / \mathrm{ml})$} & ET & $2.8 \pm 0.7$ & $3.7 \pm 1.3$ & $3.6 \pm 1.0$ & 0.487 & 0.414 & 0.432 & 0.043 \\
\hline & HT & $3.8 \pm 0.5$ & $2.8 \pm 0.3$ & $5.2 \pm 1.5$ & & & & 0.000 \\
\hline \multirow[t]{2}{*}{ Leptin (ng/ml) } & ET & $5 \pm 1$ & $5 \pm 1$ & $5 \pm 1$ & $<0.001$ & 0.445 & 0.487 & -0.063 \\
\hline & HT & $19 \pm 4$ & $22 \pm 6$ & $14 \pm 3$ & & & & -0.364 \\
\hline \multirow[t]{2}{*}{ Corticosterone (ng/ml) } & ET & $281 \pm 69$ & $413 \pm 119$ & $338 \pm 73$ & 0.090 & 0.904 & 0.497 & 0.101 \\
\hline & HT & $249 \pm 51$ & $187 \pm 82$ & $242 \pm 70$ & & & & -0.007 \\
\hline \multirow{2}{*}{$\begin{array}{l}\text { Internal } \gamma-\mathrm{HBCD}(\mathrm{mg} / \mathrm{kg} \\
\left.\qquad \mathrm{lw}^{\mathrm{a}}\right)\end{array}$} & ET & $<\operatorname{lod}$ & $56.8 \pm 7.2$ & $113.2 \pm 9.9$ & 0.092 & $<0.001$ & 0.016 & \\
\hline & HT & $<\operatorname{lod}$ & $50.1 \pm 5.5$ & $160.0 \pm 18.8$ & & & & \\
\hline
\end{tabular}

$<$ lod, below detection limit.

$n=6$ per group. Mean \pm SEM is given.

a lw, lipid weight. 

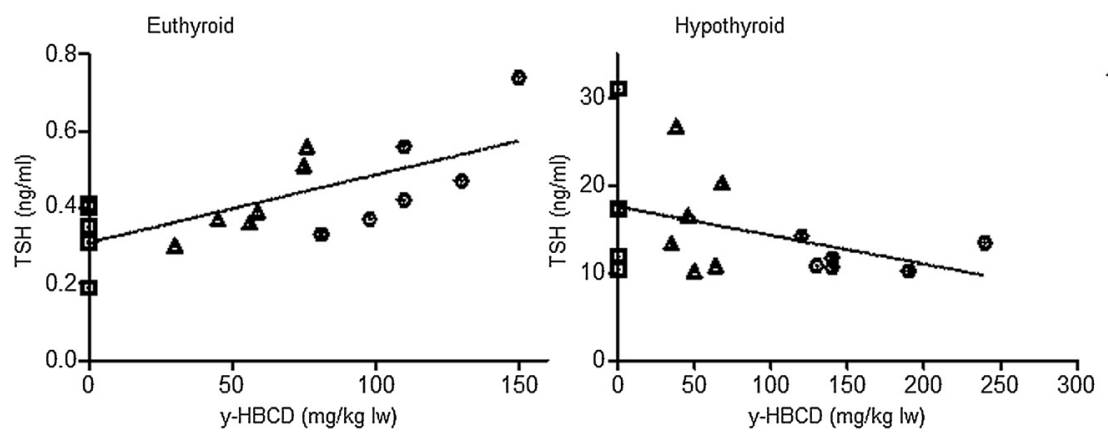

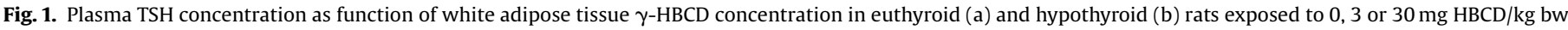

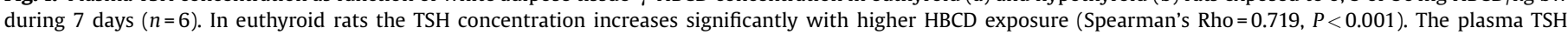
concentration in hypothyroid control rats is elevated when compared to that of euthyroid rats (Table 1).

affected functions mainly binding of different small molecules (organic cyclic or heterocyclic compounds, anions, organic acids, drugs, cofactors, carboxylic acid) and several types of catalytic or transferase activity were found. These functions are attributed preferentially to processes like response to stress, external stimuli or metal ions, regulation of apoptosis, lipid metabolism and mitochondrial transport as well as response to nutrient level and starvation. KEGG categorization further indicated that HBCD treatment of ET animals affected proteins from metabolic pathways like lipid metabolism (e.g. butanoate metabolism, ketone body synthesis and degradation), glycolysis/gluconeogenesis, and processing of different amino acids (valine, leucine, isoleucine). Proteins from HT rats are also linked to metabolic processes, mainly concerning glycolysis/gluconeogenesis and amino acids (glycine, serine, threonine) (Table 3 ).

\subsubsection{Influence of thyroid status on liver protein pattern as a function of $H B C D$ concentration}

This evaluation approach focused on the spot intensity/protein concentration differences between ET and HT animals of corresponding HBCD exposure groups, to possibly evaluate differences in susceptibility based on thyroid state. Forty-four spots were statistically significantly changed in abundance when comparing unexposed animal groups of different thyroid status (23 up- and 21 down-) and belonged to 36 proteins (Fig. 4, Table 2, Table 2c in Miller et al., submitted). This number increased considerably in rats exposed to $3 \mathrm{mg} \mathrm{HBCD} / \mathrm{kg} /$ day (102 spots from 71 proteins) and dropped again at $30 \mathrm{mg} \mathrm{HBCD} / \mathrm{kg} /$ day (49 spots from 39 proteins) (Table $2 \mathrm{~d}$ in Miller et al., submitted).

Grouping affected proteins into categories (STRING database, based on KEGG pathways) results for all three exposure

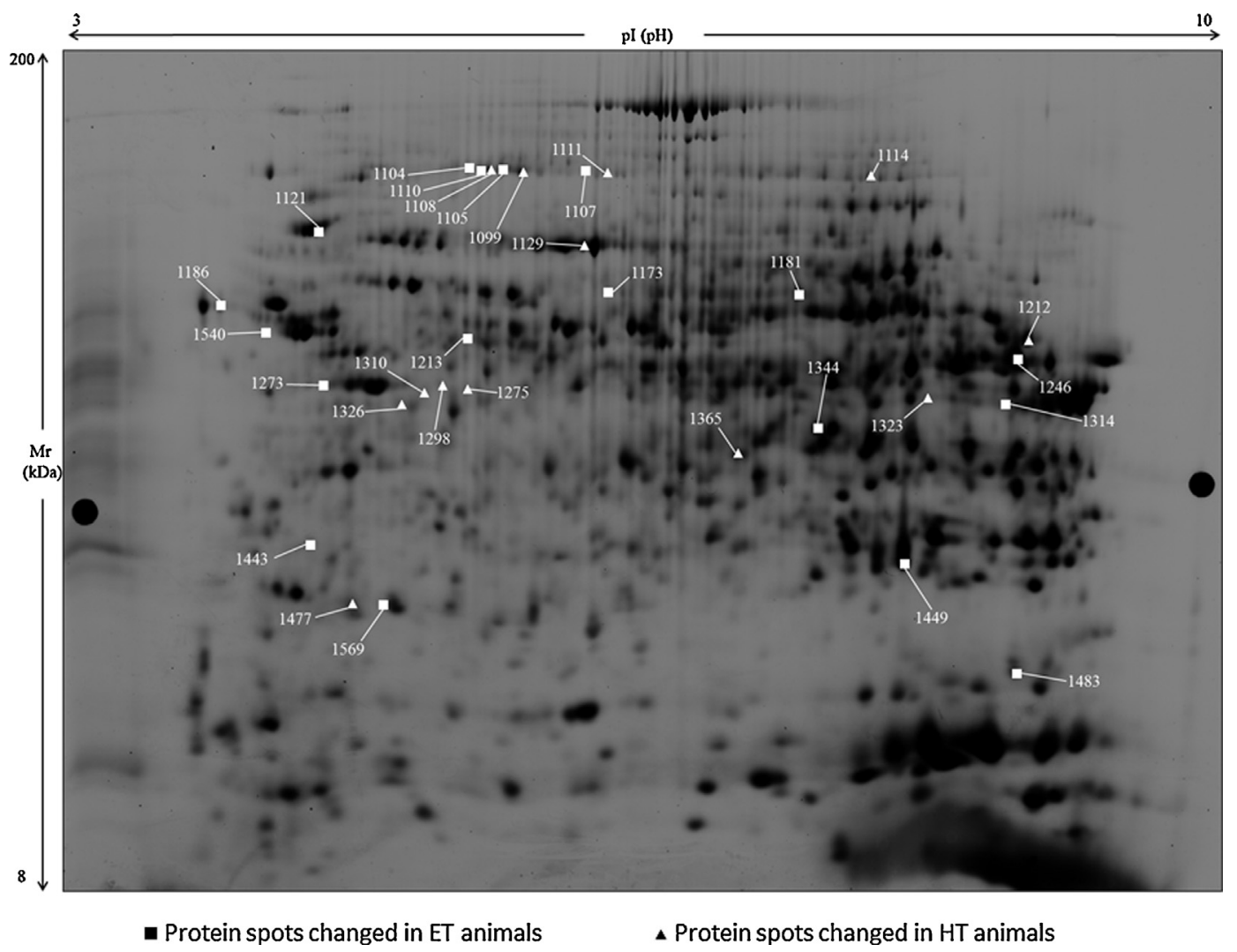

Fig. 2. Two-dimensional gel image of a rat liver sample.

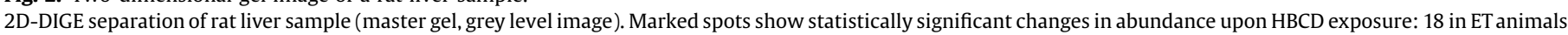
(squares), 13 in HT rats (triangles). For details on these spots (spot numbers, identifications, changes) see (Miller et al., submitted). 
Table 2

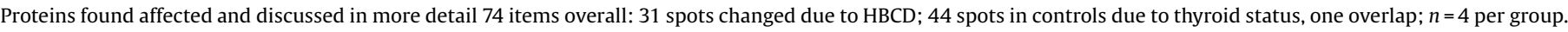
The complete dataset of affected proteins (150 spots) can be found in (Miller et al., submitted).

\begin{tabular}{|c|c|c|c|c|c|c|c|c|c|}
\hline Spot number & Name & Protein ID & $\begin{array}{l}\text { ET3/ } \\
\text { ET0 }\end{array}$ & $\begin{array}{l}\text { ET30/ } \\
\text { ET0 }\end{array}$ & $\begin{array}{l}\text { ET30/ } \\
\text { ET3 }\end{array}$ & $\begin{array}{l}\text { HT3/ } \\
\text { HT0 }\end{array}$ & $\begin{array}{l}\text { HT30/ } \\
\text { HTO }\end{array}$ & $\begin{array}{l}\text { HT30/ } \\
\text { HT3 }\end{array}$ & HTO/ETO \\
\hline 1097 & 2-Oxoglutarate dehydrogenase_mitochondrial & OD01_RAT & 0.901 & 0.917 & 1.020 & 0.800 & 0.826 & 1.030 & 1.380 \\
\hline 1314 & 3-Ketoacyl-CoA thiolase_mitochondrial & THIM_RAT & 0.800 & 1.100 & 1.370 & 0.840 & 0.901 & 1.070 & 1.120 \\
\hline 1407 & 3-Oxo-5-beta-steroid 4-dehydrogenase & AK1D1_RAT & 1.050 & 1.090 & 1.050 & 0.704 & 0.862 & 1.220 & 1.490 \\
\hline 1155 & $78 \mathrm{kDa}$ glucose-regulated protein & GRP78_RAT & 0.877 & 1.000 & 1.140 & 1.050 & 0.901 & 0.855 & 0.746 \\
\hline 1354 & Actin_cytoplasmic 1 & ACTB_RAT & 1.120 & 0.917 & 0.820 & 1.060 & 1.180 & 1.120 & 0.671 \\
\hline 1381 & Adipocyte plasma membrane-associated protein & APMAP_RAT & 1.020 & 1.070 & 1.050 & 0.980 & 0.990 & 1.010 & 0.699 \\
\hline 1260 & Alanine-glyoxylate aminotransferase 2_mitochondrial & AGT2_RAT & 0.885 & 0.926 & 1.040 & 1.020 & 0.870 & 0.855 & 1.600 \\
\hline 1111 & Aldehyde dehydrogenase 1 family_member L2 & gi|21961590 & 0.926 & 1.140 & 1.230 & 0.962 & 0.746 & 0.775 & 1.150 \\
\hline 1099 & Aldehyde dehydrogenase family 1 & AL1L1_RAT & 0.794 & 0.775 & 0.980 & 1.230 & 0.813 & 0.662 & 1.080 \\
\hline 1104 & Aldehyde dehydrogenase family 1 member L1 & AL1L1_RAT & 0.769 & 0.690 & 0.893 & 0.885 & 0.840 & 0.952 & 0.935 \\
\hline 1105 & Aldehyde dehydrogenase family 1 member L1 & AL1L1_RAT & 0.680 & 0.649 & 0.952 & 0.855 & 0.855 & 1.000 & 0.885 \\
\hline 1107 & Aldehyde dehydrogenase family 1 member L1 & AL1L1_RAT & 0.662 & 0.578 & 0.870 & 0.758 & 0.820 & 1.080 & 0.833 \\
\hline 1108 & Aldehyde dehydrogenase family 1 member L1 & AL1L1_RAT & 0.625 & 0.704 & 1.130 & 1.190 & 0.794 & 0.667 & 1.01 \\
\hline 1109 & Aldehyde dehydrogenase family 1 member L1 & AL1L1_RAT & 0.952 & 0.901 & 0.943 & 0.877 & 0.847 & 0.971 & 1.360 \\
\hline 1110 & Aldehyde dehydrogenase family 1 member L1 & AL1L1_RAT & 0.633 & 0.610 & 0.962 & 0.901 & 0.800 & 0.885 & 0.893 \\
\hline 1114 & Aldehyde dehydrogenase family 1 member L1 & AL1L1_RAT & 0.704 & 0.885 & 1.250 & 1.020 & 0.769 & 0.752 & 0.826 \\
\hline 1246 & Alpha-1-antiproteinase & A1AT_RAT & 0.699 & 0.877 & 1.260 & 1.050 & 1.030 & 0.971 & 1.030 \\
\hline 1093 & Alpha-aminoadipic semialdehyde synthase_mitochondrial & AASS_RAT & 0.971 & 0.943 & 0.971 & 0.800 & 0.746 & 0.926 & 1.570 \\
\hline 1275 & Alpha-enolase & ENOA_RAT & 0.926 & 0.909 & 0.980 & 0.935 & 0.769 & 0.826 & 1.030 \\
\hline 1393 & Arginase-1 & ARGI1_RAT & 1.070 & 1.120 & 1.050 & 0.704 & 0.877 & 1.240 & 1.780 \\
\hline 1323 & Argininosuccinate synthase & ASSY_RAT & 0.855 & 0.704 & 0.826 & 1.030 & 0.769 & 0.746 & 1.280 \\
\hline 1326 & Argininosuccinate synthase & ASSY_RAT & 1.000 & 1.030 & 1.030 & 1.060 & 0.794 & 0.752 & 1.060 \\
\hline 1337 & Aspartate aminotransferase_cytoplasmic & AATC_RAT & 1.010 & 1.050 & 1.040 & 0.893 & 0.794 & 0.893 & 1.690 \\
\hline 1298 & Betaine-homocysteine S-methyltransferase 1 & BHMT1_RAT & 1.100 & 1.040 & 0.935 & 1.010 & 0.730 & 0.719 & 1.410 \\
\hline 1310 & Betaine-homocysteine S-methyltransferase 1 & BHMT1_RAT & 0.901 & 0.862 & 0.952 & 0.990 & 0.637 & 0.645 & 1.440 \\
\hline 1063 & Carbamoyl-phosphate synthase & CPSM_RAT & 0.971 & 0.971 & 1.000 & 0.806 & 0.820 & 1.020 & 1.320 \\
\hline 1071 & Carbamoyl-phosphate synthase & CPSM_RAT & 0.901 & 0.971 & 1.080 & 0.935 & 0.901 & 0.962 & 1.380 \\
\hline 1078 & Carbamoyl-phosphate synthase & CPSM_RAT & 1.000 & 1.010 & 1.010 & 0.935 & 0.847 & 0.909 & 1.300 \\
\hline 1496 & Carbonic anhydrase 3 & CAH3_RAT & 1.010 & 1.280 & 1.270 & 0.885 & 0.917 & 1.040 & 2.080 \\
\hline 1509 & Carbonic anhydrase 3 & CAH3_RAT & 1.210 & 1.450 & 1.200 & 0.719 & 0.820 & 1.140 & 2.980 \\
\hline 1344 & Creatine kinase B-type & KCRB_RAT & 1.370 & 1.280 & 0.935 & 0.909 & 0.971 & 1.070 & 1.170 \\
\hline 1449 & D-beta-hydroxybutyrate dehydrogenase_ & BDH_RAT & 0.741 & 1.030 & 1.380 & 0.826 & 0.833 & 1.010 & 1.150 \\
\hline 1129 & Dimethylglycine dehydrogenase_mitochondrial & M2GD_RAT & 1.090 & 1.170 & 1.080 & 0.610 & 0.602 & 0.990 & 1.900 \\
\hline 1477 & Electron transfer flavoprotein subunit beta & ETFB_RAT & 1.210 & 1.280 & 1.060 & 0.763 & 1.010 & 1.310 & 1.240 \\
\hline 1483 & Electron transfer flavoprotein subunit beta & ETFB_RAT & 1.330 & 1.290 & 1.060 & 0.855 & 0.990 & 1.310 & 1.14 \\
\hline 1121 & Elongation factor 2 & EF2_RAT & 0.847 & 1.230 & 1.450 & 1.070 & 0.909 & 0.847 & 0.935 \\
\hline 1388 & Farnesyl pyrophosphate synthase & FPPS_RAT & 0.980 & 0.901 & 0.917 & 0.952 & 1.030 & 1.070 & 0.676 \\
\hline 1365 & Fructose-bisphosphate aldolase B & ALDOB_RAT & 1.050 & 0.952 & 0.901 & 1.150 & 0.833 & 0.725 & 1.160 \\
\hline 1506 & Glutathione S-transferase alpha-1 & GSTA1_RAT & 0.862 & 0.826 & 0.962 & 0.813 & 1.280 & 1.580 & 0.431 \\
\hline 1507 & Glutathione S-transferase alpha-2 & GSTA2_RAT & 0.730 & 0.769 & 1.050 & 0.952 & 1.470 & 1.550 & 0.415 \\
\hline 1508 & Glutathione S-transferase alpha-3 & GSTA3_RAT & 0.820 & 0.901 & 1.100 & 1.280 & 1.610 & 1.250 & 0.322 \\
\hline 1513 & Glutathione S-transferase alpha-4 & GSTA4_RAT & 0.746 & 0.794 & 1.060 & 0.901 & 1.130 & 1.260 & 0.629 \\
\hline 1522 & Glutathione S-transferase $\mathrm{P}$ & GSTP1_RAT & 0.305 & 0.266 & 0.870 & 0.926 & 1.080 & 1.170 & 0.215 \\
\hline 1166 & Heat shock cognate $71 \mathrm{kDa}$ protein & HSP7C_RAT & 0.935 & 1.010 & 1.080 & 0.962 & 0.971 & 1.010 & 0.746 \\
\hline 1127 & Heat shock protein HSP 90 -alpha & HS90A_RAT & 0.917 & 0.980 & 1.070 & 0.917 & 0.917 & 1.010 & 0.685 \\
\hline 1569 & Hemoglobin subunit alpha- $1 / 2$ & HBA_RAT & 1.150 & 1.340 & 1.160 & 0.826 & 0.794 & 0.962 & 0.758 \\
\hline 1273 & Hydroxymethylglutaryl-CoA synthase_mitochondrial & HMCS2_RAT & 0.769 & 0.917 & 1.190 & 0.847 & 0.833 & 0.980 & 1.100 \\
\hline 1296 & Ifi47 protein & $\begin{array}{l}\text { gil } \\
44890246\end{array}$ & 1.060 & 0.813 & 0.769 & 1.280 & 1.300 & 1.020 & 0.391 \\
\hline 1480 & Isoamyl acetate-hydrolyzing esterase 1 & IAH1_RAT & 1.080 & 1.120 & 1.040 & 0.943 & 0.943 & 1.000 & 0.730 \\
\hline 1217 & Liver carboxylesterase 4 & EST4_RAT & 0.893 & 0.926 & 1.040 & 0.952 & 0.990 & 1.030 & 0.685 \\
\hline 1471 & $\begin{array}{l}\text { Nicotinate-nucleotide pyrophosphorylase - carboxylating- } \\
\text { homolog }\end{array}$ & NADC_RAT & 1.010 & 1.020 & 1.020 & 0.909 & 1.110 & 1.210 & 0.699 \\
\hline 1460 & Nitrilase homolog 1 & NIT1_RAT & 0.847 & 0.787 & 0.926 & 0.980 & 0.962 & 0.980 & 1.360 \\
\hline 1544 & Peptidyl-prolyl cis-trans isomerase A & PPIA_RAT & 0.909 & 1.070 & 1.170 & 0.870 & 0.962 & 1.110 & 0.654 \\
\hline 1540 & Peptidyl-prolyl cis-trans isomerase F_mitochondrial & PPIF_RAT & 1.550 & 1.770 & 1.140 & 0.855 & 0.806 & 0.935 & 1.510 \\
\hline 1270 & Phenylalanine-4-hydroxylase & PH4H_RAT & 1.250 & 1.120 & 0.893 & 0.901 & 0.813 & 0.901 & 1.320 \\
\hline 1212 & $\begin{array}{l}\text { PREDICTED aldehyde dehydrogenase } 8 \text { family_member A1-like } \\
\text { isoform } 2\end{array}$ & $\begin{array}{l}\text { gi| } \\
109460389\end{array}$ & 0.794 & 0.943 & 1.190 & 1.410 & 0.893 & 0.633 & 0.901 \\
\hline 1219 & Protein disulfide-isomerase A3 & PDIA3_RAT & 0.877 & 0.971 & 1.110 & 1.020 & 0.943 & 0.926 & 0.741 \\
\hline 1495 & Protein ETHE1_mitochondrial & $\begin{array}{l}\text { gi| } \\
157819563\end{array}$ & 0.962 & 0.901 & 0.935 & 1.020 & 0.885 & 0.870 & 1.580 \\
\hline 1077 & Pyruvate carboxylase_mitochondrial & PYC_RAT & 0.855 & 0.840 & 0.980 & 0.971 & 0.893 & 0.917 & 0.714 \\
\hline 1082 & Pyruvate carboxylase_mitochondrial & PYC_RAT & 0.794 & 0.862 & 1.080 & 0.971 & 1.010 & 1.050 & 0.685 \\
\hline 1213 & Pyruvate kinase isozymes R/L & KPYR_RAT & 1.080 & 0.820 & 0.758 & 1.010 & 0.971 & 0.952 & 1.300 \\
\hline 1112 & Sarcosine dehydrogenase_mitochondrial & SARDH_RAT & 0.893 & 0.826 & 0.926 & 0.952 & 0.813 & 0.855 & 1.440 \\
\hline 1115 & Sarcosine dehydrogenase_mitochondrial & SARDH_RAT & 0.813 & 0.763 & 0.943 & 0.820 & 0.719 & 0.877 & 1.610 \\
\hline 1116 & Sarcosine dehydrogenase_mitochondrial & SARDH_RAT & 0.847 & 0.794 & 0.935 & 0.820 & 0.676 & 0.820 & 1.780 \\
\hline 1117 & Sarcosine dehydrogenase_mitochondrial & SARDH_RAT & 0.943 & 0.893 & 0.943 & 0.855 & 0.800 & 0.943 & 1.370 \\
\hline 1119 & Sarcosine dehydrogenase_mitochondrial & SARDH_RAT & 0.893 & 0.885 & 0.980 & 0.855 & 0.800 & 0.935 & 1.420 \\
\hline 1135 & Serotransferrin & TRFE_RAT & 0.735 & 0.794 & 1.080 & 1.080 & 1.040 & 0.962 & 0.667 \\
\hline 1173 & Serum albumin & ALBU_RAT & 0.617 & 0.847 & 1.370 & 0.885 & 1.010 & 1.140 & 1.080 \\
\hline 1181 & Serum albumin & ALBU_RAT & 0.662 & 0.862 & 1.300 & 0.840 & 1.050 & 1.240 & 1.130 \\
\hline 1186 & Serum albumin & ALBU_RAT & 0.625 & 0.847 & 1.360 & 0.855 & 1.040 & 1.210 & 1.060 \\
\hline
\end{tabular}


Table 2 (Continued)

\begin{tabular}{|c|c|c|c|c|c|c|c|c|c|}
\hline Spot number & Name & Protein ID & $\begin{array}{l}\text { ET3/ } \\
\text { ET0 }\end{array}$ & $\begin{array}{l}\text { ET30/ } \\
\text { ET0 } \\
\end{array}$ & $\begin{array}{l}\text { ET30/ } \\
\text { ET3 }\end{array}$ & $\begin{array}{l}\text { HT3/ } \\
\text { HT0 }\end{array}$ & $\begin{array}{l}\text { HT30/ } \\
\text { HT0 }\end{array}$ & $\begin{array}{l}\text { HT30/ } \\
\text { HT3 }\end{array}$ & HTO/ETO \\
\hline 1366 & Serum paraoxonase/lactonase 3 & PON3_RAT & 1.030 & 0.962 & 0.926 & 0.893 & 1.000 & 1.120 & 0.625 \\
\hline 1438 & Sulfotransferase $1 \mathrm{~A} 1$ & ST1A1_RAT & 0.901 & 0.935 & 1.040 & 0.935 & 0.800 & 0.855 & 1.300 \\
\hline 1473 & Thiopurine S-methyltransferase & TPMT_RAT & 1.040 & 1.070 & 1.030 & 1.010 & 0.833 & 0.826 & 1.390 \\
\hline 1443 & Thiosulfate sulfurtransferase & THTR_RAT & 0.769 & 0.943 & 1.230 & 0.893 & 0.935 & 1.040 & 1.160 \\
\hline
\end{tabular}

Bold values denote changing at least by $30 \%$ and $P<0.05$.

A

HBCD Induced Changes in ET Rats

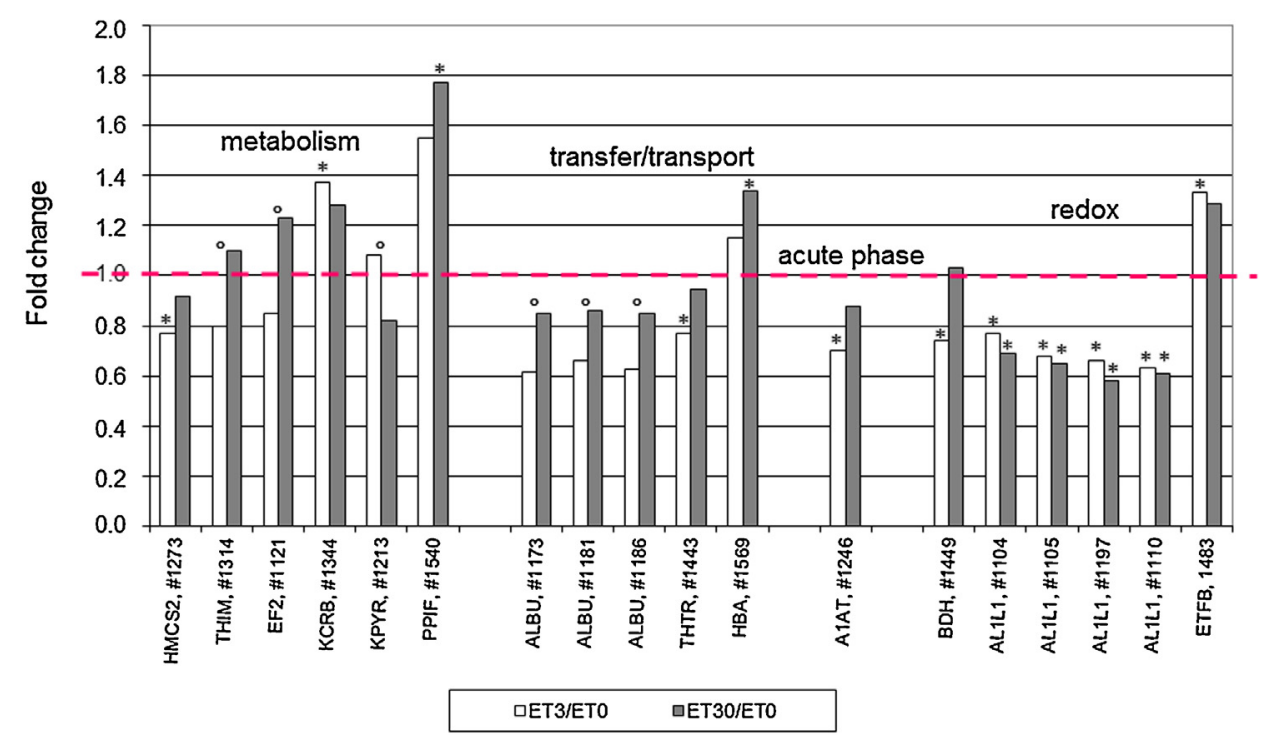

B

HBCD Induced Changes in HT Rats

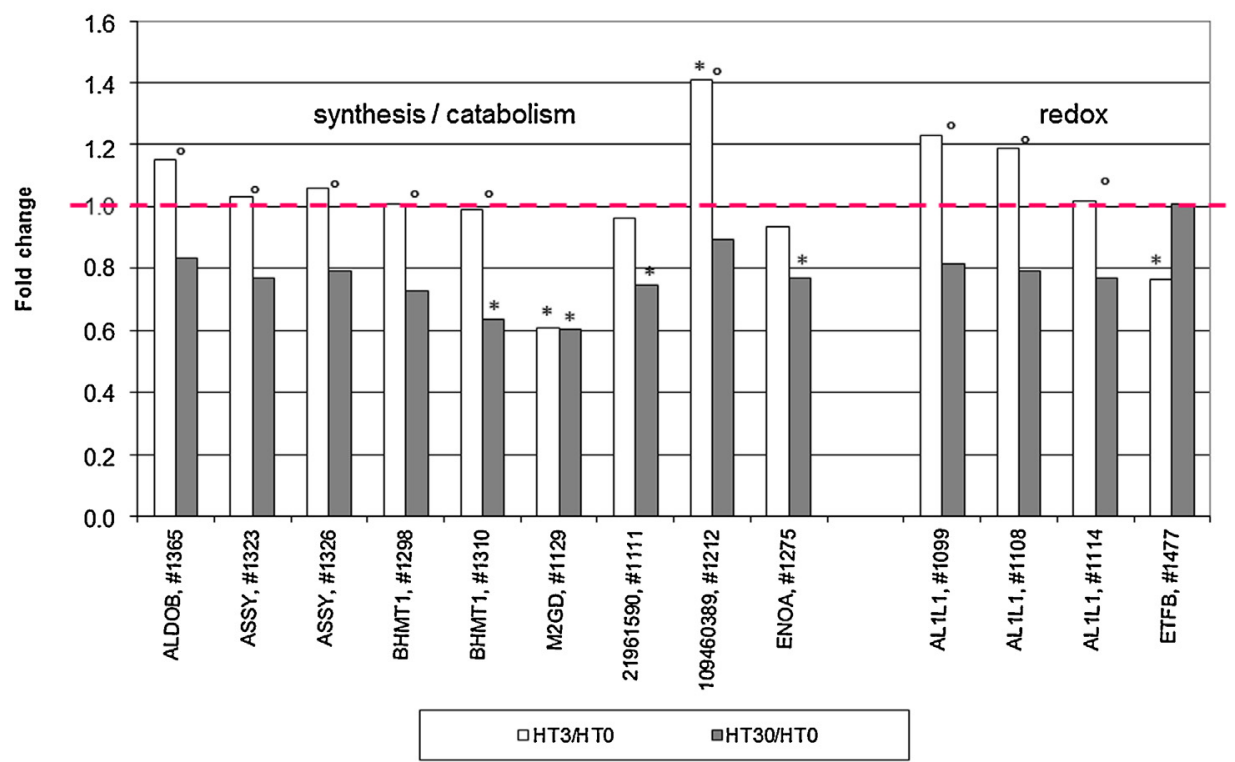

Fig. 3. HBCD induced changes in liver proteome.

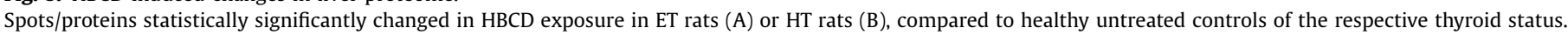

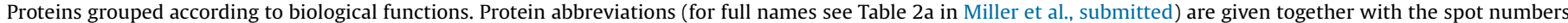

("\#”), as some proteins show up as several spots.

*: significant change to control (at least $30 \%$ change, $P \leq 0.05$, spot present in at least $75 \%$ of the gels)

$O$ : significant change between groups exposed to 3 and $30 \mathrm{mg} / \mathrm{kg}$ bw (at least $30 \%$ change, $P \leq 0.05$, spot present in at least $75 \%$ of the gels). 
concentrations in a high protein count impacting metabolic pathways (12-28 annotations, the highest number again at $3 \mathrm{mg} / \mathrm{kg} /$ day HBCD, Table 3, Supplement 3). The list suggests changes in metabolism of various amino acids, and additionally affected glycolysis/gluconeogenesis and lipid metabolism at the $3 \mathrm{mg} / \mathrm{kg} /$ day group. Interestingly, a group of 5-7 proteins involved in glutathione metabolism (mainly glutathione-S- transferases), but also in the processing of various xenobiotics or drugs by cytochrome P450, show statistical significance only in control animals and the $3 \mathrm{mg} / \mathrm{kg} /$ day group, whereas antigen processing and presenting proteins (esp. protein disulfide-isomerase A3 and $78 \mathrm{kDa}$ glucose-regulated protein) are significantly affected only under baseline and at the $30 \mathrm{mg} / \mathrm{kg} /$ day condition.

Table 3

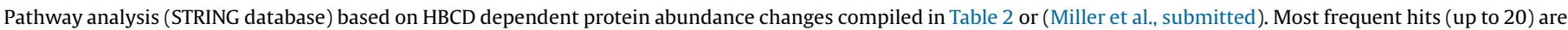
given. For HT animals not enough changed proteins were found to establish a network, therefore the combined ET + HT list was chosen.

\begin{tabular}{|c|c|c|c|c|c|}
\hline \multicolumn{6}{|c|}{ Changed proteins/KEGG } \\
\hline GO_id & Term & $\begin{array}{l}\text { HBCD and ET number of } \\
\text { genes }\end{array}$ & GO_id & Term & $\begin{array}{l}\mathrm{HBCD} \text { and }(\mathrm{HT}+\mathrm{ET}) \text { number of } \\
\text { genes }\end{array}$ \\
\hline rno01100 & Metabolic pathways & 6 & rno01100 & Metabolic pathways & 11 \\
\hline rno00650 & Butanoate metabolism & 2 & rno00010 & Glycolysis/Gluconeogenesis & 3 \\
\hline rno00280 & $\begin{array}{l}\text { Valine, leucine and isoleucine } \\
\text { degradation }\end{array}$ & 2 & rno00650 & Butanoate metabolism & 2 \\
\hline \multirow[t]{5}{*}{ rno00072 } & $\begin{array}{l}\text { Synthesis and degradation of ketone } \\
\text { bodies }\end{array}$ & 2 & rno00330 & Arginine and proline metabolism & 2 \\
\hline & & & rno00280 & $\begin{array}{l}\text { Valine, leucine and isoleucine } \\
\text { degradation }\end{array}$ & 2 \\
\hline & & & rno00270 & Cysteine and methionine metabolism & 2 \\
\hline & & & rno00260 & $\begin{array}{l}\text { Glycine, serine and threonine } \\
\text { metabolism }\end{array}$ & 2 \\
\hline & & & rno00072 & $\begin{array}{l}\text { Synthesis and degradation of ketone } \\
\text { bodies }\end{array}$ & 2 \\
\hline
\end{tabular}

Changed proteins/Pprocess

(limited to the 20 most frequent terms)

GO:0006950

GO:0051641 $\quad$ Cellular localization

GO:0043067 Regulation of programmed cell death

GO:0042981 Regulation of apoptotic process

GO:0010941

GO:0009605

GO:2001233

GO: 1902582

GO:0060548

GO:0055114

GO:0051346

GO:0044255

GO:0043086

GO:0043069

GO:0043066

GO:0042594

GO:0031667

GO:0010038

GO:0010035

GO:0009991

GO:0006839

GO:0006629
Regulation of cell death

Response to external stimulus

Regulation of apoptotic signaling pathway

Single-organism intracellular transport

Negative regulation of cell death

Oxidation-reduction process

Negative regulation of hydrolase activity

Cellular lipid metabolic process

Negative regulation of catalytic activity

Negative regulation of programmed cell death

Negative regulation of apoptotic process

Response to starvation

Response to nutrient levels

Response to metal ion

Response to inorganic substance

Response to extracellular stimulus

Mitochondrial transport

Lipid metabolic process
GO:0044699
GO:0008150
GO:0044710
GO:0008152
GO:0044763
GO:0009987
GO:0044281
GO:0044237
GO:0044238
GO:0071704
GO:0050896
GO:0019752
GO:0043436
GO:0006082
GO:1901575
GO:0009056
GO:0055114
GO:0044712
GO:1901564
GO:0006793
GO:0006950
GO:0006810

Single-organism process

Biological_process

Single-organism metabolic process

Metabolic process

Single-organism cellular process

Cellular process

Small molecule metabolic process

Cellular metabolic process

Primary metabolic process

Organic substance metabolic process

Response to stimulus

Carboxylic acid metabolic process

Oxoacid metabolic process

Organic acid metabolic process

Organic substance catabolic process

Catabolic process

Oxidation-reduction process

Single-organism catabolic process

Organonitrogen compound metabolic process

Phosphorus metabolic process

Response to stress

Transport
14

13

11

11

10

10

9

9

8

8

8

7
7

7
6

6

5

5

5

5

5

Changed proteins/Function

(limited to the 20 most frequent terms)

GO:0043168 Anion binding

GO:0016740 Transferase activity

GO:0008144 Drug binding

GO:0008289 Lipid binding

GO:0016746 Transferase activity, transferring acyl groups

GO:0005488

GO:0003674

GO:0043167

GO:0003824

GO:1901363

GO:0097159

GO:0043168

GO:0005515

GO:0016740

GO:0036094

GO:0000166

GO:1901265

GO:0005524

GO:0032559

GO:0030554

GO:0001883

GO:0032550

GO:0032549

GO:0035639

GO:0001882
Binding

Molecular_function

Ion binding

Catalytic activity

Heterocyclic compound binding

Organic cyclic compound binding

Anion binding

Protein binding

Transferase activity

Small molecule binding

Nucleotide binding

Nucleoside phosphate binding

ATP binding

Adenyl ribonucleotide binding

Adenyl nucleotide binding

Purine nucleoside binding

Purine ribonucleoside binding

Ribonucleoside binding

Purine ribonucleoside triphosphate binding

Nucleoside binding
13

13

9

8

8

8
7

7

7
6

6

5

5

4

4

4

4

4

4 


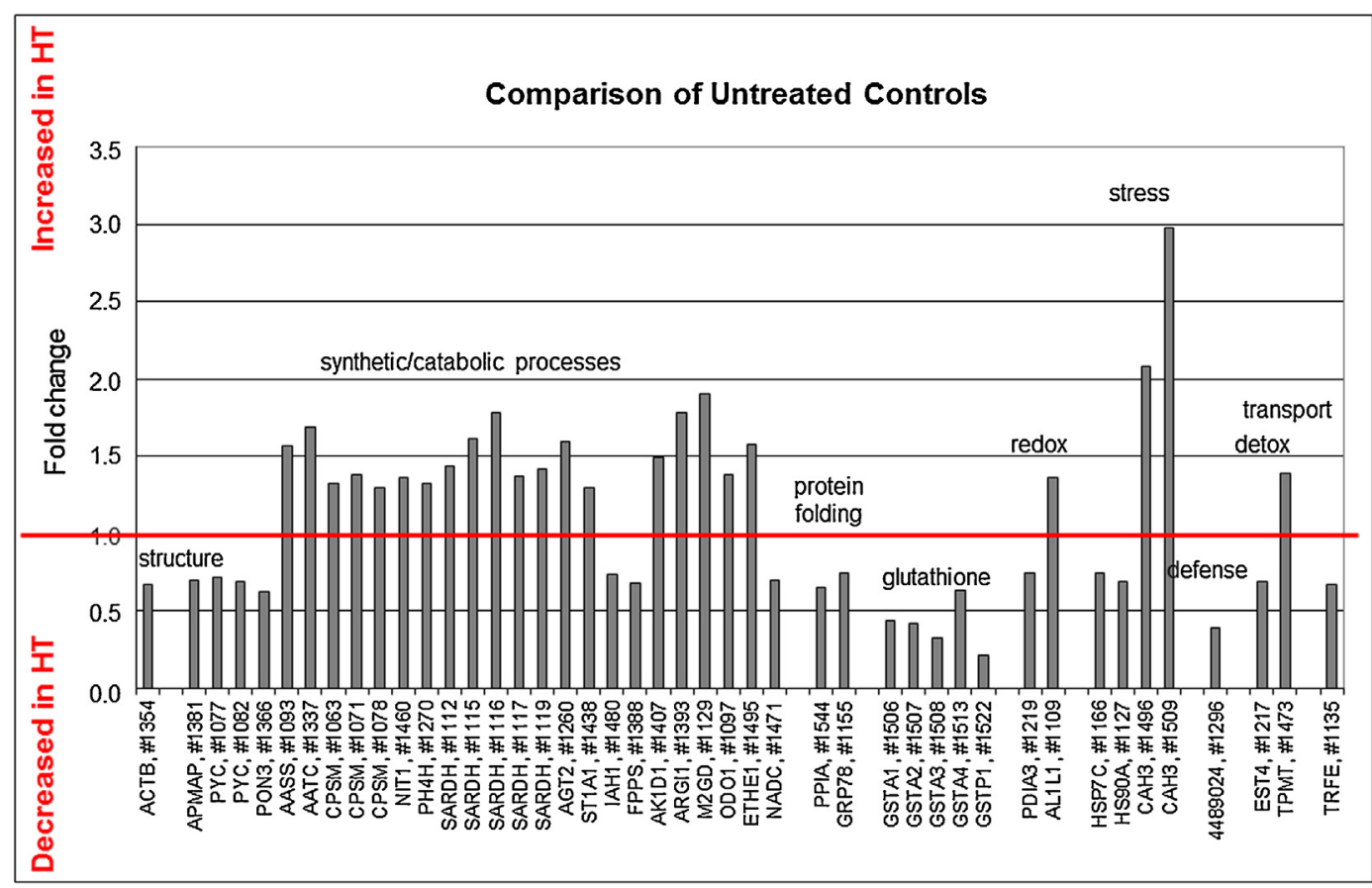

Fig. 4. Comparison of rat liver protein abundance in untreated controls of different thyroid status.

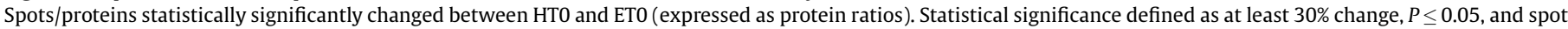

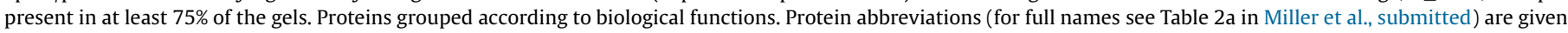
together with the spot numbers (“\#”), as some proteins show up as several spots. For detailed data on changes and identifications see (Miller et al., submitted).

The interaction of proteins found to be differently affected depending on the thyroid status is presented with one sub-figure for each selected HBCD concentration (Fig. 5, Supplement 2), as retrieved from the STRING database. In control animals, differences between ET and HT appear mainly in five separate clusters; a strongly interconnected one consisting of GSTs (glutathione-Stransferases), and four others of smaller size, mostly related to binding functions of smaller molecules and increased abundance of reaction partners (the clusters with cytoplasmic aspartate aminotransferase (gene name: Got1) and sarcosine dehydrogenase (gene name: Sardh)) as nodes, or one related to antigen processing and presentation (mostly heat shock proteins) (Fig. 5a). In the low HBCD exposure groups the previous single clusters are now interconnected; the clusters include lipid or fatty acid binding proteins (e.g. fatty acid binding protein from liver, albumin) or structural proteins (actin), and an even stronger GST cluster (Fig. 5b). In the higher HBCD exposure group, the interaction network is characterized by fewer confident connections, a larger but less confident cluster of heat-shock proteins, and disappearance of a statistically significant GST cluster (Fig. 5c).

Taking a closer look at the five most regulated members of the GST family (Fig. 4, Table 2e in Miller et al., submitted) shows clear differences in baseline values depending on thyroid status. Additionally, HBCD treatment of ET animals leads to markedly lower abundance of glutathione S-transferase P (GSTP1, $P<0.1$; Table 2).

Another protein with concentration-dependent changes is mitochondrial dimethylglycine dehydrogenase (M2GD). It is one of the few proteins found to show a clear influence of HBCD treatment in HT rats (Fig. 3b), and at the same time a 1.9-fold higher level in HTO compared to ETO. Interestingly, HBCD treatment decreases M2GD abundance of HT animals to almost ET level (which is hardly influenced by HBCD concentration, Table 2).

Database mining also locates some proteins/genes involved in KEGG pathways connected to fatty acid metabolism and fat digestion/adsorption in the $3 \mathrm{mg} / \mathrm{kg} /$ day group (Table 3, Supplement 3, pathways rno00062, rno00071, and rno04975) besides propanoate and butanoate metabolisms which include some lipid processing features (pathways rno00640, and rno00650). Members attributed to them are all increased during hypothyroidism, except for liver fatty acid binding protein (Table 2a in Miller et al., submitted), and they appear in a big multi-component cluster around Got1 and Got2 (aspartate aminotransferase, cytoplasmic and mitochondrial, respectively, Fig. 5b, Supplement 2b). Some additional proteins with functions in lipid metabolic processes are also categorized under the general term "metabolic pathways" (Supplementary 3, rno01100; e.g. mitochondrial pyruvate carboxylase, farnesyl pyrophosphate synthase, isoamyl acetate-hydrolyzing esterase 1 homolog).

\subsubsection{Influence of thyroid status on liver protein pattern independent} of $H B C D$ exposure

From the dataset reported in the previous section, eleven proteins are significantly changed over all three HT/ET comparisons. Several others showed similar patterns over all comparisons, but did not meet the very stringent filtering criteria (mainly the $P$-value cut-off; e.g. 21 additional proteins with two significant changes; Table 2e in Miller et al., submitted). Among the latter are some of the proteins with largest fold changes of this study (but $P$-values between 0.06 and 0.11 ), i.e. carbonic anhydrase 3 , which is increased in all comparisons and known as an oxidative stress indicator, but also of some GST family members that all show decreased abundance. All these proteins, which are mostly related to stress response, lipid metabolism and detoxification processes (Supplementary 3) seem to be characteristic of the altered thyroid status in all three exposure groups.

\section{Discussion}

HBCD is widespread in the environment and wildlife. Also humans are, and still will be exposed for decades to come. The 
A) HTO vs. ETO

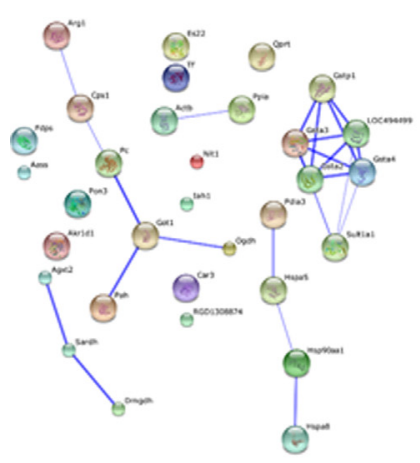

B) HT3 vs. ET3

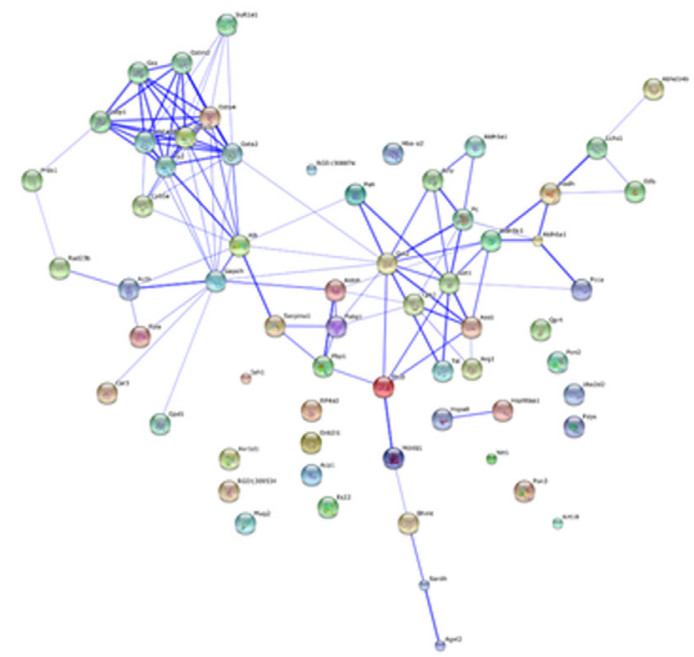

C) HT30 vs. ET30

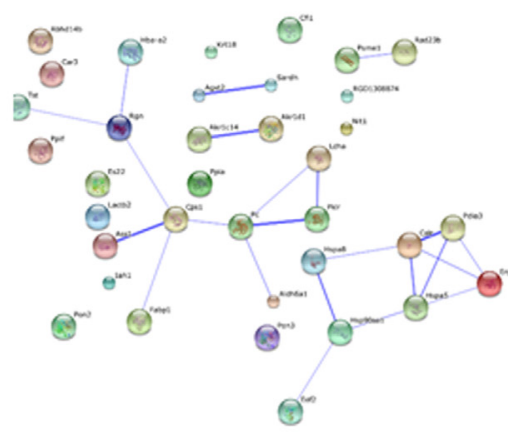

Fig. 5. Networks of proteins differentially abundant in similarly exposed animals of different thyroid status.

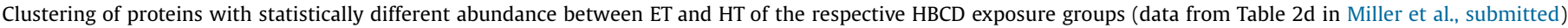

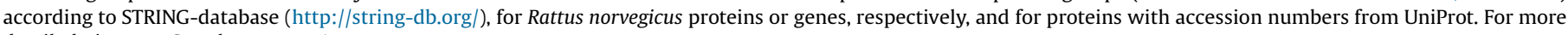
detailed view see Supplementary 1.

understanding of potential effects of this endocrine disrupting compound both in healthy as well as vulnerable groups of the population has great scientific and societal importance.

In line with earlier studies the iodide poor diet in combination with perchlorate resulted in hypothyroidism, as seen by increased plasma TSH concentrations and reduced $T_{3}$ concentrations (Rijntjes et al., 2009; van Wijk et al., 2008). This is essential to test our main hypothesis that the effects of HBCD are depending on the TH status. Gender-dependent effects of HBCD on key metabolic pathways include metabolism of lipids, triacylglycerol, and cholesterol and its derivatives like testosterone and estrogens, as well as phase I and II biotransformation in rats orally exposed to HBCD concentrations ranging from 3 to $100 \mathrm{mg} / \mathrm{kg}$ bw/d (Canton et al., 2008; van der Ven et al., 2006). The exposure concentrations in the current study were chosen based on these earlier publications. Only $\gamma$-HBCD accumulated in the exposed rats, but after 7 days tissue concentrations were not fully dose-related. The 10 -fold higher HBCD dose resulted only in 2-3-fold higher tissue concentrations, without differences between ET and HT animals. The $\gamma$-HBCD stereoisomer dominated in the white adipose tissue as the only stereoisomer above the LLOQ for the low dose exposure group. Though in contrast to observations in wildlife samples where the $\alpha$-HBCD stereoisomer was dominant (Covaci et al., 2006), our data is in line with a 28-day toxicity study that found predominance of $\gamma$-HBCD and increase of $\alpha / \gamma$-ratios only in higher dosed animal groups (van der Ven et al., 2006).

Liver was chosen as the tissue for proteomic investigation, being the main detoxifying and protein synthesizing organ and after oral exposure quickly exposed to HBCD. Two-dimensional electrophoresis using 2D-DIGE was successfully performed and revealed a complex protein spot pattern for rat liver, with a number of spots (and thus proteins) changing intensity due to $\mathrm{HBCD}$ exposure.

In ET rats, HBCD exposure affected three main groups of proteins: proteins involved in metabolic processes, some with specific transport functions (e.g. serum albumin or transthyretin), and proteins connected with oxidative stress reactions. Previous studies with rats receiving comparable to higher doses of HBCD (daily oral exposure of 30-100 $\mathrm{mg} / \mathrm{kg}$ bw) for 28 days reported that key metabolic pathways were affected including metabolism of lipids and cholesterol as well as steroids (Canton et al., 2008; van der Ven et al., 2006). Gene expression profiles were determined with microarrays and RT-PCR, and downregulation of single genes was in general less than $50 \%$ of the controls' values in the $30 \mathrm{mg} / \mathrm{kg}$ bw group after 4 weeks of exposure (Canton et al., 2008). Our present proteomic study is the first to evaluate changes on the liver protein concentrations in HBCD exposed rats, providing mechanistic information including potential post translational effects, thus giving a more functional picture of ongoing processes. Although the changes in protein levels are relatively small after a short (one week) exposure period, the same pathways, however, were as affected as after one month of exposure, although sometimes different proteins (Supplementary 4). Based on the results by van der Ven et al. (2006) (HBCD exposure range $0.1-200 \mathrm{mg} / \mathrm{kg} / \mathrm{d}$ for $28 \mathrm{~d}$ ), Canton et al. (2008) hypothesized that changes in cholesterol metabolism are related to hypothyroidism caused by HBCD exposure. The link between these two pathways is suggested to be hydroxymethyl-glutaryl-CoA (HMG-CoA), whose conversion to mevalonate is catalysed by the enzyme hydroxymethyl-glutaryl-CoA reductase (HMG-CoA reductase).

In our short-term study, liver weights were not affected by HBCD exposure (Table 1, Supplement 4), but a few proteins involved in lipid metabolism and in the $3 \mathrm{mg} / \mathrm{kg} / \mathrm{d}$ exposed group the protein hydroxymethylglutaryl-CoA synthase (substrate for HMG-CoA reductase) decreased. This supports the hypothesis by Canton, and shows how protein levels might be used as early markers. In contrast to the paper by Canton et al. (2008), our data suggest a considerable influence of HBCD on the gluconeogenesis/ glycolysis and the metabolism of several amino acids. This is not necessarily a contradiction, as carbohydrate, protein and lipid metabolisms are linked via acetyl-CoA for conversion of carbohydrates into lipids and/or for energy generation via the citric acid cycle (Engelking, 2015). There is also a close connection to the proteohormone leptin which is secreted by adipocytes and involved in regulation of energy balance and appetite (Hynes and Jones, 2001).

HBCD has been reported to induce oxidative stress (Deng et al., 2009; Hu et al., 2009; Zhang et al., 2008). Also our data reflects changes in oxidative stress related proteins like BDH (mitochondrial D-beta-hydroxybutyrate dehydrogenase), AL1L1 (aldehyde 
dehydrogenase family 1 member L1) and ETFB (electron transfer flavoprotein). While BDH (involved in ketone body metabolism) was altered only in ET animals, AL1L1 as well as ETFB (a component of the electron transport chain and essential in the oxidative phosphorylation pathway (Rakhshandehroo et al., 2007)) were influenced by HBCD levels independent of the thyroid status.

In our study we found a similar panel of proteins with metabolic, redox, or transport function as has been found in two studies on zebrafish liver cells exposed in vivo to HBCD (Kling et al., 2008) or a mixture of 11 BFRs including HBCD tested in vitro (Kling and Förlin, 2009). Differences in species, exposure and agents, however, hamper detailed comparisons with our own findings.

Interestingly, no changes of CYPs (cytochrome $\mathrm{P} 450$ proteins) were found in our proteomics approach while in a 28-day study with daily $\mathrm{HBCD}$ doses similar to ours slight concentration changes in CYP3A1 or CYP3A1 and CYP2B1/2 were reported for liver microsomes using Western blots (Germer et al., 2006). These differences may result from longer exposure, the enriched organelle fraction or a very specific and sensitive antibody used.

The rationale for including HT animals in our study on female rats was the hypothesis of Canton et al. that higher/prolonged HBCD challenge leads to hypothyroidism (Canton et al., 2008; van der Ven et al., 2006), which is a condition 10 times more frequent in human females than males (Canaris et al., 2000). We hypothesized that HT organisms cannot compensate as well as ETs, but found the same pathways were influenced by HBCD in ET and HT animals, although often different proteins were differentially expressed. Also, a larger spectrum of spot/proteins changed in exposed HT than ET rats compared to unexposed controls, and these proteins were sometimes highly interconnected, especially in the $3 \mathrm{mg} / \mathrm{kg} /$ day group. This observation was supported by the protein spot counts of significant changes.

Functional cluster analysis revealed several members of the glutathione-S-transferase (GST) family in much lower concentrations in HT compared to ET animals. This could point to greater compensation responses. GSTs are phase II metabolic enzymes that catalyse the conjugation of glutathione group (GSH) to a wide number of endogenous and exogenous hydrophobic compounds (incl. drugs and xenobiotics). The conjugated products are normally more soluble than the parent compounds, facilitating their removal from circulation through the kidney (Wu et al., 2004).

The glutathione metabolism is an important mechanism to prevent oxidative damage to cellular components by ROS (reactive oxygen species). Low levels of GSTs may render animals less protected against oxidative stress. The low levels may be due to either lower production or higher consumption of GST in detoxifying processes. Low levels of GST have been described before for human hypothyroid individuals (measured as overall GST activity (Pasupathi and Latha, 2008)) and mice (GSTA gene expression in mouse liver (Faustino et al., 2011)). The resolving power of 2D electrophoresis allows the differentiation between four different GSTAs and one GSTP.

As reported by others (Canton et al., 2008; Crump et al., 2008; Kling and Förlin, 2009), we observed upon HBCD exposure: a decrease of several proteins involved in biosynthetic processes (also lipid and glucose), upregulated proteins with catabolic functions, influence on lipid and steroid metabolism (decreased isoamyl acetate-hydrolyzing esterase 1 potentially reflecting reduced lipid degradation). Hypothyroidism reduces metabolism in general, and results in hypercholesterolaemia and influence on lipoprotein levels (Santillo et al., 1999).

In a study applying cDNA microarrays, 55 of the 2225 tested hepatic murine genes were found in vivo changed under the influence of thyroid hormone, documenting impact on gluconeogenesis, lipogenesis, insulin signalling, cell proliferation, apoptosis (Feng et al., 2000). Despite the differences in approach (species, transcriptomics), affected pathways correspond largely to our findings.

Perturbations of lipid and fatty acid metabolisms correlate well with our findings of increased leptin levels in HT animals, increased carbamoylphosphate synthase (a sign for increased triglyceride catabolism) and reduced body weight of the HT animals. Leptin plays a major role in the regulation of energy balance by modulating food intake, glucose and lipid metabolism (CettourRose et al., 2005). In thyroidectomised rats given infusions of $\mathrm{T}_{4}$ or $\mathrm{T}_{3}$, TH and leptin levels were determined as negatively correlated (Escobar-Morreale et al., 1997), and also the results from our rats suggest an inverse relationship between $\mathrm{T}_{3}$ (esp. free $\mathrm{T}_{3}$ ) and leptin concentrations (Table 1 ).

\section{Conclusions}

In the present study rats were challenged with 3 or $30 \mathrm{mg} / \mathrm{kg}$ bw/d concentrations of $\mathrm{HBCD}$ for a week. Using high-end proteomics significant effects were demonstrated on the lipid metabolism at the protein level, which until now were only shown at the level of gene regulation or as changed levels of metabolic products after longer exposure periods (Canton et al., 2008; van der Ven et al., 2006). Additionally, we revealed that HBCD also had a strong influence on general metabolic processes, mainly glucose and amino acid metabolism. It would be also interesting to perform proteomics on animals that are exposed to lower HBCD dosages over a longer period to confirm the proteins that already after one week can be indicative for adverse effects. Longer exposure time may make proteins detectable whose changes were not yet obvious (e.g. due to higher abundance and longer half-life or turnover times, as discussed in (Miller et al., 2014)) or which are signs of secondary effects. In this context pre-fractionation of the samples, e.g. enrichment of organelles, before 2D-DIGE would be helpful to target protein sub-populations and thus enhance their detectability. It also would be worthwhile to study by proteomics effects on plasma proteins of HBCD exposed organisms, as this could potentially provide non-destructive biomarkers for effects in experimental exposures over time and epidemiological studies.

\section{Funding}

This work was supported by contributions from the participating institutions. The authors do not declare any conflict of interest.

\section{Acknowledgements}

We would like to thank Hans Swarts for his help with the animal experiments. We also thank V. Peardon for language editing.

\section{Appendix A. Supplementary data}

Supplementary data associated with this article can be found, in the online version, at http://dx.doi.org/10.1016/j. toxlet.2016.01.002.

\section{References}

Bradford, M.M., 1976. A rapid and sensitive method for the quantitation of microgram quantities of protein utilizing the principle of protein-dye binding. Anal. Biochem. 72, 248-254.

Canaris, G.J., Manowitz, N.R., Mayor, G., Ridgway, E.C., 2000. The Colorado thyroid disease prevalence study. Arch. Intern. Med. 160, 526-534.

Canton, R.F., Peijnenburg, A.A., Hoogenboom, R.L., Piersma, A.H., van der Ven, L.T., van den Berg, M., Heneweer, M., 2008. Subacute effects of

hexabromocyclododecane (HBCD) on hepatic gene expression profiles in rats. Toxicol. Appl. Pharmacol. 231, 267-272.

Cettour-Rose, P., Theander-Carrillo, C., Asensio, C., Klein, M., Visser, T.J., Burger, A.G., Meier, C.A., Rohner-Jeanrenaud, F., 2005. Hypothyroidism in rats decreases 
peripheral glucose utilisation: a defect partially corrected by central leptin infusion. Diabetologia 48, 624-633.

Cooper, D.S., 2003. Hyperthyroidism. Lancet 362, 459-468.

Covaci, A., Gerecke, A.C., Law, R.J., Voorspoels, S., Kohler, M., Heeb, N.V., Leslie, H., Allchin, C.R., De Boer, J., 2006. Hexabromocyclododecanes (HBCDs) in the environment and humans: a review. Environ. Sci. Technol. 40, 3679-3688.

Crump, D., Chiu, S., Egloff, C., Kennedy, S.W., 2008. Effects of hexabromocyclododecane and polybrominated diphenyl ethers on mRNA expression in chicken (Gallus domesticus) hepatocytes. Toxicol. Sci. 106, 479-487.

Darnerud, P.O., 2003. Toxic effects of brominated flame retardants in man and in wildlife. Environ. Int. 29, 841-853.

Deng, J., Yu, L., Liu, C., Yu, K., Shi, X., Yeung, L.W., Lam, P.K., Wu, R.S., Zhou, B., 2009 Hexabromocyclododecane-induced developmental toxicity and apoptosis in zebrafish embryos. Aquat. Toxicol. 93, 29-36.

De Wit, C.A., 2002. An overview of brominated flame retardants in the environment. Chemosphere 46, 583-624.

Engelking, L.R., 2015. Tricarboxylic Acid (TCA) Cycle. Textbook of Veterinary Physiological Chemistry, In: Engelking, L.R. (Ed.), 3rd ed. Academic Press, London, UK, pp. 208-213.

Escobar-Morreale, H.F., Escobar del Rey, F., Morreale de Escobar, G., 1997. Thyroid hormones influence serum leptin concentrations in the rat. Endocrinology 138 4485-4488.

Faustino, L.C., Pires, R.M., Lima, A.C., Cordeiro, A., Souza, L.L., Ortiga-Carvalho, T.M., 2011. Liver glutathione $S$-transferase $\alpha$ expression is decreased by 3,5,3'triiodothyronine in hypothyroid but not in euthyroid mice. Exp. Physiol. 96, $790-800$.

Feng, X., Jiang, Y., Meitzer, P., Yan, P.M., 2000. Thyroid hormone regulation of hepatic genes in vivo detected by complementary DNA microarray. Mol. Endocrinol. 14 947-955.

Franceschini, A., Szklarczyk, D., Frankild, S., Kuhn, M., Simonovic, M., Roth, A., Lin, J., Minguez, P., Bork, P., von Mering, C., Jensen, L.J., 2013. STRING v9.1: proteinprotein interaction networks, with increased coverage and integration. Nucleic Acids Res. 41, D808-D815.

Germer, S., Piersma, A.H., van der Ven, L., Kamyschnikow, A., Fery, Y., Schmitz, H.-J., Schrenk, D., 2006. Subacute effects of the brominated flame retardants hexabromocyclododecane and tetrabromobisphenol A on hepatic cytochrome P450 levels in rats. Toxicology 218, 229-236.

Gutleb, A.C., Cenijn, P., van Velzen, M., Lie, E., Ropstad, E., Skaare, J.U., Malmberg, T. Bergman, Å., Gabrielsen, G.W., Legler, J., 2010. Complete saturation of thyroid hormone transport capacity of TTR in wild living polar bear (Ursus maritimus) by metabolites of PCBs. Environ. Sci. Technol. 44, 3149-3154.

Haas, B., Serchi, T., Wagner, D.R., Gilson, G., Planchon, S., Renaut, J., Hoffmann, L., Bohn, T., Devaux, Y., 2011. Proteomic analysis of plasma samples from patients with acute myocardial infarction identifies haptoglobin as a potential prognostic biomarker. J. Proteomics 75, 229-236.

Hu, J., Liang, Y., Chen, M., Wang, X., 2009. Assessing the toxicity of TBBPA and HBCD by zebrafish embryo toxicity assay and biomarker analysis. Environ. Toxicol. 24, 334-342.

Hynes, G.R., Jones, P.J., 2001. Leptin and its role in lipid metabolism. Curr. Opin. Lipidol. 12, 321-327.

Kalachova, K., Hradkova, P., Lankova, D., Hajslova, J., Pulkrabova, J., 2012. Occurrence of brominated flame retardants in household and car dust from the Czech Republic. Sci. Total Environ. 441, 182-193.

Kiciński, M., Viaene, M.K., Den Hond, E., Schoeters, G., Covaci, A., Dirtu, A.C., Nelen, V., Bruckers, L., Croes, K., Sioen, I., Baeye, W., Van Larebeke, N., Nawrot, T.S., 2012. Neurobehavioral function and low-level exposure to brominated flame retardants in adolescents: a cross-sectional study. Environ. Health 11, 86.

Kling, P., Förlin, L., 2009. Proteomic studies in zebrafish liver cells exposed to the brominated flame retardants HBCD and TBBPA. Ecotoxicol. Environ. Safety 72, 1985-1993.

Kling, P., Norman, A., Andersson, P.L., Norrgren, L., Förlin, L., 2008. Gender-specific proteomic responses in zebrafish liver following exposure to a selected mixture of brominated flame retardants. Ecotoxicol. Environ. Safety 71, 319-327.

Law, R.J., Herzke, D., Harrad, S., Morris, S., Bersuder, P., Allchinet, C.R., 2008. Levels and trends of HBCD and BDEs in the European and Asian environments: with some information for other BFRs. Chemosphere 73, 223-241.

Mattheij, J.A., Swarts, J.J., Lokerse, P., van Kampen, J.T., Van der Heide, D., 1995. Effect of hypothyroidism on the pituitary-gonadal axis in the adult female rat. J. Endocrinol. 146, 87-94.

Miller, I., Serchi, T., Murk, A.J., Gutleb, A.C., 2014. The added value of proteomic studies for toxicological studies. J. Toxicol. Environ. Health B 17, 225-246.

Miller, I., Serchi, T., Cambier, S., Diepenbroek, C., Renaut, J., Van den Berg, J.H.J., Kwadijk, C., Gutleb, A.C., Rijntjes, E., Murk, A.J., 2016. Identification of liver proteins of eu- and hypothyroid female rats changing abundance upon in vivo exposure to hexabromocyclododecane (HBCD). Data-in-brief submitted in parallel.
Montaño, M., Gutleb, A.C., Murk, A.J., 2013. Persistent toxic burdens of halogenated phenolic compounds in humans and wildlife. Environ. Sci. Technol.47, 6071-6081. Palm, I.F., van der Beek, E.M., Swarts, H.J., van der Vliet, J., Wiegant, V.M., Buijs, R.M., Kalsbeek, A., 2001a. Control of the estradiol-induced prolactin surge by the suprachiasmatic nucleus. Endocrinology 142, 2296-2302.

Palm, I.F., van der Beek, E.M., Wiegant, V.M., Buijs, R.M., Kalsbeek, A., Palm, I.F., van der Beek, E.M., Swarts, H.J., van der Vliet, J., Wiegant, V.M., Buijs, R.M., Kalsbeek, A., 2001b. The stimulatory effect of vasopressin on the luteinizing hormone surge in ovariectomized, estradiol-treated rats is time-dependent control of the estradiol-induced prolactin surge by the suprachiasmatic nucleus. Brain Res. 901, 109-116.

Pasquali, M., Serchi, T., Renaut, J., Hoffmann, L., Bohn, T., 2013. 2D difference gel electrophoresis reference map of a Fusarium graminearum nivalenol producing strain. Electrophoresis 34, 505-509.

Pasupathi, P., Latha, R., 2008. Free radical activity and antioxidant defense mechanisms in patients with hypothyroidism. Thyroid Sci. 3 CLS1-6.

Rakhshandehroo, M., Sanderson, L.M., Matilainen, M., Stienstra, R., Carlberg, C., de Groot, P.J., Müller, M., Kersten, S., 2007. Comprehensive Analysis of PPAR $\alpha-$ Dependent Regulation of Hepatic Lipid Metabolism by Expression Profiling. PPAR Res. 2007 Article ID 26839, 13.

Reeves, P.G., Nielsen, F.H., Fahey, G.C., 1993. AIN-93 purified diets for laboratory rodents: final report of the American Institute of Nutrition ad hoc writing committee on the reformulation of the AIN-76A rodent diet. J. Nutr. 123, 1939-1951.

Rijntjes, E., Swarts, H.J.M., Anand-Ivell, R., Teerds, K.J., 2009. Prenatal induced chronic dietary hypothyroidism delays but does not block adult-type Leydig cell development. Am. J. Physiol. Endocrinol. Metab. 296, E305-14.

Roberts, C.G., Ladenson, P.W., 2004. Hypothyroidism. Lancet 363, 793-803.

Santillo, M., Migliaro, A., Mondola, P., Laezza, C., Damiano, S., Stingo, S., Fiorentino, L., Andreozzi, A., Vita le, M., Bifulco, M., 1999. Dietary and hypothyroid hypercholesterolemia induces hepatic apolipoprotein E expression in the rat: direct role of cholesterol. FEBS Lett. 463, 83-86.

Schriks, M., Vrabie, C.M., Gutleb, A.C., Faassen, E.J., Rietjens, I.M.C.M., Murk, A.J., 2006. T-screen to quantify functional potentiating, antagonistic and thyroid hormone-like activities of polyhalogenated aromatic hydrocarbons (PHAHs). Toxicol. In Vitro 20, 490-498.

Schroder-van der Elst, J.P., van der Heide, D., Morreale de Escobar, G., Obregon, M.J., 1998. Iodothyronine deiodinase activities in fetal rat tissues at several levels of iodine deficiency: a role for the skin in 3,5,3'-triiodothyronine economy? Endocrinology 139, 2229-2234.

Snel, B., Lehmann, G., Bork, P., Huynen, M.A., 2000. STRING: a web-server to retrieve and display the repeatedly occurring neighbourhood of a gene. Nucleic Acids Res. 28, 3442-3444.

Szabo, D.T., Diliberto, J.J., Hakk, H., Huwe, J.K., Birnbaum, L.S., 2010. Toxicokinetics of the flame retardant hexabromocyclododecane gamma: effect of dose, timing, route, repeated exposure, and metabolism. Toxicol. Sci. 117, 282-293.

Taylor, P.N., Razvi, S., Pearce, S.H., Dayan, C.M., 2013. Clinical review: a review of the clinical consequences of variation in thyroid function within the reference range. J. Clin. Endocrinol. Metab. 98, 3562-3571.

Teng, W., Shan, Z., Patil-Sisodia, K., Cooper, D.S., 2013. Hypothyroidism in pregnancy. Lancet Diabetes Endocrinol. 1, 228-237.

ter Veld, M.G.R., Zawadzka, E., van den Berg, J.H.J., van der Saag, P.T., Rietjens, I.M.C. M., Murk, A.J., 2008. Food-associated estrogenic compounds induce estrogen receptor-mediated luciferase gene expression in transgenic male mice. Chem.Biol. Interact. 174, 126-133.

Tomko, G., McDonald, K.M., 2013. Environmental fate of hexabromocyclododecane from a new Canadian electronic recycling facility. J. Environ. Manage. 114, 324-327.

van der Ven, L.T.M., Leonards, P.E.G., Slob, W., Lilienthal, H., Litens, S., Herlin, M., Håkansson, H., Cantón, R.F., van den Berg, M., Visser, T.J., van Loveren, H., Vos, J. G. Piersma, A.H., 2006. A 28-day oral dose toxicity study enhanced to detect endocrine effects of hexabromocyclododecane in Wistar rats. Toxicol. Sci. 94, $281-292$.

van der Ven, L.T.M., van de Kuil, T., Leonards, P.E.G., Slob, W., Lilienthal, H., Litens, S. Herlin, M., Håkansson, H., Cantón, R.F., van den Berg, M., Visser, T.J., van Loveren, H., Vos, J.G., Piersma, A.H., 2009. Endocrine effects of hexabromocyclododecane (HBCD) in a one-generation reproduction study in Wistar rats. Toxicol. Lett. 185, 51-62.

van Wijk, N., Rijntjes, E., van de Heijning, B.J., 2008. Perinatal and chronic hypothyroidism impair behavioural development in male and female rats. Exp. Physiol. 93, 1199-1209.

Warner, A., an Mittag, J., 2012. Thyroid hormone and the central control of homeostasis. J. Mol. Endocrinol. 49, R29-35.

Wu, G., Fang, Y.Z., Yang, S., Lupton, J.R., Turner, N.D., 2004. Glutathione metabolism and its implications for health. J. Nutr. 134, 489-492.

Zhang, X., Yang, F., Xu, C., Liu, W., Wen, S., Xu, Y., 2008. Cytotoxicity evaluation of three pairs of hexabromocyclododecane (HBCD) enantiomers on Hep G2 cell. Toxicol. In Vitro. 22, 1520-1527. 


\title{
Data Article
}

\section{Dataset of liver proteins changed in eu- and hypothyroid female rats upon in vivo exposure to hexabromocyclododecane (HBCD)}

\author{
I. Miller ${ }^{\mathrm{a}, *}$, T. Serchi $^{\mathrm{b}}$, S. Cambier ${ }^{\mathrm{b}}$, C. Diepenbroek ${ }^{\mathrm{c}}$, J. Renaut ${ }^{\mathrm{b}}$, \\ J.H.J. van den Berg ${ }^{\text {e }}$, C. Kwadijk ${ }^{\mathrm{f}}$, A.C. Gutleb ${ }^{\mathrm{b}}$, E. Rijntjes ${ }^{\mathrm{c}, \mathrm{d}, 1}$, \\ A.J. Murk ${ }^{\mathrm{e}, 1,2}$ \\ a Institute for Medical Biochemistry, Department for Biomedical Sciences, \\ University of Veterinary Medicine Vienna, Veterinaerplatz 1, A-1210 Vienna, Austria \\ ${ }^{\mathrm{b}}$ Environmental Research and Innovation (ERIN) Department, Luxembourg Institute of Science \\ and Technology (LIST), 5, avenue des Hauts-Fourneaux, L-4362 Esch-sur-Alzette, Grand-duchy of Luxembourg \\ ${ }^{\mathrm{c}}$ Wageningen University, Human and Animal Physiology, P.O. Box 338, 6700 AH Wageningen, The Netherlands \\ d Charité-Universitätsmedizin Berlin, Institute for Experimental Endocrinology, Augustenburger Platz 1, \\ 13353, Berlin, Germany \\ e Wageningen University, Division of Toxicology, Tuinlaan 5, 6703HE Wageningen, The Netherlands \\ ${ }^{\mathrm{f}}$ Wageningen Institute for Marine Resources \&' Ecosystem Studies, IMARES, IJmuiden, The Netherlands
}

A R T I C L E I N F O

\section{Article history:}

Received 20 January 2016

Received in revised form

5 February 2016

Accepted 19 February 2016

Available online 27 February 2016

\section{Keywords:}

HBCD

Proteomics

Rat

Liver

Hypothyroidism

Lipid metabolism

\begin{abstract}
A B S T R A C T
Female Wistar rats with different thyroid status (eu-, hypothyroid) were exposed to 0,3 or $30 \mathrm{mg} / \mathrm{kg}$ body weight of the flame retardant HBCD for 7 days. Changes in protein patterns obtained by 2D-DIGE were evaluated, and different animal groups compared taking into account their exposure and thyroid status. Proteins significantly altered in abundance in any of these comparisons were identified by mass spectrometry. These data, together with hormone data of the animals, are discussed in "Hexabromocyclododecane (HBCD) induced changes in the liver proteome of eu- and hypothyroid female rats" (Miller et al., 2016) [1].

๑ 2016 The Authors. Published by Elsevier Inc. This is an open access article under the CC BY license (http://creativecommons.org/licenses/by/4.0/).
\end{abstract}

\footnotetext{
DOI of original article: http://dx.doi.org/10.1016/j.toxlet.2016.01.002

* Corresponding author.

E-mail address: ingrid.miller@vetmeduni.ac.at (I. Miller).

${ }^{1}$ Shared Senior Authorship.

${ }^{2}$ Current address: Wageningen University, Marine Animal Ecology Group, De Elst 1, 6708 WD Wageningen, The Netherlands.
} 


\section{Specifications Table}

\begin{tabular}{|c|c|}
\hline Subject area & Biology \\
\hline $\begin{array}{l}\text { More specific sub- } \\
\text { ject area }\end{array}$ & Environmental Toxicology \\
\hline Type of data & Tables, image (annotated gel image) \\
\hline $\begin{array}{l}\text { How data was } \\
\text { acquired }\end{array}$ & $\begin{array}{l}\text { 2D Fluorescence Difference Gel Electrophoresis (2D-DIGE) and mass } \\
\text { spectrometry }\end{array}$ \\
\hline Data format & Analyzed and filtered data \\
\hline $\begin{array}{l}\text { Experimental } \\
\text { factors }\end{array}$ & Liver lysates of eu- and hypothyroid female rats differently exposed to $H B C D$ \\
\hline $\begin{array}{l}\text { Experimental } \\
\text { features }\end{array}$ & $\begin{array}{l}\text { Comparative proteomic analysis of rat liver lysates using } 2 D-D I G E \text {. Proteins } \\
\text { present in differentially abundant protein spots (regarding HBCD exposure, } \\
\text { amount, and thyroid status) were identified using MALDI TOF/TOF analysis. }\end{array}$ \\
\hline Data source location & $\begin{array}{l}\text { Origin of samples: Wageningen University, Wageningen, The Netherlands } \\
\text { Data collection: Luxembourg Institute of Science and Technology, Esch-sur-Alz- } \\
\text { ette, Luxembourg }\end{array}$ \\
\hline Data accessibility & MS- and regulation data is with this article as Supplementary material \\
\hline
\end{tabular}

\section{Value of the data}

- Identification of liver proteins from female rats altered due to HBCD exposure.

- Identification of liver proteins from female rats changed in hypothyroid status.

- Data showing single and combined effects (HBCD exposure, hypothyroidism).

- Identified liver proteins form the basis for further studies to achieve a more detailed understanding of involved mechanism.

\section{Data}

Two-dimensional electrophoresis of liver protein lysates showed complex patterns of about 3000 spots per gel. Patterns of 24 gels from different exposures of eu- and hypothyroid rats were evaluated quantitatively. The data from different animals groups were compared, taking different aspects into account (HBCD exposure, thyroid status). Statistically significant fold-changes of at least $30 \%$ between groups $(P<0.05$ within group) were considered to be relevant.

The master gel is presented in Fig. 1, and all spots with significant abundance changes in any of the performed comparisons are labelled. Spot numbers refer to the protein identifications listed in Table 1 (peptide list in Supplemental Table 1), and to abundance changes in the various animal groups (Supplemental Table 2).

\section{Experimental design, materials and methods}

\subsection{Animals, treatment and experimental protocol}

The animal experiment was detailed in [1] and was approved under number 2007-041 by the Animal Welfare Committee of Wageningen University. In brief, female Wistar WU (HsdCpbWU) rats with normal or reduced thyroid function (hypothyroid) were orally exposed to 0,3 or $30 \mathrm{mg} / \mathrm{kg}$ bw/d $\mathrm{HBCD}$, respectively, for 7 consecutive days. Four liver samples per group were analyzed by proteomic methods. 


\subsection{Proteomic analysis}

Two-dimensional fluorescence difference gel electrophoresis (2D-DIGE) was performed as previously described, with minor modifications [2,3]. Rat livers were homogenized using the GE sample grinding kit in lysis buffer (urea $7 \mathrm{M}$; thiourea $2 \mathrm{M}$; CHAPS $2 \% \mathrm{w} / \mathrm{w}$; tris $30 \mathrm{mM}$ ) containing protease inhibitor Complete Mini (Roche, Brussels, Belgium). Supernatants obtained after centrifugation ( $15 \mathrm{~min}$ at $30,000 \mathrm{~g}$ ) were collected and stored at $-20^{\circ} \mathrm{C}$ until use. Protein concentration was determined according to Bradford [4]. Fifty $\mu \mathrm{g}$ per sample were labelled with CyDyes according to the manufacturer's instructions and separated on IPGs of a non-linear 3-10 pH-range. The second dimensional SDS-PAGE was performed in $12.5 \%$ precast gels (SERVA Electrophoresis GmbH, Heidelberg, Germany). Gel images (acquired on a Typhoon 9400) were analyzed with the DeCyder 7.0 software package (both GE Healthcare, Diegem, Belgium). Gels were matched and subjected to univariate and multivariate analysis in order to highlight differentially regulated spots (fold change at least 1.3) with a $P$-value in the respective univariate ANOVA or two way ANOVA $<0.05$.

Differentially abundant spots were automatically picked, tryptically digested and spotted on the MALDI target by the use of the Ettan Spot Handling Workstation (GE Healthcare, Diegem, Belgium). Protein identification was carried out on the Applied Biosystems MALDI-Tof-Tof 4800 Proteomics Analyser (Applied Biosystem, Gent, Belgium) as previously described [2]. Protein identification was performed by searching protein mass fingerprints (PMF) and MS/MS spectra against the SwissProt database with "Rattus norvegicus" as taxonomy. Searches were performed using the ProteinPilot software (Sciex, Nieuwerkerk aan den Ijssel, The Netherlands) and the searching algorithm MASCOT (Matrix Science, www.matrixscience.com, London, UK). For each spot one protein mass fingerprint and up to $8 \mathrm{MS} / \mathrm{MS}$ spectra were generated. Parameters for the search were set as follow: up to two

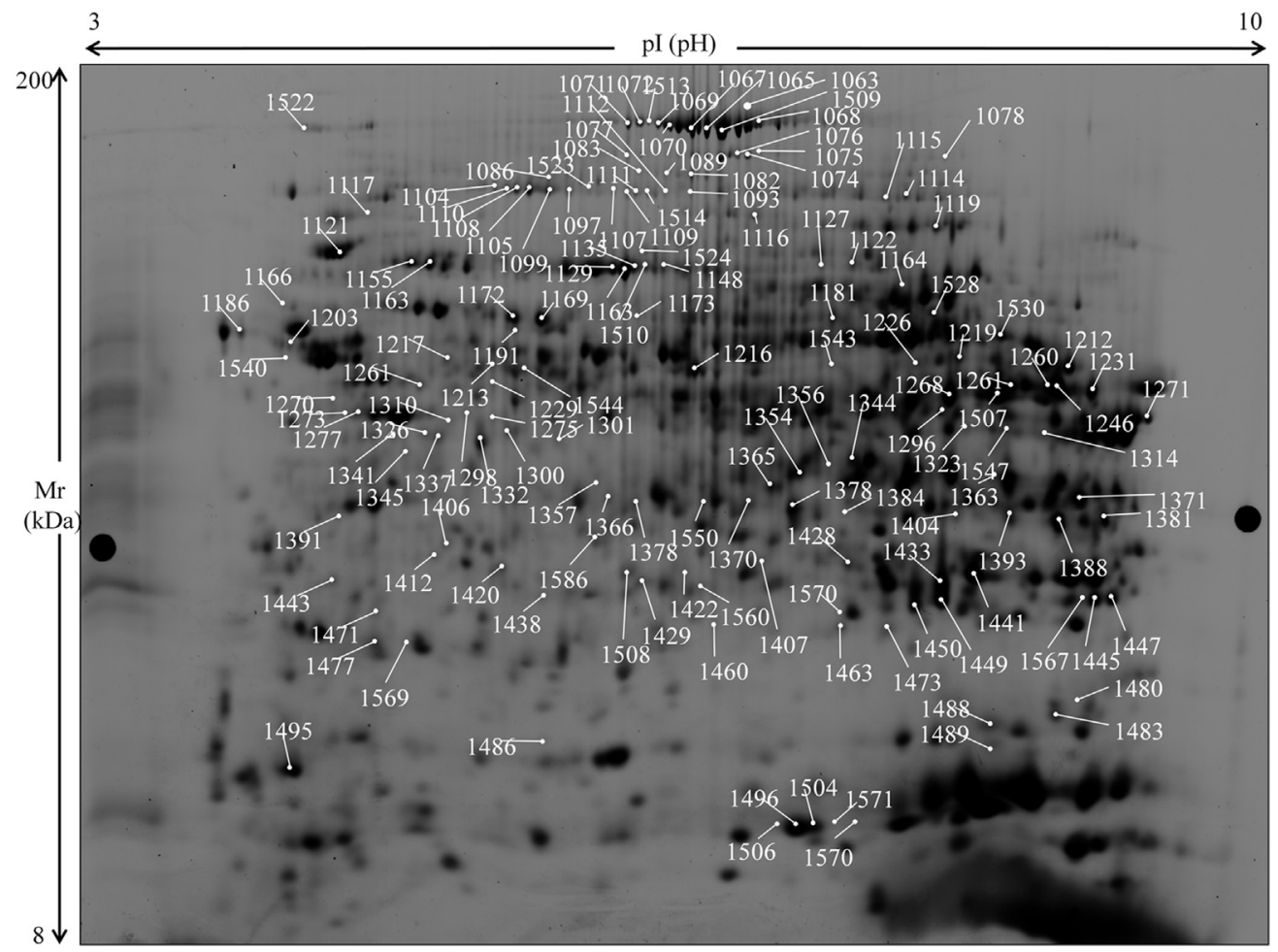

Fig. 1. Image of a rat liver 2D-DIGE gel (master gel, grey level image). All spots with statistically significant abundance changes are labelled; spot numbers refer to identifications in Table 1. For details on protein identification see Supplemental Table 1, for data on protein abundance, see Supplemental Table 2. 
Table 1

Proteins of the present dataset, identified by MALDI-TOF/TOF analysis.

\begin{tabular}{|c|c|c|c|}
\hline Spot number & Protein name & Species & $\begin{array}{l}\text { Swiss-Prot } \\
\text { Acc. } \mathbf{N}^{\circ}\end{array}$ \\
\hline $\begin{array}{l}1063,1065,1067-1071,1074- \\
1076,1078\end{array}$ & Carbamoyl-phosphate synthase[ammonia], mitochondrial & $\begin{array}{l}\text { Rattus } \\
\text { norvegicus }\end{array}$ & CPSM_RAT \\
\hline 1072 & Murinoglobulin-2 & $\begin{array}{l}\text { Rattus } \\
\text { norvegicus }\end{array}$ & MUG2_RAT \\
\hline $1077,1082,1083$ & Pyruvate carboxylase, mitochondrial & $\begin{array}{l}\text { Rattus } \\
\text { norvegicus }\end{array}$ & PYC_RAT \\
\hline 1086 & ATP-citrate synthase & $\begin{array}{l}\text { Rattus } \\
\text { norvegicus }\end{array}$ & ACLY_RAT \\
\hline 1089 & C-1-tetrahydrofolate synthase, cytoplasmic & $\begin{array}{l}\text { Rattus } \\
\text { norvegicus }\end{array}$ & C1TC_RAT \\
\hline 1093 & Alpha-aminoadipic semialdehyde synthase, mitochondrial & $\begin{array}{l}\text { Rattus } \\
\text { norvegicus }\end{array}$ & AASS_RAT \\
\hline 1094,1100 & 2-oxoglutarate dehydrogenase, mitochondrial & $\begin{array}{l}\text { Rattus } \\
\text { norvegicus }\end{array}$ & ODO1_RAT \\
\hline 1099, 1105, 1107-1110, 1114 & Aldehyde dehydrogenase family 1 member L1 & $\begin{array}{l}\text { Rattus } \\
\text { norvegicus }\end{array}$ & AL1L1_RAT \\
\hline 1111 & Aldehyde dehydrogenase 1 family, member L2 & $\begin{array}{l}\text { Mus } \\
\text { musculus }\end{array}$ & gil21961590 \\
\hline 1112, 1115-1117, 1119 & Sarcosine dehydrogenase, mitochondrial & $\begin{array}{l}\text { Rattus } \\
\text { norvegicus }\end{array}$ & SARDH_RAT \\
\hline 1121,1122 & Elongation factor2 & $\begin{array}{l}\text { Rattus } \\
\text { norvegicus }\end{array}$ & EF2_RAT \\
\hline 1123 & Cytoplasmic aconitate hydratase & $\begin{array}{l}\text { Rattus } \\
\text { norvegicus }\end{array}$ & ACOC_RAT \\
\hline 1129 & Dimethylglycine dehydrogenase, mitochondrial & $\begin{array}{l}\text { Rattus } \\
\text { norvegicus }\end{array}$ & M2GD_RAT \\
\hline 1135 & Serotransferrin & $\begin{array}{l}\text { Rattus } \\
\text { norvegicus }\end{array}$ & TRFE_RAT \\
\hline 1148 & Propionyl-CoA carboxylase alpha chain, mitochondrial & $\begin{array}{l}\text { Rattus } \\
\text { norvegicus }\end{array}$ & PCCA_RAT \\
\hline 1155 & 78kDa glucose-regulated protein & $\begin{array}{l}\text { Rattus } \\
\text { norvegicus }\end{array}$ & GRP78_RAT \\
\hline 1161, 1165 & Heat shock cognate $71 \mathrm{kDa}$ protein & $\begin{array}{l}\text { Rattus } \\
\text { norvegicus }\end{array}$ & HSP7C_RAT \\
\hline 1163,1164 & rCG56002 & $\begin{array}{l}\text { Rattus } \\
\text { norvegicus }\end{array}$ & gil149036727 \\
\hline $1169,1172,1173,1181,1186$ & Serum albumin & $\begin{array}{l}\text { Rattus } \\
\text { norvegicus }\end{array}$ & ALBU_RAT \\
\hline 1191 & $\begin{array}{l}\text { Delta-1-pyrroline-5-carboxylate dehydrogenase, } \\
\text { mitochondrial }\end{array}$ & $\begin{array}{l}\text { Cricetulus } \\
\text { griseus }\end{array}$ & gil344249754 \\
\hline 1203 & UV excision repair protein RAD23 homolog B & $\begin{array}{l}\text { Rattus } \\
\text { norvegicus }\end{array}$ & RD23B_RAT \\
\hline 1212 & $\begin{array}{l}\text { PREDICTED: aldehyde dehydrogenase } 8 \text { family, member } \\
\text { A1-like isoform } 2\end{array}$ & $\begin{array}{l}\text { Rattus } \\
\text { norvegicus }\end{array}$ & gil109460389 \\
\hline 1213 & Pyruvatekinase isozymes $\mathrm{R} / \mathrm{L}$ & $\begin{array}{l}\text { Rattus } \\
\text { norvegicus }\end{array}$ & KPYR_RAT \\
\hline 1216,1219 & Proteindisulfide-isomerase A3 & $\begin{array}{l}\text { Rattus } \\
\text { norvegicus }\end{array}$ & PDIA3_RAT \\
\hline 1217 & Liver carboxylesterase 4 & $\begin{array}{l}\text { Rattus } \\
\text { norvegicus }\end{array}$ & EST4_RAT \\
\hline 1226 & Formimidoyl transferase-cyclodeaminase & $\begin{array}{l}\text { Rattus } \\
\text { norvegicus }\end{array}$ & FTCD_RAT \\
\hline 1229 & Calreticulin & $\begin{array}{l}\text { Rattus } \\
\text { norvegicus }\end{array}$ & CALR_RAT \\
\hline 1231 & $\begin{array}{l}\text { Methylmalonate-semialdehyde dehydrogenase[acylating], } \\
\text { mitochondrial }\end{array}$ & $\begin{array}{l}\text { Rattus } \\
\text { norvegicus }\end{array}$ & MMSA_RAT \\
\hline 1246 & Alpha-1-antiproteinase & $\begin{array}{l}\text { Rattus } \\
\text { norvegicus }\end{array}$ & A1AT_RAT \\
\hline 1260,1268 & Alanine-glyoxylate aminotransferase 2 , mitochondrial & & AGT2_RAT \\
\hline
\end{tabular}


Table 1 (continued)

\begin{tabular}{|c|c|c|c|}
\hline Spot number & Protein name & Species & $\begin{array}{l}\text { Swiss-Prot } \\
\text { Acc. } \mathrm{N}^{\circ}\end{array}$ \\
\hline & & $\begin{array}{l}\text { Rattus } \\
\text { norvegicus }\end{array}$ & \\
\hline 1261 & Glutathione synthetase & $\begin{array}{l}\text { Rattus } \\
\text { norvegicus }\end{array}$ & GSHB_RAT \\
\hline 1262 & 4-trimethylaminobutyraldehyde dehydrogenase & $\begin{array}{l}\text { Rattus } \\
\text { norvegicus }\end{array}$ & AL9A1_RAT \\
\hline 1270, 1277 & Phenylalanine-4-hydroxylase & $\begin{array}{l}\text { Rattus } \\
\text { norvegicus }\end{array}$ & PH4H_RAT \\
\hline 1271 & Succinate-semialdehyde dehydrogenase, mitochondrial & $\begin{array}{l}\text { Rattus } \\
\text { norvegicus }\end{array}$ & SSDH_RAT \\
\hline 1273 & Hydroxymethylglutaryl-CoA synthase, mitochondrial & $\begin{array}{l}\text { Rattus } \\
\text { norvegicus }\end{array}$ & HMCS2_RAT \\
\hline 1275 & Alpha-enolase & $\begin{array}{l}\text { Rattus } \\
\text { norvegicus }\end{array}$ & ENOA_RAT \\
\hline 1296 & Ifi47 protein & $\begin{array}{l}\text { Rattus } \\
\text { norvegicus }\end{array}$ & gil44890246 \\
\hline $1298,1301,1310$ & Betaine-homocysteine S-methyltransferase 1 & $\begin{array}{l}\text { Rattus } \\
\text { norvegicus }\end{array}$ & BHMT1_RAT \\
\hline 1300 & Eukaryotic initiation factor $4 \mathrm{~A}-\mathrm{II}$ & $\begin{array}{l}\text { Rattus } \\
\text { norvegicus }\end{array}$ & IF4A2_RAT \\
\hline 1314 & 3-ketoacyl-CoA thiolase, mitochondrial & $\begin{array}{l}\text { Rattus } \\
\text { norvegicus }\end{array}$ & THIM_RAT \\
\hline 1323,1326 & Argininosuccinate synthase & $\begin{array}{l}\text { Rattus } \\
\text { norvegicus }\end{array}$ & ASSY_RAT \\
\hline 1332 & Keratin, type I cytoskeletal 18 & $\begin{array}{l}\text { Rattus } \\
\text { norvegicus }\end{array}$ & K1C18_RAT \\
\hline 1337 & Aspartate aminotransferase, cytoplasmic & $\begin{array}{l}\text { Rattus } \\
\text { norvegicus }\end{array}$ & AATC_RAT \\
\hline 1341, 1345, 1354 & Actin, cytoplasmic 1 & $\begin{array}{l}\text { Rattus } \\
\text { norvegicus }\end{array}$ & ACTB_RAT \\
\hline 1344 & Creatinekinase B-type & $\begin{array}{l}\text { Rattus } \\
\text { norvegicus }\end{array}$ & KCRB_RAT \\
\hline 1356 & Aspartate aminotransferase, mitochondrial & $\begin{array}{l}\text { Rattus } \\
\text { norvegicus }\end{array}$ & AATM_RAT \\
\hline 1357 & Serum paraoxonase/arylesterase2 & $\begin{array}{l}\text { Rattus } \\
\text { norvegicus }\end{array}$ & PON2_RAT \\
\hline 1363,1365 & Fructose-bisphosphate aldolase B & $\begin{array}{l}\text { Rattus } \\
\text { norvegicus }\end{array}$ & ALDOB_RAT \\
\hline 1366 & Serum paraoxonase/lactonase 3 & $\begin{array}{l}\text { Rattus } \\
\text { norvegicus }\end{array}$ & PON3_RAT \\
\hline $1370,1371,1374,1378,1384$ & Fructose-1,6-bisphosphatase 1 & $\begin{array}{l}\text { Rattus } \\
\text { norvegicus }\end{array}$ & F16P1_RAT \\
\hline 1381 & Adipocyte plasmamembrane-associated protein & $\begin{array}{l}\text { Rattus } \\
\text { norvegicus }\end{array}$ & APMAP_RAT \\
\hline 1388 & Farnesyl pyrophosphate synthase & $\begin{array}{l}\text { Rattus } \\
\text { norvegicus }\end{array}$ & FPPS_RAT \\
\hline 1391, 1393 & Arginase-1 & $\begin{array}{l}\text { Rattus } \\
\text { norvegicus }\end{array}$ & ARGI1_RAT \\
\hline 1404,1417 & 3-oxo-5-beta-steroid 4-dehydrogenase & $\begin{array}{l}\text { Rattus } \\
\text { norvegicus }\end{array}$ & AK1D1_RAT \\
\hline 1406 & Glyceraldehyde-3-phosphate dehydrogenase & $\begin{array}{l}\text { Rattus } \\
\text { norvegicus }\end{array}$ & G3P_RAT \\
\hline 1412 & 3-alpha-hydroxy steroid dehydrogenase & $\begin{array}{l}\text { Rattus } \\
\text { norvegicus }\end{array}$ & DIDH_RAT \\
\hline 1420,1429 & $\begin{array}{l}\text { Glycerol-3-phosphate dehydrogenase[NAD+], } \\
\text { cytoplasmic }\end{array}$ & $\begin{array}{l}\text { Rattus } \\
\text { norvegicus }\end{array}$ & GPDA_RAT \\
\hline 1422 & L-lactate dehydrogenase A chain & $\begin{array}{l}\text { Rattus } \\
\text { norvegicus }\end{array}$ & LDHA_RAT \\
\hline 1428 & Beta-lactamase-like protein 2 & $\begin{array}{l}\text { Rattus } \\
\text { norvegicus }\end{array}$ & LACB2_RAT \\
\hline
\end{tabular}


Table 1 (continued)

\begin{tabular}{|c|c|c|c|}
\hline Spot number & Protein name & Species & $\begin{array}{l}\text { Swiss-Prot } \\
\text { Acc. } \mathbf{N}^{\circ}\end{array}$ \\
\hline 1433 & Ester hydrolase $\mathrm{C} 11$ orf 54 homolog & $\begin{array}{l}\text { Rattus } \\
\text { norvegicus }\end{array}$ & CK054_RAT \\
\hline 1438 & Sulfotransferase $1 \mathrm{~A} 1$ & $\begin{array}{l}\text { Rattus } \\
\text { norvegicus }\end{array}$ & ST1A1_RAT \\
\hline 1441,1443 & Thiosulfate sulfurtransferase & $\begin{array}{l}\text { Rattus } \\
\text { norvegicus }\end{array}$ & THTR_RAT \\
\hline 1445 & Guanine nucleotide-binding protein subunit beta-2-like1 & $\begin{array}{l}\text { Rattus } \\
\text { norvegicus }\end{array}$ & GBLP_RAT \\
\hline 1447 & Regucalcin & $\begin{array}{l}\text { Rattus } \\
\text { norvegicus }\end{array}$ & RGN_RAT \\
\hline 1449 & D-beta-hydroxybutyrate dehydrogenase, mitochondrial & $\begin{array}{l}\text { Rattus } \\
\text { norvegicus }\end{array}$ & BDH_RAT \\
\hline 1450 & Hydroxyacyl-coenzyme A dehydrogenase, mitochondrial & $\begin{array}{l}\text { Rattus } \\
\text { norvegicus }\end{array}$ & HCDH_RAT \\
\hline 1460 & Nitrilase homolog 1 & $\begin{array}{l}\text { Rattus } \\
\text { norvegicus }\end{array}$ & NIT1_RAT \\
\hline 1463 & Proteasome activator complex subunit1 & $\begin{array}{l}\text { Rattus } \\
\text { norvegicus }\end{array}$ & PSME1_RAT \\
\hline 1471 & Nicotinate-nucleotide pyrophosphorylase [carboxylating] & $\begin{array}{l}\text { Rattus } \\
\text { norvegicus }\end{array}$ & NADC_RAT \\
\hline 1473 & Thiopurine S-methyltransferase & $\begin{array}{l}\text { Rattus } \\
\text { norvegicus }\end{array}$ & TPMT_RAT \\
\hline 1477,1483 & Electron transfer flavoprotein subunit beta & $\begin{array}{l}\text { Rattus } \\
\text { norvegicus }\end{array}$ & ETFB_RAT \\
\hline 1480 & Isoamyl acetate-hydrolyzing esterase 1 homolog & $\begin{array}{l}\text { Rattus } \\
\text { norvegicus }\end{array}$ & IAH1_RAT \\
\hline 1486 & Glutathione S-transferase Mu2 & $\begin{array}{l}\text { Rattus } \\
\text { norvegicus }\end{array}$ & GSTM2_RAT \\
\hline 1488 & Glutathione S-transferase alpha-5 & $\begin{array}{l}\text { Rattus } \\
\text { norvegicus }\end{array}$ & GSTA5_RAT \\
\hline 1489 & Peroxiredoxin-4 & $\begin{array}{l}\text { Rattus } \\
\text { norvegicus }\end{array}$ & PRDX4_RAT \\
\hline 1495 & protein ETHE1, mitochondrial & $\begin{array}{l}\text { Rattus } \\
\text { norvegicus }\end{array}$ & gil157819563 \\
\hline $1496,1509,1510$ & Carbonic anhydrase 3 & $\begin{array}{l}\text { Rattus } \\
\text { norvegicus }\end{array}$ & CAH3_RAT \\
\hline 1504 & Endoplasmic reticulum resident protein 29 & $\begin{array}{l}\text { Rattus } \\
\text { norvegicus }\end{array}$ & ERP29_RAT \\
\hline 1506 & Glutathione S-transferase alpha-1 & $\begin{array}{l}\text { Rattus } \\
\text { norvegicus }\end{array}$ & GSTA1_RAT \\
\hline 1507 & Glutathione S-transferase alpha-2 & $\begin{array}{l}\text { Rattus } \\
\text { norvegicus }\end{array}$ & GSTA2_RAT \\
\hline 1508 & Glutathione S-transferase alpha-3 & $\begin{array}{l}\text { Rattus } \\
\text { norvegicus }\end{array}$ & GSTA3_RAT \\
\hline 1512 & Glutathione S-transferase alpha- 4 & $\begin{array}{l}\text { Rattus } \\
\text { norvegicus }\end{array}$ & GSTA4_RAT \\
\hline 1514 & $\begin{array}{l}\text { NADH dehydrogenase [ubiquinone] flavoprotein } 2 \text {, } \\
\text { mitochondrial }\end{array}$ & $\begin{array}{l}\text { Rattus } \\
\text { norvegicus }\end{array}$ & NDUV2_RAT \\
\hline 1522 & Glutathione S-transferase P & $\begin{array}{l}\text { Rattus } \\
\text { norvegicus }\end{array}$ & GSTP1_RAT \\
\hline 1523 & $\begin{array}{l}\text { biliverdin reductase B (flavinreductase(NADPH)) (pre- } \\
\text { dicted), isoform CRA_c }\end{array}$ & $\begin{array}{l}\text { Rattus } \\
\text { norvegicus }\end{array}$ & gil149056527 \\
\hline 1524 & Peroxiredoxin-1 & $\begin{array}{l}\text { Rattus } \\
\text { norvegicus }\end{array}$ & PRDX1_RAT \\
\hline 1528,1530 & Abhydrolase domain-containing protein $14 \mathrm{~B}$ & $\begin{array}{l}\text { Rattus } \\
\text { norvegicus }\end{array}$ & ABHEB_RAT \\
\hline 1540 & Peptidyl-prolyl cis-trans isomerase F, mitochondrial & $\begin{array}{l}\text { Rattus } \\
\text { norvegicus }\end{array}$ & PPIF_RAT \\
\hline 1543 & Cofilin-1 & $\begin{array}{l}\text { Rattus } \\
\text { norvegicus }\end{array}$ & COF1_RAT \\
\hline
\end{tabular}


Table 1 (continued)

\begin{tabular}{|c|c|c|c|}
\hline Spot number & Protein name & Species & $\begin{array}{l}\text { Swiss-Prot } \\
\text { Acc. } \mathbf{N}^{\circ}\end{array}$ \\
\hline 1544 & Peptidyl-prolyl cis-trans isomerase A & $\begin{array}{l}\text { Rattus } \\
\text { norvegicus }\end{array}$ & PPIA_RAT \\
\hline 1547 & Low molecular weight phosphotyrine protein phosphatase & $\begin{array}{l}\text { Rattus } \\
\text { norvegicus }\end{array}$ & PPAC_RAT \\
\hline 1550 & Ubiquitin-conjugating enzyme E2D2 & $\begin{array}{l}\text { Rattus } \\
\text { norvegicus }\end{array}$ & UB2D2_RAT \\
\hline 1560 & Cytochrome b5 & $\begin{array}{l}\text { Rattus } \\
\text { norvegicus }\end{array}$ & CYB5_RAT \\
\hline 1567-1569 & Hemoglobin subunit alpha-1/2 & $\begin{array}{l}\text { Rattus } \\
\text { norvegicus }\end{array}$ & HBA_RAT \\
\hline 1570,1571 & Fatty acid-binding protein, liver & $\begin{array}{l}\text { Rattus } \\
\text { norvegicus }\end{array}$ & FABPL_RAT \\
\hline 1586 & Enoyl-CoA hydratase, mitochondrial & $\begin{array}{l}\text { Rattus } \\
\text { norvegicus }\end{array}$ & ECHM_RAT \\
\hline
\end{tabular}

missed cleavages allowed, 100 ppm tolerance in PMF, 0.75 Da mass tolerance for precursor ion mass, carbamidomethyl cysteine as fixed modification, oxidation of methionine and oxidation of tryptophan (single oxidation, double oxidation and kynurenin) as variable modifications. Identifications were considered to be significant when the combined MOWSE score had $P<0.05$.

Statistics, including univariate analysis (ANOVA and $t$-test) and multivariate analysis (two way ANOVA), was performed using the Extended Data Analysis (EDA) module, which is present inside the Decyder 7.0 software package.

\section{Appendix A. Supplementary material}

Supplementary data associated with this paper can be found in the online version at http://dx.doi. org/10.1016/j.dib.2016.02.047.

\section{References}

[1] I. Miller, T. Serchi, S. Cambier, C. Diepenbroek, J. Renaut, J.H.J. Van den Berg, C. Kwadijk, A.C. Gutleb, E. Rijntjes, A.J. Murk, Hexa bromocyclododecane (HBCD) induced changes in the liver proteome of eu- and hypothyroid female rats, Toxicol. Lett. 245 (2016) 40-51. http://dx.doi.org/10.1016/j.toxlet.2016.01.002.

[2] B. Haas, T. Serchi, D.R. Wagner, G. Gilson, S. Planchon, J. Renaut, L. Hoffmann, T. Bohn, Y. Devaux, Proteomic analysis of plasma samples from patients with acute myocardial infarction identifies haptoglobin as a potential prognostic biomarker, J. Proteom. 75 (2011) 229-236. http://dx.doi.org/10.1016/j.jprot.2011.06.028.

[3] M. Pasquali, T. Serchi, J. Renaut, L. Hoffmann, T. Bohn, 2D difference gel electrophoresis reference map of a Fusarium graminearum nivalenol producing strain, Electrophoresis 34 (2013) 505-509. http://dx.doi.org/10.1002/elps.201200256.

[4] M.M. Bradford, A rapid and sensitive method for the quantitation of microgram quantities of protein utilizing the principle of protein-dye binding, Anal. Biochem. 72 (1976) 248-254. 



\section{Chapter 5}

\section{Gender specific differences in the liver proteome of rats exposed to hexabromocyclododecane (HBCD)}

Miller, I, Diepenbroek, C, Rijntjes, E, Renaut, J, Teerds, KJ, Kwadijk, C, Cambier, S, Murk, AJ, Gutleb, AC, Serchi, T.

Gender specific differences in the liver proteome of rats exposed to hexabromocyclododecane (HBCD)

Toxicology Research, submitted.

Miller, I, Renaut, J, Cambier, S, Murk, AJ, Gutleb, AC, Serchi, T.

Dataset of liver proteins of eu- and hypothyroid rats affected in abundance by any of three factors: in vivo exposure to hexabromocyclododecane (HBCD), thyroid status, gender differences

Data in Brief, submitted.

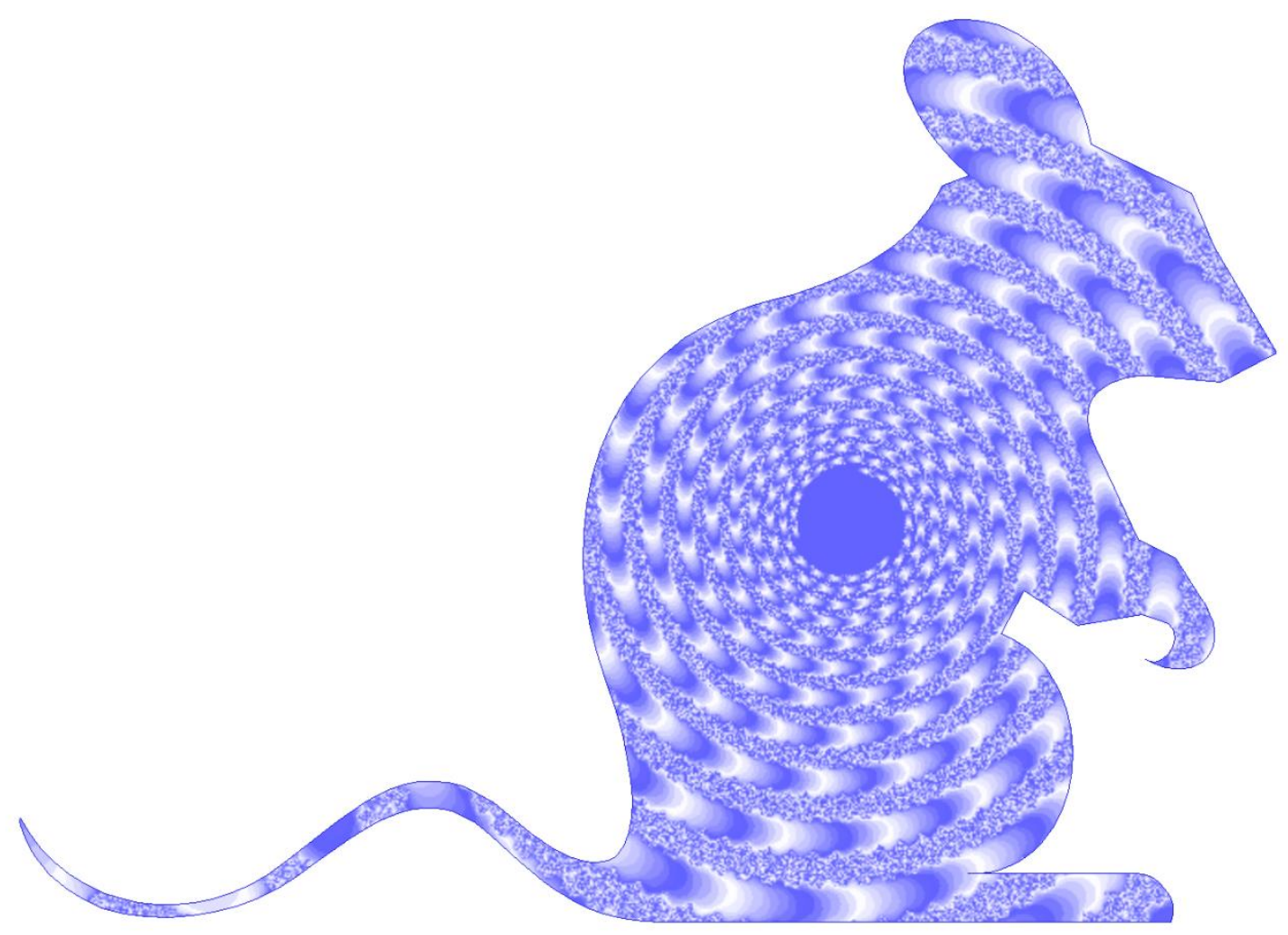





\section{Gender specific differences in the liver proteome of rats exposed to hexabromocyclododecane (HBCD)}

Miller, I. ${ }^{1}$, Diepenbroek, C. ${ }^{2}$, Rijntjes, E. ${ }^{2,3}$, Renaut, J. ${ }^{4}$, Teerds, K.J. ${ }^{2}$, Kwadijk, C. ${ }^{5}$, Cambier, S. ${ }^{4}$, Murk, A.J. ${ }^{6}$, Gutleb, A.C. ${ }^{4} \uparrow$, Serchi, T. ${ }^{4}{ }^{+*} *$

Short title:

Gender specific impact of HBCD on rat liver proteome

${ }^{1}$ Institute for Medical Biochemistry, Department for Biomedical Sciences, University of Veterinary Medicine Vienna, Veterinaerplatz 1, A-1210 Vienna, Austria; e-mail: ingrid.miller@vetmeduni.ac.at

${ }^{2}$ Wageningen University, Human and Animal Physiology, P.O. Box 338, 6700 AH Wageningen, The Netherlands

3 Charité-Universitätsmedizin Berlin, Institute of Experimental Endocrinology, Augustenburger Platz 1, 13353, Berlin, Germany

${ }^{4}$ Environmental Research and Innovation (ERIN) Department, Luxembourg Institute of Science and Technology (LIST), 5, avenue des Hauts-Fourneaux, L-4362 Esch-surAlzette, Grand-duchy of Luxembourg

${ }^{5}$ Wageningen Institute for Marine Resources \& Ecosystem Studies, IMARES, IJmuiden, The Netherlands

${ }^{6}$ Wageningen University, Wageningen University, Marine Animal Ecology Group, De Elst 1, 6708 WD Wageningen, The Netherlands.

$†$ Shared Senior Authorship

* Corresponding author: T. Serchi

Tel: $+352-470261$

e-mail: tommaso.serchi@list.lu 


\begin{abstract}
The influence of short-term (7-day) exposure of male rats to the brominated flame retardant hexabromocyclododecane (HBCD) was studied by investigation of the liver proteome, both in euthyroid and hypothyroid rats and by comparing results with general data on animal physiology and thyroid hormone, leptin, insulin and gonadotropin concentrations determined in parallel. Proteome analysis of liver tissue by twodimensional fluorescence difference gel electrophoresis (2D-DIGE) revealed that only small protein pattern changes were induced by exposure in males, on just a few proteins with different functions and not involved in pathways in common. This is in contrast to previous findings in similarly exposed eu- and hypothyroid female rats, where general metabolic pathways had been shown to be affected. The largest gender-dependent effects concerned basal concentrations of liver proteins already in control and hypothyroid animals, involving mainly the pathways which were also differently affected by HBCD exposure. Among them were differences in lipid metabolism, which - upon exposure to HBCD - may also be the reason for the considerably higher ratio of $\gamma$-HBCD accumulated in white adipose tissue of exposed female rats compared to males. The results further elucidate the already suggested different sensitivity of genders towards HBCD exposure on the protein level, and confirm the need for undertaking toxicological animal experiments in both genders.
\end{abstract}




\section{Abbreviations}

2D-DIGE, two-dimensional fluorescence difference gel electrophoresis

CYP, cytochrome P450

ET, euthyroid

$\mathrm{f}$, female

FSH, follicle-stimulating hormone

GO, Gene ontology

HBCD, hexabromocyclododecane

HT, hypothyroid

KEGG, Kyoto Encyclopedia of Genes and Genomes

LC, liquid chromatography

$\mathrm{m}$, male

MS, mass spectrometry

PMF, peptide mass fingerprint

PON, paraoxonase/arylesterase

RIA, radioimmunoassay

SEM, standard error of the mean

STRING, functional protein association networks

$\mathrm{T}_{3}$, triiodothyronine

$\mathrm{T}_{4}$, thyroxine

$\mathrm{TH}$, thyroid hormone

$\mathrm{TSH}$, thyroid stimulating hormone

Keywords: HBCD, proteomics, rat, liver, hypothyroidism, gender-specific effects 


\section{Introduction}

Since 2013, the brominated flame retardant hexabromocyclododecane (HBCD) is banned in most European countries, but outside Europe still being produced and widely used (e.g. in the US). HBCD mainly serves as an additive in building industry (in polystyrene foams), but is also used for impregnation of equipment. Due to its persistent nature, HBCD is expected to remain present in food chains for several years to come. Like other substances of this chemical class, HBCD is lipophilic and accumulates in adipose tissue, not only in experimental animals but also in humans (Covaci et al., 2006; Darnerud, 2003; De Wit, 2002; Kalachova et al., 2012; Tomko and McDonald, 2013). While animal studies have shown low acute toxicity of HBCD, there are toxicological effects, especially in liver, on the immune system and on serum thyroid hormone (TH) dependent developmental processes as well as indications of endocrine disrupting properties (Canton et al., 2008; Germer et al., 2006; van der Ven et al., 2006; 2009; Miller et al., 2016). Further elucidation of the underlying mechanisms of HBCD action would be needed for a better understanding of its adverse effects, and specific investigations applying modern analytical methods are likely to help in this task.

Previous studies with 28d exposure of rats and variable doses of HBCD (between 0 and $200 \mathrm{mg} / \mathrm{kg}$ bw per day) revealed dose- and gender-dependent effects on body and organ weights as well as on TH levels, suggesting that female rats were more sensitive to exposure than male rats (van der Ven et al., 2006). In a similar experimental setup, transcriptomic data of rat liver and specific investigation of cytochrome P450 family members (CYPs) (Canton et al., 2008; Germer et al., 2006) indicated gender-specific differences concerning affected genes/proteins related to metabolic pathways. Chronic exposure over longer intervals of time is likely to cause also secondary effects, which are likewise detected when screening for overall gene or protein level changes. Therefore, short term exposure may result in a different data set, better revealing primary effects of exposure to HBCD. Similarly, proteomic investigations are preferable to transcriptomic studies, as they show the actual protein concentrations in the organs under investigation (Greenbaum et al., 2003; Tian et al., 2004).

A recent $\mathrm{HBCD}$ short term (7 day) exposure study investigated the changes in the liver proteome of female rats and found a number of proteins differentially regulated in abundance, mainly related to general metabolic processes (Miller et al., 2016). In the present study, this investigation is extended to male rats and the experiment was performed under identical setup and conditions. This included euthyroid and hypothyroid animals as 
well as different HBCD exposure groups. Influences of dose, thyroid status and gender (including data from the previous experiment) on changes of the liver proteome are compared and further related to general animal data and hormone status determined in parallel. In the following, animal groups were named with an additional " $\mathrm{m}$ " and " $\mathrm{f}$ " depending on the gender (male, female) for easier comparison.

\section{Animals, Material and Methods}

\subsection{Animals, treatment and experimental protocol}

The animal experiment was performed as the one described in detail in Miller et al. (2016), except that for the present investigation male euthyroid and hypothyroid rats were used instead of females. Hypothyroidism was induced during foetal life by feeding the dams an iodide-poor diet based on AIN 1993 requirements, supplemented with 0.75\% sodium perchlorate to deplete endogenous iodide stores, as described in detail by Rijntjes et al. (2009). After weaning the offspring continued on the same diet as the dams until the experimental intervention. In brief, 86-day-old male healthy euthyroid controls (mET) or hypothyroid (mHT) rats were fed 0,3 or $30 \mathrm{mg}$ of $\mathrm{HBCD} / \mathrm{kg}$ body weight added to commercial custard pudding for 7 days. Group size was 6 animals (6 groups). At the termination of the experiment, blood was collected by heart puncture (5 IU heparin per $\mathrm{ml}$ blood), and animals were sacrificed by decapitation. Liver and white adipose tissues were collected, snap frozen and stored at $-80{ }^{\circ} \mathrm{C}$, plasma was prepared and stored at $-20^{\circ} \mathrm{C}$. The animal experiment was approved under number 2006-051 by the Animal Welfare Committee of Wageningen University.

\subsection{Hormone measurements}

Concentrations of total and free triiodothyronine $\left(\mathrm{T}_{3}\right)$, corticosterone, leptin, luteinizing hormone $(\mathrm{LH})$, follicle-stimulating hormone $(\mathrm{FSH})$, and thyroid stimulating hormone (TSH) were determined by radioimmunoassays (RIAs), as previously described (Rijntjes et al., 2009; Miller et al., 2016). In addition, RIAs for total thyroxine ( $\mathrm{T}_{4}$ ) (Diagnostic Systems Laboratories, Texas, USA) (DSL-3200), testosterone (DSL-4100), and insulin (Linco Research, St. Charles, USA) were performed according to the manufacturers' protocols. The detection limits of these assays were: $5 \mathrm{ng} / \mathrm{ml}$ for total $\mathrm{T}_{4}, 0.1 \mathrm{ng} / \mathrm{ml}$ for testosterone and $0.5 \mathrm{ng} / \mathrm{ml}$ for insulin. Intra- and interassay variations were determined using several pools of rat sera and were less than $10 \%$. 


\subsection{Determination of internal $H B C D$ dose}

Chemical analyses to determine the internal levels of HBCD were performed at IMARES, The Netherlands. In brief, adipose tissue samples spiked with ${ }^{13} \mathrm{C}$-labeled $\mathrm{HBCD}$ as internal standards. Samples were then extracted and $\alpha$-, $\beta$ - and $\gamma$-diastereomeres were determined by LC-ESI-MS as described by Miller et al. (2016).

\subsection{Statistical Analysis (for hormonal measurements)}

Data is expressed as mean \pm standard error of the mean (SEM). Statistical analysis was carried out using SPSS 19.0 for Windows. Data was tested for normality using the ShapiroWilk test. If normality could not be assumed, data were LOG10 transformed. Group means were compared using a two-way Univariate Analysis of Variance (ANOVA). Correlation between internal $\gamma$-HBCD dose and other parameters was tested with the Spearman's rank correlation test. Values of $P<0.05$ were considered to be significant.

\subsection{Proteomics}

For the proteomic experiments, four liver samples per experimental group (mET and mHT; 0,3 and $30 \mathrm{mg} / \mathrm{kg} /$ day $\mathrm{HBCD}$, respectively) were randomly selected, subjected to twodimensional fluorescence difference gel electrophoresis (2D-DIGE) and further evaluated as previously described (Miller et al., 2016). In brief, rat livers were homogenized in lysis buffer (urea 7M; thiourea 2M; CHAPS $2 \% \mathrm{w} / \mathrm{w}$; tris $30 \mathrm{mM}$, containing protease inhibitor) and proteins in the supernatant after centrifugation minimally labelled with CyDyes. Separation was performed on $24 \mathrm{~cm}$ IPGs of a non-linear 3-10 pH-range followed by SDSPAGE in $12.5 \%$ gels, and images were captured on a Typhoon 9400 (DeCyder 7.0 software package, GE Healthcare, Diegem, Belgium). Gels were matched and subjected to univariate and multivariate analysis in order to determine differentially regulated spots with following criteria: fold change of at least 1.3 and $P$-value $<0.05$. These spots were automatically picked, tryptically digested and underwent MALDI-TOF/TOF analysis. Protein identification was performed by searching spectra against the SwissProt database with Rattus norvegicus as taxonomy, usually one PMF and up to 8 MS/MS spectra per spot. Parameters for the search were set as follow: up to two missed cleavages allowed, 100 ppm tolerance in PMF, 0.75 Da mass tolerance for precursor ion mass, carbamidomethyl cysteine as fixed modification, oxidation of methionine and oxidation of 
tryptophan (single oxidation, double oxidation and kynurenin) as variable modifications. Identifications were considered to be significant when the combined MOWSE score had $P<0.05$.

Statistics, including univariate analysis (ANOVA and t-test) and multivariate analysis (two-way ANOVA), was performed using the Extended Data Analysis (EDA) module, which is present inside the Decyder 7.0 software package.

Additional information on proteins (localization, function) and pathway analysis were retrieved from publicly available databases: UniProtKB database (http://www.uniprot.org/), STRING: functional protein association networks, v 9.1 (http://string-db.org/) (Snel et al., 2000; Franceschini et al., 2013), for Rattus norvegicus proteins or genes, respectively, and for proteins with accession numbers from UniProt.

\section{Results and Discussion}

\subsection{Male rats}

\section{Basic animal data and hormone measurements}

The mHT rats had significantly higher serum TSH and significantly lower free $\mathrm{T}_{3}$, total $\mathrm{T}_{3}$ and total $\mathrm{T}_{4}$ concentrations than mET rats (for all $P<0.001$ ), which is in accordance with earlier work (Rijntjes et al., 2009) (Table 1). HBCD did not induce any significant changes in total $\mathrm{T}_{4}$ and $\mathrm{T}_{3}$ concentrations, only free $\mathrm{T}_{3}$ concentrations showed a mild $\mathrm{HBCD}$ effect in males $(P=0.044)$. The Spearman's correlation for free $T_{3}$ and HBCD, however, was not significant. The already increased corticosterone concentrations of mHT tended to increase further with $\mathrm{HBCD}$ exposure $(P=0.056)$. Serum leptin concentrations were not further influenced by HBCD exposure, but only by thyroid status $(P=0.006)$ (in line with EscobarMorreale et al. (1997)). Insulin secretion capacity is known to be reduced in the offspring of hypothyroid dams, in the current experiment, however, the rats were not fasted prior to sacrifice, so this effect could not be reliably determined (measured insulin concentrations were significantly lower in HT animals, $P<0.001)$. The internal HBCD concentration in the white adipose tissue, however, was negatively correlated to insulin (Rho=-0.613, $\mathrm{p}<0.01$ ) in the hypothyroid rats (Table 1). The HBCD-related alterations of insulin and 


\section{Table 1}

Male rats' hormone data

Animals were exposed to 0,3 , or $30 \mathrm{mg} / \mathrm{kg} \mathrm{bw} / \mathrm{d}$ for 7 days

\begin{tabular}{|c|c|c|c|c|c|c|c|c|}
\hline & HBCD-group & 0 & 3 & 30 & $\begin{array}{c}\text { Thyroid effect } \\
(P \text {-value })\end{array}$ & $\begin{array}{c}\text { HBCD effect } \\
(P \text {-value })\end{array}$ & $\begin{array}{r}\text { Interaction } \\
(P \text {-value })\end{array}$ & $\begin{array}{c}\text { Spearman } \\
\text { 's Rho }\end{array}$ \\
\hline \multirow{2}{*}{ Body weight (g) } & ET & $427 \pm 15$ & $428 \pm 14$ & $430 \pm 12$ & \multirow{2}{*}{$<0.001$} & \multirow{2}{*}{0.828} & \multirow{2}{*}{0.736} & \begin{tabular}{|l|}
-0.045 \\
\end{tabular} \\
\hline & $\mathrm{HT}$ & $165 \pm 9$ & $153 \pm 18$ & $146 \pm 13$ & & & & -0.272 \\
\hline \multirow{2}{*}{ Liver weight (g) } & ET & $16.30 \pm$ & $16.14 \pm$ & $16.44 \pm$ & \multirow{2}{*}{$<0.001$} & \multirow{2}{*}{0.867} & \multirow{2}{*}{0.766} & 0.058 \\
\hline & $\mathrm{HT}$ & $5.49 \pm$ & $5.12 \pm$ & $4.78 \pm$ & & & & -0.295 \\
\hline \multirow{2}{*}{ TSH (ng/ml) } & ET & $0.38 \pm$ & $1.27 \pm$ & $0.49 \pm$ & \multirow{2}{*}{$<0.001$} & \multirow{2}{*}{0.81} & \multirow{2}{*}{0.409} & 0.168 \\
\hline & $\mathrm{HT}$ & $17.01 \pm$ & $14.51 \pm$ & $16.76 \pm$ & & & & -0.012 \\
\hline \multirow{2}{*}{ total T4 $(\mu \mathrm{g} / \mathrm{dl})$} & ET & $4.4 \pm 0.1$ & $3.9 \pm 0.3$ & $4.2 \pm 0.2$ & \multirow{2}{*}{$<0.001$} & \multirow{2}{*}{0.189} & \multirow{2}{*}{0.229} & -0.306 \\
\hline & HT & $<$ lod & $<$ lod & $<$ lod & & & & 0.433 \\
\hline \multirow{2}{*}{ total T3 $(\mathrm{ng} / \mathrm{ml})$} & ET & $230 \pm 20$ & $234 \pm 17$ & $196 \pm 4$ & \multirow{2}{*}{$<0.001$} & \multirow{2}{*}{0.189} & \multirow{2}{*}{0.587} & -0.35 \\
\hline & $\mathrm{HT}$ & $165 \pm 5$ & $177 \pm 10$ & $161 \pm 19$ & & & & -0.148 \\
\hline \multirow{2}{*}{ free T3 (pg/ml) } & ET & $5.95 \pm$ & $6.30 \pm$ & $5.27 \pm$ & \multirow{2}{*}{$<0.001$} & \multirow{2}{*}{0.044} & \multirow{2}{*}{0.326} & -0.341 \\
\hline & $\mathrm{HT}$ & $1.56 \pm$ & $2.39 \pm$ & $1.80 \pm$ & & & & 0.041 \\
\hline \multirow{2}{*}{ LH (ng/ml) } & ET & $0.61 \pm$ & $1.22 \pm$ & $0.88 \pm$ & \multirow{2}{*}{0.002} & \multirow{2}{*}{0.021} & \multirow{2}{*}{0.088} & 0.33 \\
\hline & $\mathrm{HT}$ & $0.54 \pm$ & $0.62 \pm$ & $0.55 \pm$ & & & & 0.018 \\
\hline \multirow{2}{*}{ FSH (ng/ml) } & ET & $3.81 \pm$ & $5.04 \pm$ & $4.00 \pm$ & \multirow{2}{*}{0.065} & \multirow{2}{*}{0.039} & 0.491 & 0.161 \\
\hline & $\mathrm{HT}$ & $3.72 \pm$ & $4.16 \pm$ & $2.91 \pm$ & & & 0.491 & -0.359 \\
\hline & ET & $2.23 \pm$ & $1.09 \pm$ & $1.24 \pm$ & 0645 & 0751 & 0217 & -0.308 \\
\hline lestosterone (ng/mI) & $\mathrm{HT}$ & $0.98 \pm$ & $1.35 \pm$ & $1.64 \pm$ & 0.040 & 0.151 & 0.217 & 0.233 \\
\hline lentin (na/ml) & ET & $8 \pm 1$ & $7 \pm 1$ & $8 \pm 1$ & 0.006 & 0.205 & 0.134 & 0.022 \\
\hline Leptin (ng/mil) & $\mathrm{HT}$ & $13 \pm 2$ & $12 \pm 2$ & $8 \pm 2$ & 0.000 & $0 .<00$ & 0.104 & -0.428 \\
\hline Insulin (na/ml) & ET & $6.02 \pm$ & $5.18 \pm$ & $8.81 \pm$ & $<0001$ & 0174 & 0035 & 0.261 \\
\hline Insuint (ng/min) & $\mathrm{HT}$ & $4.38 \pm$ & $2.26 \pm$ & $2.09 \pm$ & $<0.001$ & 0.174 & 0.035 & $-0.613^{\star \star}$ \\
\hline & ET & $149 \pm 29$ & $103 \pm 25$ & $222 \pm 31$ & 0.027 & & & 0.35 \\
\hline Lorticosterone (ng/mi) & $\mathrm{HT}$ & $183 \pm 19$ & $242 \pm 46$ & $353 \pm 106$ & 0.021 & 0.056 & 0.549 & 0.193 \\
\hline$\gamma-\mathrm{HBCD}(\mathrm{r}$ & ET & $<$ lod & $25.5 \pm 2.1$ & $81.0 \pm$ & 0002 & $<0$ & 0013 & \\
\hline$\gamma-\operatorname{HBCD}$ (ming & $\mathrm{HT}$ & $<$ lod & $40.7 \pm 3.5$ & $130.0 \pm$ & 0.002 & $<0.001$ & 0,013 & \\
\hline
\end{tabular}

$<$ lod, below detection limit

$\mathrm{n}=6$ per group. Mean \pm SEM is given.

Iw, lipid weight

n.a., not analysed 
partly also leptin levels may indicate an influence of HBCD on glucose and lipid metabolism (Hynes and Jones, 2001).

Body weights and liver weights (given in Table 1) were both considerably smaller in mHT animals (similar to Rijntjes et al. (2009)), but did not differ between HBCD treated and non-treated groups of the same thyroid status.

Overall, the observed changes upon exposure to HBCD in mET animals were consistent with earlier reported HBCD effects on TH levels in the 28d study by van der Ven et al. (2006) with ET rats. No studies have been reported with mHT rats.

\section{HBCD adipose tissue concentrations}

The $\alpha$ - and $\beta$-HBCD concentrations in the white adipose tissue were below the lower limit of quantification for all groups. $\gamma-\mathrm{HBCD}$ was detected in HBCD treated rats, and was significantly higher in mHT animals compared with mET animals (by about $60 \%$ ). This cannot be explained by the smaller body weight of the HT animals, as the HBCD dose to which animals were exposed was related to the body weight. Accumulated $\gamma$-HBCD content was about 2 to 3 times higher in both $30 \mathrm{mg} / \mathrm{kg} / \mathrm{day}$ groups compared to the respective $3 \mathrm{mg} / \mathrm{kg} /$ day groups (Table 1). $\gamma$-HBCD was the dominating stereoisomer in adipose tissue, similar to what was observed in a $28 \mathrm{~d}$ study performed in ET animals (van der Ven et al., 2006). Both in vitro as well as in vivo research has shown that $\gamma$-HBCD can interfere with $\mathrm{TH}$-functioning in the presence of $\mathrm{TH}$, but not without (Schriks et al, 2006a;b).

\section{Proteomics:}

Two-dimensional electrophoresis of liver protein gave complex patterns of about 3000 spots per gel (Figure 1) and the evaluation included 24 gels of male rats' samples of different exposure and thyroid state. Only a few spots were of significantly different abundance due to HBCD exposure or thyroid state (Figure 1, Table 2), and were subjected to MS analyses (Suppl. Table 2; Miller et al., submitted).

\section{Influence of $\mathrm{HBCD}$ on liver protein patterns of male rats}

Pairwise comparison of mET animals with different exposure to $\operatorname{HCBD}(0,3,30$ $\mathrm{mg} / \mathrm{kg} /$ day) revealed only two proteins with significant changes between 3 and $30 \mathrm{mg} / \mathrm{kg} / \mathrm{d}$ 


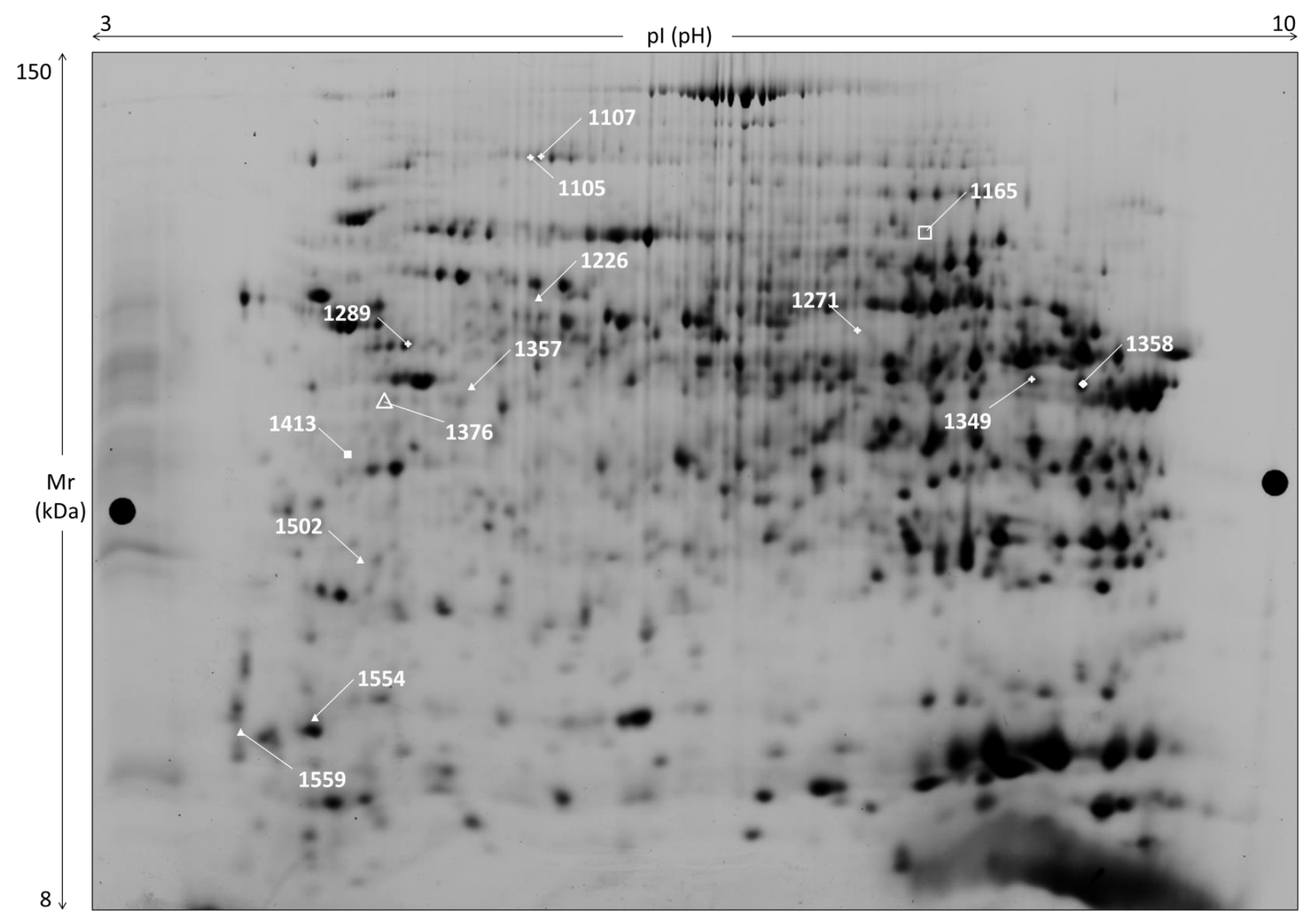

Figure 1: Two-dimensional gel image of a rat liver sample

2D-DIGE separation of rat liver sample (master gel, grey level image). Marked spots show statistically significant changes in abundance upon HBCD exposure:

2 in mET animals (white squares), 6 in mHT rats (white triangles). In addition, 8 spots are of different abundance in ET and HT males (6 white diamonds + spots \#1165, \#1376 with other symbols). Detailed data on identifications is compiled in Suppl. Table 2. 
Table 2

Comparison of HBCD-treated male rats

a) Effect of $\mathrm{HBCD}$ in ET-animals

significant changes

\begin{tabular}{|c|c|c|c|c|c|c|c|c|c|c|c|}
\hline Spot number & Protein Name & UniProt ID & mET3/ & & mET30 & & mET30/ & ET3 & keywords/GO & keywords/GO & keywords/GO \\
\hline & & & Av. Ratio & T-test & \begin{tabular}{l|} 
Av. Ratio \\
\end{tabular} & T-test & \begin{tabular}{l|} 
Av. Ratio \\
\end{tabular} & T-test & biological process & cellular component & molecular function \\
\hline 1165 & rCG56002 & & 0.877 & 0.548 & 1.310 & 0.135 & 1.490 & 0.0189 & & & \\
\hline 1413 & $\begin{array}{l}\text { Small glutamine-rich tetratricopeptide repeat- } \\
\text { containing protein alpha }\end{array}$ & SGTA_RAT & 0.980 & 0.897 & 1.270 & 0.0527 & 1.300 & 0.00644 & $\begin{array}{l}\text { binds directly to HSC70 } \\
\text { and HSP70 and }\end{array}$ & cytoplasm & chaperone \\
\hline
\end{tabular}

b) Effect of HBCD in HT-animals

\begin{tabular}{|c|c|c|c|c|c|c|c|c|c|c|c|}
\hline Spot number & Protein Name & UniProt ID & $\mathrm{mHT} 3 / \mathrm{r}$ & & $\mathrm{mHT30/}$ & & $\mathrm{mHT} 30$ & & keywords/GO & keywords/GO & keywords/GO \\
\hline & & & Av. Ratio & T-test & Av. Ratio & T-test & Av. Ratio & T-test & biological process & cellular component & molecular function \\
\hline 1226 & Formimidoyltransferase-cyclodeaminase & FTCD_RAT & 0.676 & 0.00852 & 0.800 & 0.0378 & 1.180 & 0.0753 & His metabolism & $\begin{array}{l}\begin{array}{l}\text { cytoplasm, cytoskeleton, } \\
\text { Golgi }\end{array} \\
\end{array}$ & $\begin{array}{l}\text { folic acid binding, His } \\
\text { catabolic process }\end{array}$ \\
\hline 1357 & Serum paraoxonase/arylesterase 2 & PON2_RAT & 0.877 & 0.193 & 1.340 & 0.144 & 1.530 & 0.0436 & $\begin{array}{l}\begin{array}{l}\text { aromatic compound } \\
\text { catabolic process }\end{array} \\
\end{array}$ & membrane & arylesterase activity \\
\hline 1376 & Serum paraoxonase/arylesterase 1 & PON1_RAT & 1.050 & 0.619 & 1.660 & 0.0501 & 1.580 & 0.0387 & $\begin{array}{l}\text { multiple } \\
\text { regulation/response }\end{array}$ & secreted, HDL & hydrolase \\
\hline 1502 & Guanidinoacetate N-methyltransferase & GAMT_RAT & 1.340 & 0.292 & 1.380 & 0.0477 & 1.030 & 0.708 & $\begin{array}{l}\text { biosynthetic/metabolic } \\
\text { processes }\end{array}$ & & $\begin{array}{l}\text { methyltransferase, } \\
\text { transferase }\end{array}$ \\
\hline 1554 & Cytochrome b5 & CYB5_RAT & 0.658 & 0.0411 & 0.877 & 0.512 & 1.330 & 0.22 & $\begin{array}{l}\text { electron transport, } \\
\text { transport }\end{array}$ & $\begin{array}{l}\text { ER, membrane, } \\
\text { microsome }\end{array}$ & $\begin{array}{l}\text { metal ion binding } \\
\text { electron carrier activity }\end{array}$ \\
\hline 1559 & Calmodulin & CALM_RAT & \begin{tabular}{l|l}
1.560 \\
\end{tabular} & 0.041 & 1.390 & 0.341 & 0.885 & 0.588 & multitude of regulations & cytoplasm, cytoskeleton & modulation by $\mathrm{Ca}++$ \\
\hline
\end{tabular}

\section{c) Effect of TH status (same HBCD treatment)}

\begin{tabular}{|c|c|c|c|c|c|c|c|c|c|c|c|}
\hline Spot number & Protein Name & UniProt ID & mHTO/ & ETO & $\mathrm{mHT} 3 / \mathrm{I}$ & & mHT30/ & ET30 & keywords/GO & keywords/GO & keywords/GO \\
\hline & & & Av. Ratio & T-test & Av. Ratio & T-test & Av. Ratio & T-test & biological process & cellular component & molecular function \\
\hline 1105 & Aldehyde dehydrogenase family 1 member L1 & AL1L1_RAT & 0.917 & 0.528 & 1.070 & 0.668 & 0.741 & 0.0407 & one-carbon metabolism & cytoplasm & oxidoreductase \\
\hline 1107 & \begin{tabular}{|l} 
Aldehyde dehydrogenase family 1 member $\mathrm{L}$ \\
\end{tabular} & AL1L1 RAT & 0.877 & 0.625 & 1.080 & 0.729 & 0.595 & 0.0245 & one-carbon metabolism & cytoplasm & oxidoreductase \\
\hline 1165 & rCG56002 & & 0.847 & 0.46 & 1.350 & 0.0618 & 0.621 & 0.00384 & & & \\
\hline 1271 & $\begin{array}{l}\text { Succinate-semialdehyde } \\
\text { dehydrogenase_mitochondrial }\end{array}$ & SSDH_RAT & 0.806 & 0.0326 & 0.763 & 0.0404 & 1.200 & 0.416 & $\begin{array}{l}\text { succinate metabolism, } \\
\text { central nervous system }\end{array}$ & mitochondrion & oxidoreductase \\
\hline 1289 & Keratin type I cytoskeletal 18 & K1C18 RAT & 0.909 & 0.438 & 0.438 & 0.952 & 0.735 & 0.05 & & $\begin{array}{l}\text { cytoplasm, intermediate } \\
\text { filament, keratin nucleus }\end{array}$ & $\begin{array}{l}\begin{array}{l}\text { Structural molecule } \\
\text { activity }\end{array} \\
\end{array}$ \\
\hline 1349 & Cystathionine gamma-lyase & CGL_RAT & 0.684 & 0.00202 & 1.070 & 0.82 & 0.820 & 0.655 & $\begin{array}{l}\text { amino acid biosynthesis, } \\
\text { Cys biosynthesis }\end{array}$ & cytoplasm & lyase \\
\hline 1358 & Cystathionine gamma-lyase & CGL RAT & 0.735 & 0.00429 & 1.000 & 0.989 & 0.820 & 0.545 & $\begin{array}{l}\text { amino acid biosynthesis, } \\
\text { Cys biosynthesis }\end{array}$ & cytoplasm & lyase \\
\hline 1395 & Serum paraoxonase/arylesterase 1 & PON1 RAT & 0.980 & 0.952 & 0.769 & 0.0394 & 1.130 & 0.305 & $\begin{array}{l}\text { multiple } \\
\text { regulation/response }\end{array}$ & secreted, HDL & hydrolase \\
\hline
\end{tabular}


exposure (Table $2 \mathrm{a}$ ). In mHT animals 6 proteins were significantly altered, most of them having regulatory or transfer functions (Table $2 \mathrm{~b}$ ). In particular, two of the affected proteins belong to the paraoxonase family (PON1, PON2), a group of enzymes involved in the hydrolysis of organophosphates and lactones. Members of this family differ in cellular localization (PON1 is secreted into circulation, PON2 is present in tissues) and activity, but all act as cellular antioxidants (Li et al., 2003).

In any of these group comparisons, pathway analyses failed to find connections between these few regulated proteins.

\section{Influence of thyroid status on liver proteome}

This evaluation focused on comparison of male rats of different thyroid status but similar HBCD exposure. Six proteins (8 protein spots) showed statistical differences in pairwise comparison (mHT/mET), but in general only within one of the HBCD dose groups (Table 2c). All 6 proteins were involved in metabolic processes and decreased in hypothyroid status. One of them, serum paraoxonase/arylesterase 1 (PON1), was also differentially abundant in hypothyroid animals as a function of HBCD challenge, at least when comparing responses between 3 and $30 \mathrm{mg} / \mathrm{kg} / \mathrm{d}$ dose groups.

In summary, only very limited alterations of the liver proteome of male rats were observed between any of the exposed groups and thyroid status. Although a few significant changes of single proteins are noticed, they do not seem functionally connected, belonging to quite different pathways. The only protein family with more than one regulated member in these group comparisons are the PONs. One of their main functions is to metabolize toxic oxidized lipids in LDL (low-density lipoproteins) and HDL (high-density lipoproteins) particles, which may be created by environmental factors or drugs (Costa et al., 2005). The noticed small impacts on PON abundance in our experiments, in parallel to changes seen in leptin concentrations (Table 1), both dependent on HBCD exposure and/or thyroid status, may be interpreted as a small disturbance of lipid metabolism in the liver of male animals.

\subsection{Comparison of changes in male and female animals}

A previous study from our groups has reported proteomic data as well as hormonal and general animal data in an identical experimental setup with female rats (Miller et al., 2016) 
and performed in parallel. This allows the comparison with the here presented data of males in order to filter for gender specific effects.

General animal and hormone data of animals of both genders are summarized in Suppl. Table 1 and show the expected differences in body weight, liver weight and gonadotropins between males and females. Especially in ET status, male rats accumulate much less HBCD in adipose tissue compared to female animals (gender effect $P=0.001$ ). Van der Ven et al. (2006) also reported a lower accumulation of $\gamma$-HBCD in liver lipid for mET than for fET rat. However, a major difference between the present study and the investigation by van der Ven and colleagues is that most of their animals received much higher doses of HBCD (up to $200 \mathrm{mg} / \mathrm{kg}$ bw/d), and the overall exposure time was 4 times longer compared to the present study. This resulted in changes in liver weights in females, an observation that was not confirmed in our studies, neither for ET nor for HT animals.

\subsubsection{Comparison of $\mathrm{HBCD}$ affected liver proteins of male and female rats}

Protein regulation data of all 12 animal groups (all genders, treatments, thyroid states) were filtered by ANOVA evaluation and resulted in 496 differentially regulated protein spots (Miller et al., submitted). PCA analysis of this spot set showed a clear grouping of values, resulting in three different populations: fET, fHT, and all male animal groups independent of treatment (Figure 2a). mET and mHT group close together, and there is also no major dispersion in the fET and fHT groups induced by HBCD exposure. Similarly, a heat map and hierarchical clustering based on single spot abundance changes sorted animal groups according to gender and clearly differentiated between thyroid states in females (Miller et al., submitted).

The loading plot of the 496 regulated spots visualizes similarity of single spot abundance between PCA1 and PCA2, and most spots group in a compact cluster (Figure 2b). The distance of the spots from the centre of the cluster reflects their similarity in regulation behaviour. Some spots/proteins at the border area of the cluster are the ones that had already been found regulated in female rats depending on thyroid status (e.g. glutathioneS-transferases, Miller et al., 2016), but also some typical serum proteins with known functions as protease inhibitors or reactants in inflammation, being known for their concentration differences between genders (Miller et al., 1999). The spots farthest from the centre are those with most different behaviour between PC1 and PC2, i.e. three spots in the lower right, belonging to the protein carbonic anhydrase 3. Carbonic anhydrase 3 is known 
Experimental Groups (Score Plot)

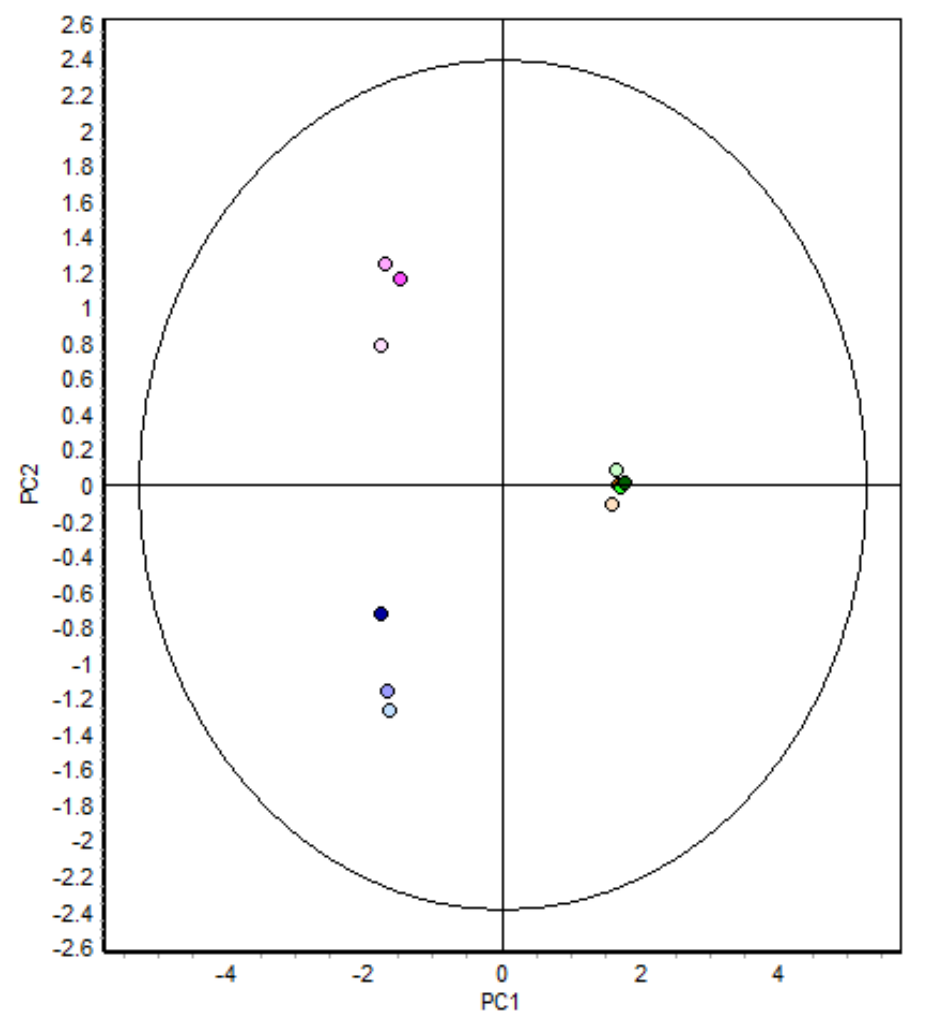

Proteins (Loading Plot)

Female ET 0 Female ET 3 Female ET 30 Female HT - Female HT 30 Pemale HT Male ET

Male ET 3

Male ET 30

Male HT

Male HT 30

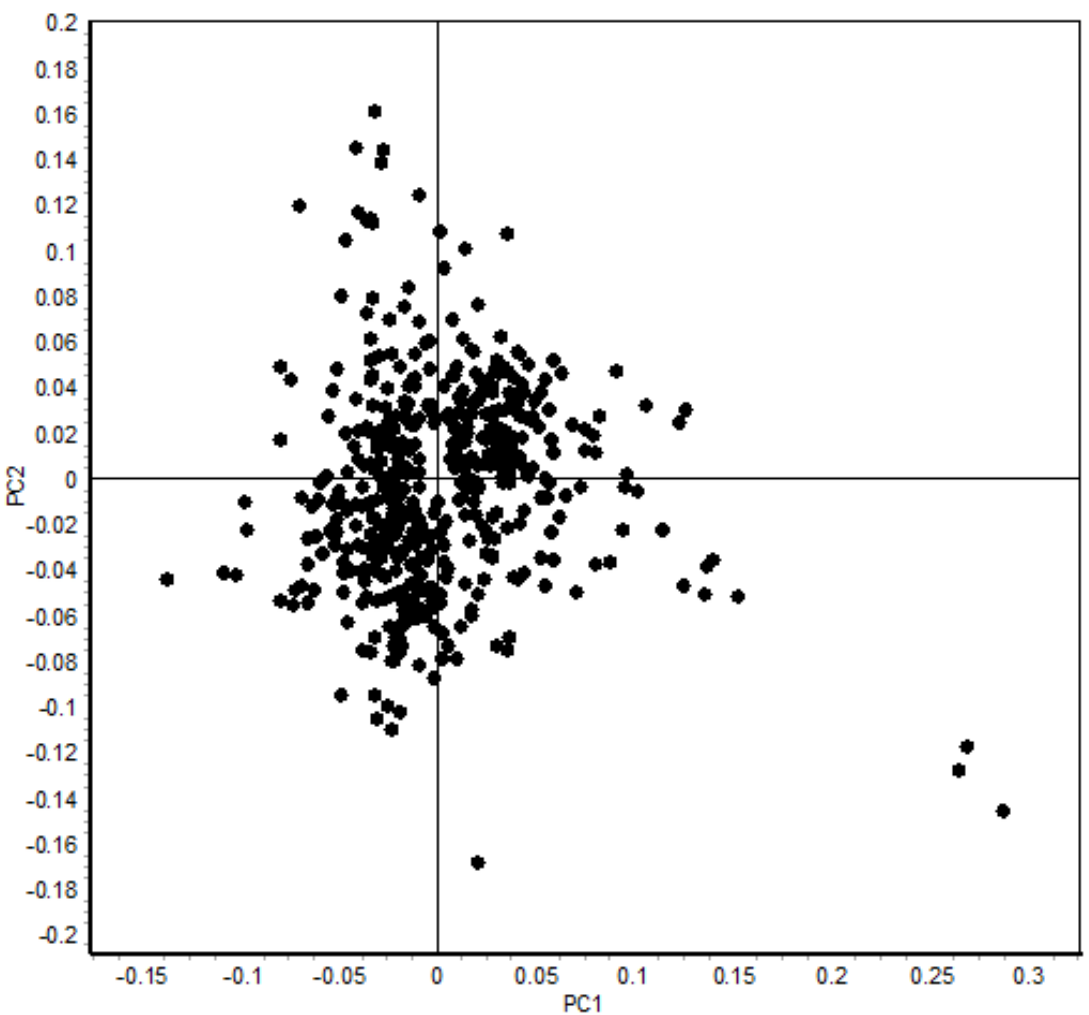

Figure 2: PCA of proteomic data

PCA of the 496 differentially regulated protein spots (from ANOVA):

A) comparison of experimental groups (scope plot), B) comparison of all selected proteins (loading plot). 
as a growth hormone-dependent liver enzyme, its concentration is gender-dependent, and changed in diabetes/obesity (Shiels et al., 1983; Lynch et al., 1993; Nishita et al., 1995). It is one of the proteins already noticed in a previous paper as consistently increased in fHT liver (Miller et al., 2016). Frémont et al. (1987) have reported previously the presence of a connection between thyroid status and carbonic anhydrase 3 concentration in skeletal muscle. Gender-dependent abundance differences noticed in this study are even higher, more than 10-fold in mET and more than 5-fold in mHT rats with comparable HBCD exposure, and all highly significant.

Gender-influence in response towards HBCD exposure has been shown on the transcriptomic level, in a study with a much longer exposure time and different doses (most of them much higher than ours), in ET rats (Canton et al., 2008). In the study by Canton in females genes related to lipid metabolism, triacylglycerol and cholesterol metabolism were markedly down-regulated. In contrast, genes involved in phase I and II metabolism were found upregulated, especially in males, which, for the authors, represented the reason of the lower susceptibility to HBCD of males as compared to females. The described changes were more obvious at higher HBCD doses, and at doses similar to our study, the overall differences between genders and between exposed and unexposed were rather limited. In our study, investigating the proteome, and after the one week exposure, we detected only minor changes in male rats, limited to very few singular proteins. Compared to previous reports, this is a much shorter exposure time, and a time delay between gene regulation and protein synthesis has to be expected. Still, in an identical experiment with females rats (Miller et al., 2016) changes in lipid and carbohydrate metabolism were clearly visible, which is in accordance with the transcriptomics results reported by Canton et al. (2008). The only other proteomic study that involved HBCD (administered in a mixture with other flame retardants) and determined its impact on the liver proteome was performed in zebrafish (Kling et al., 2008). Though different to the present study in many main parameters (species, mixed compound, exposure time), it also reported gender-specific effects.

\subsubsection{Comparison of liver proteins of unexposed male and female rats}

Gender specific differences in response towards HBCD administration led us to take a closer look at the liver proteome of control rats of both genders and check for gender differences in the 2D-DIGE pattern, by comparing previous data on female animals (Miller 
et al., 2016) with the here presented data for male rats. Unexposed animal groups displayed 109 spots (belonging 76 proteins) with statistically significant differential abundance between genders for ET, and 201 spots (belonging 109 proteins) for HT. Changes included an almost similar number of increased and decreased proteins (Figure 3).

Figure 3:

Significant changes between male and female rats (controls)

changed spots

higher in females higher in males changed proteins euthyroid hypothyroid

109201

$53 \quad 117$

$56 \quad 84$

$76 \quad 109$

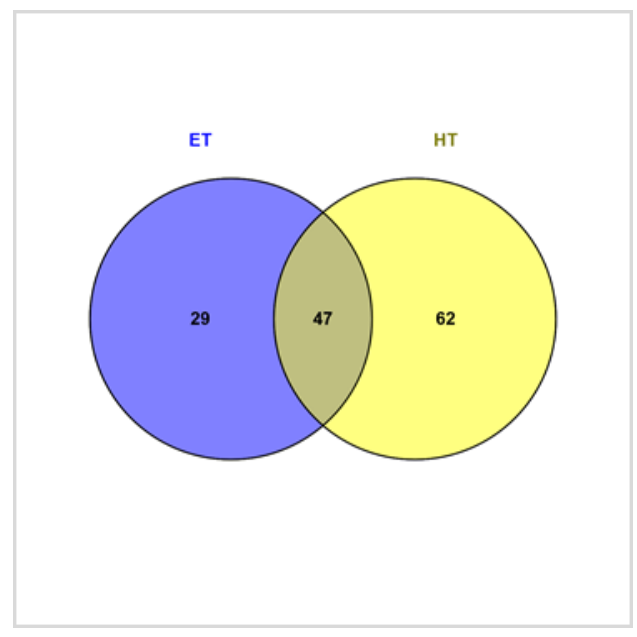

Venn diagram illustrates protein numbers

Grouping of these spots and network analysis put the vast majority of these proteins in connection with metabolic processes (Suppl. Table 3). For ET animals, there were strong clusters of differentially regulated proteins between genders related to cytochrome P450 (drug metabolism, metabolism of xenobiotics) and glutathione metabolism. Many more members of these protein families were represented in ET animals than in HT animals. In HT animals quite a number of proteins from the fatty acid metabolism were differentially regulated between male and female rats (Suppl. Table 3, Figure 4). Comparison of figures $4 \mathrm{a}$ and $4 \mathrm{~b}$ (as well as Suppl. Fig. 1) shows gender differences in the number of interacting proteins, influenced by thyroid status.

Several gender-specific differences in lipid metabolism have been reported earlier, e.g. in rats fed a high fat diet different strategies to maintain energetic and metabolic homeostasis in response to feeding have been elicited (Amengual-Cladera et al., 2012; Nadal-Casellas et al., 2010), in the liver proteome (Wang et al., 2012), as well as in plasma proteins (Liu et al., 2012) and in a rat model of alcoholic steatohepatitis (Banerjee et al., 2008). These reports on gender-dependency in lipid metabolism confirm our proteomic results. We noticed small changes in the leptin levels, which were significant in gender*thyroid status 

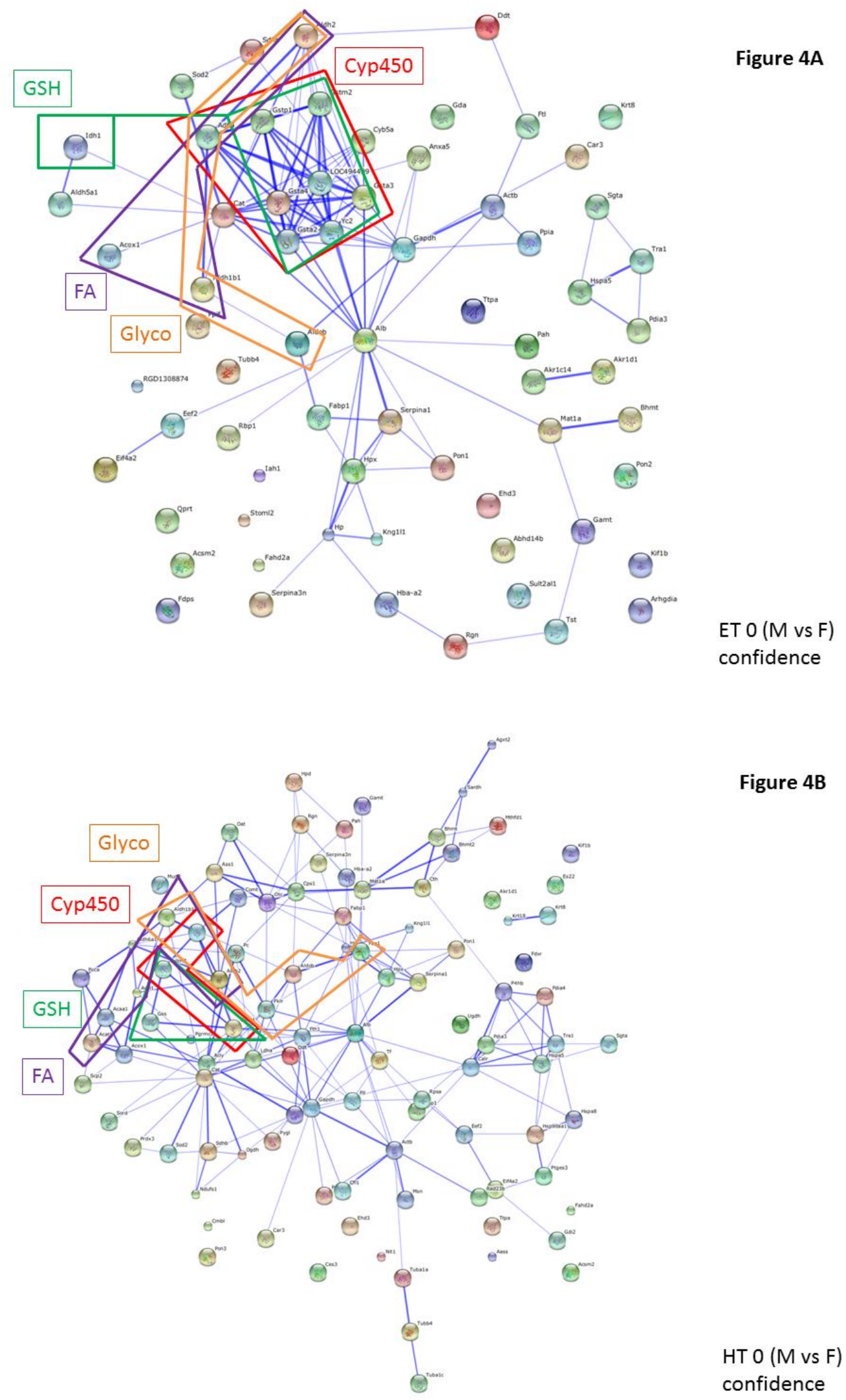

Figure 4B

Pathway analysis (STRING): Networks created from proteins differentially regulated in male and female rats (controls) in ET animals (A) or HT rats (B). Members from pathways related to Glycolysis / Gluconeogenesis (Glyco), Fatty acid metabolism (FA), Drug metabolism or Metabolism of xenobiotics by cytochrome P450 (Cyp450), Glutathione metabolism (GSH) are boxed. Further details on pathways and gene/protein names are compiled in Suppl. Table 3. 
interaction, but not in gender effect alone (MANOVA 0.167). Still, gender-related differences in lipid metabolism may also be the reason for the gender differences in HBCD accumulation in adipose tissue in our rats (Suppl. Table 1). Studies on liver mitochondrial oxidative metabolism showed gender dimorphism as well (Borras et al., 2003, Ståhlberg et al., 2004; Justo et al., 2005), namely a different profile of Cyp450 isoforms in microsomes (Nisar et al., 2004; Germer et al., 2006; Huang et al., 2011). In our study we could not detect any differentially regulated Cyp450 proteins, probably due to the choice of analysing complete, unfractionated liver lysates, however pathway analysis (Figure 4, Suppl. Table 3) clearly filtered out gender-specific differences in proteins connected to metabolism of xenobiotics/drug metabolism, specifically members of the GST family. Interestingly, the observed gender-specifically regulated pathways are also the ones affected by HBCD exposure in a gender specific way in the present (and previous) study. Also other reports have shown differences in gender-susceptibility (in rat serum proteins in health and inflammation (Miller et al., 1999; Ballerio et al., 2007), in mouse proteins in muscle (Dimova et al., 2011) or in the aging kidney (Amelina and Cristobal, 2009)). This approach is in line with a recent NIH directive/recommendation for gender-balance in further biomedical research studies (Clayton and Collins, 2014; Clayton, 2016).

\section{Conclusions}

In male rats exposed to levels up to $30 \mathrm{mg} / \mathrm{kg} \mathrm{HBCD}$ during 7 days, only limited changes in liver protein content and plasma hormone concentrations could be observed. This is in clear contrast to previous findings in female rats (Miller et al., 2016) using the same model. Based on pathway analysis involving the whole set of proteins separated and identified by this proteomic study, we could attribute these differences to alterations in metabolism in male and female rats, both under ET and HT conditions, mainly in lipid metabolism and glycolysis/gluconeogenesis, but also in redox and CYP protein related responses. This supports the need to include both genders in animal experiments.

Proteomics proved its usefulness in toxicological investigations, detecting i) first signs of dysregulation on the protein level after only one week of HBCD exposure, ii) protein pattern differences in female rats based on thyroid status and - as a main influence - iii) gender-dependent protein regulation of metabolic pathways, which have a major impact on the body's reactivity towards noxious substances. 


\section{Funding information}

This work was supported by contributions from the participating institutions. The authors do not declare any conflict of interest.

\section{Acknowledgements}

We would like to thank Hans van den Berg and Hans Swarts for their help with the animal experiments.

\section{References}

Amelina, H., and Cristobal, S. (2009). Proteomic study on gender differences in aging kidney of mice. Proteome Sci., 7, 16. doi:10.1186/1477-5956-7-16.

Amengual-Cladera, E., Lladó, I., Gianotti, M., and Proenza, A. M. (2012). Sex differences in the effect of high-fat diet feeding on rat white adipose tissue mitochondrial function and insulin sensitivity. Metab. Clin. Experim. 61, 1108-1117.

Ballerio, R., Gianazza, E., Mussoni, L., Miller, I., Gelosa, P., Guerrini, U., Eberini, I., Gemeiner, M., Belcredito, S., Tremoli, E., and Sironi, L. (2007). Gender differences in endothelial function and inflammatory markers along the occurrence of pathological events in stroke-prone rats. Exp. Molec. Pathol. 82, 33-41.

Banerjee, A., Russell, W. K., Jayaraman, A., and Ramaiah, S. K. (2008). Identification of proteins to predict the molecular basis for the observed gender susceptibility in a rat model of alcoholic steatohepatitis by 2-D gel proteomics. Proteomics. 8, 43274337.

Borras, C., Sastre, J., Garcia-Sala, D., Lloret, A., Pallardo, F. V., and Vina, J. (2003). Mitochondria from females exhibit higher antioxidant gene expression and lower oxidative damage than males. Free Radical Biol. Med. 34, 546-552.

Canton, R. F., Peijnenburg, A. A., Hoogenboom, R. L., Piersma, A. H., van der Ven, L. T., van den Berg, M., and Heneweer, M. (2008). Subacute effects of hexabromocyclododecane (HBCD) on hepatic gene expression profiles in rats. Toxicol. Appl. Pharmacol. 231, 267-272.

Clayton, J. A. (2016). Studying both sexes: a guiding principle for biomedicine. FASEB J. 30, article fj.15-279554. Published online October 29, 2015; no pages yet.

Clayton, J. A., and Collins, F. S. (2014). NIH to balance sex in cell and animal studies. Nature 509, 282-283.

Costa, L. G., Vitalone, A., Cole, T. B., and Furlong, C. E. (2005). Modulation of paraoxonase (PON1) activity. Biochem. Pharmacol. 69, 541-550.

Covaci, A., Gerecke, A. C., Law, R. J., Voorspoels, S., Kohler, M., Heeb, N. V., Leslie, H., Allchin, C. R., and De Boer, J. (2006). Hexabromocyclododecanes (HBCDs) in the environment and humans: A review. Environ. Sci. Technol. 40, 3679-3688.

Darnerud, P. O. (2003). Toxic effects of brominated flame retardants in man and in wildlife. Environ. Int. 29, 841-853. 
De Wit, C. A. (2002). An overview of brominated flame retardants in the environment. Chemosphere 46, 583-624.

Dimova, K., Metskas, L. A., Kulp, M., and Scordilis, S. P. (2011). Skeletal muscle gender dimorphism from proteomics. J. Vis. Exp. 58, e3536, doi: 10.3791/3536.

Escobar-Morreale, H. F., Escobar del Rey, F., and Morreale de Escobar, G. (1997). Thyroid hormones influence serum leptin concentrations in the rat. Endocrinology 138, 4485-4488.

Franceschini, A., Szklarczyk, D., Frankild, S., Kuhn, M., Simonovic, M., Roth, A., Lin, J., Minguez, P., Bork, P., von Mering, C., and Jensen, L. J. (2013). STRING v9.1: protein-protein interaction networks, with increased coverage and integration. Nucleic Acids Res. 41, D808-D815.

Frémont, P., Lazure, C., Tremblay, R. R., Chrétien, M., and Rogers, P. A. (1987). Regulation of carbonic anhydrase III by thyroid hormone: opposite modulation in slow- and fast-twitch skeletal muscle. Biochem. Cell. Biol. 65, 790-797.

Germer, S., Piersma, A. H., van der Ven, L., Kamyschnikow, A., Fery, Y., Schmitz, H.-J., and Schrenk, D. (2006). Subacute effects of the brominated flame retardants hexabromocyclododecane and tetrabromobisphenol A on hepatic cytochrome P450 levels in rats. Toxicology 218, 229-236.

Greenbaum, D., Colangelo, C., Williams, K., and Gerstein, M. (2003). Comparing protein abundance and mRNA expression levels on a genomic scale. BMC Genome Biol. 4, 117; doi: 10.1186/gb-2003-4-9-117.

Huang, H. J., Tsai, M. L., Chen, Y. W., and Chen, S. H. (2011). Quantitative shot-gun proteomics and MS-based activity assay for revealing gender differences in enzyme contents for rat liver microsome. J. Prot. 74, 2734-2744.

Hynes, G. R, and Jones, P. J. (2001). Leptin and its role in lipid metabolism. Curr. Opin. Lipidol. 12, 321-327.

Justo, R., Boada, J., Frontera, M., Oliver, J., Bermudez, J., and Gianotti, M. (2005). Gender dimorphism in rat liver mitochondrial oxidative metabolism and biogenesis. Am. J. Physiol. Cell Physiol. 289, C372-C378.

Kalachova, K., Hradkova, P., Lankova, D., Hajslova, J., and Pulkrabova, J. (2012). Occurrence of brominated flame retardants in household and car dust from the Czech Republic. Sci. Total Environ. 441, 182-193.

Kling, P., Norman, A., Andersson, P. L., Norrgren, L., and Förlin, L. (2008). Genderspecific proteomic responses in zebrafish liver following exposure to a selected mixture of brominated flame retardants. Ecotoxicol. Environ. Saf. 71, 319-327.

Li, H. L., Liu, D. P., and Liang, C. C. (2003). Paraoxonase gene polymorphisms, oxidative stress, and diseases. J. Mol. Med. (Berl.) 81, 766-779

Liu, H., Choi, J.-W., and Yun, J. W. (2012). Gender differences in rat plasma proteome in response to high-fat diet. Proteomics 12, 269-283.

Lynch, C. J., Brennan, W. A. Jr., Vary, T. C., Carter, N., and Dodgson, S. J. (1993). Carbonic anhydrase III in obese Zucker rats. Am. J. Physiol. 264, E621-E630.

Miller, I., Haynes, P., Eberini, I., Gemeiner, M., Aebersold, E., and Gianazza, E. (1999). Proteins of Rat Serum: III. Gender-related differences in protein concentration under baseline conditions and upon experimental inflammation as evaluated by two-dimensional electrophoresis. Electrophoresis 20, 836-845.

Miller, I., Serchi, T., Cambier, S., Diepenbroek, C., Renaut, J., Van den Berg, J. H. J., Kwadijk, C., Gutleb, A. C., Rijntjes, E., and Murk, A. J. (2016). Hexabromocyclododecane (HBCD) induced changes in the liver proteome of euand hypothyroid female rats, Toxicol. Lett. 245, 40-51. 
Miller, I., Renaut, J., Cambier, S., Murk, A.J., Gutleb, A. C., Serchi, T. Dataset of liver proteins of eu- and hypothyroid rats affected in abundance by any of three factors: in vivo exposure to hexabromocyclododecane (HBCD), thyroid status, gender differences, Data-in-brief, submitted in parallel.

Nadal-Casellas, A., Amengual-Cladera, A., Proenza, A. M., Lladó, I., and Gianotti, M. (2010). Long-term High-fat-diet Feeding Impairs Mitochondrial Biogenesis in Liver of Male and Female Rats. Cell Physiol. Biochem. 26, 291-302.

Nisar, S., Lane, C.S., Wilderspin, A. F., Welham, K. J., Griffiths, W. J., and Patterson, L. H. (2004). A proteomic approach to the identification of cytochrome P450 isoforms in male and female rat liver by nanoscale liquid chromatography-electrospray ionization-tandem mass spectrometry. Drug Metab. Disp. 32, 382-386.

Nishita. T., Igarashi, S., and Asari, M. (1995) Determination of carbonic anhydrase-III by enzyme-immunoassay in liver, muscle and serum of male rats with streptozotocininduced diabetes mellitus. Int. J. Biochem. Cell Biol. 27, 359-364.

Rijntjes, E., Swarts, H. J. M., Anand-Ivell, R., and Teerds, K. J. (2009). Prenatal induced chronic dietary hypothyroidism delays but does not block adult-type Leydig cell development. Amer. J. Physiol. Endocrinol. Metab. 296, E305-E314.

Schriks, M., Vrabie, C. M., Gutleb, A. C., Faassen, E., Rietjens, I. M. C. M., and Murk, A. J. (2006a). T-screen to quantify potentiating, antagonistic and thyroid hormone-like activities of polyhalogenated aromatic hydrocarbons (PHAHs). Toxicol. In Vitro 20, 490-498.

Schriks, M., Zvinavashe, E., Furlow, J. D., and Murk, A. J. (2006b). Disruption of thyroid hormone-mediated Xenopus laevis tadpole tail tip regression by hexabromocyclododecane (HBCD) and 2,2',3,3',4,4',5,5',6-nona brominated diphenyl ether (BDE206). Chemosphere 65, 1904-1908.

Shiels, A., Jeffery, S., Phillips, I. R., Shephard, E. A., Wilson, C. A., and Carter, N. D. (1983). Sexual differentiation of rat liver carbonic anhydrase III. Biochim. Biophys. Acta 760, 335-342.

Snel, B., Lehmann, G., Bork, P., and Huynen, M. A. (2000). STRING: a web-server to retrieve and display the repeatedly occurring neighbourhood of a gene. Nucleic Acids Res. 28, 3442-4.

Ståhlberg, N., Rico-Bautista, E., Fisher, R. M., Wu, X., Cheung, L., Flores-Morales, A., Tybring, G., Norstedt, G., and Tollet-Egnell, P. (2004). Female-Predominant Expression of Fatty Acid Translocase/CD36 in Rat and Human Liver. Endocrinology. 145, 1972-1979.

Tian, Q., Stepaniants, S.B., Mao, M., Weng, L., Feetham, M. C., Doyle, M. J., Yi, E. C., Dai, H., Thorsson, V., Eng, J., Goodlett, D., Berger, J. P., Gunter, B., Linseley, P.S., Stoughton, R. B., Aebersold, R., Collins, S. J., Hanlon, W.A., and Hood, L. E. (2004). Integrated Genomic and Proteomic Analyses of Gene Expression in Mammalian Cells. Mol. Cell. Proteomics 3, 960-969.

Tomko, G., and McDonald, K.M. (2013). Environmental fate of hexabromocyclododecane from a new Canadian electronic recycling facility. J. Environ. Manage. 114, 324327.

van der Ven, L. T. M., Leonards, P. E. G., Slob, W., Lilienthal, H., Litens, S., Herlin, M., Håkansson, H., Cantón, R. F., van den Berg, M., Visser, T. J., van Loveren, H., Vos, J. G., and Piersma, A. H. (2006). A 28-day oral dose toxicity study enhanced to detect endocrine effects of hexabromocyclododecane in Wistar rats. Toxicol. Sci. 94, 281-292.

van der Ven, L. T. M., van de Kuil, T., Leonards, P. E. G., Slob, W., Lilienthal, H., Litens, S., Herlin, M., Håkansson, H., Cantón, R. F., van den Berg, M., Visser, T. J., van 
Loveren, H., Vos, J. G., and Piersma, A. H. (2009). Endocrine effects of of hexabromocyclododecane (HBCD) in a one-generation reproduction study in Wistar rats. Toxicol. Lett. 185, 51-62.

Wang, X., Choi, J. W., Oh, T. S., Choi, D. K., Mukherjee, R., Liu, H., and Yun, J. W. (2012) Comparative hepatic proteome analysis between lean and obese rats fed a high-fat diet reveals the existence of gender differences. Proteomics 12, 284-299.

\section{Supplementary Data}

\section{Suppl. Table 1:}

Complete set of animal data (females and males).

\section{Suppl. Table 2:}

MALDI TOF/TOF data of identified protein spots regulated in concentration in male rats. Numbering as in Figure 1. For regulation data see Table 2, complete peptide list is to be found in (Miller et al., submitted). Abbreviations: Protein Id (protein identification, from UniProt or NCBI database), Cov. \% (sequence coverage).

\section{Suppl. Table 3:}

Proteins with significant abundance changes between male and female rats (controls) were classified according to STRING (KEGG), in ET and HT status. Members of different pathways found in the present study are detailed.

\section{Suppl. Figure 1: Pathway analysis (STRING)}

Identical to Figure 4 (for print version, colour). 


\title{
Data article
}

Title: Dataset of liver proteins of eu- and hypothyroid rats affected in abundance by any of three factors: in vivo exposure to hexabromocyclododecane (HBCD), thyroid status, gender differences Authors: Miller, I. ${ }^{1}$, , Renaut, J. ${ }^{2}$, Cambier, S. ${ }^{2}$, Murk, A.J. ${ }^{3}$, Gutleb, A.C. ${ }^{2} \dagger$, Serchi, T. $^{2} \dagger$

\begin{abstract}
Affiliations:
${ }^{1}$ Institute for Medical Biochemistry, Department for Biomedical Sciences, University of Veterinary Medicine Vienna, Veterinaerplatz 1, A-1210 Vienna, Austria; e-mail: ingrid.miller@vetmeduni.ac.at

${ }^{2}$ Environmental Research and Innovation (ERIN) Department, Luxembourg Institute of Science and Technology (LIST), 5, avenue des Hauts-Fourneaux, L-4362 Esch-sur-Alzette, Grand-duchy of Luxembourg

${ }^{3}$ Wageningen University, Marine Animal Ecology Group, De Elst 1, 6708 WD Wageningen, The Netherlands.
\end{abstract}

+ Shared Senior Authorship

* Contact email: ingrid.miller@vetmeduni.ac.at

\begin{abstract}
Effects of exposure of male Wistar rats with different thyroid status (eu-, hypothyroid) to 0, 3 or $30 \mathrm{mg} / \mathrm{kg}$ body weight of the flame retardant HBCD for 7 days were studied in comparison with a previous study in females [1]. Proteomic investigation of liver protein patterns obtained by 2D-DIGE was performed and differences between animals groups recorded, based on the factors exposure, thyroid status and gender. All proteins with significantly changed abundance in any of these comparisons were identified by mass spectrometry. General, hormone and proteomic data of both the present and the previous studies are discussed in "Hexabromocyclododecane (HBCD) induced changes in the liver proteome of eu- and hypothyroid female rats" [1] and in "Gender specific differences in the liver proteome of rats exposed to hexabromocyclododecane (HBCD)" [2].
\end{abstract}


Specifications Table

\begin{tabular}{|l|l|}
\hline Subject area & Biology \\
\hline $\begin{array}{l}\text { More specific subject } \\
\text { area }\end{array}$ & Environmental Toxicology \\
\hline Type of data & Tables, figure (PCA), image (annotated gel image) \\
\hline How data was acquired & $\begin{array}{l}\text { 2D Fluorescence Difference Gel Electrophoresis (2D-DIGE) and mass } \\
\text { spectrometry }\end{array}$ \\
\hline Data format & Analyzed and filtered data \\
\hline Experimental factors & $\begin{array}{l}\text { Liver lysates of eu- and hypothyroid male and female rats exposed to } \\
\text { different concentrations of HBCD }\end{array}$ \\
\hline Experimental features & $\begin{array}{l}\text { Comparative proteomic analysis of rat liver lysates using 2D-DIGE. } \\
\text { Proteins present in differentially abundant protein spots (regarding } \\
\text { HBCD exposure, amount, thyroid status, and gender) were identified } \\
\text { using MALDI TOF/TOF analysis. }\end{array}$ \\
\hline Data source location & $\begin{array}{l}\text { Origin of samples: Wageningen University, Wageningen, The } \\
\text { Netherlands } \\
\text { Data collection: Luxembourg Institute of Science and Technology, Esch- } \\
\text { sur-Alzette, Luxembourg }\end{array}$ \\
\hline Data is with this article as Supplementary Material \\
\hline
\end{tabular}

Value of the data

- Identification of liver proteins from male rats altered due to HBCD exposure

- Identification of liver proteins from male rats changed in hypothyroid status

- Comparison of male and female rats exposed in a similar exposure experiment, but showing different response in the liver proteome

- Identified liver proteins form the basis for a more detailed understanding of involved mechanisms for the investigated compound, of differences in gender susceptibility and of gender dimorphic liver protein composition.

\section{Data}

Rat liver protein lysates show a complex spot pattern in high-resolution two-dimensional electrophoresis (about 3000 spots per gel). Patterns of 24 gels from different exposures of eu- and hypothyroid male rats were evaluated quantitatively. The same number of gels from an identical experiment with female rats from a previously described study [1,3] was re-evaluated together with the newly obtained males' data, and additional MS identifications of regulated spots in females vs. males were performed. Data from different animals groups in both genders were compared, taking different aspects into account (HBCD exposure, thyroid status, gender). Statistically significant fold-changes of at least $30 \%$ between groups ( $P<0.05$ within group) were considered to be relevant. 
Suppl. Figure 1 presents the master gel of the combined gel set, and all spots with significant abundance changes in any of the performed comparisons are labelled. Overall, single proteins in 496 spots, selected by ANOVA evaluation, were successfully identified by MS analyses. Their spot numbers together with relevant peptide identifications are listed in Suppl. Table 1. Abundance changes of the various animal groups are compiled in Suppl. Table 2. Hierarchical clustering gave a clear grouping of regulated spots according to gender, and in females also according to thyroid state (Suppl. Figure 2). This is in line with PCA results (score plot of experimental groups) reported in [2]. The loading plot of this PCA is shown in more detail in Figure 1, with additional identification of single proteins in the border area or close to the main cluster.

\section{Experimental Design, Materials and Methods}

\section{Animals, treatment and experimental protocol}

The animal experiment was detailed in [1, 2] and approved under number 2006-051 by the Animal Welfare Committee of Wageningen University. In brief, male Wistar WU (HsdCpbWU) rats with normal or reduced thyroid function (hypothyroid) were orally exposed to 0,3 or $30 \mathrm{mg} / \mathrm{kg} \mathrm{bw} \mathrm{/} \mathrm{d}$ $\mathrm{HBCD}$, respectively, for 7 consecutive days. Four liver samples per group were analyzed by proteomic methods. The experimental setup was identical to the one used in [1], but applying it on male rats.

\section{Proteomic Analysis}

Rat liver lysates were subjected to two-dimensional fluorescence difference gel electrophoresis (2DDIGE) as previously described, without modifications, to make it compatible to the previously performed study in females [1-3]. This comprised a classical 2D-DIGE experiment, by separating CyDye-labeled proteins from liver lysates in a non-linear 3-10 pH-range and subsequently in largeformat SDS-PAGE gels (260 × $200 \times 1 \mathrm{~mm}$ ). Gel images (acquired on a Typhoon 9400) were evaluated with the DeCyder 7.0 software package (both GE Healthcare, Diegem, Belgium), including all gels of the previous study on females in matching and statistics [1,3]. Univariate and multivariate analyses were applied to highlight differentially regulated spots (fold change at least 1.3 ) with a $P$ value in the respective univariate ANOVA or two way ANOVA $<0.05$. 
Spots differentially regulated in any of the group comparisons (including samples/gels from males and females) were automatically picked, trypsin digested and proteins identified by MALDI-TOF/TOF 5800 (Sciex) as previously described [1-3]. This included also spots from female rat livers previously not analyzed, as only now they were found regulated in the comparison with male rats' data. Protein identification was based on searches of mass fingerprints (PMF) and MS/MS spectra against the SwissProt database with "Rattus norvegicus" as taxonomy, using the ProteinPilot software (Sciex, Nieuwerkerk aan den ljssel, The Netherlands) and the searching algorithm MASCOT (Matrix Science, www.matrixscience.com, London, UK). For each spot one protein mass fingerprint and up to $8 \mathrm{MS} / \mathrm{MS}$ spectra were generated. Parameters for the search were set as in the previous study [1, 3]: up to two missed cleavages allowed, $100 \mathrm{ppm}$ tolerance in PMF, 0.75 Da mass tolerance for precursor ion mass, carbamidomethyl cysteine as fixed modification, oxidation of methionine and oxidation of tryptophan (single oxidation, double oxidation and kynurenin) as variable modifications. Identifications were considered to be significant when the combined MOWSE score had $P<0.05$.

For statistics the Extended Data Analysis (EDA) module as well as univariate analysis (ANOVA and ttest) and multivariate analysis (two way ANOVA), all part of the Decyder 7.0 software package, were applied.

\section{References}

[1] Miller, I, Serchi, T, Cambier, S, Diepenbroek, C, Renaut, J, Van den Berg, JHJ, Kwadijk, C, Gutleb, AC, Rijntjes, E, Murk, AJ. (2016). Hexabromocyclododecane (HBCD) induced changes in the liver proteome of eu- and hypothyroid female rats, Toxicol Lett 245, 40-51.

http://dx.doi.org/10.1016/j.toxlet.2016.01.002.

[2] Miller, I, Diepenbroek, C, Rijntjes, E, Renaut, J, Swarts, H, Kwadijk, C, Cambier, S, Murk, AJ, Gutleb, AC, Serchi, T. Gender specific differences in the liver proteome of rats exposed to short term and low-concentration hexabromocyclododecane (HBCD), Toxicol Res, submitted in parallel.

[3] Miller, I, Serchi, T, Cambier, S, Diepenbroek, C, Renaut, J, Van den Berg, JHJ, Kwadijk, C, Gutleb, AC, Rijntjes, E, Murk, AJ. (2016). Dataset of liver proteins of eu- and hypothyroid female rats changing abundance upon in vivo exposure to hexabromocyclododecane (HBCD), Data in Brief 7, 386-392.

http://dx.doi.org/10.1016/j.dib.2016.02.047. 


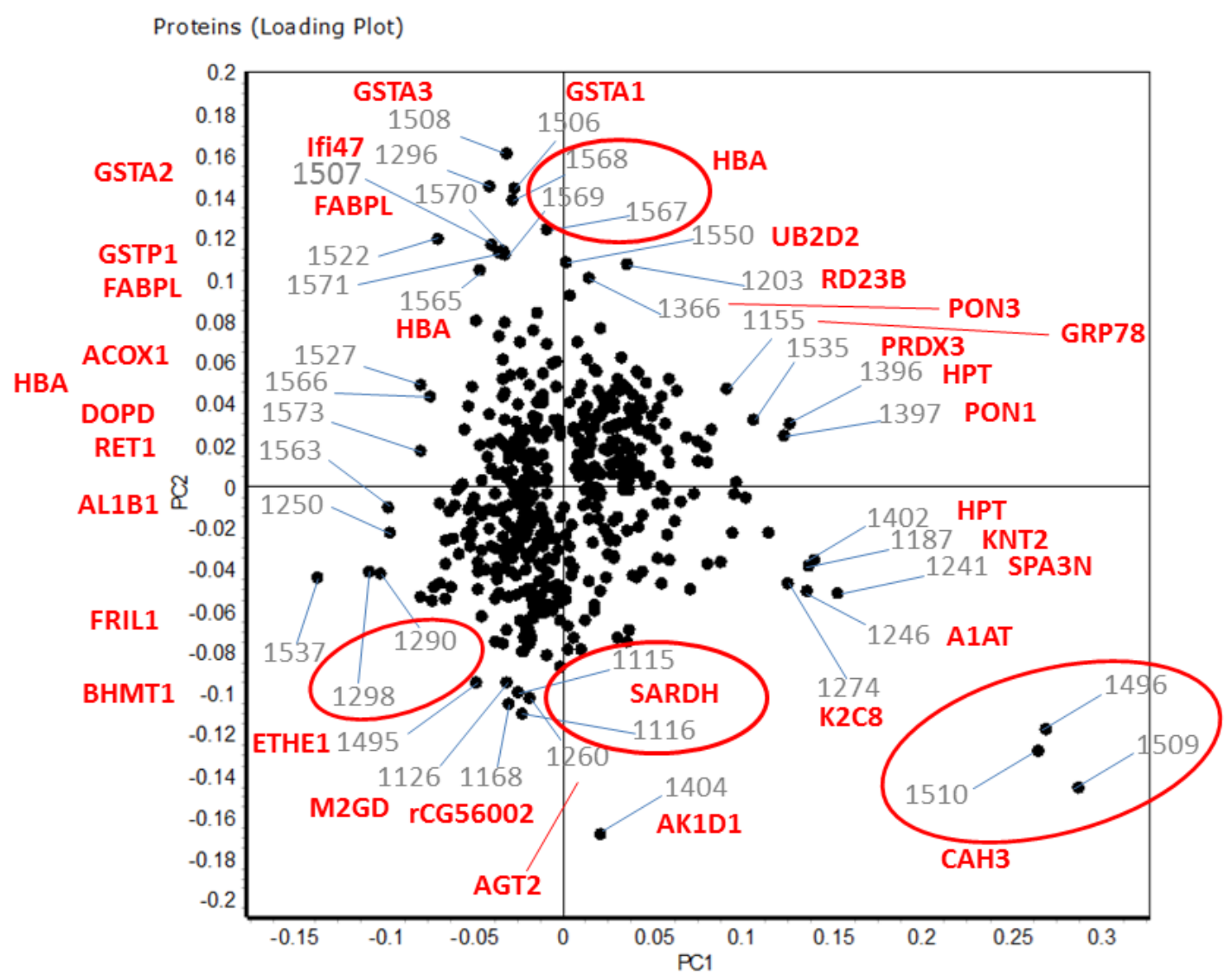

Figure 1:

PCA Loading plot of the 496 differentially regulated spots. Spot numbers (corresponding to labelling in gel image in Suppl. Figure 1 and regulation data in Suppl. Table 2) and UniProt accession numbers (Suppl. Table 1) used for labelling.

Abbreviations:

A1AT_RAT, Alpha-1-antiproteinase

ACOX1_RAT, Peroxisomal acyl-coenzyme A oxidase 1

AGT2_RAT, Alanine--glyoxylate aminotransferase 2_mitochondrial

AK1D1_RAT, 3-oxo-5-beta-steroid 4-dehydrogenase

AL1B1_RAT, Aldehyde dehydrogenase X_mitochondrial

BHMT1_RAT, Betaine--homocysteine S-methyltransferase 1

CAH3_RAT, Carbonic anhydrase 3

DOPD_RAT, D-dopachrome decarboxylase

protein ETHE1_mitochondrial

FABPL_RAT, Fatty acid-binding protein_liver

FRIL1_RAT, Ferritin light chain 1

GRP78_RAT, 78 kDa glucose-regulated protein

GSTA1_RAT, Glutathione S-transferase alpha-1 
GSTA2_RAT, Glutathione S-transferase alpha-2

GSTA3_RAT, Glutathione S-transferase alpha-3

GSTP1_RAT, Glutathione S-transferase P

HBA_RAT, Hemoglobin subunit alpha-1/2

HPT_RAT, Haptoglobin

Ifi47 protein

K2C8_RAT, Keratin_type II cytoskeletal 8

KNT2_RAT, T-kininogen 2

M2GD_RAT, Dimethylglycine dehydrogenase_mitochondrial

PON1_RAT, Serum paraoxonase/arylesterase 1

PON3_RAT, Serum paraoxonase/lactonase 3

PRDX3_RAT, Thioredoxin-dependent peroxide reductase_mitochondrial

rCG56002

RD23B_RAT, UV excision repair protein RAD23 homolog B

RET1_RAT, Retinol-binding protein 1

SARDH_RAT, Sarcosine dehydrogenase_mitochondrial

SPA3N_RAT, Serine protease inhibitor A3N

UB2D2_RAT, Ubiquitin-conjugating enzyme E2 D2

\section{Supplemental material:}

Suppl. Figure 1: Image of a rat liver 2D-DIGE gel (master gel, grey level image). All spots with statistically significant abundance changes in any of the different comparisons (HBCD exposure, thyroid state, gender) are labelled; spot numbers refer to identifications in Suppl. Table 1. For data on protein abundance, see Suppl. Table 2.

Suppl. Figure 2: Heat map and hierarchical clustering of all 496 differentially regulated spots.

Suppl. Table 1: Protein identifications by MALDI-TOF/TOF analysis. For spot locations on the gel see gel image in Suppl. Figure 1.

Suppl. Table 2: All spots found affected in the complete/combined dataset (male and female rats). Ratios between different animal groups $(n=4)$. Abbreviations: $f$, females; $m$, males; $E T$, euthyroid rats; $\mathrm{HT}$, hypothyroid rats; 0, 3, 30 refer to amounts of $\mathrm{HBCD}(\mathrm{mg} / \mathrm{kg}$ bw / d) administered in the 7day exposure period. 


\section{Chapter 6}

\section{Gender-related differences in rat serum proteome under baseline conditions and in inflammation}

Miller, I., Haynes, P., Eberini, I., Gemeiner, M., Aebersold, R., Gianazza, E. Proteins of rat serum: III. Gender-related differences in protein concentration under baseline conditions and upon experimental inflammation as evaluated by twodimensional electrophoresis

Electrophoresis 20 (1999), 836-845.

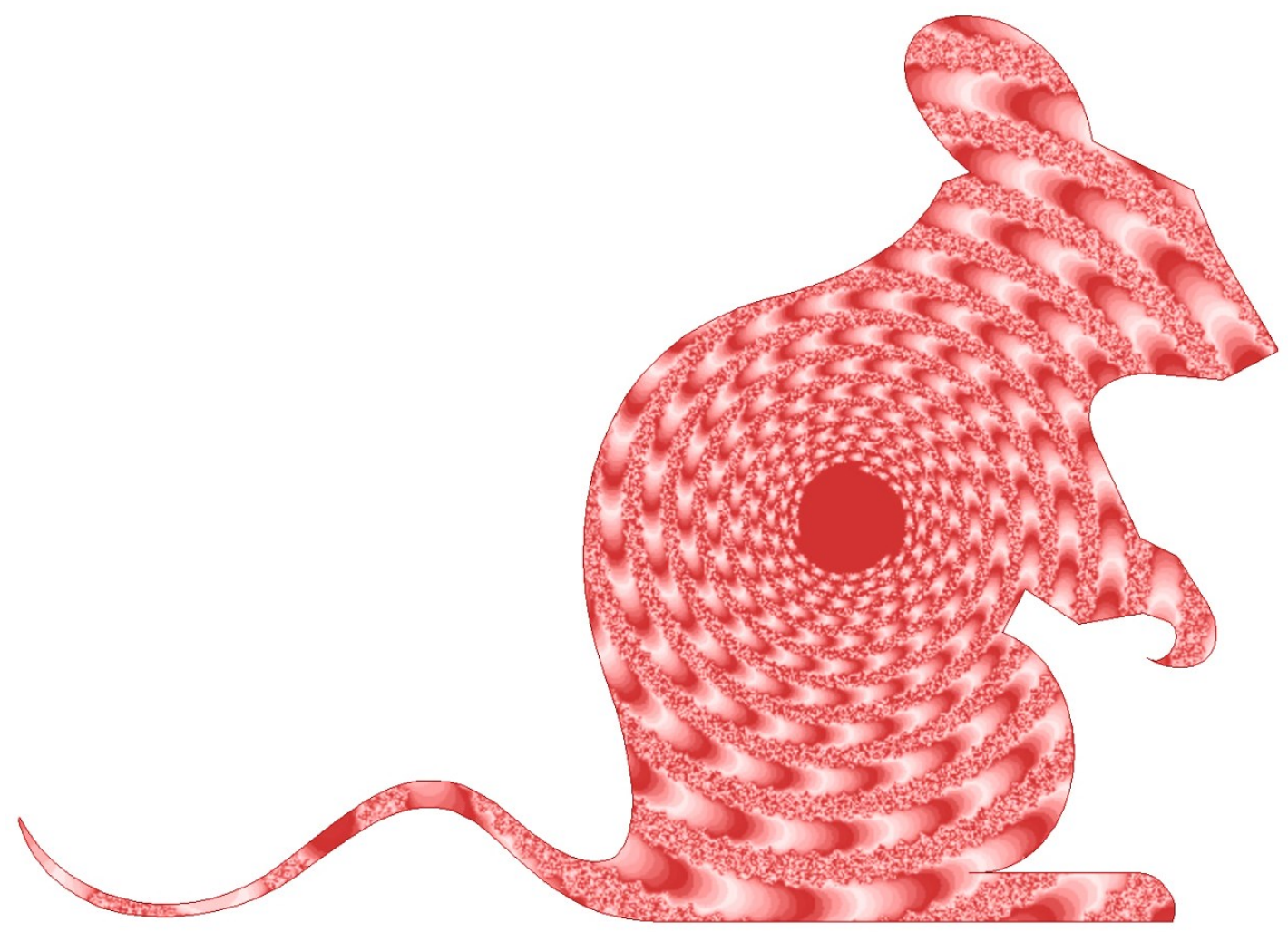





\author{
Ingrid Miller ${ }^{1}$ \\ Paul Haynes $^{2}$ \\ Ivano Eberini $^{3}$ \\ Manfred Gemeiner ${ }^{1}$ \\ Ruedi Aebersold ${ }^{2}$ \\ Elisabetta Gianazza ${ }^{3}$ \\ ${ }^{1}$ Veterinärmedizinische \\ Universität, Institut für \\ Medizinische Chemie, \\ Wien, Austria \\ ${ }^{2}$ University of Washington, \\ School of Medicine, \\ Department of Molecular \\ Biotechnology, \\ Seattle, WA, USA \\ ${ }^{3}$ Universitá degli Studi, \\ Istituto di Scienze \\ Farmacologiche, \\ Milano, Italy
}

\section{Proteins of rat serum: III. Gender-related differences in protein concentration under baseline conditions and upon experimental inflammation as evaluated by two-dimensional electrophoresis}

\begin{abstract}
We have previously described the major components of rat serum (Electrophoresis 1998, 19, 1484-1492 and 1493-1500). In this report we examine sex-related differences in protein concentrations, both in control animals and upon experimentally induced inflammation. Under baseline conditions approximately one third of the spots resolved in serum by two-dimensional electrophoresis (2-DE) are expressed at levels $\geq 25 \%$ higher in female rats than in male rats and a further $10 \%$ at levels $\geq 25 \%$ lower. Inflammation increases the expression of the positive acute-phase reactants: hemopexin, ceruloplasmin, $\alpha_{1}$-antitrypsin (all approximately 2 -fold), C-reactive protein (3- to 5-fold), serine protease inhibitor-3 (4- to 5-fold), thiostatin ( $>5$-fold in females, $>20$-fold in males), clusterin, orosomucoid, haptoglobin chains and $\alpha_{2}$-macroglobulin. The baseline level of the last four markers is below the detection limit, hence no percent increase can be computed. Conversely, negative acute-phase reactants are reduced on inflammation: $\alpha_{1}$-inhibitor III, $\alpha_{2}$-HS-glycoprotein, kallikrein-binding protein and transthyretin (all reduced to between $1 / 2$ to $1 / 3$ of the baseline levels), retinol-binding protein (to about $1 / 2$ to 1/4) and albumin (to 2/3). Except for thiostatin, the changes in acute-phase protein levels are similar in male and female rats. ${ }^{*}$
\end{abstract}

Keywords: Rat serum / Two-dimensional polyacrylamide gel electrophoresis / Inflammation / Sex / Acute-phase reactants

EL 3364

\section{Introduction}

Our groups have recently detailed the 2-DE map of rat serum by identifying the major protein components through a combination of immunoblotting and HPLC-MS/MSbased protein identification [1]. In a further step, the proteins typical of the acute-phase response to experimental inflammation have been identified [2]. Altogether, the above include 28 proteins, corresponding to about 80 individual spots. A compilation of all our rat data can be accessed $[3,4]$. We wish to extend this database through the addition of further spot identifications and, furthermore, of annotations on physiological and pathological properties for individual components. One condition of special interest to our current research is experimental in-

Correspondence: Dr. Elisabetta Gianazza, Istituto di Scienze Farmacologiche, Facoltá di Farmacia, Universitá degli Studi di Milano, via Balzaretti 9, I-20133 Milano, Italy

E-mail: elisabetta.gianazza@unimi.it

Fax: +39-02-29404961

Abbreviations: apo, apolipoprotein; CRP, C-reactive protein; Gc, Gc-globulin; Hp, haptoglobin; Hpx, hemopexin; $\alpha_{1}-I_{3}, \alpha_{1}$-inhibitor III; $\alpha_{1}-\mathbf{M}, \alpha_{1}$-macroglobulin; $\alpha_{1}$-MAP, thiostatin (1 and 2); $\alpha_{2}-\mathbf{M}, \alpha_{2}$-macroglobulin; NC, nitrocellulose; OD, optical density; PAA, polyacrylamide; RBP, retinol binding protein; Tf, transferrin flammation. We examine whether evaluation of serum levels of the acute-phase reactants may become a useful tool for the screening of anti-inflammatory drugs [5]. Detailed quantitative parameters characterizing the acutephase response are a preliminary step towards this goal. Additional aspects of this investigation are sex-related differences in serum protein expression after inflammation as well as under control conditions; a typical animal model for chronic inflammation is adjuvant arthritis in female Lewis rats. Preliminary data [2] imply that the baseline concentrations of some of the acute-phase markers, e.g., kallikrein-binding protein and thiostatin, differ significantly between male and female rats. For humans, in the compilation by Putnam [6], different normal concentration ranges are reported for men and women for $\alpha_{2}$-macroglobulin, IgM, and $\beta$-lipoprotein.

\footnotetext{
* Procedures involving animals and their care were conducted at Istituto di Scienze Farmacologiche, Universitá di Milano, in conformity with the institutional guidelines that comply with national (D.L. No. 116, G.U. Suppl. 40, February 18, 1992 and Circolare No. 8, G.U. July 1994) and international laws and policies (EEC Council Directive 86/609, OJ L 358.1, December 12,1987 , and Guide for the Care and Use of Laboratory Animals, US National Research Council, 1996).
} 


\section{Materials and methods}

\subsection{Samples}

Three female and three male Sprague Dawley rats, 10 weeks old, 230-250 g, on a standard chow diet, were probed both before (control) and $48 \mathrm{~h}$ after intramuscular injection of $5 \mathrm{~mL}$ turpentine/kg body weight (as a stimulus inducing inflammation) [7]. Blood was drawn from the caudal vein under diethylether anesthesia at the beginning of the test period; the animals were killed by decapitation at the end of the treatment. Aliquots of the sera were stored at $-20^{\circ}$.

\subsection{Electrophoresis}

Most analytical procedures were identical to those already detailed in the previous papers of this series $[1,2]$. 2-DE maps were obtained by IPG-DALT [8] on $5 \mu \mathrm{L}$ aliquots of sera. Under standard conditions, whole serum proteins were resolved on a nonlinear $\mathrm{pH} 4-10$ IPG [9] and SDS-PAGE was then run on $7.5-17.5 \%$ T polyacrylamide (PAA) gradients; the slab size was $16 \times 14 \mathrm{~cm}$. Protein patterns were stained with $0.3 \% \mathrm{w} / \mathrm{v}$ Coomassie; $\alpha$-mannose-containing glycoproteins were revealed by concanavalin $\mathrm{A} /$ peroxidase interaction $[10,11]$ after blotting onto a nitrocellulose (NC) membrane. In addition to the standard 2-DE protocol given above, enhanced resolution of individual areas or for a given class of proteins was achieved by variation of $\mathrm{pH}$ gradient or acrylamide concentration of the gels. Orosomucoid from $7.5 \mu \mathrm{L}$ serum was focused on a $\mathrm{pH}$ 2.5-5 IPG [12] prior to SDSPAGE as above. For glycoprotein detection (required for theresolution of even the basic isoforms of hemopexin), $2 \mu \mathrm{L}$ of serum were run under standard conditions, then blotted on an NC membrane and affinity-stained with Concanavalin A-peroxidase [10]. For proteins in the crowded area around $\alpha_{2}-\mathrm{HS}$ glycoprotein, 2-DE was also performed on a pH 4-6 IPG (the acidic $60 \%$ of the wide range above) followed by SDS-PAGE on 4.5-9\% PAA gradient gels. With high $M_{\mathrm{r}}$ proteins, showing minimal overlap in size, 1-DE gave satisfactory results even on $6 \times 8 \mathrm{~cm}$ slabs. The best resolution was achieved by SDS-PAGE on a 4-6\%T PAA gradient, with sample loads of $0.1 \mu \mathrm{L}$ per lane for Coomassie stain and of $0.002 \mu \mathrm{L}$ per lane for glycoprotein detection. Ceruloplasmin was immunostained with an antiserum raised in goats against the human protein (Sigma, St. Louis, MO, USA).

\subsection{Protein quantitation}

The 2-DE gels and the blots were scanned with a video camera (Sony, Japan) under the control of NIH Image, release 1.52, and analyzed with the software PDQUEST
Version 5.1 (PDI, Huntington Station, NY, USA) run on a Sun SPARCstation 4 (Sun Microsystems, Mountain View, CA, USA). A matchset was created from the patterns of the four pools of rat sera (control males, inflamed males, control females and inflamed females) in a given run. A standard gel (master) was generated out of the image with the highest spot number by including additional spots from the other three gels [13]. As all gels within one series were processed "in one batch", results were evaluated in terms of spot volumes without further correction/normalization. The reports for individual proteins (spots, or spot chains, already identified by immunological or physicochemical means [1, 2]) (or single, unidentified spots) are referred to by percentage values of the highest figure among the four samples. Albumin was determined by the immediate bromocresol green assay $[14,15]$.

\subsection{Protein identification by peptide mapping through HPLC-MS/MS}

Some proteins influenced in their expression by inflammation and not already included in our database [3, 4] were identified by HPLC-MS/MS. After blotting and staining with Amido Black, material from individual spots was digested with trypsin according to [16]. The resulting peptides were resolved by chromatography on microbore HPLC system (Ultrafast Microprotein Analyzer; Michrom Bioresources, Auburn, CA, USA) equipped with a $100 \AA$, $5 \mu \mathrm{m}$ Reliasil C18 BDX column (0.5 × $150 \mathrm{~mm}$; Michrom). Peptides were eluted using buffer A (6\% v/v acetonitrile, $0.1 \%$ acetic acid, $0.005 \% \mathrm{v} / \mathrm{v}$ heptafluorobutyric acid) and buffer B (80\% v/v acetonitrile, $0.1 \%$ acetic acid, $0.005 \%$ $\mathrm{v} / \mathrm{v}$ heptafluorobutyric acid), at a flow rate of $15 \mu \mathrm{L} / \mathrm{min}$. The gradient used was $0 \% \mathrm{~B}$ for $2 \mathrm{~min}$, followed by a linear increase to $60 \%$ B over 48 min. Tandem mass spectrometry was performed on-line in a triple quadrupole mass spectrometer (TSQ 7000; Finnigan, San Jose, CA, USA) connected to the HPLC via a microspray interface [17]. Spectra were scanned over a range of 380-1500 mass units at $1.5 \mathrm{~s}$ intervals. Automatic peak recognition and daughter ion scanning were performed using the built-in instrument control language (ICL) [18]. Tandem mass spectra were analyzed using SEQUEST, which allows the correlation of experimental data with theoretical spectra generated from known protein sequences [19, 20]. Briefly, SEQUEST matches a precursor ion of a given mass with any peptide present within the protein sequences of a given database, within a specified mass accuracy. An initial ranking is obtained by considering the presence and intensity of the peptide fragment ions in the experimental spectrum. A theoretical collision-induced dissociation (CID) spectrum of the five hundred bestranked peptides is then generated and correlated with the experimental CID spectrum to find the best match. All 
spectra were searched against the OWL protein database, release V30.1 [21, 22]. The criteria used for positive peptide identification were a correlation factor greater than 2.0, a delta cross-correlation factor greater than 0.1 (indicating a significant difference between the best match reported and the next best match), and a high preliminary score [17]. The search data were summarized using the sequest_summary program [19, 20], which assigns a dimensionless numerical value to search results based on a sliding scale where 10 units are given for a peptide ranked as the best match, 8 units for a secondbest match, 6 for a third-best match, 4 for a fourth-best match and 2 for a fifth-best match. The scores assigned to peptides from a common protein are summed, to give a sequest_summary score for each potential protein match. The criterium we used for a positive protein identification was a sequest_summary score of greater than 20 , indicating at least two peptides from a potential matching protein had been positively identified [17].

\subsection{Lipoprotein purification and analysis}

Total lipoproteins were collected by flotation on a $\mathrm{KBr}$ solution $(d=1.21 \mathrm{~g} / \mathrm{mL})$ and delipidated by treatment with diethylether:ethanol 3:1 v:v [23]. Equal amounts of the purified apoproteins $(10 \mu \mathrm{g})$ were run in SDS-PAGE on a 4-
$20 \%$ T PAA gradient in order to resolve components of such different size as apoB and apoC at the same time.

\section{Results}

\subsection{HPLC-MS/MS protein identifications}

Three proteins not included in our previous database were identified by HPLC-MS/MS as being among the spots whose expression was modulated upon inflammation. Their positions in the 2-DE map are indicated (by ovals) in Fig. 1. The identifications of these three (Table 1) were $\alpha_{1}$-inhibitor III [24-26], C-reactive protein (CRP) $[27,28]$ and clusterin $[29,30] . \alpha_{1}$-Inhibitor III was analyzed on a blot from 2-DE as well as on the SDS-PAGE of a control serum; clusterin was identified next to orosomucoid on a map from a 2.5-5 IPG. The component identified as CRP is located in the immunoglobulin light chain region (results from immunoblotting [1]) which extends to acidic $\mathrm{p} / \mathrm{s}$. One spot close to CRP had been previously identified as belonging to the immunoglobulin $\kappa$ isotype (spot 50 of Fig. 2 in [1]) by HPLC-MS/MS in the serum of normal male rats. No peptides of this protein were found in the present analysis when investigating samples from normal and inflamed animals. Since immunoglobulin populations are known to be heterogeneous and variable, depending on the individuals (outbred mice share only $30 \%$

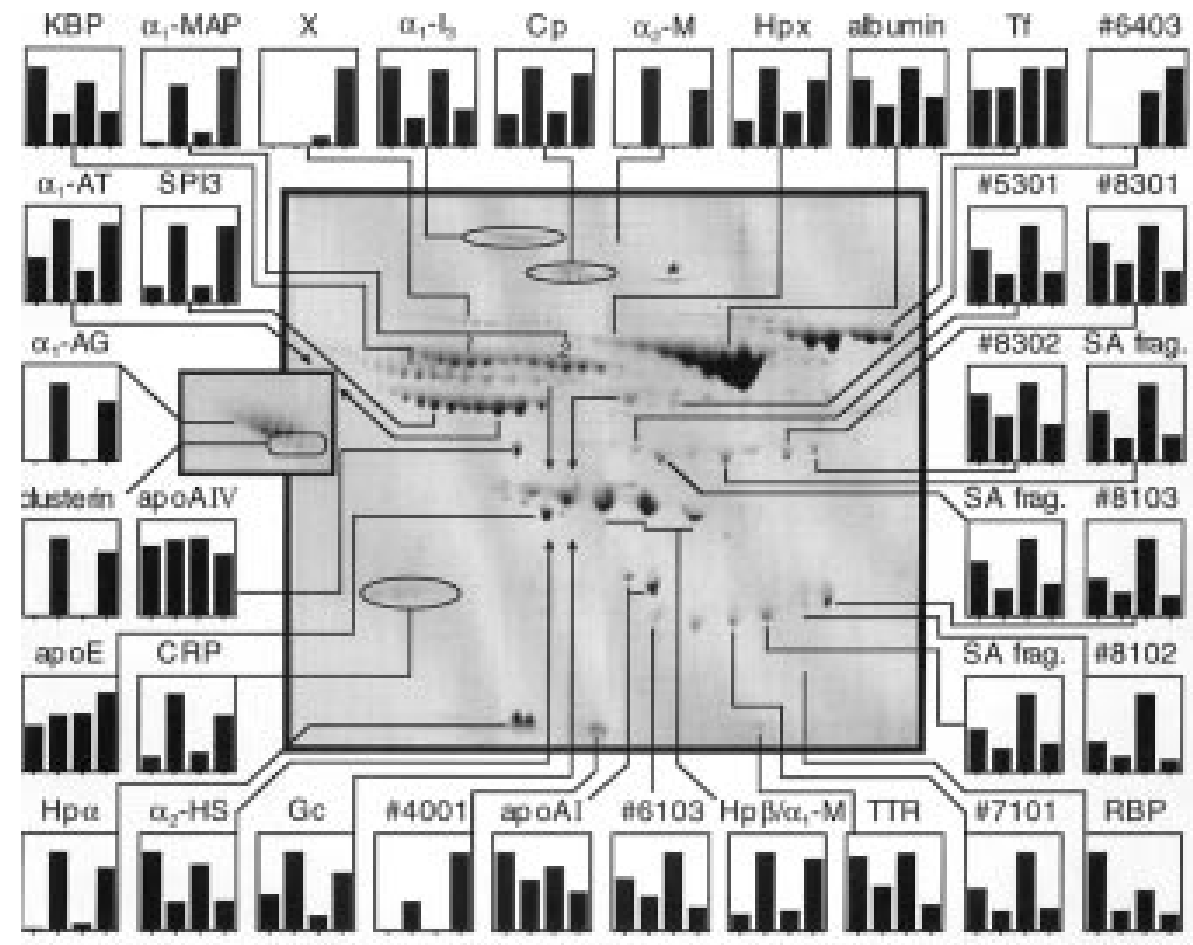

Figure 1. 2-DE map of serum proteins from female rats $48 \mathrm{~h}$ after the intramuscular injection of turpentine; Coomassie stain on a $5 \mu \mathrm{L}$ sample. The inset is from a 2-DE gel whose first dimension was run on a 2.5-5 IPG, with a serum load of 7.5 $\mu \mathrm{L}$. Histograms of the abundance of the various proteins, as marked on the top of each panel, in the sera of (from left to right) control males, inflamed males, control females, inflamed females. All data are referred to as $\%$ value to the highest figure among the four samples. Arrows point to the prolongation of broken lines (for $\alpha_{1}-\mathrm{AT}, \alpha_{2}-\mathrm{HS}$ and Gc). $\alpha_{1}-A G, \alpha_{1}$-acid glycoprotein; $\alpha_{1}$-AT, $\alpha_{1}$-antitrypsin; $\alpha_{1}-I_{3}$, $\alpha_{1}$-inhibitor III; $\alpha_{1}-\mathrm{M}, \alpha_{1}$-macroglobulin; $\alpha_{1}$-MAP, thiostatin (1 and 2); $\alpha_{2}-\mathrm{HS}, \alpha_{2}$-HS-glycoprotein; $\alpha_{2}-\mathrm{M}, \quad \alpha_{2}$-macroglobulin; apo, apolipoprotein; $\mathrm{Cp}$, ceruloplasmin; CRP, C-reactive protein; Gc, Gc-globulin; Hp, haptoglobin; Hpx, hemopexin; KBP, kallikrein-binding protein; RBP, retinol-binding protein; SPI3, serine protease inhibitor-3; Tf, transferrin; TTR, transthyretin. The spots outlined by ovals correspond to proteins newly identified by HPLC-MS/MS; the asterisk marks a further spot identified as ceruloplasmin. 
Table 1. Proteins identified by HPLC-MS/MS

\begin{tabular}{llll}
\hline Protein (abbreviation) & ID OWL [21] & Sequest_scores ${ }^{\text {a) }}$ & Notes \\
\hline$\alpha_{1}$-Inhibitor III $\left(\alpha_{1}-I_{3}\right)$ & A1I3_RAT & Total of 368 & $\begin{array}{l}\text { 32 peptide best matches } \\
+3 \text { peptides of s 15904 } \\
\text { (a variant of A1I3_RAT) }\end{array}$ \\
& & & $\begin{array}{l}\text { Confirmation of data from } \\
\text { immunoblotting [1] }\end{array}$ \\
$\alpha_{2}$-Macroglobulin $\left(\alpha_{2}-\mathrm{M}\right)$ & A2MG_RAT & 144 & Overlap with RNITIH4 \\
& & & \\
Ceruloplasmin $(\mathrm{Cp})$ & CERU_RAT & 130 & 4 different analyses \\
Cp & CERU_RAT & 128 & 2 different analyses \\
C-reactive protein (CRP) & CRP_RAT & $118,144,146,78$ & \\
Clusterin & CLUS_RAT & 48,68 & \\
Inter- $\alpha$-inhibitor H4 & RNITIH4 & 52 &
\end{tabular}

a) See Section 2.4 for further details

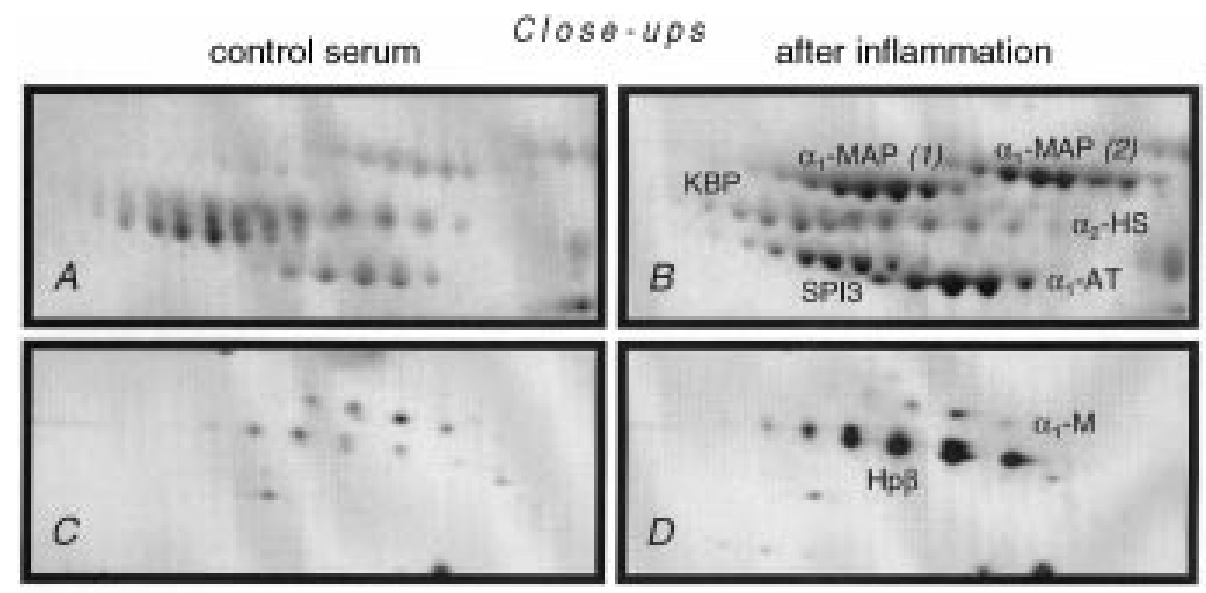

Figure 2. (A, B) Close-up of the 2-DE region of $\mathrm{pH} 4.5-5.5$ and $M_{\mathrm{r}}$ 45-65 kDa for control female (on the left) and inflamed female animals (on the right). The second dimension was run on a 4.5-9\% T slab. (C, D) Details from 2-DE using standard IPG, but $10-15 \%$ gels in second dimension, run for an extended period (migration distance for apoAl $12 \mathrm{~cm}$ instead of $6 \mathrm{~cm}$ ) and silver-stained; patterns correspond to $0.2 \mu \mathrm{L}$ serum. $\alpha_{1}-\mathrm{M}$ light chain (upper row) and $\mathrm{Hp}$ $\beta$-chain (lower double row) are resolved. Control female animal on the left, inflamed female on the right.

of their Ig light chain spots, and inbred mice 70-80\% [31]), it appears that this isotype was not present at significant levels in the animals used in these studies. HPLCMS/MS was also used to identify some of the high $M_{\mathrm{r}}$ spots (Fig. 1). Ceruloplasmin [32, 33] was found to overlap with an inter- $\alpha$-inhibitor $\mathrm{H} 4[34,35]$. Ceruloplasmin was also detected at the position marked with an asterisk. One further protein, previousy detected only by immunoblotting, was confirmed by HPLC-MS/MS to be $\alpha_{2}$-macroglobulin.

\subsection{Protein evaluation}

2-DE evaluation of the rat sera for spot quantitation was only performed on gel series which had been processed in the same batch (in all steps, i.e., from IPG to destaining after 2-DE and scanning) to keep variation levels as low as possible. A constant volume of serum was loaded onto the gel, although samples from inflamed animals are known to vary slightly in protein concentration and distribution [7]. All quantitations were based on (absolute) spot volumes; it was a priori not clear which protein was unaf- fected in its level and could serve as internal standard. As serum protein content varies upon inflammation [7], \% based on total optical density (OD) in a given slab appear less reliable than constant serum volume. The reproducibility of the system was tested by running several gels of the same sample (male rat serum), in different batches. Gels were evaluated in the way described, and variation was determined for all proteins. Variation coefficients whithin one batch were $20 \%$ on average, smaller for compact, round and darker spots, e.g., transferrin (Tf) 7-9\%, apolipoprotein (apo) AIV $7-11 \%$, haptoglobin ( $\mathrm{Hp}$ ) $\beta / \alpha_{1}-\mathrm{M}$ $9 \%$ and higher for the more diffuse, fainter, and ovalshaped ones, e.g., $\alpha_{1}$-inhibitor III $\left(\alpha_{1}-I_{3}\right)$ within $36 \%$. No correlation between $M_{\mathrm{r}}$ of the protein and variation coefficient was found.

\subsection{Protein concentration in control and inflamed rats}

The master gel pattern produced by PDQUEST software contains 151 different single spots resolved under standard conditions (as in Fig. 1). For males the number of 
quantitated spots is lower (113 for control animals, 124 for inflamed) than for females (120 for control, 148 for inflamed animals), with more saturated spots for females than for males (mainly albumin and Tf). Under baseline conditions, $29 \%$ of the single spots are expressed at levels at least $25 \%$ higher in females than in males, $10 \%$ at levels at least $25 \%$ higher in males than in females. Upon experimental treatment, an increase above control levels exceeding $25 \%$ is recorded for $25 \%$ of the protein spots in males and for $28 \%$ in females, a decrease exceeding $25 \%$ for 32 and $34 \%$ of the spots, respectively.

The largest number of protein spots is found in the serum of inflamed female rats; the 2-DE map of such a sample is shown in Fig. 1, with an inset from a 2-DE gel from a 2.55 IPG to fully resolve orosomucoid and clusterin. A closeup details the region with the most dramatic changes in protein patterns due to the treatment, i.e., the region of $\mathrm{p} /$ 4.5-5.5 and molecular mass 45-65 kDa (Fig. 2, panels A-B). For identified proteins, single spot volumes of the respective chain were summed and plotted, while unidentified spots were treated individually. Figure 1 shows the identified proteins and single spots of high intensity (cutoff chosen arbitrarily). Histograms are linked to the protein, or protein spot, to which each refers, and are marked with the protein abbreviation, or a spot number (according to PDQUEST listing). For one as yet unidentified protein, designated $\mathrm{X}$, the sum of volumes for all spots in a row was computed. In each histogram, the series, from left to right, includes: control males, inflamed males, control females, inflamed females.

Thiostatin $\left(\alpha_{1}-\mathrm{MAP}\right)$ is five times higher in females than in males, hemopexin (Hpx) almost 50\% higher, CRP and apoE ca. $25 \%$ higher in females. Gc-globulin (Gc) and retinol-binding protein (RBP) are about twice as high in males, and $\alpha_{2}$-HS glycoprotein and $\alpha_{1}$-antitrypsin about 25 and $30 \%$ higher in males than in females, respectively. Once expressed after inflammation, the concentration of $\alpha_{2}$-macroglobulin is about $40 \%$ higher, and that of orosomucoid about $30 \%$ higher in male rats. Among the nonidentified proteins, protein X and spot 6403 are found only in females, being either strongly or slightly up-regulated in inflammation. Spot 4001 appears only in the course of treatment, and several others are reduced in concentration (\#5301, 7101, 8103, 8301, 8302).

Variations in serum levels are brought about by the experimental treatment for virtually all proteins, although the order of magnitude of the changes differs widely. Among the major identified proteins only transferrin does not seem to change its absolute concentration (also see [5]). Inflammation increases the expression of the positive acute-phase reactants hemopexin, ceruloplasmin and $\alpha_{1}$ antitrypsin (all approximately 2-fold), C-reactive protein (3- to 5-fold), serine protease inhibitor-3 (4- to 5-fold), thiostatin (> 5-fold in females, > 20-fold in males), clusterin, orosomucoid, haptoglobin chains, and $\alpha_{2}$-macroglobulin. The baseline level of the last four markers is below the detection limit, hence no percent increase may be computed. Upon inflammation orosomucoid represents ca. 2$3 \%$, haptoglobin $\alpha$-chain 3-4\%, haptoglobin $\beta$ (together with $\alpha_{1}$-macroglobulin $\left(\alpha_{1}-\mathrm{M}\right) 13-14 \%$ and $\alpha_{2}$-macroglobulin $5 \%$ of total serum proteins. Among the nonidentified components, spot \#4001 is only detected after inflammation. Conversely, negative acute-phase reactants are reduced on inflammation: for example, $\alpha_{1}$-inhibitor III, $\alpha_{2}$ HS glycoprotein, kallikrein-binding protein and transthyretin (all of them being reduced to $1 / 2$ or $1 / 3$ of their baseline levels), retinol binding protein (to $1 / 2$ or $1 / 4$ ), transthyretin (to $1 / 2$ to $1 / 3$ ) as well as a number of relatively faint, unidentified protein spots (not included in the histograms of Fig. 1). Albumin is reduced to about $2 / 3$ of its concentration by inflammation; the same is observed for some spots previously identified as albumin fragments [1].

As for apolipoproteins, the amount of apoE is increased, while that of apoAl is decreased by inflammation (Fig. 1). If the percent concentrations of the various apoproteins in a purified lipoprotein preparation are computed (Fig. 3), the reduction for apoAl equals $50 \%$, while the level of apoB doubles. As discussed (see [5]), the distribution among $\mathrm{p} /$ isoforms is not influenced by the experimental treatment (not shown).

Concordance is usually observed between the sexes as for the extent of the changes following inflammation. A strong difference is only found for thiostatin, for which the increase in males is four times higher than in females.

Percent distribution of different apo's in the lipoproteins from

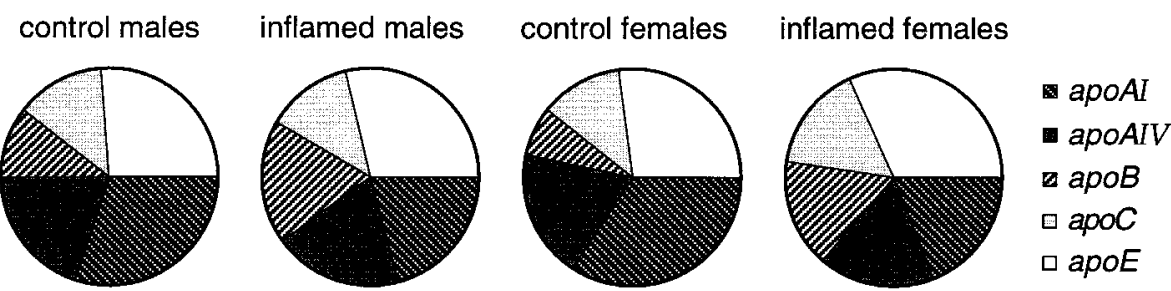

Figure 3. Percent distribution of the various apoproteins in the lipoproteins of (from left to right) control males, inflamed males, control females, inflamed females. 
Protein stain $\square$ versus glycoprotein stain $\mathrm{D}$

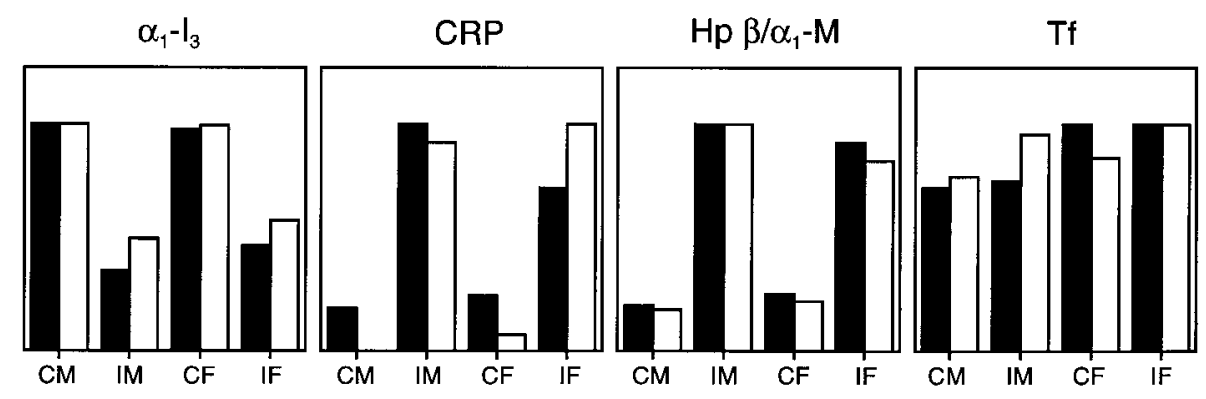

Figure 4. Comparison between the quantitations from Coomassie-stained pattern (solid bars) and concanavalin-positive affinity blotting for the glycyl moiety (open bars) of some glycoproteins. In each series the sequence of the samples is, from left to right: control males (CM), inflamed males (IM), control females (CF), inflamed females (IF); for each type of staining, data are referred to as percentage values relative to the highest figure among the four samples.

\section{Discussion}

\subsection{Assessment of the quantitation procedures}

As detailed under Section 2.3, as a second step after 2-DE under standard conditions, the quantitations for many proteins were repeated under electrophoretic conditions maximizing resolution in specific areas. A countercheck of values revealed consistency of the trends observed throughout all the methods, although absolute spot volumes differed. The spots of the two proteins with the highest concentration in serum, albumin and Tf, were usually saturated in 2-DE with standard sample loads. Transferrin could be evaluated after 1-D SDS-PAGE on a $4-6 \%$ T gel. Albumin was determined by a photometric assay based on the reaction with bromocresol green [36]. Two proteins could not be fully resolved from neighbors with overlapping molecular properties. In the Hpx/albumin pair, lectin affinity staining was able to clearly differentiate the glycoprotein from the nonglycoprotein component and was used for quantitation (histogram in Fig. 1). The spots of $\alpha_{1}$-macroglobulin light chain and haptoglobin $\beta$-chain overlap almost completely in the standard 2-DE system; both proteins are glycosylated and no cross-reactive antibody is available [2]. Improved resolution in 2-DE was obtained by prolonging the second-dimension runs, lowering sample loading amounts, and using silver staining as a detection method [37, 38]. In this way, $\alpha_{1}-\mathrm{M}$ (a single row) was found to remain constant, whereas the levels of $\mathrm{Hp} \beta$ (a double chain) rose 9-10 times (Fig. 2 C-D).

\subsection{Newly identified proteins}

In the course of our new experiments several spots were investigated in more detail, especially those showing variations in serum levels upon treatment. All of the proteins newly identified by HPLC-MS/MS showed considerable differences from the human homologs. CRP, a pentameric glycoprotein with identical subunits, displays a much more acidic $p /$ in rats than in humans. It is one of the early markers of inflammation in humans [39] and is reported to be little affected in rats (by a factor of 2 versus 1000 [40]). In contrast to the human counterpart, rat CRP is present in serum at higher baseline levels [41], it is a glycoprotein (see Fig. 4) [28], and its binding properties for phosphorylcholine differ (it contains three instead of five binding sites [42]). Rat clusterin is also much more acidic than the human homolog. In mice and humans, this protein, an extensively glycosylated disulfide-linked heterodimer with subunits of similar $M_{\mathrm{r}}$, is known as apo $\mathrm{J}$ and is associated with apoptosis and inflammation [29]. $\alpha_{1}-I_{3}$ is a ratspecific protein, belonging to the macroglobulin family and acting as a protease inhibitor [25]. Whereas the first two proteins described are increased upon inflammation, the level of $\alpha_{1}-l_{3}$ drops.

During the search for new inflammation markers, two high $M_{\mathrm{r}}$ spots were identified as ceruloplasmin (Cp) by HPLCMS/MS. The previously described immunostaining of ceruloplasmin [1] had been performed with a weakly crossreacting antibody raised against the human protein. It produced multiple spots or spot chains of different intensity, among them the position indicated in Fig. 2 of [1] and the spot named $\mathrm{Cp}$ in Fig. 1 of this paper. When performing the immunoblot after 1-D SDS-PAGE, there was also a fainter double band with lower $M_{r}$. As it could not be verified whether the latter was identical to spot $\mathrm{Cp}^{*}$ (Fig. 1), quantitation was only based on the main cross-reactive component. Human $\mathrm{Cp}$ is thought to be a single-chain polypeptide, but was found as a major type I with four sugar chains and a minor type II with three sugar chains [43], which could also correspond to the general $\mathrm{Cp}$ pattern given in SWISS-2DPAGE [42]. Rat Cp is reported to be more acidic than the human homolog [32] and contains an even larger number of potential glycosylation sites (6 versus 4). However, these different properties cannot completely explain the spot pattern in our 2-DE runs. 
Table 2. Changes reported for rat serum proteins upon inflammation

\begin{tabular}{|c|c|c|}
\hline Protein & Type of change & Reference \\
\hline$\alpha_{1}-A G$ & $\begin{array}{l}\uparrow 20 \times \\
\uparrow 20 \times \text { in } 24 \mathrm{~h}, \\
\uparrow 14 \times \text { in day } 3\end{array}$ & Urban et al., 1979 [60] \\
\hline$\alpha_{1}-\mathrm{AT}$ & $\begin{array}{l}\uparrow 2 \times \text { in day } 2 \\
\uparrow 2 \times \\
\uparrow<1.50 \times\end{array}$ & $\begin{array}{l}\text { Gauthier et al., } 1978 \text { [24] } \\
\text { Urban et al., } 1979 \text { [60] } \\
\text { Koj et al., } 1982 \text { [61] }\end{array}$ \\
\hline$\alpha_{1}-I_{3}$ & $\begin{array}{l}\downarrow 0.3 \times \text { in day } 2 \\
\downarrow 0.5 \times \text { in day } 2 \\
\downarrow 0.3-0.25 \times \text { in } 24 \mathrm{~h} \\
\downarrow 0.25-0.2 \times \text { in } 24 \mathrm{~h}\end{array}$ & $\begin{array}{l}\text { Gauthier et al., } 1978 \text { [24] } \\
\text { Lonberg-Holm et al., } 1987 \text { [25] } \\
\text { Braciak, } 1988 \text { [26] } \\
\text { Aiello et al., } 1988 \text { [62] }\end{array}$ \\
\hline$\alpha_{1}-\mathrm{M}$ & $\begin{array}{l}\uparrow 1.4 \times \text { in day } 3 \\
\leftrightarrow \\
\leftrightarrow \\
\uparrow<1.5 \times\end{array}$ & $\begin{array}{l}\text { Gordon et al., } 1976 \text { [63] } \\
\text { Gauthier et al., } 1978 \text { [24] } \\
\text { Lonberg-Holm et al., } 1987 \text { [25] } \\
\text { Koj et al., } 1982 \text { [61] }\end{array}$ \\
\hline$\alpha_{1}-\mathrm{MAP}$ & $\begin{array}{l}\uparrow 20 \times \text { in } 24 \mathrm{~h} \\
\uparrow 20 \times \text { in } 24 \mathrm{~h}, \\
\uparrow 18 \times \text { in day } 3 \\
\uparrow 20 \times\end{array}$ & $\begin{array}{l}\text { Urban et al., } 1979 \text { [60] } \\
\text { Schreiber et al., } 1982 \text { [7] } \\
\text { Cole et al., } 1985 \text { [64] }\end{array}$ \\
\hline$\alpha_{2}-\mathrm{HS}$ & $\downarrow$ & Schreiber et al., 1988 [45] \\
\hline$\alpha_{2}-M$ & $\begin{array}{l}\uparrow 90 \times \text { in day } 2 \\
\uparrow(\text { rapid) } \\
\uparrow 110-140 \times \text { in } 24 \mathrm{~h} \\
\uparrow 70 \times \text { in day } 2\end{array}$ & $\begin{array}{l}\text { Gordon et al., } 1976 \text { [63] } \\
\text { Gauthier et al., } 1978 \text { [24] } \\
\text { Okubo et al., } 1981 \text { [65] } \\
\text { Lonberg-Holm et al., 1987 [25] }\end{array}$ \\
\hline Albumin & $\begin{array}{l}\downarrow 0.6 \times \\
\downarrow 0.4 \times \text { in } 24 \mathrm{~h}, \\
\downarrow 0.6 \times \text { in day } 3\end{array}$ & $\begin{array}{l}\text { Urban et al., } 1979 \text { [60] } \\
\text { Schreiber et al., } 1982 \text { [7] }\end{array}$ \\
\hline ApoAl & $\leftrightarrow$ & Schreiber et al., 1989 [45] \\
\hline ApoAIV & $\downarrow$ & Schreiber et al., 1989 [45] \\
\hline ApoE & $\downarrow$ & Schreiber et al., 1989 [45] \\
\hline Clusterin & $\begin{array}{l}\text { Associated with } \\
\text { apoptosis }\end{array}$ & {$[42]$} \\
\hline $\mathrm{Cp}$ & $\uparrow$ & Schreiber et al., 1989 [45] \\
\hline CRP & $\uparrow 2 \times$ & Kushner et al., 1988 [41] \\
\hline & Undetectable & Schreiber et al., 1989, [45] \\
\hline Gc & $\leftrightarrow$ & Schreiber et al., 1989 [45] \\
\hline $\mathrm{Hp}$ & $\begin{array}{l}\uparrow 10 x \\
\uparrow 3 x\end{array}$ & $\begin{array}{l}\text { Lombart et al., } 1965 \text { [66] } \\
\text { Koj et al., } 1982 \text { [61] }\end{array}$ \\
\hline $\mathrm{Hpx}$ & $\uparrow$ & Kushner, 1984 [40] \\
\hline $\mathrm{KBP}$ & $\begin{array}{l}\downarrow \\
\downarrow \\
\downarrow\end{array}$ & $\begin{array}{l}\text { Chao et al., } 1990 \text { [67] } \\
\text { Pages et al., } 1990 \text { [68] } \\
\text { Chai et al., } 1991 \text { [47] }\end{array}$ \\
\hline RBP & $\downarrow$ & Schreiber et al., 1989 [45] \\
\hline SPI-3 & $\uparrow$ & Pages et al., 1990 [68] \\
\hline Tf & $\uparrow 1.3 \times$ in $24 \mathrm{~h}$ & Schreiber et al., 1982 [7] \\
\hline Transthyretin & $\downarrow$ & Schreiber et al., 1989 [45] \\
\hline
\end{tabular}

$\uparrow$, increased

$\leftrightarrow$, no change

$\downarrow$, decrease in concentration

\subsection{Changes in protein levels}

With ELISA, Ikawa and Shozen [44] have determined normal values of several acute phase proteins in an (unspe- cified) rat strain. The detection system was validated and found to have a variation of less than $10 \%$ for most proteins, but the concentration ranges reported for some of the analytes vary between 10 and 25\% (e.g., Hp, Hpx, orosomucoid). Sprague-Dawley as an outbred strain may also be expected to display a certain degree of variation in serum protein levels. Most changes noticed in inflammation are much more marked than the error in our quantitation (determined in the reproducibility testing) or the normally expected variation in the respective rat population.

Several procedures have been reported in the literature to induce inflammation processes, most often injection of turpentine. However, the strength of the stimulus used varied among authors, as well as the time intervals after which the shifts in protein levels were recorded (usually one to three days), which results in differences in the magnitude of the changes described. For an overview on previous results, see Table 2. As for the major proteins, our present findings confirm current knowledge about positive and negative acute-phase reactants, although the extent of variation we report sometimes differs from literature data. As for CRP, we could only confirm a much lower rise than in humans [40] but still a clear-cut increase in its levels. Contrary to Schreiber et al. [45] who report Gc and apoAl not to be affected by the acute-phase response, we observe an increase for the former and a decrease for the latter. Rat Tf has been reported to change little in inflammation [7] and has therefore been suggested for reference as an internal standard. Tf data at the time point chosen for our present investigation would support this hypothesis; however, detailed studies in time course experiments provide evidence for a more complex behavior [5]. Some of the changes in protein levels brought about by acute experimental inflammation are reproduced by such different noxious stimuli as exposure to solvents in toxicological tests (dimethylformamide [46]).

Slight to moderate differences were found in baseline levels for single proteins when comparing male and female rats. Sevenfold higher kallikrein-binding protein (KBP) and $\alpha_{1}$-antitrypsin $\left(\alpha_{1}-\mathrm{AT}\right)$ values have been reported for male rats [47]; a similar trend was noticed in our animals, but not exceeding a factor of 2 [2]. Gc and RBP level of our male and female controls also varied. The most marked difference was the almost complete absence of thiostatin $\left(\alpha_{1}-\mathrm{MAP}\right)$ in the serum of healthy males, whereas it was clearly detectable in control females [2]. Except for the latter, the changes in acute-phase protein levels were similar in male and female rats. $\alpha_{2}$-Macroglobulin was higher in inflamed males, in agreement with earlier reports [48]. 
The major acute-phase protein $\left(\alpha_{1}\right.$-MAP) of rat serum has been given different synonymous designations, to stress one or another of its functions. It is also named T-kininogen 1 precursor, after the sequence of T-kinin it contains, and thiostatin, after its inhibitory effect on cysteine proteases. Two genes exist for this protein, resulting from a duplication event: MAP1 and MAP2 [49, 50]. Two types of proteins are indeed found in plasma, differing in their $\mathrm{p} /$ by about $0.3 \mathrm{pH}$ units, in agreement with computation based on amino acid composition [42]. Their baseline levels are different: $\alpha_{1}$-MAP (2) is more abundant than $\alpha_{1}$-MAP (1) in female rats, and is also the only form present (in very small amounts) in control males. The concentration of each peptide and, in detail, of each glycoform, appears to be raised to a similar extent by acute inflammation (not shown). Strict coregulation of $\alpha_{1}$-MAP (1) and $\alpha_{1}$-MAP (2) is not a rule, however. Pharmacological treatments [5] as well as different phlogistic stimuli may bring about a differential modulation of the two peptides.

The glycosylation pattern of serum proteins has been reported to change under various physiological and pathological conditions [51], including inflammation [52]. In humans, detailed studies have been devoted, for instance, to Tf [53] and to orosomucoid [54]. In the present investigation no systematic comparison of the differences in glycosylation between control and inflamed pattern was performed since the concentrations were adjusted to the detection of few proteins of specific interest while the stainability of the various glycoproteins differs widely (as shown in [2]). Quantitations after protein blotting are further complicated by the limited binding capacity of the NC membrane as well as by the narrow dynamic range of the zymograming techniques. However, among the assayed serum components, for $\alpha_{1}-I_{3}$ and Tf the protein secreted during inflammation appears more glycosylated than under basal conditions (Fig. 4).

\subsection{Biological aspects}

It has been shown that the concentration of about $30 \%$ of the liver proteins differs between male and female Wistar rats, the reason for this gender-related distinction being the level of estrogen [55]. It is not surprising that a similar trend is likewise observed for the plasma proteins, also synthesized by the liver and then secreted to the circulatory stream instead of being released within the parenchymal cells. With a cut-off at $25 \%$ difference in baseline levels, and with reference to individual spots, approximately $40 \%$ of the serum components were found to be present at higher concentrations in females, while only $10 \%$ of the serum components were found to be higher in males. For almost all proteins the responses to the inflammatory stimulus were found to be similar in male and female rats. The effects of the mediators of inflammation and of the steroid hormones thus appear additive and not synergistic. The only major exception to this trend is thiostatin, for which, however, the baseline level for most of the isoforms in males is almost below the detection limit so that computations of percent increase are highly inaccurate.

The overall impression from the observations above is that serum proteins behave as a coordinate system. In fact, the concentration of virtually all serum components is affected by inflammation, which means - owing to our selection on data reduction - that their synthesis rate is modified. The total protein concentration in inflamed sera changes slightly [7]. A significant drop is observed for the most abundant among the serum proteins, albumin. It might be speculated that its levels could decrease during inflammation by a compensatory effect, so that down-regulation would not occur at the genetic level, but rather as a result of competition for available resources, such as aminoacyl-tRNA or ATP. The opposite situation has been described in detail, namely the compensatory adjustments observed in the serum of analbuminemic rats [56]; the concentration of globulins $\left(\alpha_{1}-\mathrm{AT}, \mathrm{Tf}, \mathrm{Cp}, \operatorname{IgG}, \operatorname{IgA}\right.$ and IgM but not orosomucoid) rises [57], with especially large effects on high $M_{r}$ components such as $\alpha_{2}-\mathrm{M}$ (whose concentration increases 12-fold) and $\alpha_{1}-I_{3}$ (whose concentration doubles) [58]. Also, in humans, lack of albumin is compensated for so as to obtain unchanging total protein concentration and oncotic pressure [59].

The authors thank Profs. Philippe Arnaud and Adriana Maggi for fruitful discussion. When Papers I and II of this series were prepared, E.G. was awfully inept with all image treatment programs; she is very grateful to Mr. Antonio Del Rio for all his teaching and all his help. P.H. and R.A. wish to acknowledge funding support from the National Science Foundation as part of the Science and Technology Center for Molecular Biotechnology at the University of Washington.

Received October 31, 1998

\section{References}

[1] Haynes, P., Miller, I., Aebersold, R., Gemeiner, M., Eberini, I., Lovati, M. R., Manzoni, C., Vignati, M., Gianazza, E., Electrophoresis 1998, 19, 1484-1492.

[2] Miller, I., Haynes, P., Gemeiner, M., Aebersold, R., Manzoni, C., Lovati, M. R., Vignati, M., Eberini, I., Gianazza, E., Electrophoresis 1998, 19, 1493-1500.

[3] http://weber.u.washington.edu/ ruedilab/aebersold.html

[4] http://imiucca.csi.unimi.it/ ratserum/homeframed.html 
[5] Eberini, I., Miller, I., Zancan, V., Bolego, C., Puglisi, L., Gemeiner, M., Gianazza, E., Electrophoresis 1999, 20, 846-853.

[6] Putnam, F. W. (Ed.), The Plasma Proteins Academic Press, Orlando 1975, 1977, 1984, Vol. I-IV.

[7] Schreiber, G., Howlett, G., Nagashima, M., Millership, A., Martin, H., Urban, J., Kotler, L., J. Biol. Chem. 1982, 257, 10271-10277.

[8] Gianazza, E., in: Link, A. J. (Ed.), 2-D Proteome Analysis Protocols, Humana Press, Totowa 1998.

[9] Gianazza, E., Giacon, P., Sahlin, B., Righetti, P. G., Electrophoresis 1985, 6, 53-56.

[10] Hawkes, R., Anal. Biochem. 1982, 123, 143-146.

[11] Taketa, K., Electrophoresis 1987, 8, 409-414.

[12] Gianazza, E., Celentano, F., Ettori, C., Righetti, P. G., Electrophoresis 1989, 10, 806-808.

[13] Garrels, J. I., J. Biol. Chem. 1989, 25, 5269-5282.

[14] Rodkey, F. L., Clin. Chem. 1965, 11, 478-487.

[15] Doumas, B. T., Watson, W. A., Biggs, H. G., Clin. Chim. Acta 1971, 31, 87-96.

[16] van Oostveen, I., Ducret, A., Aebersold, R., Anal. Biochem 1997, 247, 310-318.

[17] Haynes, P. A., Fripp, N., Aebersold, R., Electrophoresis 1998, 19, 939-945.

[18] Ducret, A., van Oostveen, I., Eng, J. K., Yates, J. R. I., Aebersold, R., Prot. Sci. 1997, 7, 706-719.

[19] Eng, J., McCormack, A. L., Yates, J. R. I., J. Am. Soc. Mass Spectrom. 1994, 5, 976-989.

[20] Yates, J. R. I., Eng, J. K., McCormack, A. L., Schieltz, D. Anal. Chem. 1995, 67, 1426-1436.

[21] http://bmbsgi11.leeds.ac.uk/bmb5dp/owl.html

[22] Bleasby, A. J., Akrigg, D., Attwood, T. K., Nucleic Acids Res. 1994, 22, 3574-3577.

[23] Schumaker, V. N., Puppione, D. L., Methods Enzymol. 1986, 128, 155-170.

[24] Gauthier, F., Ohlsson, K., Hoppe-Seylers Z. Physiol. Chem. 1978, 359, 987-992.

[25] Lonberg-Holm, K., Reed, D. L., Roberts, R. C., Hebert, R. R., Hillman, M. C., Kutney, R. M., J. Biol. Chem. 1987, 262 438-445.

[26] Braciak, T. A., Northemann, W., Hudson, G. O., Shiels, B. R., Gehring, M. R., Fey, G. H., J. Biol. Chem. 1988, 263 3999-4012.

[27] Rassouli, M., Sambasivam, H., Azadi, P., Dell, A., Morris, H. R., Nagpurkar, A., Mookerjea, S., Murray, R. K., J. Biol. Chem. 1992, 267, 2947-2954.

[28] Sambasivam, H., Rassouli, M., Murray, R. K., Nagpurkar, A., Mookerjea, S., Azadi, P., Dell, A., Morris, H. R., J. Biol. Chem. 1993, 268, 10007-10016.

[29] Collard, M. W., Griswold, M. D., Biochemistry 1987, 26 3297-3303.

[30] Bettuzzi, S., Hilipakka, R. A., Gilna, P., Liao, S. T., Biochem. J. 1989, 257, 293-296.

[31] Anderson, N. L., Immunol. Lett. 1981, 2, 195-199.

[32] Manolis, A., Cox, D. W., Prep. Biochem. 1980, 10, 121-132.

[33] Fleming, R. E., Gitlin, J. D., J. Biol. Chem. 1990, 265 7701-7707.
[34] Daveau, M., Jean, L., Soury, E., Olivier, E., Masson, S., Lyoumi, S., Chan, P., Hiron, M., Lebreton, J. P., Husson, A., Jegou, S., Vaudry, H., Salier, J. P., Arch. Biochem. Biophys. 1998, 350, 315-323.

[35] Soury, E., Olivier, E., Daveau, M., Hiron, M., Claeyssens, S., Risler, J. L., Salier, J. P., Biochem. Biophys. Res. Commun. 1998, 243, 522-530.

[36] Keay, G., Doxeny, D. L., Res. Vet. Sci. 1983, 35, 58-60.

[37] Heukeshoven, J., Dernick, R., in: Radola, B. J. (Ed.), Elektrophorese Forum '86, Technical University, Munich 1986, pp. 22-27.

[38] Miller, I., Gemeiner, M., Electrophoresis 1992, 13, 450-453.

[39] Schwick,H. G., Haupt, H., Behring Inst. Mitt. 1986, 80, $1-10$.

[40] Kushner, I., in: Arnaud, P., Benvenu, J., Laurent, P. (Eds.), Marker Proteins in Inflammation, W. deGruyter, Berlin 1984, Vol. 2, pp. 3-14.

[41] Kushner, I., Methods Enzymol. 1988, 163, 373-383.

[42] http://expasy.hcuge.ch/sprot/

[43] Arnaud, P., Gianazza, E., Miribel, L., Methods Enzymol. 1988, 163, 441-452.

[44] Ikawa, M., Shozen, Y., J. Immunol. Methods 1990, 143, 101-106.

[45] Schreiber, G., Tsykin, A., Aldred, A. R., Thomas, T., Fung, W.-P., Dickson, P. W., Cole, T., Birch, H., De Jong, F. A., Milland, J., Ann. N. Y. Acad. Sci. 1989, 557, 61-85.

[46] Marshall, T., Williams, K. M., Vesterberg, O., Electrophoresis 1985, 6, 392-398.

[47] Chai, K. X., Ma, J.-X., Murray, S. H., Chao, J., Chao, L., J. Biol. Chem. 1991, 266, 16029-16036.

[48] Baldo, B. A., Chow, S. C., Euers, C., Agents Actions 1981, 11, 482-489.

[49] Kageyama, R., Kitamura, N., Ohkubo, H., Nakanishi, S., J. Biol. Chem. 1985, 260, 12060-12064.

[50] Kitagawa, H., Kitamura, N., Hayashida, H., Miyata, T., Nakanishi, S., J. Biol. Chem. 1987, 262, 2190-2198.

[51] Baenziger, J. U., in: Putnam, F. W. (Ed.), The Plasma Proteins, Academic Press, Orlando 1984, Vol. 4, pp. 271315.

[52] Van Dijk, W., Mackiewicz, A., Ann. N. Y. Acad. Sci. 1995, 762, 319-330.

[53] de Jong, G., van Noort, W. L., Feelders, R. A., de Jeu-Jaspars, C. M., van Eijk, H. G., Clin. Chim. Acta 1992, 212, 27-45.

[54] Hansen, J. E., Bøg-Hansen, T. C., Pedersen, B., Neland, K., Electrophoresis 1989, 10, 574-578.

[55] Anderson, N. L., Giere, F. A., Nance, S. L., Gemmell, M. A., Tollaksen, S. L., Anderson, N. G., in: Galteau, M.-M., Siest, G. (Eds.), Recent Progresses in 2D Electrophoresis, Presses Universitaires de Nancy, Nancy 1986, pp. 253260

[56] Nagase, S., Shimamune, K., Shumiya, S., Science 1979, 205, 590-591.

[57] Emori, T., Takahashi, M., Sugiyama, K., Shumiya, S. Nagase, S., Jikken-Dobutsu 1983, 32, 123-132.

[58] Stevenson, F. T., Greene, S., Kaysen, G. A., Kidney Int. 1998, 53, 67-75.

[59] Peters, T., Adv. Protein Chem. 1985, 37, 161-245. 
[60] Urban, J., Chan, D., Schreiber, G., J. Biol. Chem. 1979, 254, 10565-10568.

[61] Koj, A., Dubin, A., Kasperczyk, H., Bereta, J., Gordon, H., Biochem. J. 1982, 206, 545-553.

[62] Aiello, L. P., Shia, M. A., Robinson, G. S., Pilch, P. F., Farmer, S. R., J. Biol. Chem. 1988, 263, 4013-4022.

[63] Gordon, A. H., Biochem. J. 1976, 159, 643-650.

[64] Cole, T., Inglis, A. S., Roxburgh, C. M., Howlett, G. J., FEBS Lett. 1985, 182, 57-61.
[65] Okubo, H., Miyanaga, O., Nagano, M., Ishibashi, H., Kudo, J., Ikuta, T., Shibata, K., Biochim. Biophys. Acta 1981, 668, 257-267.

[66] Lombart, C., Dautrevaux, M., Moretti, J., Biochim. Biophys. Acta 1965, 97, 270-274.

[67] Chao, J., Chai, K. X., Xiong, W., Chao, S., Woodley-Miller, C., Wang, L., Lu, H. S., Chao, L., J. Biol. Chem. 1990, 265, 16394-16401.

[68] Pages, G., Rouayrenc, J. F., Le Cam, G., Mariller, M., Le Cam, A., Eur. J. Biochem. 1990, 190, 385-391. 


\section{Chapter 7}

General discussion and conclusions

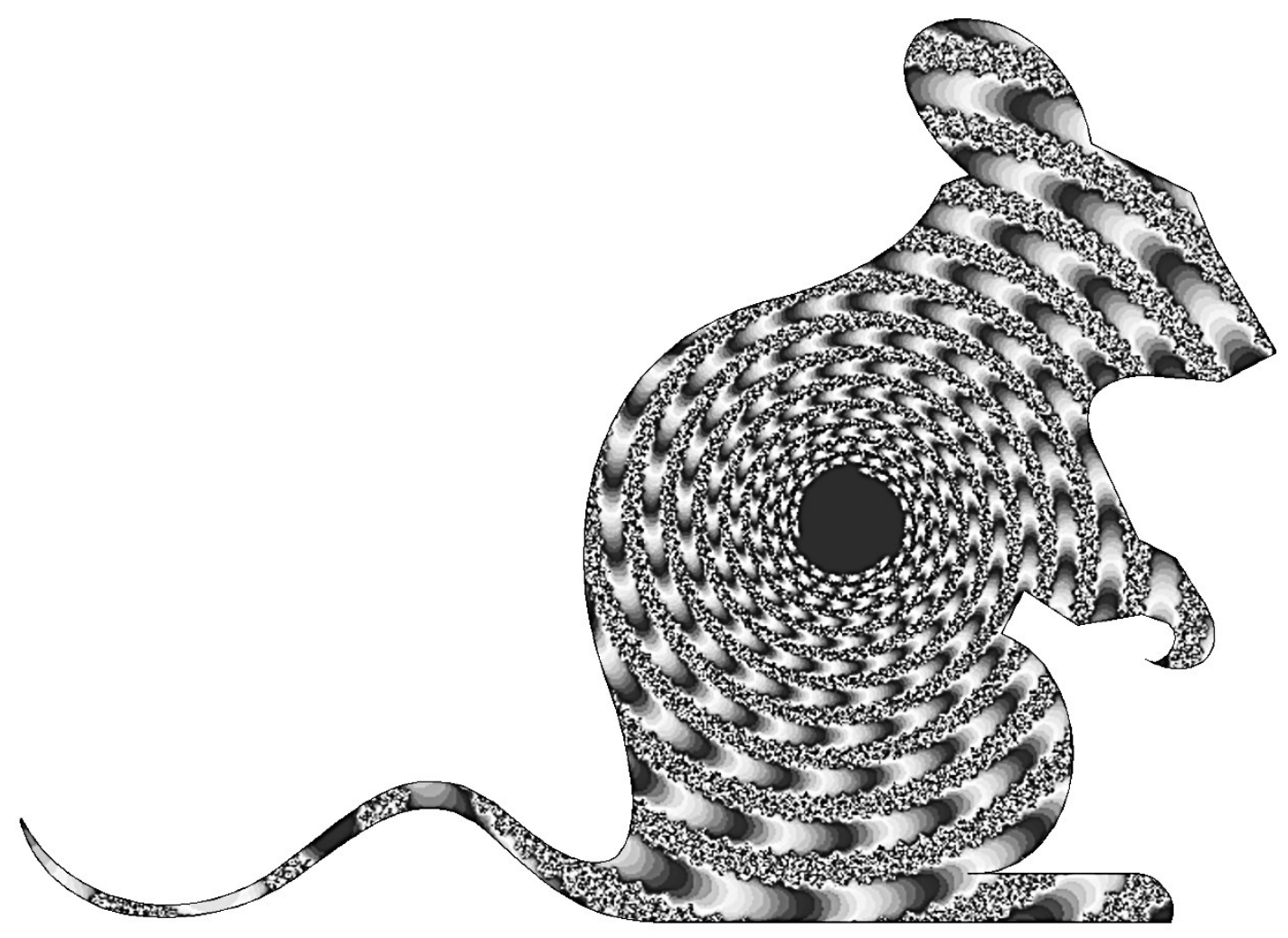





\section{General discussion}

The mechanisms of action of sub-lethal effects of toxic compounds can be hard to explain based on general toxicological data from animal experiments only or from determination of single biochemical parameters which are hypothesized to be altered. Sometimes results are inconsistent or even contradictory, and mechanisms of actions are not clear (yet). In these cases, modern analytical methods like proteomics, offering a holistic and non-targeted approach, may help to shed light to specific aspects and add a new perspective to research in this field. Proteomic methods investigate all proteins detectable in an analytical system under clearly defined conditions and not specifically a few that had been preselected by induction based on previous results. Thus, proteomic methods are able to detect not yet known to be affected or still little explored proteins and to relate them to specific pathways. In this way proteomics may help to reveal new or clarify ill understood mechanisms of actions of different toxic compounds. Proteomics of serum/plasma offers as a non-invasive technique also the possibility to study exposure induced effects over time getting more data from the same number of animals. This can also greatly contribute to the $3 \mathrm{R}$ strategy of replacement, reduction and refinement of animal experiments.

This thesis aims at evaluating the use of proteomics in toxicological research both by compiling proteomic literature data on halogenated organic compounds in a review and by experimentally investigating effects of a model halogenated organic compound. To achieve this, gel-based proteomics is applied to study the influence of the brominated flame retardant hexabromocyclododecane (HBCD) on the liver proteome of female and male rats exposed to sub-lethal doses of this compound for one week. The animals had either a normal thyroid status (euthyroid, ET) or were hypothyroid (HT) as it was suggested that a HT status could render animals more susceptible to HBCD [van der Ven et al., 2006].

Liver is chosen as target tissue, as it is the main detoxifying and protein synthesizing organ and one of the first tissues exposed to HBCD after oral uptake. Rats of both genders are studied in separate groups because gender-specific responses have been indicated [van der Ven et al., 2006, Cantón et al., 2008; Germer et al., 2006]. 
Firstly, in Chapter 2 a general overview about possibilities and strategies in gel-based proteomics is provided, taking into account different separation strategies as well as adaptations of the workflow made necessary by the sample type under investigation. It contains also a brief survey on sample pre-fractionation options to facilitate investigation of minor proteins.

Next a more detailed overview about proteomic methods is given in Chapter 3, with special attention for the additional benefit of proteomic methods in toxicological investigations. Compounds of interest are halogenated organic compounds like dioxins, polychlorinated biphenyls (PCBs), and polybrominated diphenyl ethers (PBDEs) whose influence on the liver proteome of various species had been studied by different proteomic approaches.

Thus, based on literature data, these two chapters give a detailed and positive answer to research question 1: What are the possibilities and strategies in proteomics as a tool to study sub-lethal toxicological effects of compounds with a long term effect? The following chapters provide answers obtained from own experiments.

Chapters 4 and 5 investigate pattern changes in the liver proteome of ET and HT rats which underwent short-time exposure with HBCD: Chapter 4 in females, Chapter 5 in males, both in an identical experimental setup.

Proteomic analysis and data evaluation allow answering the following research questions:

\section{2) Is it possible to see changes in the rat liver proteome in sub-lethal and short-term exposure to HBCD, by using a modern gel-based proteomic method?}

Two-dimensional fluorescence difference gel electrophoresis (2D-DIGE), as applied in the presented proteomic studies, is known as a very sensitive method, allowing determination of small relative abundance differences between single proteins/protein spots in complex samples with high precision [Marouga et al., 2005; Timms and Cramer, 2008]. These requirements are especially important in studies like the presented ones 
where only small changes in the protein pattern were expected. The large gel size in the selected 2D-DIGE system resulted in complex protein spot patterns of about 3000 protein spots. Stringent statistical evaluation of patterns of the differently exposed animals (12 groups of 4 animals each) revealed that the majority of spots in the patterns $(>80 \%)$ were of constant appearance, only a small percentage of them showing significant changes in abundance due to HBCD exposure, thyroid state and gender. Thus, the test system proved suitable for in-depth investigation of different factors of influence, as addressed in research questions 3 and 4.

This was the first proteomic study investigating HBCD effects on rat liver, whereas previous reports described changes on the gene level, consisting of transcriptional data from microarrays and quantitative PCR [Cantón et al., 2008]. Such changes on the transcriptional level may be transient only and not translated into changes of the proteome at all, as has been shown in other investigations [Greenbaum et al., 2003; Tian et al., 2004]. Proteomics in turn has the advantage to give a functional picture of ongoing processes in which changed proteins are involved. Furthermore, the present investigation studied direct effects of short term exposure, with a lower chance to monitor also secondary effects of chronic exposure. Therefore, short term exposure may result in a different data set, better reflecting primary effects of exposure to $\mathrm{HBCD}$, though it bears the risk of smaller changes of fewer analytes, showing only the early response.

\section{3) Which liver proteins and pathways are influenced by short-term exposure to HBCD in euthyroid versus hypothyroid animals?}

Though gender is the topic of research question 4 , it proved to have a considerable (and combined) effect in response to $\mathrm{HBCD}$, also in proteomic studies. In female rats, about 1 $\%$ of all spots detected in the overall liver protein pattern were significantly altered in abundance due to HBCD exposure, in either ET or HT status, while in male rats very limited effects were found. Affected proteins were mainly related to general metabolic pathways like lipid metabolism, glycolysis/gluconeogenesis, and processing of different amino acids, but also to oxidative stress response. This confirmed findings of previous studies with female ET rats receiving higher doses of HBCD (daily oral exposure of 30 to $100 \mathrm{mg} / \mathrm{kg}$ bw for 28 days) which had reported an influence on gene expression of key 
metabolic pathways including metabolism of lipids and cholesterol as well as steroids [Cantón et al., 2008; van der Ven et al., 2006].

In contrast to females, the liver proteome of male animals showed only a few differentially abundant protein spots, which belonged to different metabolic pathways with no obvious connection. Gene microarray data on chronically exposed ET rats had reported an influence of HBCD in lipid metabolism also in males [Cantón et al., 2008], whereas in the present study only a not significant influence on (the increased) serum leptin concentrations of HT males was noticed. This might be interpreted as a preliminary stage for changes in the lipid metabolism also on the protein level, possibly also as a sign for different susceptibility depending on thyroid status. Clear differences in gene expression levels of various glutathione transferases (proteins which help excrete e.g. xenobiotics) after 28d [Cantón et al., 2008] were also in contrast to their unchanged protein concentrations after one week (Chapter 5), both determined in males rats. The latter may be either explained by the differing exposure times (development of chronic effects) or by discrepancy between gene and protein levels.

It is interesting to note that hypothyroid state alone has a marked impact on the protein pattern of female rats with similar (or no) exposure (about 1.5-3.4 \% of the detected spots were significantly thyroid-regulated). In unexposed females proteins with changed abundance are connected to metabolism of various amino acids, glycolysis/gluconeogenesis, and especially lipid metabolism. Cantón et al. hypothesized that the reported effects are the indirect consequences of higher/prolonged HBCD challenge leading to hypothyroidism [Cantón et al., 2008; van der Ven et al., 2006]. In the present study, however, with a much shorter exposure period the same pathways were found influenced by HBCD both in ET and HT females. Reported perturbations of genes related to lipid and fatty acid metabolisms [Cantón et al., 2008] correlate well with proteomic findings of increased triglyceride catabolism in female HT, and of increased levels of the satiety hormone leptin, and reduced body weight. In the $3 \mathrm{mg} / \mathrm{kg} /$ day group comparison, additionally 5-7 proteins (mainly glutathione-S-transferases) were found differentially regulated, these are proteins involved in both the glutathione metabolism and the processing of various xenobiotics or drugs by cytochrome P450. Eleven proteins were consistently changed between female animals of similar exposure but different thyroid state. They are mostly related to stress response, lipid metabolism and detoxification processes and seem to be characteristic of the altered thyroid status. 
In contrast to this, a similar evaluation of the male rat liver patterns found only a few single proteins affected by thyroid state, mainly involved in metabolic processes.

Thus, proteomic investigation in this short-term model showed for female rats the following interesting findings: i) liver protein patterns reflect thyroid status, and ii) there is an overlap in pathways influenced by HBCD exposure and thyroid status. At the same time, both factors have little impact on the liver proteome of male rats, at least in shorttime exposure. This goes in parallel with values for HBCD accumulation in white adipose tissue, where a clear gender dependent effect $(P=0.001)$ was noticed, with less accumulation in male rats. Female rats thus seem much more vulnerable to HBCD accumulation, and effects from both HBCD exposure as well as thyroid status.

The proteomic investigation on liver thus confirms (and details) findings from previous studies with a much longer exposure time and higher total and often daily doses [Cantón et al, 2008] regarding HBCD influence on to lipid metabolism, triacylglycerol and cholesterol metabolism in female ET. In the reported study, especially in males, genes involved in phase I and II metabolism were upregulated, which the authors explained as the cause for lower susceptibility to HBCD of males as compared to females. In the present proteomic studies, no influence on corresponding proteins could be seen. This might be related to shorter and lower exposure as only limited differences in those gene levels were found at daily doses similar to our study [Cantón et al., 2008]. Similarly, changes in the liver weight of exposed animals were only found in female rats of the 28 day study with high exposure [van der Ven et al., 2006] and not in our present experimental setup, in neither of the thyroid states.

\section{4) What is the impact of gender on the liver proteome?}

The gender aspect on the liver proteome, already demonstrated to be important in the previous question in relation to $\mathrm{HBCD}$, was additionally studied in more depth in the complete proteomic data set of unexposed male and female rats. This revealed a considerable number of significant gender-related abundance changes in spots belonging to 76 proteins in ET state (corresponding to $3.6 \%$ of all detected spots), and even to 109 proteins in HT state (about $6.7 \%$ of overall spots), with an almost similar number of up- 
and downregulated proteins. The vast majority of them were connected to metabolic processes, but there was also a strong cluster of proteins related to cytochrome P450 (drug metabolism, metabolism of xenobiotics) and glutathione metabolism, especially in ET animals. In HT animals a considerable number of proteins from the fatty acid metabolism were differentially affected between genders. This is confirmed by literature data on rat feeding experiments to investigate obesity and alcoholic steatohepatitis in rats [Amengual-Cladera et al., 2012; Nadal-Casellas et al., 2010; Banerjee et al., 2008, Wang et al., 2012]. Gender-related differences in lipid metabolism may be the reason for the observed different accumulation of HBCD in adipose tissue in the present studies.

Previous studies report also gender dimorphism in liver mitochondrial oxidative metabolism [Borras et al., 2003, Ståhlberg et al., 2004; Justo et al., 2005], namely in CYP450 isoforms in microsomes [Nisar et al., 2004; Germer et al., 2006; Huang et al., 2011]. The present proteomic study, investigating complete unfractionated liver, detected - though not differentially regulated CYP450 proteins - but gender-specific differences in proteins connected to metabolism of xenobiotics/drug metabolism, specifically members of the glutathione S-transferase family. It is not yet clarified whether CYP450 concentrations were not significantly changed in the present study or whether they were too low abundant to be detected in the chosen setup using complete liver lysates.

Interestingly, there is a large overlap between pathways reported in this section as gender-dependently regulated and the previous section about HBCD-influenced proteins. This leads to the hypothesis that physiological differences in protein concentrations between genders may be the reason for different susceptibility towards HBCD between male and female rats. This aspect should be detailed/deepened in further studies, also focusing on single pathways to further elucidate gender- and HBCD-specific reactions and protein modifications. Understanding this aspect will enable predictions of other pathways that can expected to be affected in a gender-specific way.

Chapter 6 connects research question 4 from recent liver proteomic studies with a previous study on gender specific serum proteome differences of rats under control conditions or during inflammation. Though performed on a quite different sample set and not in connection to a toxicology study, results from this chapter help to discuss the question: 


\section{5) Is gender reflected in serum protein composition and what implications does this have on the search for biomarkers?}

Serum and plasma represent body fluids potentially interesting also for toxicological screening, allowing less invasive and multiple testing on the same individual over time, to study time-dependent changes in protein patterns. Protein pattern comparison in sera of male and female Sprague Dawley rats has been performed in a classical 2-DE setup with a colorimetric stain and was the first proteomic study of this effect. It was performed both in healthy controls and after stimulation of an acute phase reaction, i.e. induction of the body's first and general reaction in defence against bacteria or viruses. In healthy controls about one third of the high to medium abundance proteins were shown to differ in concentrations in a gender-dependent way, with at least $25 \%$ change in concentration. Experimentally induced inflammation influenced the overall abundance of proteins known to be involved in the acute phase reaction (increase of positive and decrease of negative acute phase proteins), mostly in a very similar way for males and females.

Several of these inflammation markers or enzymes with inhibitory properties had also been detected in the gender-specifically regulated liver protein set (question 4), connecting the outcomes derived from the liver and the plasma samples. Similarly, serum protein composition reflected gender-specific differences in lipid and lipoprotein metabolism, namely in the distribution of serum apolipoproteins. This fits very well to the noticed lipid metabolism changes in liver proteins in this study and in literature. A few studies on rats have connected gender-dimorphism in plasma proteins with susceptibility to diseases such as diabetes [Choi et al., 2013], hypertension, renal and brain damage [Ballerio et al., 2007]), but also to protein modulation in high fat diet [Liu et al., 2012].

Serum and plasma represent body fluids potentially interesting also for toxicological screening, allowing less invasive and multiple testing on the same individual over time, to study time-dependent proteome changes. However, there are a few points to consider:

- Serum contains large amounts of proteins with concentrations spanning over more than ten orders of magnitude [Anderson and Anderson, 2002]. Only a very small fraction of them are considered as molecules potentially interesting as reflecting health/disease status of organ systems, i.e. tissue leakage products. Selected and specific markers reflecting e.g. status of the liver have to be very well distinguishable from the overwhelming amount of serum proteins, and need very specific and sensitive detection. 
Compared to abundance in the target organ, they often appear delayed in time in serum or altered in structure, and are likely diluted within the circulation [Hartwell et al., 2006]. This aim is easier to reach in chronic biomonitoring, with higher or accumulated compound load, but more prone to detect secondary (e.g. compensation) effects. Therefore, primary research will still focus on the target organ, e.g. liver, and - after careful validation of these findings - potentially interesting and specific marker proteins could in a second step be searched for in blood with a very sensitive assay.

- Potentially interesting biomarkers need to be carefully selected to characterize the condition of interest (and clearly distinct from other disorders that occur frequently or to be easily confused with) and the regulation, taking into account also factors like age or life stage. Over the years proteomic studies have become more and more sensitive and found out that - in contrast to previous assumptions - disease or exposure induced alternations are seldom appearance / disappearance of proteins but are of quantitative nature or affect only single modifications (e.g. due to glycosylation or phosphorylation) or forms of a protein (e.g. truncated or breakdown products), the so-called proteoforms or protein species [Smith et al., 2013; Jungblut et al., 2008]. A mixture of these effects was also seen in serum under inflammation (Chapter 6). Proteoforms are influenced also by the cellular location of the protein, e.g. the secretion of a protein into blood circulation, compared to its appearance in liver tissue.

- The previous paragraph already pointed out the importance of selecting appropriate marker proteins. An additional point to consider is that exposure to agents often leads to a combination of general and specific protein responses. There is a general reaction of the organism/cell giving rise to changes in an often similar set of proteins (general stress proteins as described by [Petrak et al., 2008; Wang et al., 2009]) apart from specific reactions such as induced by a toxic agent like PCB-153 [Berg et al., 2011]. Candidates of interest should ideally be related to specific responses or be a set of candidates which are supposed to react in a specific manner.

\section{Concluding remarks}

Proteomics is a promising analytical method presently underrepresented in toxicological studies, but may well contribute to gain more insight into yet not fully understood mechanisms. This is equally illustrated in a review on previously published studies 
dealing with liver proteome changes due to exposure to selected organic compounds known to act as endocrine disruptors, and in own studies on the HBCD induced effects detectable in exposed rats of bother genders.

Described investigations on the liver proteome were the first performed in a short-term low concentration HBCD model, selected based on literature findings, trying to avoid monitoring also protein changes arising from secondary effects. Clear gender dependent influence of HBCD was noticed, affecting primarily female rats and influencing mainly proteins involved in lipid metabolism, in gluconeogenesis/glycolysis and metabolism of different amino acids, as well as response to oxidative stress. This had till now only be shown at the level of gene regulation or as changed levels of metabolic products after longer exposure periods. Additionally, this is the first comparison on the liver proteomes of eu- and hypothyroid rats, showing altered levels of a number of proteins in females, but no marked influence in males. The largest influence in protein pattern came from animal gender, and involved main metabolic pathways, mainly those which were also affecting in HBCD exposure. Thus, it is hypothesized that those gender differences are also the reason for higher susceptibility of female rats indicated by other authors in investigations focusing on single analytes. Liver is not the only organ whose protein composition is influenced by gender, this effect has also been seen e.g. in serum/plasma (affecting lipid metabolism, but also acute phase reaction).

The gender-specific aspects noticed in our own studies (on liver, but also serum proteins) and literature reports underline the importance to study toxicological effects in males and females, also in pharmacological models. This is in line with a recent NIH directive/recommendation for clinical studies [Clayton, 2014; Clayton, 2016].

Presented results point out not only the sensitivity of proteomics as a family of methods suitable to study sub-lethal toxicological effects which may cause only minor changes in the proteome, but also provide evidence for differences in the liver and serum proteome of rats, offering a good basis for further studies in this field.

\section{Future perspectives}

Basic research, on the effect of the investigated compounds, e.g. HBCD, as well as evaluation of gender and life stage specific baseline patterns in the sample material and 
the influence on different parameters, e.g. gender, is paramount as a first step towards developing alternative biochemical methods for early detection of toxicological effects. Future studies should aim at deepening research in this field, for example by a) a follow-up of single proteins found regulated in the present studies and impact of their regulation of the respective pathways.

b) by focusing on a more detailed characterization of the candidates filtered out in the present studies: most proteins exist in multiple proteoforms (different modifications, e.g. post-translational like glycosylation or phosphorylation, or breakdown products). Many of the proteoforms differ in their electrophoretic migration behaviour in gel-based proteomics and can thus be detected [Rogowska-Wrzesinska et al., 2013; Oliveira et al., 2014]. Determination of the nature of the modification needs often sophisticated mass spectrometry methods which go beyond the setup for determining protein identity. Still, the importance of these modifications is presently more and more acknowledged, as studies show that 1) differently modified proteins are processed in the organism in a different way, and 2) the modification depends on the appearance and localization of the protein in the body which may change [Jungblut et al., 2016].

c) by pre-fractionation of the samples to mine deeper into the liver proteome, e.g. to investigate different cell compartments (enrichment of organelles, see Chapter 2 and [Germer et al., 2006; Nürnberger et al, 2012]). This may for instance help to find out whether the lack of detecting CYP450 proteins in the present studies was due to the short exposure time, too variable or too low concentrations of these proteins.

d) by investigating slightly different exposure schemes (concentration, times) to evaluate influence of $\mathrm{HBCD}$ on the proteome as a function of time.

In chronic experiments with higher accumulated exposure, additional monitoring of the serum proteome would be advisable and would allow studying time-course dependent variations. However, prerequisite for this would be a previous selection of one or more promising specific candidates, preferably not generally detectable in serum (or prefractionated serum).

\section{References:}

Amengual-Cladera, E., Lladó, I., Gianotti, M., Proenza, A. M. (2012). Sex differences in the effect of high-fat diet feeding on rat white adipose tissue mitochondrial function and insulin sensitivity. Metab. Clin. Experim. 61, 1108-1117. 
Anderson, N. L., Anderson, N. G. (2002). The human plasma proteome: history, character, and diagnostic prospects. Mol. Cell. Proteomics 1, 845-867.

Ballerio, R., Gianazza, E., Mussoni, L., Miller, I., Gelosa, P., Guerrini, U., Eberini, I., Gemeiner, M., Belcredito, S., Tremoli, E., Sironi, L. (2007). Gender differences in endothelial function and inflammatory markers along the occurrence of pathological events in stroke-prone rats. Exp. Molec. Pathol. 82, 33-41.

Banerjee, A., Russell, W. K., Jayaraman, A., Ramaiah, S. K. (2008). Identification of proteins to predict the molecular basis for the observed gender susceptibility in a rat model of alcoholic steatohepatitis by 2-D gel proteomics. Proteomics. 8, 4327-4337.

Berg, K., Puntervoll, P., Klungsøyr, J., Goksøyr, A. (2011). Brain proteome alterations of Atlantic cod (Gadus morhua) exposed to PCB 153. Aquat. Toxicol. 105, 206-217.

Borras, C., Sastre, J., Garcia-Sala, D., Lloret, A., Pallardo, F. V., Vina, J. (2003). Mitochondria from females exhibit higher antioxidant gene expression and lower oxidative damage than males. Free Radical Biol. Med. 34, 546-552.

Cantón, R. F., Peijnenburg, A. A., Hoogenboom, R. L., Piersma, A. H., van der Ven, L. T., van den Berg, M., Heneweer, M. (2008). Subacute effects of hexabromocyclododecane (HBCD) on hepatic gene expression profiles in rats. Toxicol. Appl. Pharmacol. 231, 267-272.

Choi, J.-W., Aseer, K. R., Chaudhari, H. N., Mukherjee, R., Cho, M., Yun, H. W. (2013). Gender dimorphism in regulation of plasma proteins in streptozotocin-induced diabetic rats. Proteomics 13, 2482-2494.

Clayton, J. A. (2016). Studying both sexes: a guiding principle for biomedicine. FASEB $J .30$, article fj.15-279554. Published online October 29, 2015 (epub ahead of print).

Clayton, J. A., Collins, F. S. (2014). NIH to balance sex in cell and animal studies. Nature 509, 282-283.

Germer, S., Piersma, A. H., van der Ven, L., Kamyschnikow, A., Fery, Y., Schmitz, H.J., Schrenk, D. (2006). Subacute effects of the brominated flame retardants hexabromocyclododecane and tetrabromobisphenol A on hepatic cytochrome P450 levels in rats. Toxicology 218, 229-236.

Greenbaum, D., Colangelo, C., Williams, K., Gerstein, M. (2003). Comparing protein abundance and mRNA expression levels on a genomic scale. BMC Genome Biology 4, 117; doi: $10.1186 / \mathrm{gb}-2003-4-9-117$.

Hartwell, L., Mankoff, D., Paulovich, A., Ramsey, S, Swisher, E. (2006). Cancer biomarkers: A systems approach. Nature Biotechnol. 24, 905-908.

Huang, H. J., Tsai, M. L., Chen, Y. W., Chen, S. H. (2011). Quantitative shot-gun proteomics and MS-based activity assay for revealing gender differences in enzyme contents for rat liver microsome. J. Proteomics 74, 2734-2744. 
Jungblut, P., Thiede, B., Schlüter, H. (Eds.) (2016), Thematic Issue "Towards deciphering proteome via the proteoform, protein speciation, moonlighting and protein code concepts" in J. Proteomics 134.

Jungblut, P. R., Holzhütter, H. G., Apweiler, R., Schlüter, H. (2008). The speciation of the proteome. Chem. Cent. J. 2, 16.

Justo, R., Boada, J., Frontera, M., Oliver, J., Bermudez, J., Gianotti, M. (2005). Gender dimorphism in rat liver mitochondrial oxidative metabolism and biogenesis. Am. J. Physiol. Cell Physiol. 289, C372-C378.

Liu, H., Choi, J.-W., Yun, J. W. (2012). Gender differences in rat plasma proteome in response to high-fat diet. Proteomics 12, 269-283.

Marouga, R., David, S., Hawkins, E. (2005). The development of the DIGE system: 2D fluorescence difference gel analysis technology. Anal. Bioanal. Chem. 382, 669-678.

Nadal-Casellas, A., Amengual-Cladera, A., Proenza, A. M., Lladó, I., Gianotti, M. (2010). Long-term High-fat-diet Feeding Impairs Mitochondrial Biogenesis in Liver of Male and Female Rats. Cell Physiol. Biochem. 26, 291-302.

Nisar, S., Lane, C. S., Wilderspin, A. F., Welham, K. J., Griffiths, W. J., Patterson, L. H. (2004). A proteomic approach to the identification of cytochrome P450 isoforms in male and female rat liver by nanoscale liquid chromatography-electrospray ionization-tandem mass spectrometry. Drug Metab. Disp. 32, 382-386.

Nürnberger, S., Miller, I., Duvigneau, J. C., Kavanagh, E. T., Gupta, S., Hartl, R. T., Hori, O., Gesslbauer, B., Samali, A., Kungl, A., Redl, H., Kozlov, A. V. (2012). Impairment of endoplasmic reticulum in liver as an early consequence of the systemic inflammatory response in rats. Am. J. Physiol. Gastrointest. Liver Physiol. 303, G13731383.

Oliveira, B.M., Coorssen, J.R., Martins-de-Souza, D. (2014). 2DE: The Phoenix of Proteomics. J. Proteomics 104, 140-150.

Petrak, J., Ivanek, R., Toman, O., Cmejla, R., Cmejlova, J., Vyoral, D., Zivny, J., Vulpe, C. D. (2008). Déjà vu in proteomics. A hit parade of repeatedly identified differentially expressed proteins. Proteomics 8, 1744-1749.

Rogowska-Wrzesinska, A., Le Bihan, M.-C., Thaysen-Andersen, M., Roepstorff, P. (2013). 2D gels still have a niche in proteomics. J. Proteomics 88, 4-13.

Smith, L. M., Kelleher, N. L., The Consortium of Top-Down Proteomics (2013).

Proteoform: a single term describing protein complexity. Nat. Methods 573, 186-187.

Ståhlberg, N., Rico-Bautista, E., Fisher, R. M., Wu, X., Cheung, L., Flores-Morales, A., Tybring, G., Norstedt, G., Tollet-Egnell, P. (2004). Female-Predominant Expression of Fatty Acid Translocase/CD36 in Rat and Human Liver. Endocrinology. 145, 1972-1979. 
Tian, Q., Stepaniants, S.B., Mao, M., Weng, L., Feetham, M. C., Doyle, M. J., Yi, E. C., Dai, H., Thorsson, V., Eng, J., Goodlett, D., Berger, J. P., Gunter, B., Linseley, P.S., Stoughton, R. B., Aebersold, R., Collins, S. J., Hanlon, W. A., Hood, L. E. (2004).

Integrated Genomic and Proteomic Analyses of Gene Expression in Mammalian Cells. Mol. Cell. Proteomics 3, 960-969.

Timms, J.F., Cramer, R. (2008). Difference gel electrophoresis. Proteomics 8, 48864897.

van der Ven, L. T. M., Leonars, P. E. G., Slob, W., Lilienthale, H., Litens, S., Herlin, M., Håkansson, H., Cantón, R. F., van den Berg, M., Visser, T. J., van Loveren, H., Vos, J. G., Piersma, A. H. (2006). A 28-day oral dose toxicity study enhanced to detect endocrine effects of hexabromocyclododecane in Wistar rats. Toxicol. Sci. 94, 281-292.

Wang, P., Bouwman, F. G., Mariman, E. C. M. (2009). Generally detected proteins in comparative proteomics - A matter of cellular stress response? Proteomics 9, 2955-2966.

Wang, X., Choi, J. W., Oh, T. S., Choi, D. K., Mukherjee, R., Liu, H., Yun, J. W. (2012) Comparative hepatic proteome analysis between lean and obese rats fed a high-fat diet reveals the existence of gender differences. Proteomics 12, 284-299. 


\section{Summary}

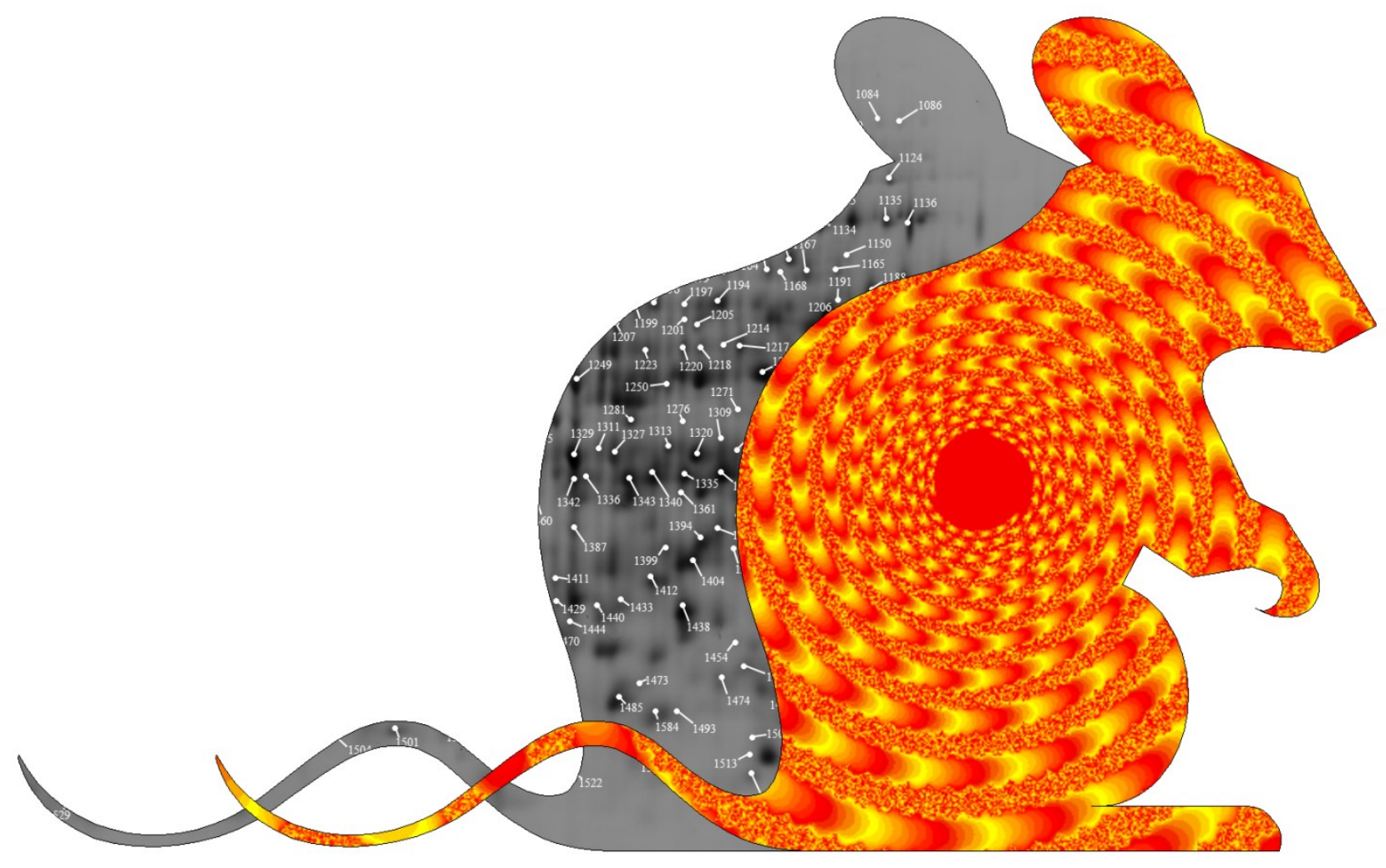



This thesis aims at evaluating the use of proteomics in toxicological research both by compiling proteomic literature data on halogenated organic compounds in a review and by experimentally investigating effects of a model halogenated organic compound. To achieve this, a gel-based proteomic approach was applied to study the influence of the brominated flame retardant hexabromocyclododecane (HBCD) on the liver proteome of female and male rats of different thyroid state exposed to sub-lethal doses of this compound for one week.

In Chapter 1 background information is presented on proteomics in general, but also specifically on gel-based approaches, as well as on HBCD, the chemical compound of interest, its industrial use and its known adverse effects, as potential risk for humans and environment.

Proteomics, the study of the complete, unfiltered set of proteins in a given complex sample, is a modern biochemical analytical family of methods that may help to further elucidate underlying mechanisms of HBCD action to better understand its adverse effect. HBCD is a lipophilic compound that accumulates in adipose tissue from which it is only slowly metabolized and excreted. Although the use of HBCD has been banned in most European countries in 2013, it is still produced and intensively used in other industrial countries, mainly in the building industry. Due to its persistence, accumulation and a not fully understood mechanism of action, it still remains a potential risk for humans, animals and environment, also in countries where its use has been abolished.

Proteomics can be applied as a gel-based approach (by separating proteins by twodimensional electrophoresis prior to identification by mass spectrometry), but also in a gel-free setup, where proteins are enzymatically digested into peptides which are separated and detected by a combination of chromatographic steps, followed by massspectrometric analyses. Chapter 2 gives an overview on strategies applied in gel-based proteomic approaches. A variety of modifications for this separation in two successive steps of electrophoresis exist, depending on the sample type, analysis conditions and methods to detect the separated proteins. There are also a number of possibilities for sample pretreatment and fractionation, usually to reduce the complexity of the specimen and to enrich minor components. Proteins of high to medium abundance often are not the main molecules of interest and responsible for adverse effects noticed in exposure/disease. 
Chapter 3 summarizes main strategies in the field of proteomics, stressing the specific needs and issues in toxicology which often investigate animal species with not completely annotated proteomes. Main examples to illustrate the application and additional benefit of proteomic methods in this field are taken from studies of halogenated compounds such as dioxins, polychlorinated biphenyls (PCBs), and polybrominated diphenyl ethers (PBDEs). Special focus is also on liver as target organ, as it is the main detoxifying and protein synthesizing organ and also the tissue of choice for investigations in the two following chapters. Compiled studies show that, due to its non-targeted and holistic nature, proteomics can both confirm findings of other methods and detect connections to not yet known to be affected proteins or pathways.

Chapters 4 and 5 investigate the influence of low dose and short time orally administered HBCD on the liver proteome of male and female rats of different thyroid state (eu-, hypothyroid). High-resolution 2D-DIGE with subsequent identification of differentially regulated spots was performed, comparing 12 animal groups differing in gender, exposure and thyroid state. Findings were put in relation to basic animal data and hormone values.

Chapter 4 focused on female rats and detected distinct regulation of proteins involved in general metabolism (carbohydrate, lipids, aminoacids), together with oxidative stress related reactions. This is the first study to show HBCD influence on rat liver at the protein level and confirms previous findings from gene regulation studies. However, it is also the first investigation of this kind in hypothyroid animals, being performed as it has been postulated in literature that an altered thyroid status will increase susceptibility to HBCD. In the present short-term study, exposure-induced changes in eu- and hypothyroid status affected similar pathways, but thyroid status per se had a much stronger influence on the spot pattern than exposure.

The same experiment was also performed in male rats, as presented in Chapter 5. In contrast to females, hardly any regulated spots/proteins due to exposure could be detected, and also little influence of thyroid status on the overall protein pattern. This is in line with published observations of different susceptibility of male and female rats towards HBCD, though these experiments had been performed in longer exposure (up to 4 times) experiments with higher doses (daily doses up to 7 times larger). Further investigation of unexposed control groups revealed a considerable gender-specific 
difference in the liver protein composition with altered concentrations of protein involved in glycolysis/gluconeogenesis, fatty acid and metabolism of xenobiotics/drugs. These pathways are also the ones which are affected in females due to HBCD exposure, thus it can be hypothesized that their involvement may be the reason for gender-dimorphic reaction towards $\mathrm{HBCD}$.

Chapter 6 provides evidence for gender-specific protein concentration differences in rat serum, both under baseline conditions and in inflammation. It also links this former approach, on a different set of animals, to the recent studies performed in liver, as also a few serum proteins with known gender-dependent concentrations had been detected in the control group comparisons.

Chapter 7 discusses the benefit and contribution of proteomics to the existing knowledge about HBCD specific effects in rats of both genders. Collected data demonstrate that the proteomic approach was successful, proving the usefulness of gel-based proteomics in the field of environmental proteomics. They also underline the importance of performing animal studies in bother genders, whereas the proteomic results can help explain and predict gender-specific sensitivities. Suggestions to deepen knowledge on the changed proteins and pathways are provided and usefulness of other sample material obtained by less invasive methods is discussed. 


\section{Appendix}

Acknowledgements

About the author

List of selected publications

SENSE diploma 



\section{Acknowledgements}

At this point I would like to thank all who have, directly or indirectly, contributed to the completion of this thesis, who have aroused and encouraged my interest in scientific questions and my curiosity to learn more. It is not possible to give a detailed or comprehensive list, so I will mention just a few. There are of course Tinka, Arno, and Tommaso, and all my co-authors in the publications of the present thesis (as well as all involved institutions), people at my own university in Vienna including my boss for years, Manfred Gemeiner, but also colleagues at other places, like Elisabetta, for continuous support, encouragement and friendship, over years. Last, but not least, this could not have been done without family support, over long years, though unfortunately not all of them lived to see this. A big thank-you to all!

I am also grateful for regulations in the Netherlands allowing me to make my $\mathrm{PhD}$ here, and finally for the existence of modern means of electronic communication; otherwise exchange and close collaboration/communication between places in Austria, the Netherlands and Luxembourg would not have been possible! 


\section{About the author}

Ingrid Miller was born on July 25, 1957 in Vienna, Austria. In 1975, after finishing high school she pursued her studies at the "HBLVA für Chemische Industrie" in Vienna (“post-sekundäres Kolleg für technische Chemie”). After her final exam in 1977 (resulting in the title "Ingenieur" in 1981) she started working at the University of Veterinary Medicine Vienna. First she was employed at the "Ludwig Boltzmann Institut für veterinärmedizinische Endokrinologie", and from early 1979 on at the Institute of Medical Chemistry (present name: Institute of Medical Biochemistry), which is still her employer. Although originally trained in technical chemistry, she focused now on protein chemistry and protein analytics, all centered around proteins of animal origin and from biological sources. Besides protein chromatography, electrophoresis and its different separation approaches based on molecule properties became her specific interest and particularly the newly emerging two-dimensional electrophoretic methods later on called "proteomics". She is a member of several editorial boards of proteomic and analytical journals and regular reviewer. She has been the Austrian representative in the EuPA (European Proteomics Association) General Council for several years and was one of the founding members of the Austrian proteomics society. Since September 2009 she is Executive Editor for Animal Proteomics in the Journal of Proteomics, and has been acting twice as guest editor of thematic issues in Journal of Proteomics (Farm Animal Proteomics, J. Prot. 75/14, 2012; Environment and (Prote)-OMICS, J. Prot. 137, 2016). She has 100 publications cited in Scopus and an h-factor of 19.

Eager to study further, and thanks to advice of Dr. Arno Gutleb, a friend and colleague formerly coming from the University of Veterinary Medicine Vienna, she applied and was admitted to the $\mathrm{PhD}$ program of Wageningen University and was able to perform a thesis in the Toxicology Section under the supervision of Prof. Tinka Murk and at the Centre de Recherche Public - Gabriel Lippmann (now: Luxembourg Institute of Science and Technol-ogy) under the supervision of Dr. Arno Gutleb (co-supervision Dr. Tommaso Serchi) in Belvaux, Luxembourg. In this research on the influence of a brominated flame retardant on the rat liver proteome it was possible to combine results from toxicological studies with data of modern proteomic investigations. 


\section{List of selected publications \\ (Q1 with relevance for this thesis)}

1) Haynes, P., Miller, I., Aebersold, R., Gemeiner, M., Eberini, I., Lovati, M.R., Manzoni, C., Vignati, M., Gianazza, E. (1998). Proteins of Rat Serum: I. Establishing a Reference 2-DE Map by Immunodectection and Microbore High Performance Liquid Chromatography - Electrospray Mass Spectrometry. Electrophoresis 19, 14841492.

2) Miller, I., Haynes, P., Gemeiner, M., Aebersold, R., Manzoni, C., Lovati, M.R., Vignati, M., Eberini, I., Gianazza, E. (1998). Proteins of Rat Serum: II. Influence of Some Biological Parameters on the 2-DE Pattern. Electrophoresis 19, 1493-1500.

3) Miller, I., Haynes, P., Eberini, I., Gemeiner, M., Aebersold, R., Gianazza, E. (1999). Proteins of Rat Serum: III. Gender-related differences in protein concentration under baseline conditions and upon experimental inflammation as evaluated by twodimensional electrophoresis. Electrophoresis 20, 836-845.

4) Eberini, I., Miller, I., Zancan, V., Bolego, C., Puglisi, L., Gemeiner, M., Gianazza, E. (1999). Proteins of Rat Serum: IV. Time-course of acute-phase protein expression and its modulation by indomethacine. Electrophoresis 20, 846-853.

5) Eberini, I., Miller, I., Gemeiner, M., Haynes, P., Aebersold, R., Puglisi, L., Sirtori, C.R., Gianazza, E. (1999). A web site for the Rat Serum Protein Study Group. Electrophoresis 20, 3599-3602.

6) Eberini, I., Agnello, D., Miller, I., Villa, P., Fratelli, M., Ghezzi, P., Gemeiner, M., Chan, J., Aebersold, R., Gianazza, E. (2000). Proteins in rat serum V: Adjuvant arthritis and its modulation by nonsteroidal anti-inflammatory drugs. Electrophoresis $21,2170-2179$.

7) Sironi, L., Tremoli, E., Miller, I., Guerrini, U., Calvio, A.M., Eberini, I., Gemeiner, M., Asdente, M., Paoletti, R., Gianazza, E. (2001). Acute-phase proteins before cerebral ischemia in stroke-prone rats: identification by proteomics. Stroke 32, 753760 .

8) Wait, R., Gianazza, E., Eberini, I., Sironi, L., Dunn, M.J., Gemeiner, M., Miller, I. (2001). Proteins of rat serum, urine, and cerebrospinal fluid: VI. Further protein identifications and interstrain comparison. Electrophoresis 22, 3043-3052. 
9) Miller, I., Teinfalt, M., Leschnik, M., Wait, R., Gemeiner, M. (2004). Nonreducing two-dimensional gel electrophoresis for the detection of Bence Jones proteins in serum and urine. Proteomics 4, 257-260.

10) Sironi, L., Guerrini, U., Tremoli, E., Miller, I., Gelosa, P., Lascialfari, A., Zucca, I., Eberini, I., Gemeiner, M., Paoletti, R., Gianazza, E. (2004). Analysis of Pathological Events at the Onset of Brain Damage in Stroke-Prone Rats: A Proteomics and Magnetic Resonance Imaging Approach. J. Neurosci. Res. 78, 115-122.

11) Wait, R., Chiesa, G., Parolini, C., Miller, I., Begum, S., Brambilla, D., Galluccio, L., Ballerio, R., Eberini, I., Gianazza, E. (2005). Reference maps of mouse serum acutephase proteins: Changes with LPS-induced inflammation and apolipoprotein A-I and A-II transgenes. Proteomics 5, 4245-4253.

12) Miller, I., Radwan, M., Strobl, B., Müller, M., Gemeiner, M. (2006). Contribution of cell culture additives to the two-dimensional protein patterns of mouse macrophages. Electrophoresis 27, 1626-1629.

13) Miller, I., Crawford, J., Gianazza, E. (2006) Protein stains for proteomic applications: Which, when, why? Proteomics 6, 5385-5408.

14) Winkler, W., Zellner, M., Diestinger, M., Babeluk, R., Marchetti, M., Goll, A., Zehetmayer, S., Bauer, P., Rappold, E., Miller, I., Roth, E., Allmaier, G., Oehler, R. (2008). Biological Variation of the Platelet Proteome in the Elderly Population and Its Population for Biomarker Research. Mol. Cell. Proteomics 7, 193-203.

15) Radwan, M., Miller, I., Grunert, T., Marchetti, M., Vogl, C., O'Donoghue, N., Dunn, M.J., Kolbe, T., Allmaier, G., Gemeiner, M., Müller, M., Strobl, B. (2008). The impact of Tyrosine kinase 2 (Tyk2) on the proteome of murine macrophages and their response to lipopolysaccharide (LPS). Proteomics 8, 3469-3485.

16) Kozlov, A.V., Duvigneau, J.C., Miller, I., Nürnberger, S., Gesslbauer, B., Kungl, A., Öhlinger, W., Hartl, R.T., Gille, L., Staniek, K., Gregor, W., Haindl, S., Redl, H. (2009) Endotoxin causes functional endoplasmic reticulum failure, possibly mediated by mitochondria. Biochim. Biophys. Acta - Mol. Basis Dis. 1792, 521-530. 
17) Duvigneau, JC., Kozlov, A.V., Zifko, C., Postl, A., Hartl, R.T., Miller, I., Gille, L., Staniek, K., Moldzio, R., Gregor, W., Haindl, S., Behling, T., Redl, H., Bahrami, S. (2010). Reperfusion does not induce oxidative stress but sustained endoplasmic reticulum stress in livers of rats subjected to traumatic hemorrhagic shock. Shock 33, 289-298.

18) Miller, I., Eberini, I., Gianazza, E. (2010). Other than IPG-DALT: two-dimensional electrophoresis variants. Proteomics 10, 586-610.

19) Kozlov, A.V., Duvigneau, J.C., Hyatt, T.C., Raju, R., Behling, T., Hartl, R.T., Staniek, K., Miller, I., Gregor, W., Redl, H., Chaudry, I.H. (2010). Effect of estrogen on mitochondrial function and intracellular stress markers in rat liver and kidney following trauma-hemorrhagic shock and prolonged hypotension. Mol. Med. 16, 254261.

20) Radwan, M., Stiefvater, R., Grunert, T., Sharif, O., Miller, I., Marchetti-Deschmann, M., Allmaier, G., Gemeiner, M., Knapp, S., Kovarik, P., Müller, M., Strobl, B. (2010). Tyrosine Kinase 2 Controls IL-1ß Production at the Translational Level. $J$. Immunol. 185, 3544-3553.

21) Grunert, T., Leitner, N.R., Marchetti-Deschmann, M., Miller, I., Wallner, B., Radwan, M., Vogl, C., Kolbe, T., Kratky, D., Gemeiner, M., Allmaier, G., Müller, M., Strobl, B. (2011). A comparative proteome analysis links tyrosine kinase 2 (Tyk2) to the regulation of cellular glucose and lipid metabolism in response to poly(I:C). J. Proteomics 74, 2866-2880.

22) Zellner, M., Graf, A., Zehetmayer, S., Winkler, W., Staes, A., Gevaert, K., Vanderkerckhove, J., Marchetti-Deschmann, M., Miller, I., Bauer, P., Allmaier, G., Oehler, R. (2012). How many spots with missing values can be tolerated in quantitative two-dimensional gel electrophoresis when applying univariate statistics? J. Proteomics 75, 1792-1802.

23) Gianazza, E., Vegeto, E., Eberini, I., Sensi, C., Miller, I. (2012). Neglected markers: Altered serum proteome in murine models of disease. Proteomics 12, 691-707.

24) Gianazza, E., Wait, R., Eberini, I., Sensi, C., Sironi, L., Miller, I. (2012). Proteomics of rat biological fluids - The tenth anniversary update. J. Proteomics 75, 3113-3128. 
25) Nürnberger, S., Miller, I., Duvigneau, J.C., Kavanagh, E.T., Gupta, S., Hartl, R.T., Hori, O., Gesslbauer, B., Samali, A., Kungl, A., Redl, H., Kozlov, A.V. (2012). Impairment of endoplasmic reticulum in liver as an early consequence of the systemic inflammatory response in rats. Am. J. Physiol. Gastrointest. Liver Physiol. 303, G1373-1383.

26) Miller, I., Serchi, T., Murk, A.J., Gutleb, A.C. (2014). The Added Value of Proteomics for Toxicological Studies. J. Toxicol. Environ. Health B, 17, 225-246.

27) Weidinger, A., Müllebner, A., Paier-Pourani, J., Banerjee, A., Miller, I., Lauterböck, L., Duvigneau, J.C., Skulachev, V.P., Redl, H., Kozlov, A.V. (2015). Vicious Inducible Nitric Oxide Synthase-Mitochondrial Reactive Oxygen Species Cycle Accelerates Inflammatory Response and Causes Liver Injury in Rats. Antioxid. Redox Signal. 22, 572-586.

28) Miller, I., Serchi, T., Cambier, S., Diepenbroek, C., Renaut, J., van den Berg, J.H.J., Kwadijk, C., Gutleb, A.C., Rijntjes, E., Murk, A.J. (2016). Hexabromocyclododecane (HBCD) induced changes in the liver proteome of eu- and hypothyroid female rats. Toxicol. Lett. 245, 40-51.

29) Gianazza, E., Parravicini, C., Primi, R., Miller, I., Eberini, I. (2016). In silico prediction and characterization of protein post-translational modifications. $J$. Proteomics 134, 65-75.

30) Gianazza, E., Miller, I., Palazzolo, L., Parravicini, C., Eberini, I. (2016). With or without you - Proteomics with or without major plasma/serum proteins. $J$. Proteomics 140, 62-80. 


\section{SENSE}

Netherlands Research School for the

Socio-Economic and Natural Sciences of the Environment

\section{I P L O M A}

For specialised PhD training

The Netherlands Research School for the Socio-Economic and Natural Sciences of the Environment (SENSE) declares that

\section{Ingrid Miller}

born on 25 July 1957 in Vienna, Austria

has successfully fulfilled all requirements of the Educational Programme of SENSE.

Wageningen, 7 July 2016

the Chairman of the SENSE board

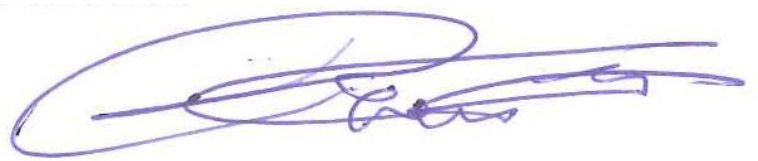

Prof. dr. Huub Rijnaarts the SENSE Director of Education

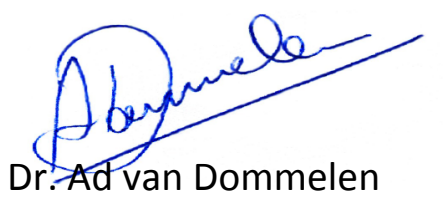

The SENSE Research School has been accredited by the Royal Netherlands Academy of Arts and Sciences (KNAW)

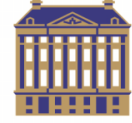

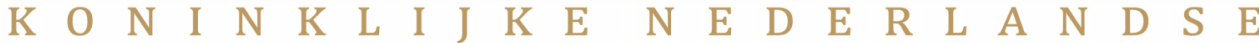
$\begin{array}{llllllllllllllllllllllll}\text { A } & K & A & D & E & M & I & E & V & A & N & W & E & T & E & N & S & C & H & A & P & P & E & N\end{array}$ 


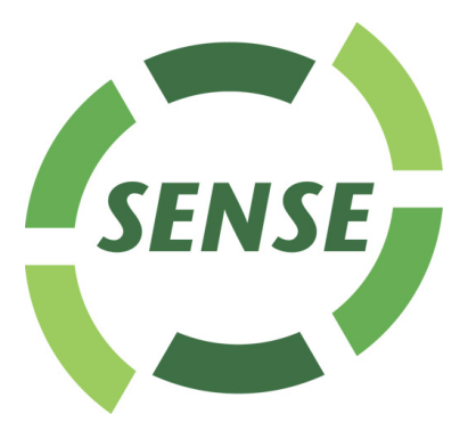

The SENSE Research School declares that Ms Ingrid Miller has successfully fulfilled all requirements of the Educational PhD Programme of SENSE with a work load of $45 \mathrm{EC}$, including the following activities:

\section{SENSE PhD Courses}

- Research in Context Activity: Writing press release 'Gender difference relevant for toxicology research too?' (2016)

\section{Other PhD and Advanced MSc Courses}

o Training for editors, Elsevier (2009)

\section{External training at a foreign research institute}

- Unconventional 2DE-setups (non-IPG-DALT) training, The University of Milan, Italy (2008)

- Topic-related adaptation of proteomic workflow, CRP-Gabriel Lippmann, Germany (2010)

- Interpretation of preliminary proteomics data in context with basic animal data from previous experiments, CRP-Gabriel Lippmann, Luxembourg (2011)

\section{Management and Didactic Skills Training}

- Teaching high school practicals on 'Electrophoretic methods', University of Veterinary Medicine Vienna, Austria (2006-2011)

- Training in proteomic, Universitat Autonoma de Barcelona, Spain (2007)

- Supervising PhD practicals on 'Applied proteomics', University of Veterinary Medicine Vienna, Austria (2008)

- Executive Editor for Animal Proteomics, Journal of Proteomics (2009-present)

- Teaching International Summer School on Proteomics, Porto Conte Ricerche, Sardinia (2011)

- Teaching 'Gel-based proteomics', COST Action FA1002 Proteomics training school, University of Porto, Portugal (2012)

- Organising Proteomic workshop (DIGE-training), University of Veterinary Medicine Vienna, Austria (2012)

\section{Selection of Oral Presentations}

- Staining and Quantification in Proteomics: Does the Dye make a Difference? $4^{\text {th }}$ Austrian Proteome Research Symposium, 21 September 2006, Vienna, Austria

- Endotoxin induced liver failure: more damage to endoplasmic reticulum than to mitochondria? $2^{\text {nd }}$ International Conference of the Hellenic Proteomics Society in Kolimbari, 23-25 May 2007, Kolimbari, Greece

- Comparative proteome analysis of subcellular fractions of livers obtained from rats subjected to endotoxic shock. $8^{\text {th }}$ World Congress on Trauma, Shock, Inflammation and Sepsis (TSIS 2010), 11 March 2010, Munich, Germany

\section{SENSE Coordinator PhD Education}

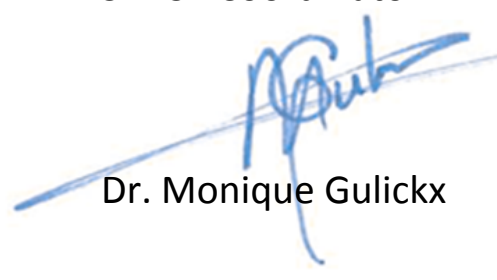


Cover and separator sheets designed by Werner Miller

Printed by GVO drukkers \& vormgevers B.V., Ede, The Netherlands 